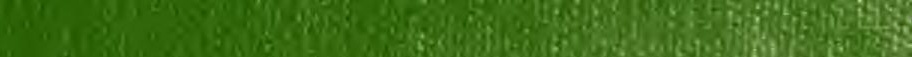

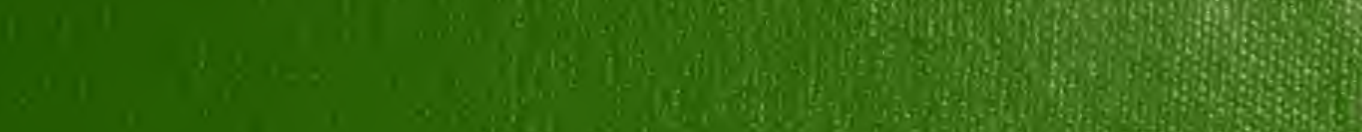

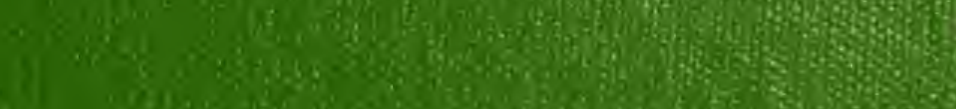
youstoly

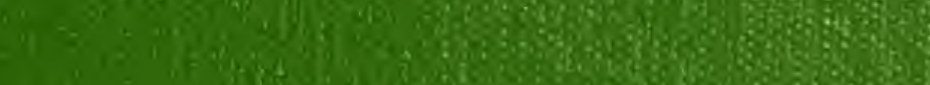
4.t.

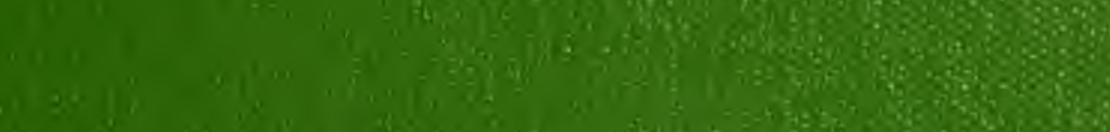

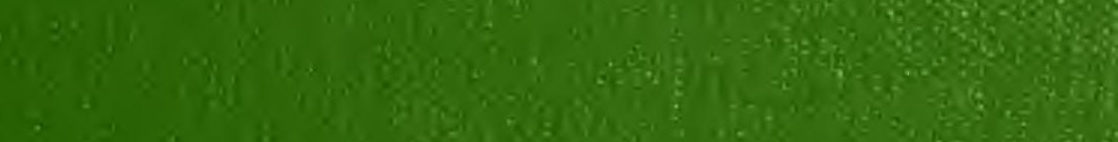

Iing inis
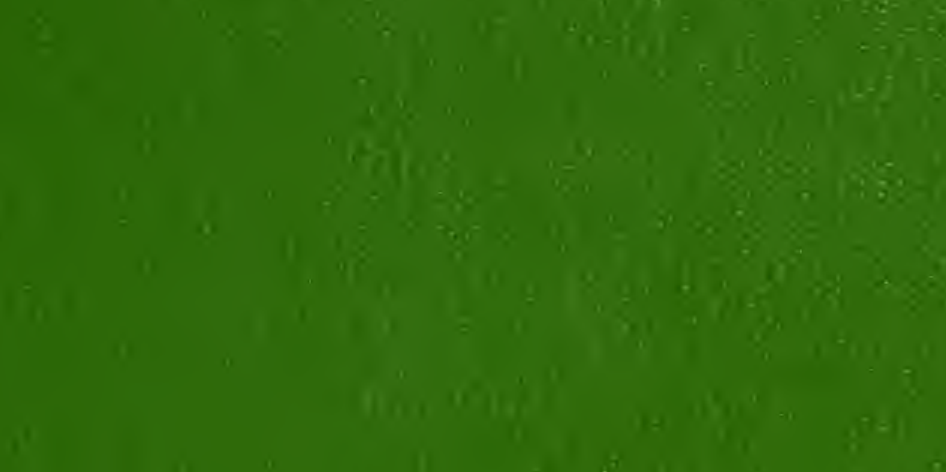
is avisin

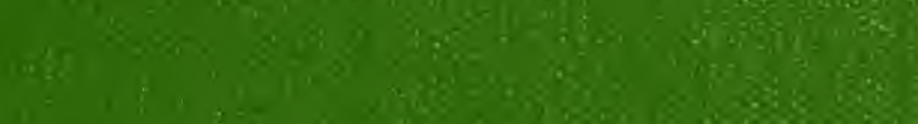

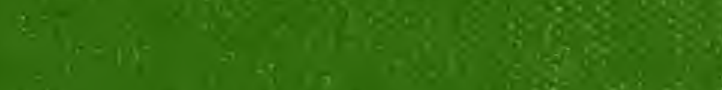

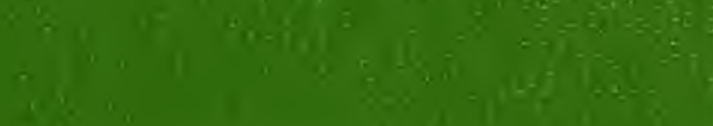
$\cos 20$ 


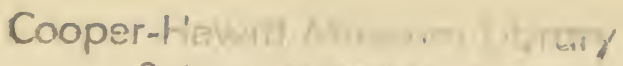

2 tast yisi viluet

New York, New York 10028 


Serithonte EHuststätlen (c) 20. 14

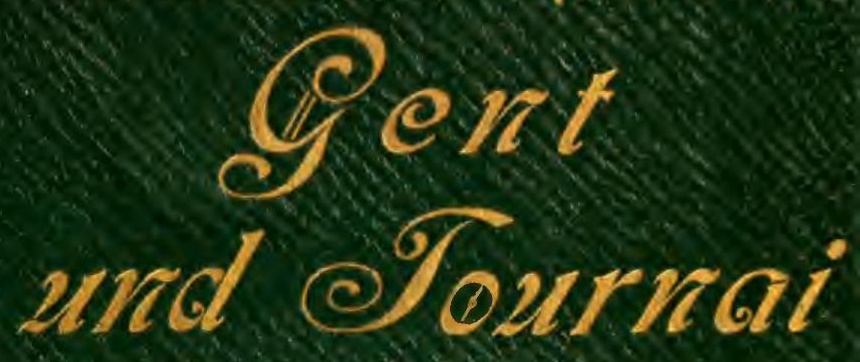

9R6 it 120 Rbbitoungen

$$
\begin{aligned}
& \text { Ceipxig } \\
& \text { E. H. Seemann } \\
& \text { Berlin }
\end{aligned}
$$




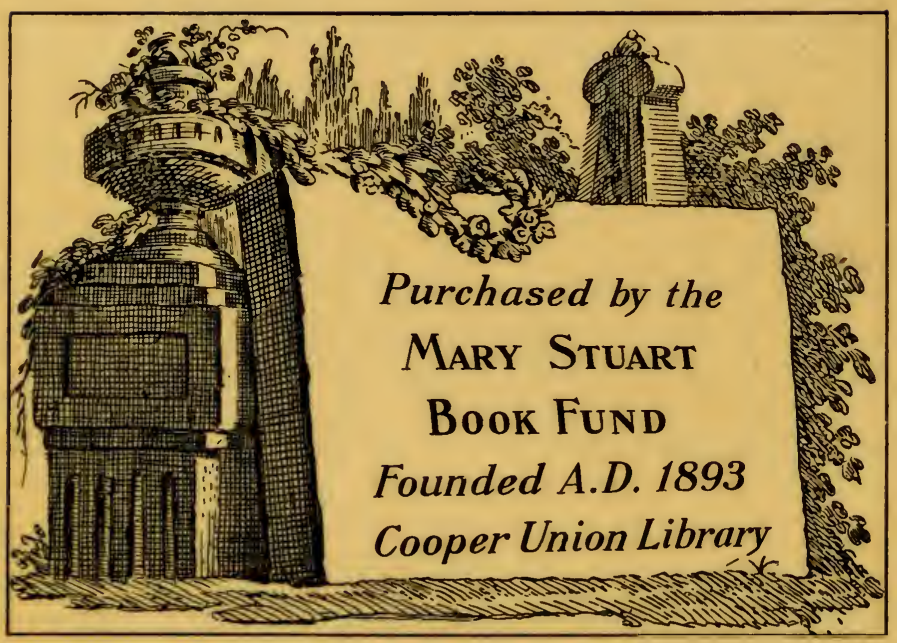




\title{
Berïbmte Kumititätten
}

\author{
$27 r .14$
}

Eent und Tournai 



\title{
(5ent uno Tournai
}

Don

henri hymans

\author{
2lïit 120 2łbbildungen
}

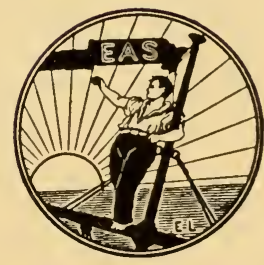

Seipjig und Berlin

Derlag von E. 2r. Seemann 


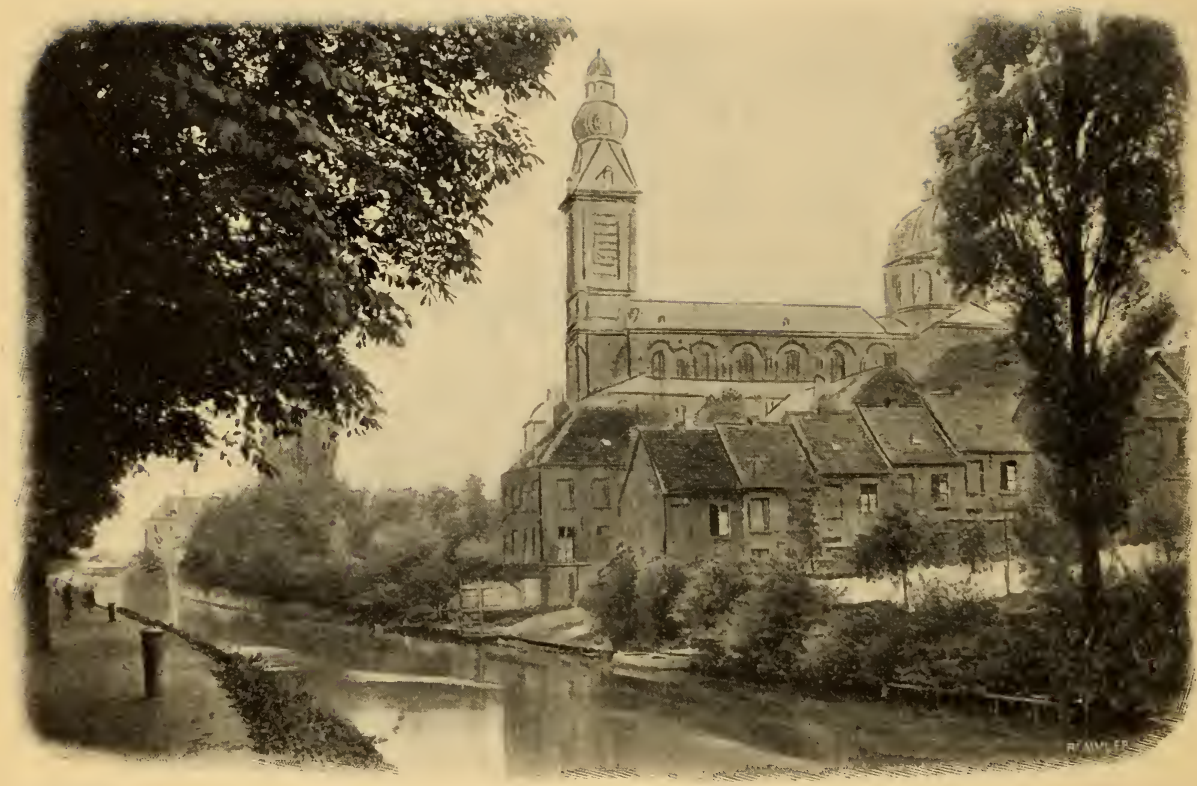

Der Miönţ̦fai mit der petersfirche in Gent.

Zlle Redįte vorbehalten.

Drud von Ermft Gedrich 2Tahf., G. m. b. G., Eeipjig. 


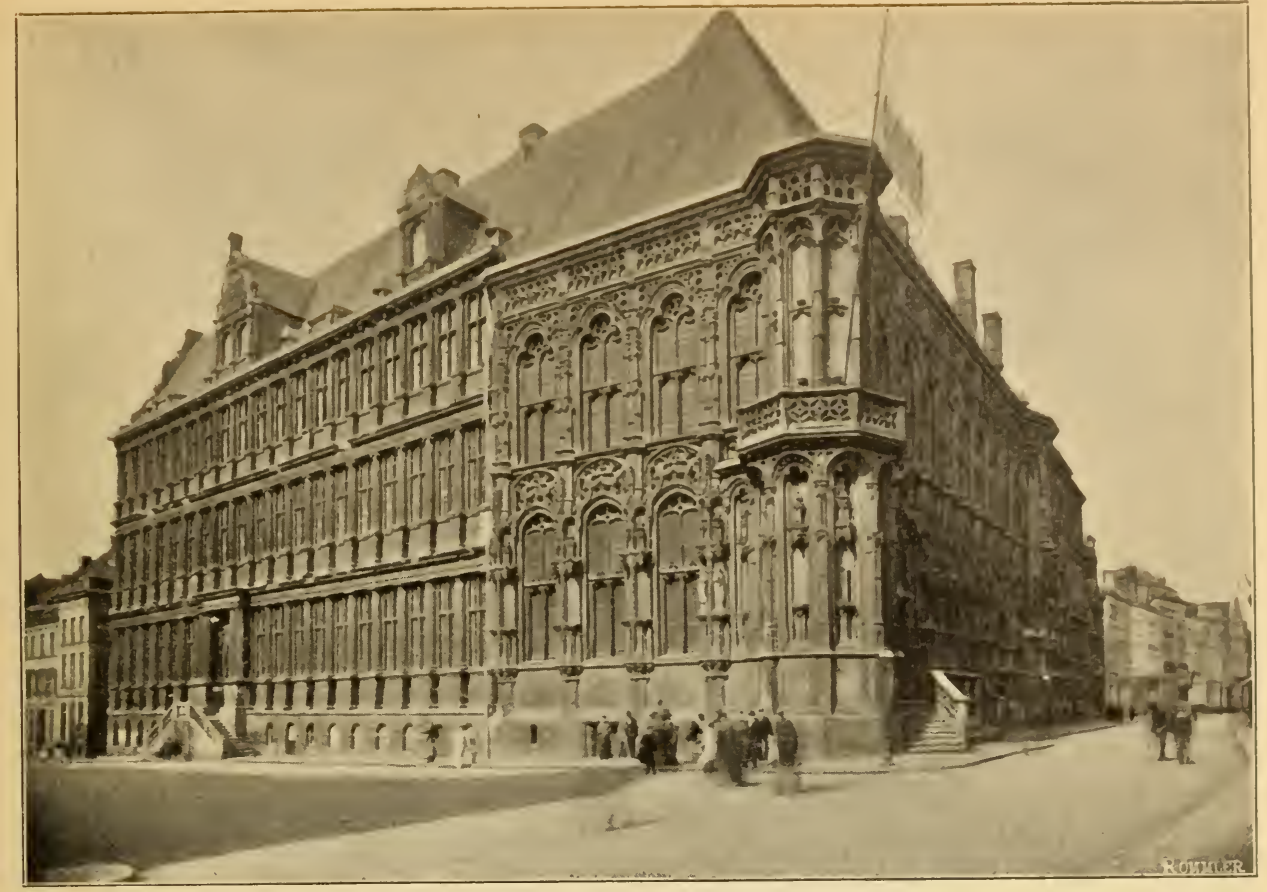

2lbb. 1. Das Etadthaus.

\section{(bint.}

"Die grofie und wunderbare Stadt", von der 2llbreḑt Dïrer fpridht, hat it nener eెeit an ihrem Körper die folgen ihres induftriellen Zuffdywunges erfahren miiffen. Bei der Ziiederfdyrift diefer Jeilen nimmt einte weitgehende LImgeftaltung

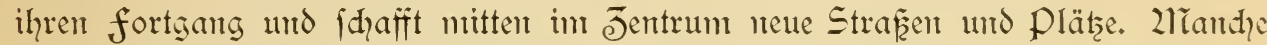
feffelnde Erimentung nimmt fie hinweg, aber fie jieht and langfant verfhwundente ehrwürdige Refte ans Tageslidgt. Ein verdienftlidhes Werf diefer Zlrt war vor allem die freilegung des alten Sdhloffes der Grafen von flandern, das allmählid durd? einert wirrent Gaufen vort $\mathfrak{U}_{\mathrm{nb}}$ auten fo überwudhert war, da官 eben mur die $\mathbb{E}_{\mathrm{r}}=$ innerung daran übrig geblieben; hier hat man eine der ergreifendfen Gefant= anlagen der fendalen Epodhe wieder erftehen Iaffer.

Keine Stadt flanderns wird in Gleidhem Frade wie Fent von dem Wider= ftreit einer Jahrhunderte alten Dergangenheit mit cinem Eqeute berïhrt, bas forglid, feine Rechte wahrjunehmen traḑtet. Zeein Syftem und Fein Typus ift liter don Bammeiftern vorgefhrieben; 2laterial und Stil, der Eintönigeit in gleidyer Weife abhold, erzählen von einer reidhen und verjüngten Etadt. Das Zlentere der Wohnungen neueren Datums trägt im allgemeinen den Sharafter der Praḑt oder beffer den Stempel des Wohlitands. Eifen findet vielfadhe 2lnwendung. Die faffaden find meift hod und von mäḑ̧tigen Relief, iḩr Stil ijt mitunter ein wentg phantaftifh, fündigt aber niđht durdy Lleberladung mit Drnament oder Originalitätsfuḑt um jeden Preis. Hebrigens werdent wir int (5)ent altent Bauten 
begegnen, deren ornamentaler Reiḑtum und deren Erfindung den Dergleidh mit den anfpruchsvolliten Konjeptionen von heute aushält.

Der allgemeine 2Inblick der Stadt hat weder 2lionumentalität noch befondere

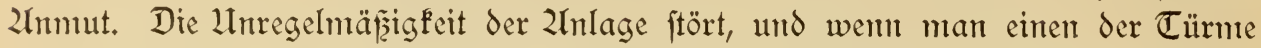
wie den Belfried oder den von St. Bavo, befteigt, bemerft man, daf es fid hier

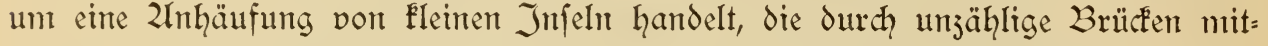
einander verbutden find. Don diefen aus aber find malerifhe Durdblicke im 1 leber= flu vorhanden. Die 2riäander der Shelde, der $\mathbb{E}$ ys (Seie), der Sieve und der 2lioere jwingen den Wandernden jul häufigen 2 tmwegen; dafür fütdet er auf feinem $\mathfrak{W}_{\text {ege }}$

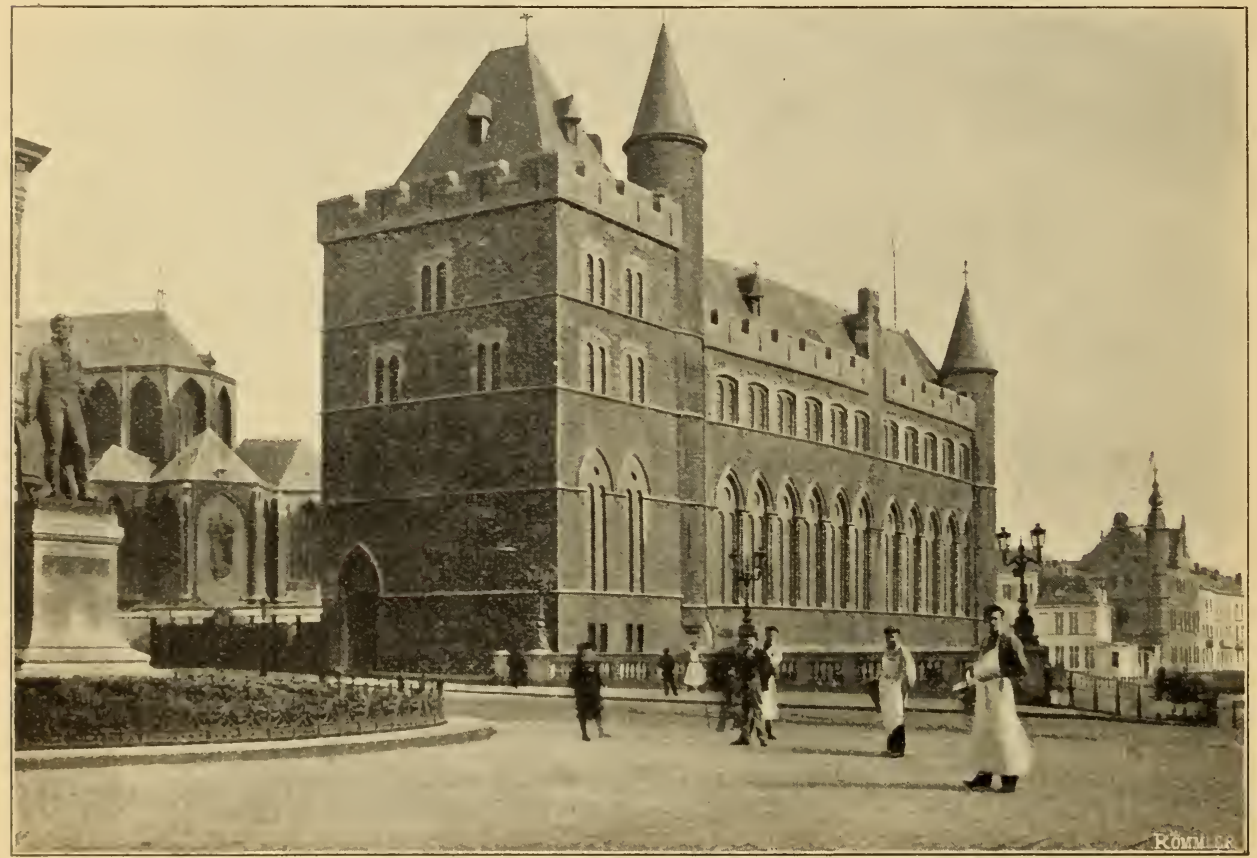

ubb. 2. Der "Steen Gerhard des Tenfels", das jetjige Provinjialardiviv.

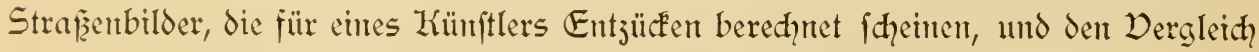
mit den berülhmteften Städten Elollands aushalten Förtnen.

Zlber das befamte Wort Karls V. "Je mettrais Paris dans mon gant" ent= fpriḑt längft nicht mehr den Thatjadhen. Euicciardint namte die Gauptjtadt von flandern eine der größzten, went niḑt die größzte Stadt Europas, "obwohl int Innern an einigen Stellen weitläufig", was nod hente jutrifft. Der nidht bebaute

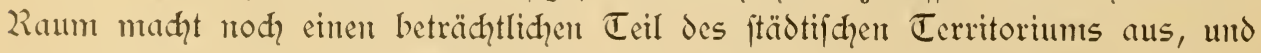
abgefehen davon, da zie Entfernungen groz fund, ift das Juredthinden für den fremben eine jientlid unbequeme Sadhe.

Zlls günftiger 2 Imftand erweift es fich, da ż man die Stadt vom Bahnhof aus mittels eintes Bündels von Trambahnlinten nady allen Ridhtungen durḑfahren Eann. Wem der fremte den Wagen, der nađ dem Rabot führt, benutzt, famt er madh 


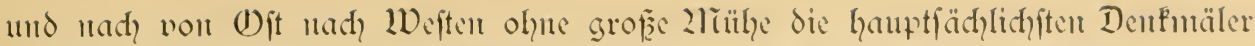

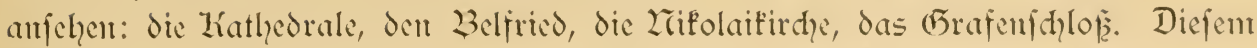
Wege wollen wir folgen und mu dann und wann cinten flemten 2lbftetyer ju entigen

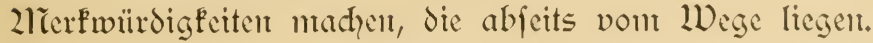

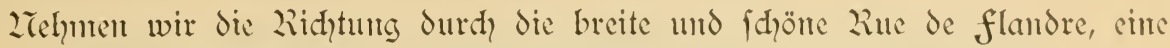
nenere Sdyoppung, jur Eape der Rue du Simbourg und des Quais der unteru

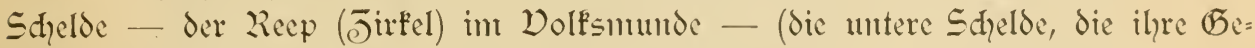

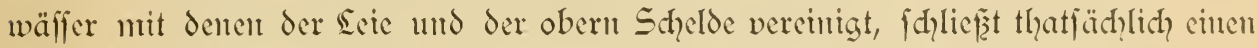
guten Teil der Läufermaffen eiu), fo fehen wir ju unferer liedten cin (5ebäude von ermfter Erfdeinumg, ente 2lut Caftel. Dies ift der ehemalige Steen von (5erhard dem Teufel (2lbb.2), Dogt vou Gent im 13. Jahrlundert. Don den jahlreiḑen, befeftigten Wohnfätten des 2littelalters ift er das einzige lleberbleibfel, das de modernen Deränderungen refpeftiert haben: er rülyrt ans dem Jahre 1216

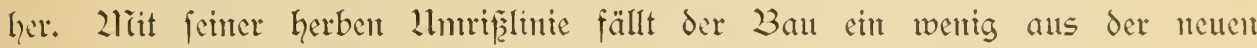
llungebung heraus. Während der Dauer feines naheju fiebenlyundertjährigen Beftehens ift er niemals leer geblieben. Ladhentander Zllofter, Gefängnis, Jrtenlyaus, hat er von allen etwas. Begenwärtig gient er als Provinjalardiu= gebäude einen befferen Rahumen für jeine neue Beftimmung ab. Er hat, mit Der= ftändnis ernenert, feinen hergebraḑten ftrengen Ernjt niḑt abgelegt, der ibut in fenter hentigen Rolle als Wäd hter des Dergangenen wohl antfteht. Eine niedrige Thür, dic

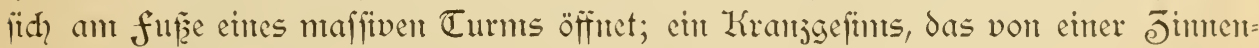
reike überragt wird; Türntden, die feine breite faffade cmmahmen, darimen () willingsfenfter nit gebrodhenen 20 gen. Diefe faffade grenjt mit den llnterbau an das Ulfer des Waffers. Sie ruht auf einer Grumbmaner, durd die sidht in einen unteren Saal oder eine Irrypta fällt, in der gedrungene Säulen anf runden Bafen mit romanifhen Kapitälen von fḑönfer Wirfung fid befinden (2lbb. 3).

Dicht dabei erhebt fich das Standbild des Sivimus Baumens (1769-1822), eines grofent 2lit: bürgers, der mit $\mathfrak{b e}=$ fabr feines sebens und bedeutender 2lrittel Spimmeifter aus Eng= land nad feiner $\mathcal{D}$ ater $=$ ftadt berief und fo deren moderne Jn= ouftrie gefdafien hat. Er ftarb in frant $=$ reid) als armer 2liam. Die Statue ift vou Devigne=Quyo.

Der mene Jo= hannesplatz jeigt unts eit anderes 2lromu= ment, das ebenfalls

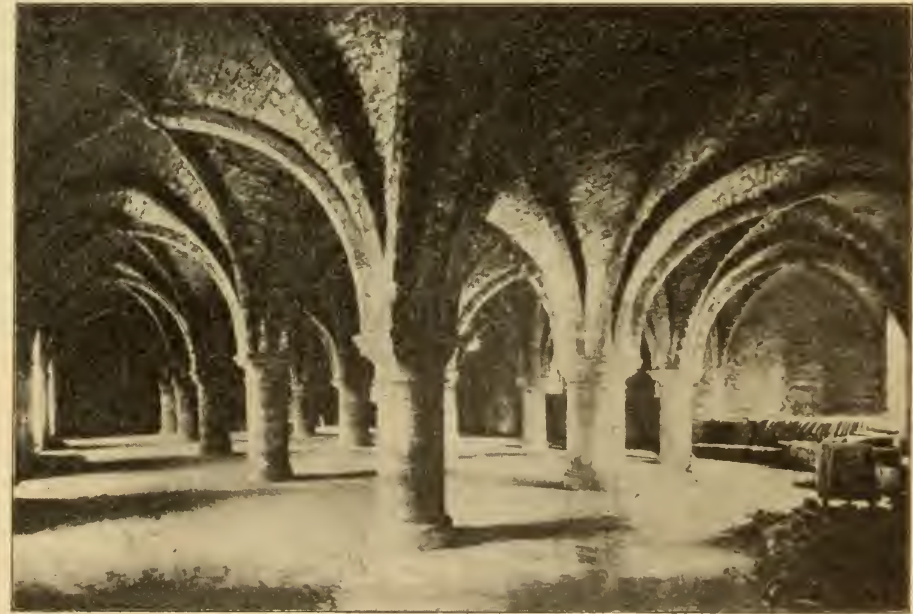

2ubb. 3. Krypta des Eteen Gerhard des Teufels. (Zaw dem ... Inventaire archéologique de frand*.) 
einem hervorragenden Dlamen erridgtet. Worden ift: J. F. Willems, dem förderer der vlämifdyen 23ewegutg. Es ift ein Werk volt Jfidor de Rudder, 1899 enthïllt, ju gleiher ōeit mit der Einweihung des benahbarten vlämifdhen Theaters. Eetzteres ift von cinem 2trditeften, der ebenfalls den Lamen $\mathbb{E}$. Devigne fülhrt, gefḑaffen worden. Ein Ban von eleganter, gewinnender Einfadheit.

Die grope vor uns aufftrebende Zirdhe iit St. 3 avo, urfprünglid St. Johanm

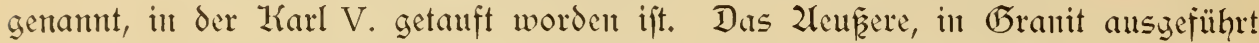
und jeder SFulptur beraubt, ift volt reḑt froftiger Wirfung. Fine int Innern eingemanerte Platte in der Zrähe des grofien Dortals jählt die Phajen der $E_{r}=$ baunng anf: 941 Errichtung der Irrpta oder LltFirde, refonftruiert 1228 und

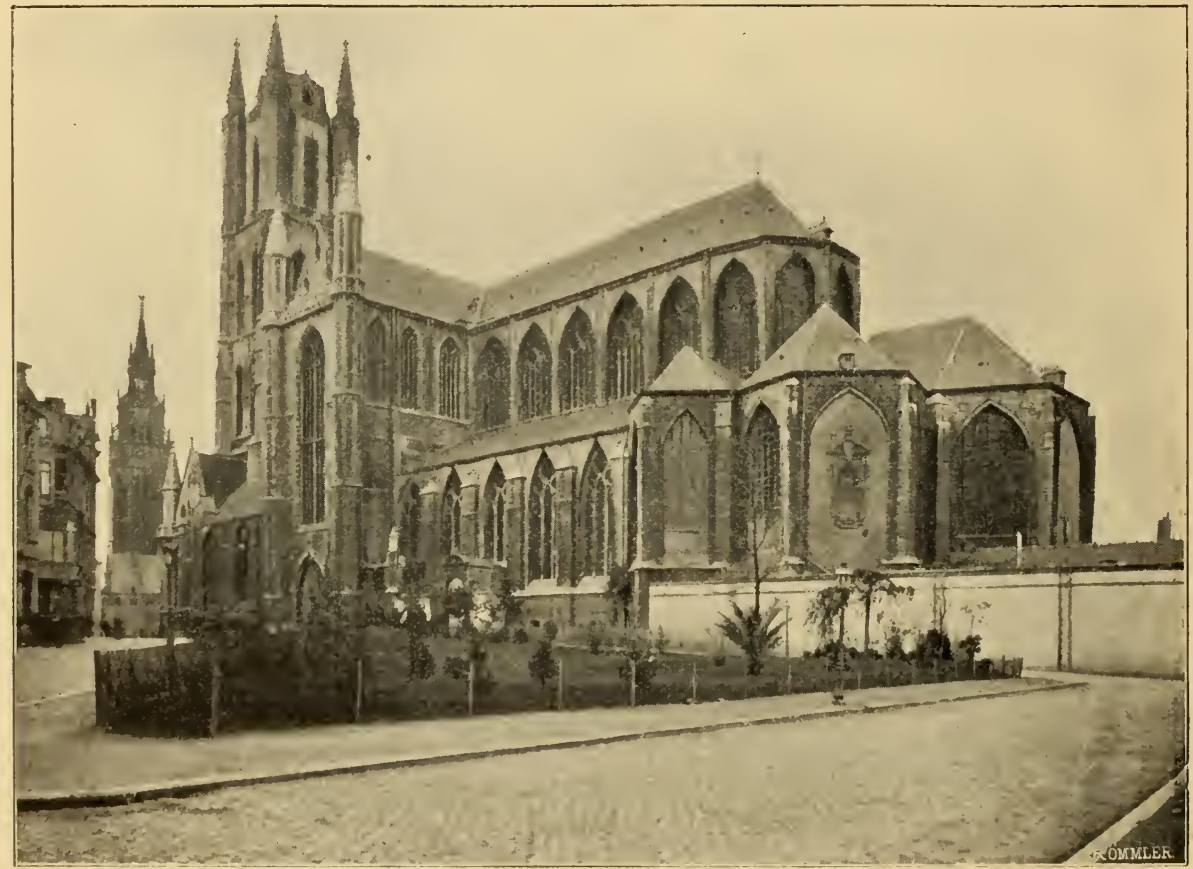

2lbb. 4. Die Katheorale voll 5t. Bavo.

1274. Der Turm volt 1461 bis 1534; 21rdhiteft Johann Etaffins; Sḑiffe und Tranfept 1533-1554. Jur Zathedrale erhoben feit 1559.

Die fehr ausgedehnten Derhältniffe verleihen dem 23au 2liajeftät. Der maffine Turm endigt in ciner Plattform, feitbem int Jahr 1603 cine fenersbrunft ihn

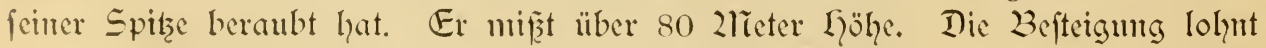

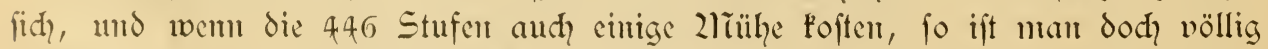

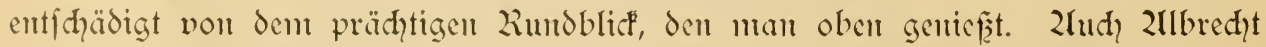
Dïrer maḑte diefen Zuffiteg und war betroffen vou der ungeheuren Zusdehnumg der Stadt, wo man, wie er mit Stolz fagt, "ihn felbjt für grof́z hielt. Im erften Stockwerk des Turms wird das 2lrchiv der Kathedrale aufbewahrt. Don den folgenden zwei Stockwerken ift das obere ahtfeitig mo trägt an den Esken fialen, 
die mit dem Lern durd Strebebogen verbutden find. Lohe und fdumale adteckige Türmdhen flanfieren den Launtgiebel und fteigen über ill̨n hinans. Fine unge: heure fenfteröfinumg nimm faft die ganje Sübfaffade cint.

Das Jumere, ein lateinifhes Ifreuz, von einer doppelten zeihe von Peilem

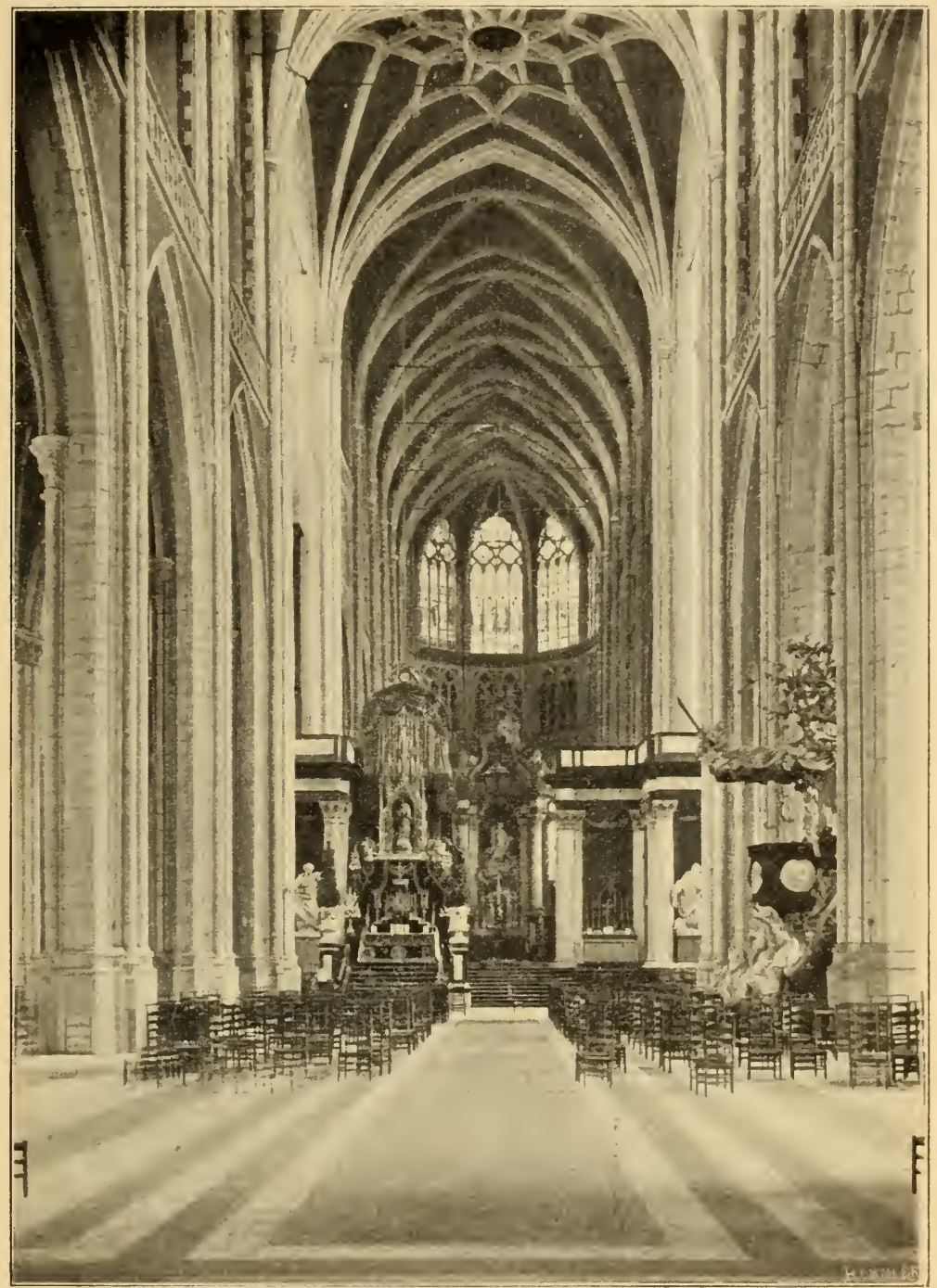

2ubb. 5. ङt. 23avo. Imteres.

mit prismatifhen Rippen in orei Edhiffe geteilt, ift von vornehuren Derhältniffen. Es hat einen unt jehn Stufen erhöhten Chor, deffen Zlıblid leider jun grofen

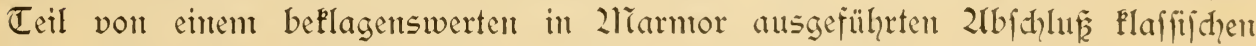

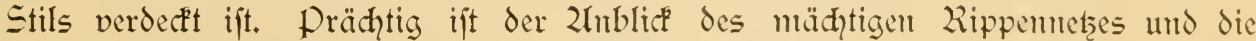
Sidytfülle. Der-ganz int Ginterarunde befindliche riefige 2larmoraltar mit Porinthifden

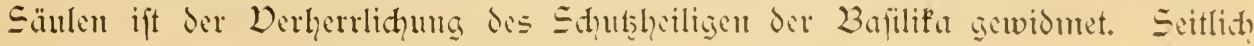


befinden fich Thüren von Zupfer mit reicher 2lrbeit, und Statuen der Feiligen Zmandus und sivinns, der Zrpoftel von flandern, die von P. G. Derbruggen herrühren. Jnt Chor befinden fith vier bifhöfliche (Frabmäler, von denen das des 2unton Trieft zu den berühunten Sp̈ulpturwerfen Belgiens zählt; es ift ein Werḱ des Gieronymus Duquesnoy, eines grofenen Künftlers, deffen Ruhnt freilich vor dem

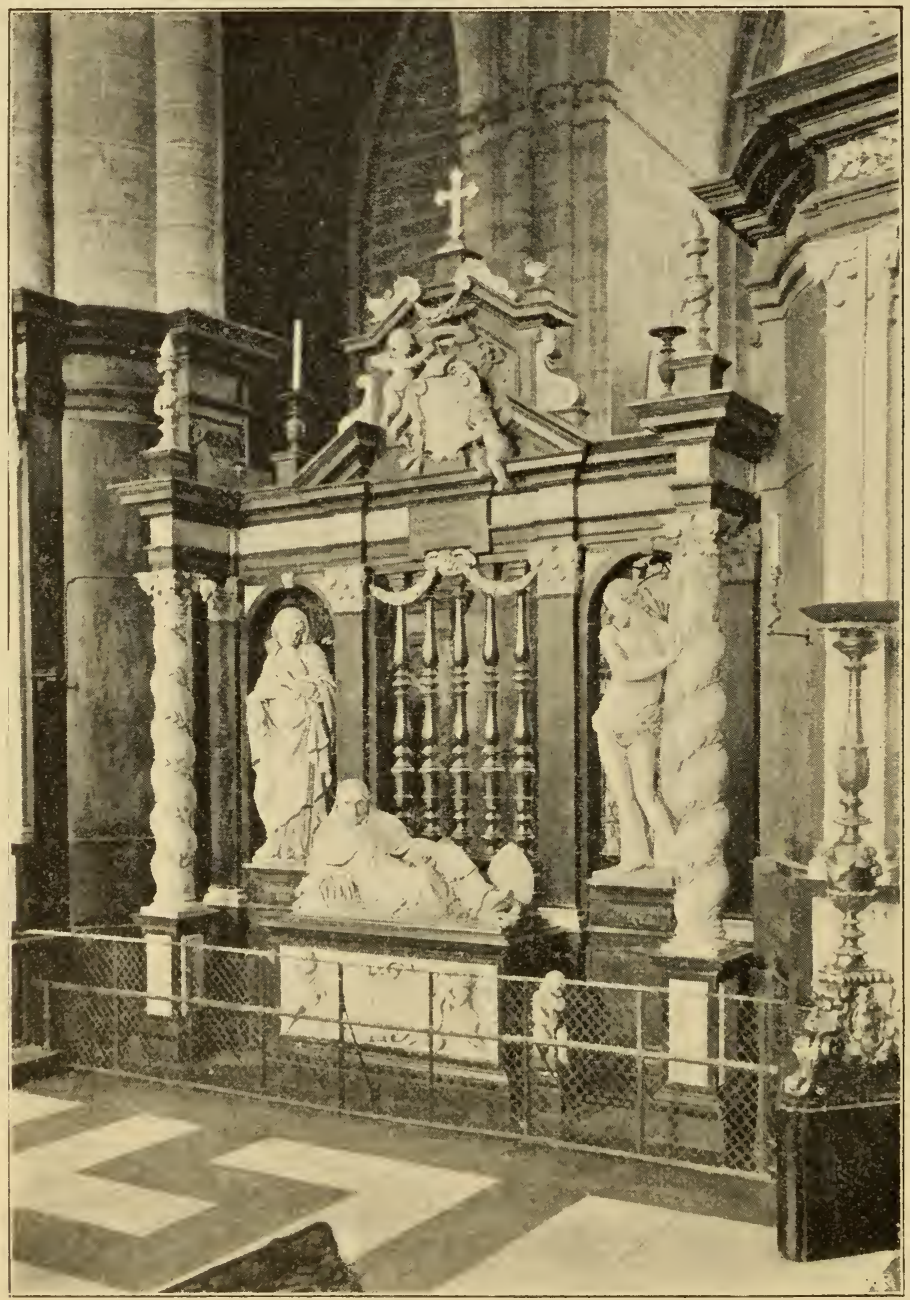

21bb. 6. St. Bavo. Grabmal des Bifinofs 211ton שriejt.

feines 23ruders franz verblap̧t ift. Trieft felbit wollte die 2lusführuna diefes ungewöbulidy grofen Sfulpturwerf's Iciten, wo er halb aufgerichtet auf dem Sartophage dargeftellt ift, das Lreuj betradtend, das cill ftarf von zlidhel= angelo infpirierter Chriftus (in S. Lliarta fopra zlïnerva in Riom) hält. Sint's von Befhaner hält Lliaria fürbitte für den Prälaten (Recordare fili 2liifericordia Tua), dur die Dollendung diefes (5rabuts (1654) nodh un drei Jabue riberlebt hat. 2lllenthalben tritt uns in der Kathedrale die Erimermus 
an ihren Bifdyof Trieft entgegen. 2ln vielen Stellen erfheint fein Wappen, jwei Jagdhörner unt ein laufender Windhund int fdywarjen felde, das an manchem Jengniffe feiner freigebigfeit angebraḑt ift. Wian fieht es an dem fdiönen (Drgel= gehäuje, das fid in Tranjept befindet, und anf den präd)tigen Fupfernen Thüren von 1635, die die bifhöflidye Kapelle abjhlię̧en. Dort bemerft man and einen

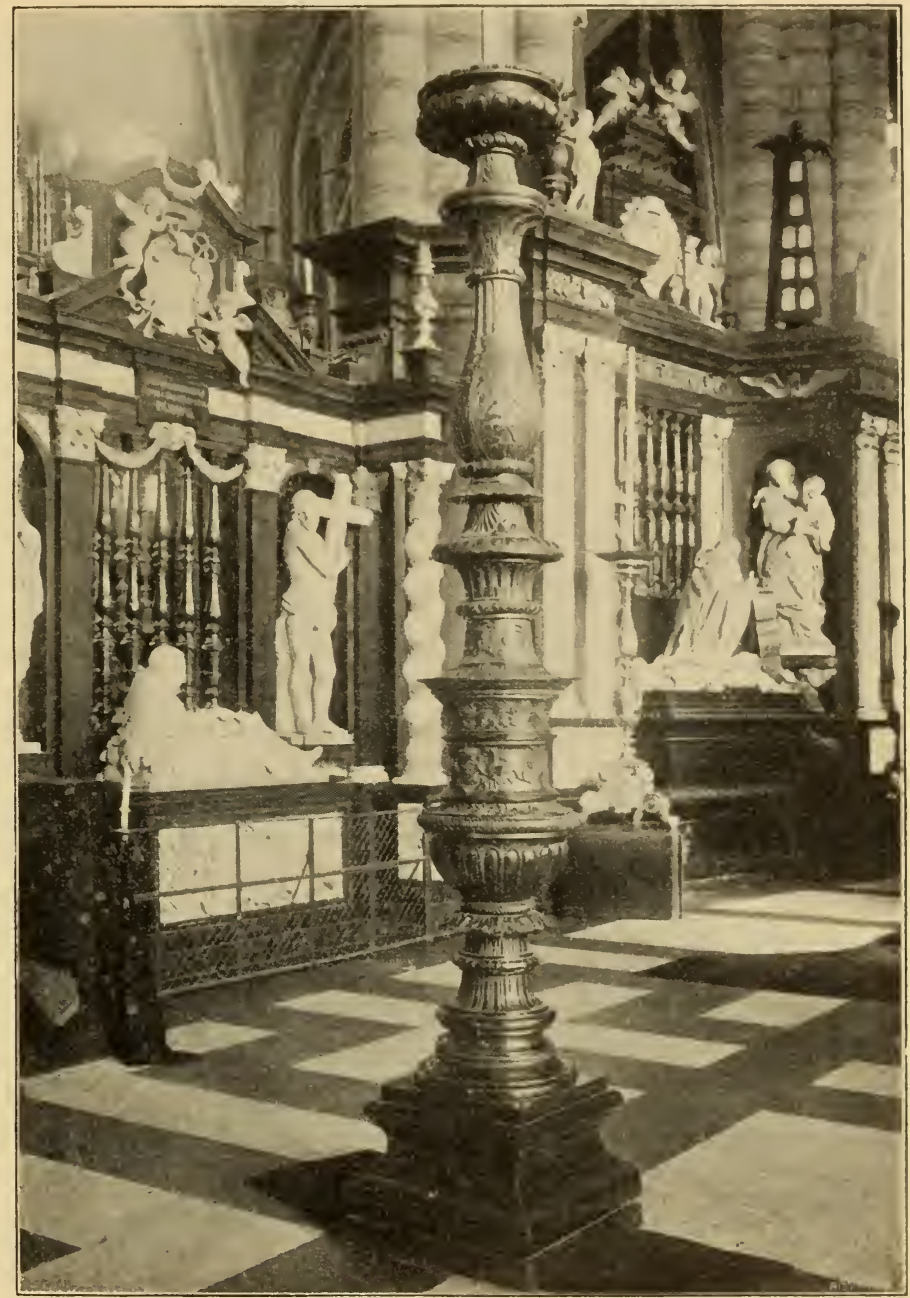

2ubb. 7. Der Chor von Et. Bavo mit einemt der Kandelaber volt Lenedetto da Rovejzano 1525.

merfwürdigen fhmiedeeifernen Kronlenḑter vont Jahre 1434, den das Wahlv= jeidhen Gents, der Dradhe, überragt.

Der Bifḑof Trieft hat and die Táathedrale mit den vier ungeheuren Kandelabern in rotem getriebenen Zupfer ansgeftattet, die man im Chor gewahr

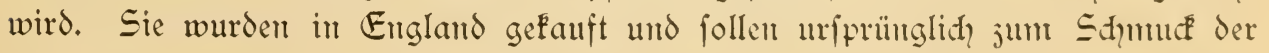
föniglidgen Kapelle unter Zarl I. gedient haben. Dod, fint fie volt nod früheret 
3eit: fie follen gefhafien worden fein, um als Edfäulen eines Grabmonnments 3u dierren, das Leimrid VIII. für fich geplaint hatte. In England felbft hat man bis heute darüber nod nidhts feftjuftellen vermodht. Die Kathedrale von St. Paul in Sondon hat diefe gisantifḑen Sendhter naḑbilden laffen. Sie find von Benedetto

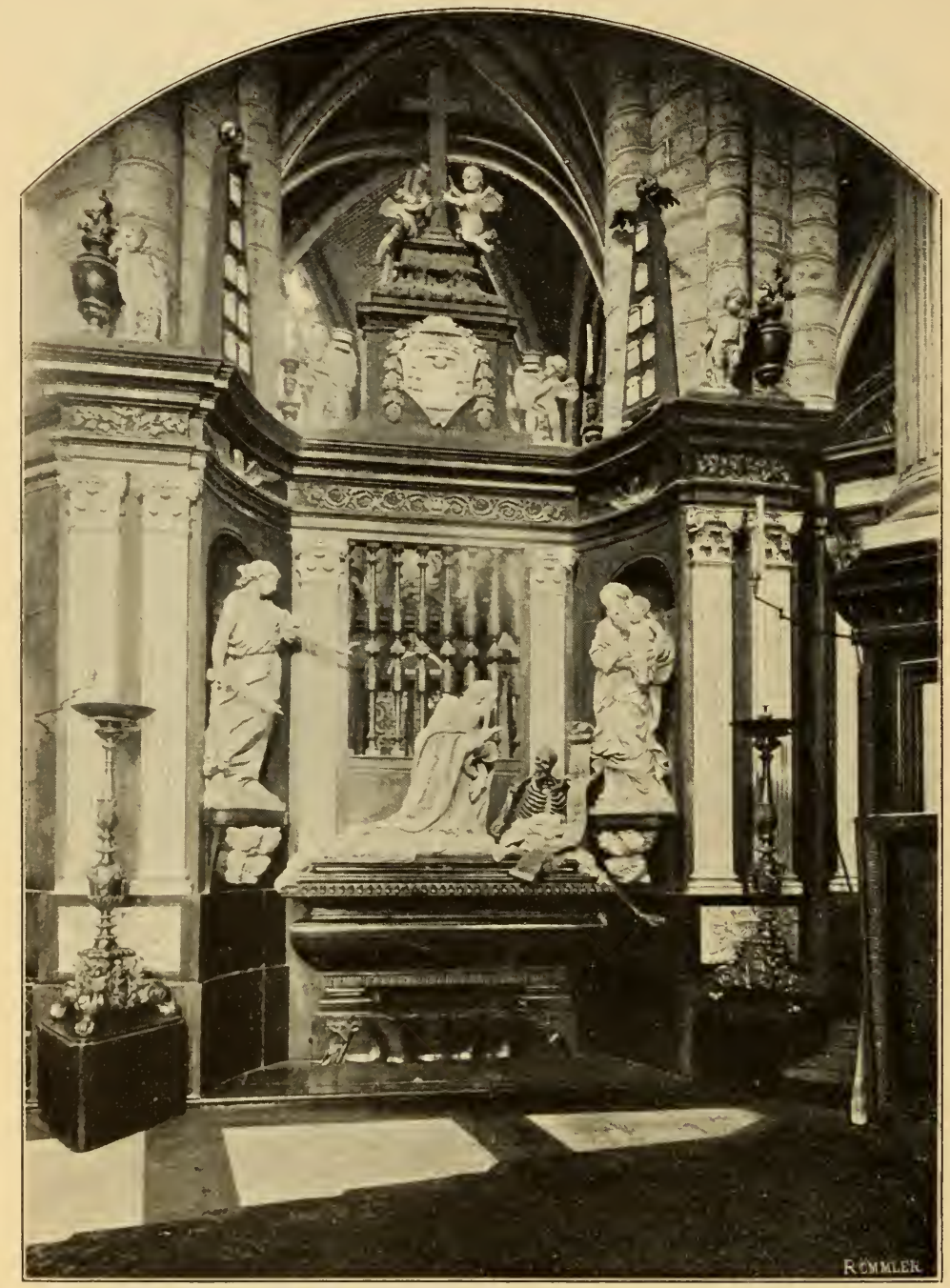

2bb. 8. St. 23avo. 2Manfoleum des Biftiofs D'ullamont ( $\dagger$ 1673).

da Rovejzano 1525 bejeidhnet. Benedetto war in Sondon im Dienfte Leinrids VIII. Redhts vom 2lltar befundet fidh das fdüne Denfmal des 23ifhofs 2llbert von 2llla=

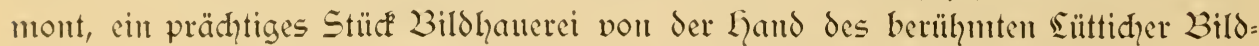
hauers Jean Delcourt. Der Prälat, der 1673 in 2liadrid, wo er gefangen gehalten wurde, geftorben ift, ift knicend dargeftellt, wie er die heilige Jungfran anfleht. Der Tod, ein Skelett aus vergoldeter 3ronje gemahut den Bifhof an das Ende aller Dinge: Statutum est hominibus semel mori. - 
Ein Engel mit flammendem Sdhwerte fteht jur Sinfen des (5̃rabdentumals. In Tranfept, an der redhten Seite, faun man die Reilge fhöner Wappent= fhilder der Ritter vom goldenen Vlieje fehen, die für das Kapitel - das letzte des Drdens - das Philipp II. Lier 1559 abhielt, ausgcfüḩrt murden; nan fdreibt fie sucas de Lieeri ju.

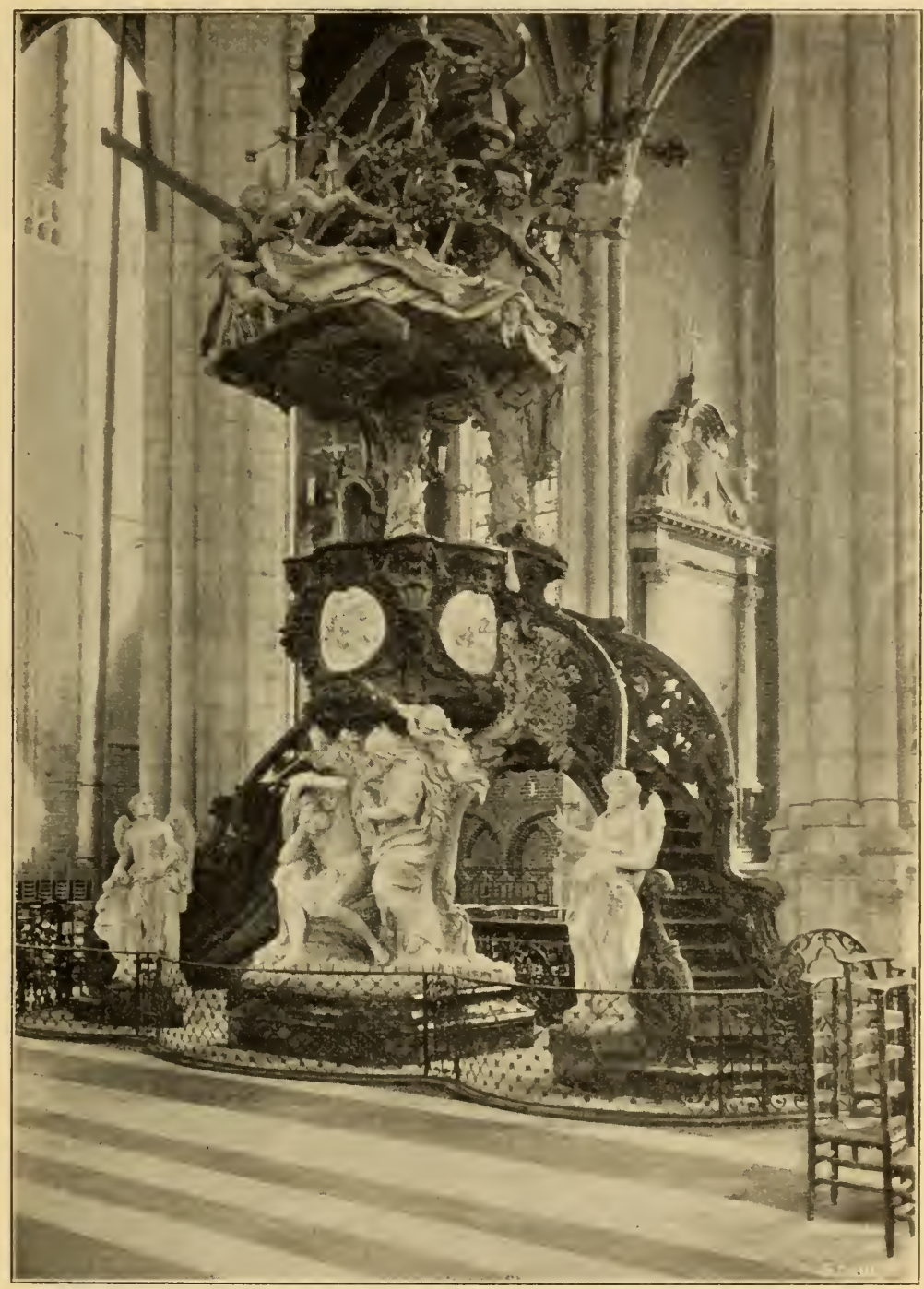

2ubb. 6. Kanjel in St. Bavo.

Die Kantjel von St. Bavo wird als das 2lieiftermet' von Sorenj Delvam. angefehen und ftammt aus dem Jahre 1745. Sie hat 15000 (5) ben gefoftet und ging aus einem Wettbewerbe hervor. Es ift cin untzufanmenthängendes (5emif th

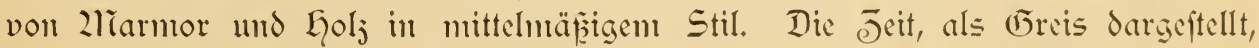
ift ant fule cines 3 anmes cingefd̨lafen; die Wahrheit wedt ilnt nit ben Worten: 
Surge qui dormis, et exsurge a mortuis et illuminabit te Christus! Die Kantjel ift bejeidhnet L. Delvaux Gandavensis invenit et fecit.

2lber die Kathedrale von $\subseteq$ t. Bavo befitht Kunftidäaze von weniger

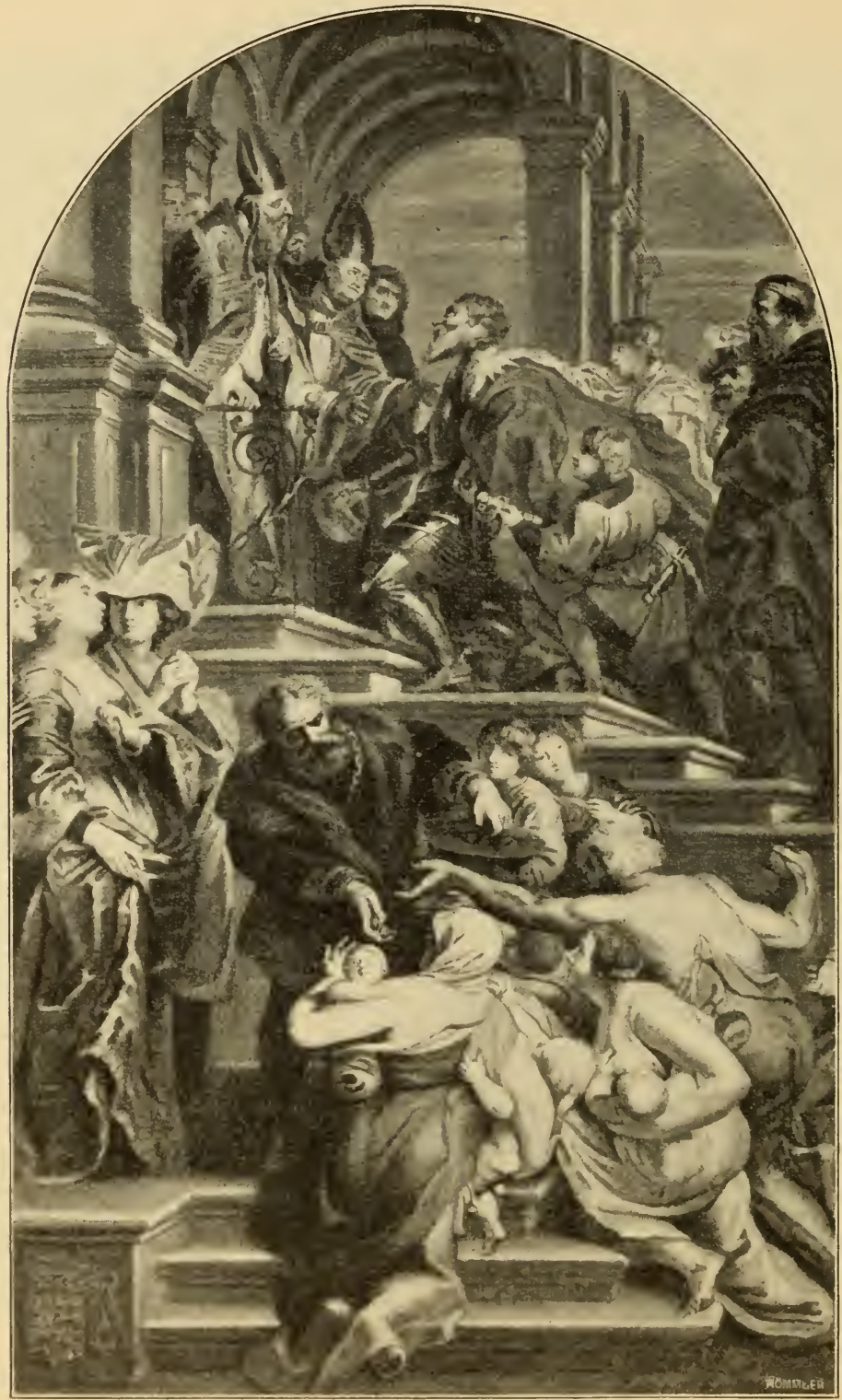

21bb. 10. St. Zavo: Ziubens, Z3efehrung des hl. Bavo.

jweifelhaftem Werte: die 2Unbetung des myjtifden Sammes von den 23rüdern van Eyck reidyt hin, um ihr cinen Weltruhn ju verfhaffer. Die Bekehrung des

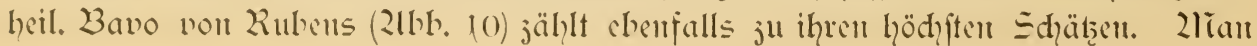


verfteht niḑt recht, warum diefes grofe 2lltarblatt, das von 2luton Trieft hei dem 2lialer in Jahre 1624 beftellt worden ift, niḑt mehr ben Lauptaltar, feiner urfprünglidgen und natürlidgen 23eftummung gentär, fdynüd. Lente hängt es in einer engen Iapelle, die nadh dem hl. Sebaftian benannt ift, feiner Whirfung durd ungefdyidte "Riffaurationen" der Gauptfache nady beraubt. Dem 23ilde gegenüber befindet fid, was bei cinent $\mathcal{L}_{\text {erfe }}$ von Rubens felten vorfommt, eirt (Eemälde feines Sehrers (Dtto Dentus, die 2lufermeffung des sajarus, das befte Werf, das ntan von diefent lleifter fehen fantm.

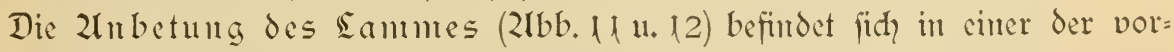
Seren Kapellen, der jehnten, nad 2roam und Eva benamt. Das erftantiche Werk, vort Jodocus Dydt, Lerrn vort Pamele, 1420 beftellt, wurde erft nad jwölf Jahrelt, ant 6. 2liai 1452, beendigt. Fqubert van Elet, der ältere der 23rïder, war damals fayon geftorben und der jüngere Jan führte das riefenhafte Werk ju gutem Ende. 2lian Fent feine wedffelnden Sdyiffale; die zahlreidzen Reftantationen, denen es ausgefeţt war, die (5efahren, die ihm drohten; feine Jerftïffelung, chmmal durd? die franjofen in Jahre 1794 und einige Jahre nad feiner kiüfifellumg im Jahr 1815 , der dic endgültige 2lusentanderreižntug folgte. Die Driginalflügel fint gegenwärtig im Befits der Minfeen von 23erlin und Briffel, währent IFopien ihyen Platz in der Kathedrale felbft und in den Galerien von Berlin und 2liünthen gefunden haben. Diefe Kopien wurden 1558 von 2lìdqael Corcie für Philipp II. ausgeführt. 2ln Stelle der Bildniffe des Jodocus D plot und feiner frau, die auf den unteren äuperen flïgeht dargeftellt find (2lbb. 13 u. 14), hat der Ifopift dic grau it grau gentalten figuren der drei Evantgeliften und die des hl. Johammes

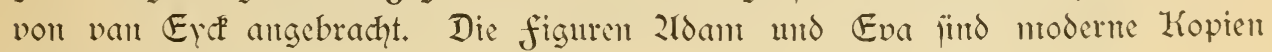
voll Dictor sagye.

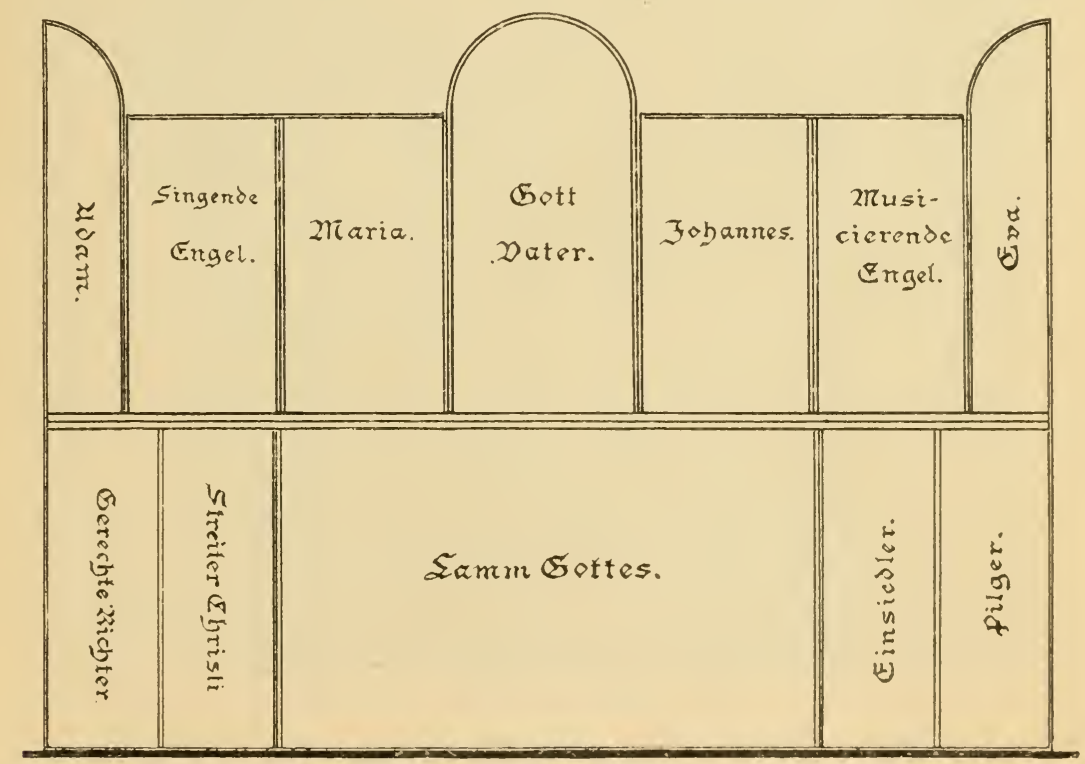

2bb. 11. Edyema des (5enter 2ulturs hei geöfinteten fliigelu. 


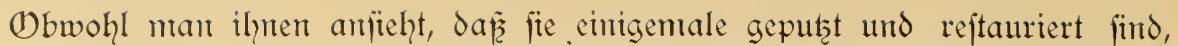
bleiben dod die in St. Bavo aufbemahrten Tafeln der grofzartigite Zusdruck der frühvläntifhent ミchule. 2lian ift hente darüber faft einig, Gubert die figuren (5ott Daters, der Jungfran (2rbb. 15) und des Johannes jujuldyreiben, die von ganj mäh̆tiger Zuffaffung find und deren reiches Kolorit die bewunderumgswürdige Tedhuif erhöht. Das untere 2littelfitül", die eigentlidye 2lnbetung, wurde, wie van 2liander fagt,

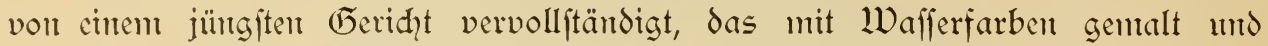

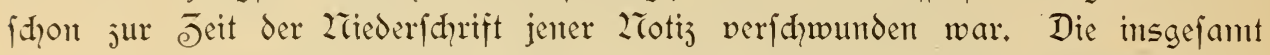
248 figuren befunden cine ungeheure 2lrbeitsleiftung und eine wirflid über= rafhende Ifemtnis der 2litttel der Delmalerei. Lleber den fünitlerifhen Wert noch ju fprechen, ift umtötig.

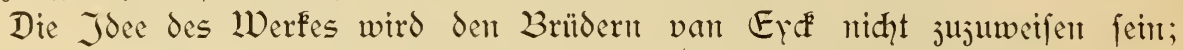
fie waren natürlich von der Erlendhtung irgend cines gelehrten Theologen unter= ftüţt. 2uls Jan van Eych die durd den Tod feines Bruders 1426 unterbrodyente 2rbeit aufnahm, ftand er in der vollen Reife des Zllters und Könmens. Ziehts ipriḑt dafür, da er fïh jentals in Eent aufgehalten habe, und feine angeblidhe Jugehörigkeit jur Gillde der Genter Vraler beruht auf einer fälfhung, die, wic es fheint, von einem Eenter Sammler vom Beginn des 19. Jahrhunderts be: gangen und fürjlidh von Dictor van der Gaeghen, 21rchivar der Stadt, entbecft worden ift. Gqubert ftarb ant 18. September 1426 und wurde in der

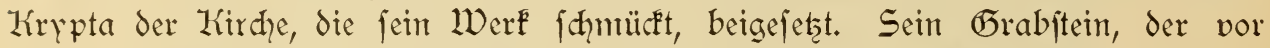
einigen Jahren wieder aufgefunden wurde, befindet fid int 2lülée lapidaire, das

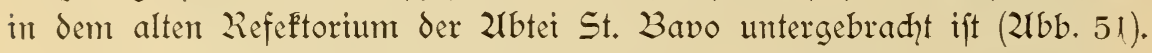

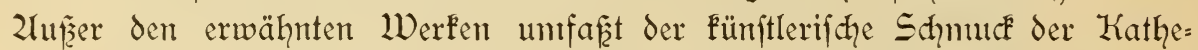
drale rodh cinige Shöpfungen, die der Zufmerfiantét des Kenners empfohlen feien. Juntähjt in der St. Zegidius=Kapelle ein Triptydyon, das Eerhard van

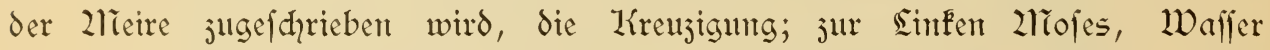
aus dem feljen fhlazend, jur zReḑten die cherne Sḑlange. Diejes Werk foll feines Wertes nicht durh die Bemerfuntg beraubt werden, da é es fein all= gemeines Jntereffe beanfpruden fann. Gerhard van der Zleire's Perfönlidłét ift bis heute nod ein 2liythus. Eine Eroberung Jernfalems, die jetzt in Privat= befits in (5)ent ift und proviforifh in $2 l$ lufeum ausgeftellt ift, gill für die Predella

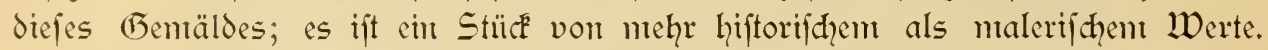

Die erfte Chorfapelle redhts, nad dem heiligen 2Cifolaus benant, zeigt uns ein fehr intereffantes Triptydyon des franj Dourbus, 1571 gemalt, mit den drei Darftelhungen Chrifti unter den Sdyriftgelehrten, der Befdqueidung und der Taufe Chrifti. Der zlialer hat auf dem zlittelbilde Iarl V., Philipp II., den Gerjog vont

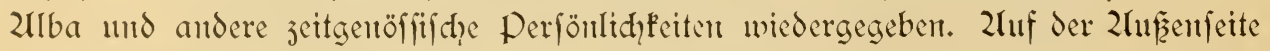

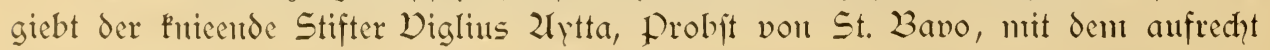
ftehenden Geiland ein fehr fhönes Bitd ab. Égenüber unter einer 2rufade das Brabural des Stifters; es bietet wentiger Jutereffe.

Jut der Kapelle des hl. Juos exiffiert ein 23ild, das beinalye als sine Kuriofität an= gefehen werden darf, die Lëüigin non Saba vor Salonto, eine der in Belaien feltenen

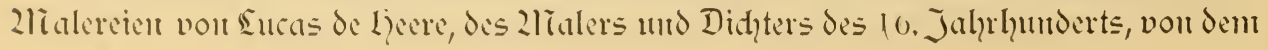


England ausgejeidunete 23ilduiffe bifitit. Das Werf ift bejeidynet I ucas I )erus Inv. et fecit 1559. Dies ift das Jahr des von Whilipp II. alogehaltenten Líapitels des goldenen

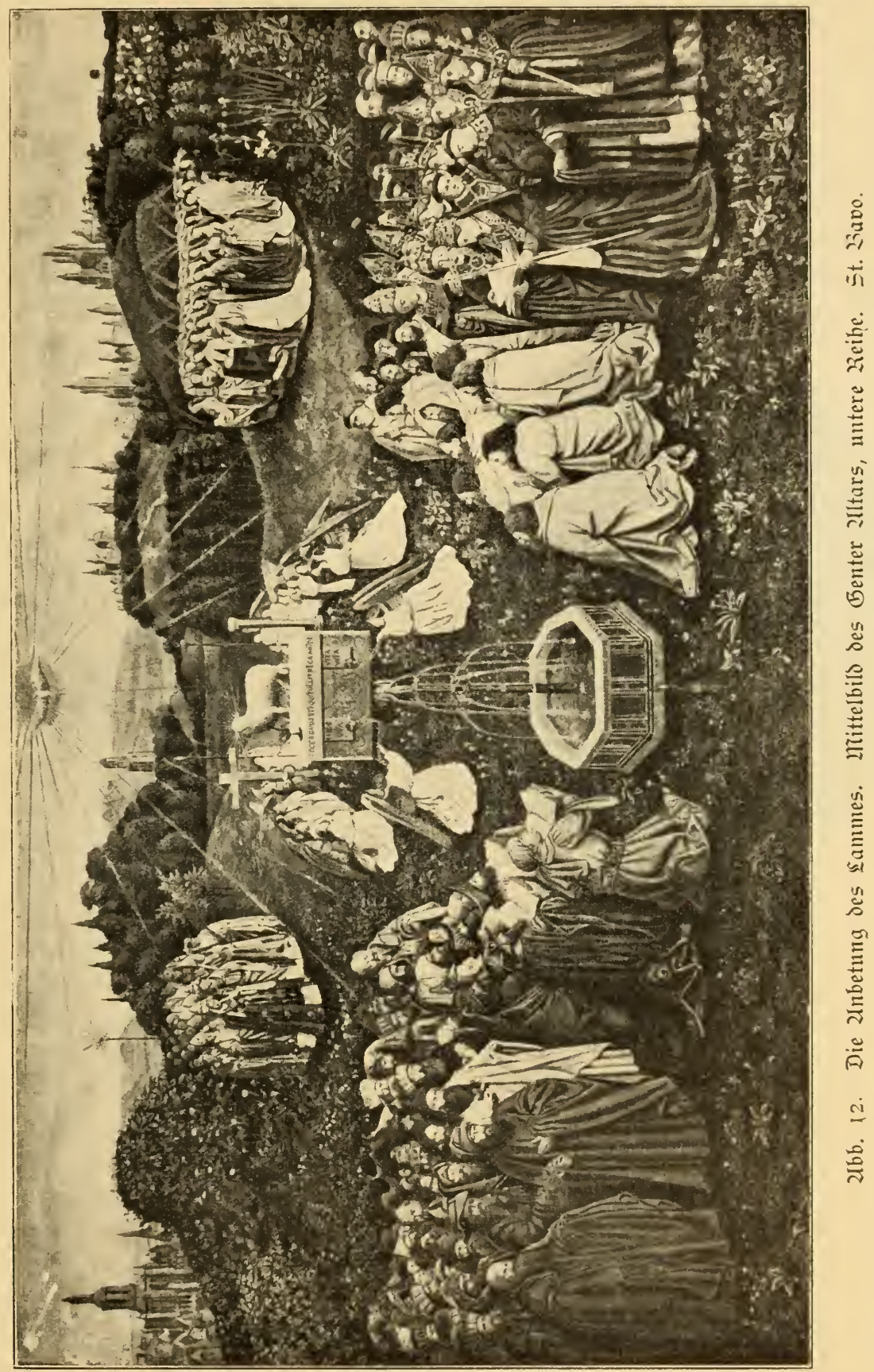

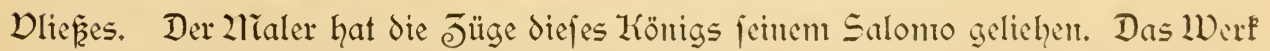
verrät den Einfluz von franj floris; es hat fehr unter ber Wirfung jul ftarker 
Bent.

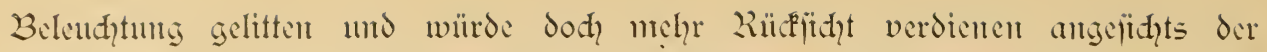
widytigen siolle die fein Lrheber in der (5ejdyiḑte von Gent gefpielt hat. In derfelben Kapelle ift nodh das Grabural der beiden erften Bifdqöfe Cornelins Janfentus $(\dagger 1576)$ und Wilhelm Sindanus $(\dagger$ 1588) ju beaḑten, das 1595 erriḑtet worden ift. Es ift von Golj, vergoldet und polydyromiert, und fehr beaḑtenswert.

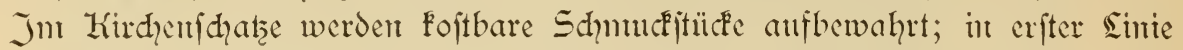
der jog. Chormantel des hl. Sivimus, 1525 nadh delt Jetdyumgen von (5erhard horenbault gejtift für den Probit Lugenois. Die Ziompofitionen, die diefes anerer=

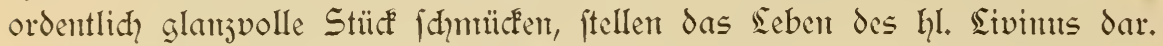

Der Reliquienfhrein des hl. 2lacararius in der än tempels ift von cifeliertem Silber und trägt das Wappen der Stadt 2lions; ev jeigt in getriebenter 2rbeit Darftellumgent ans dem Seben des Leiligen. 2lian Fam darauf folgende Jufhrift lejen:

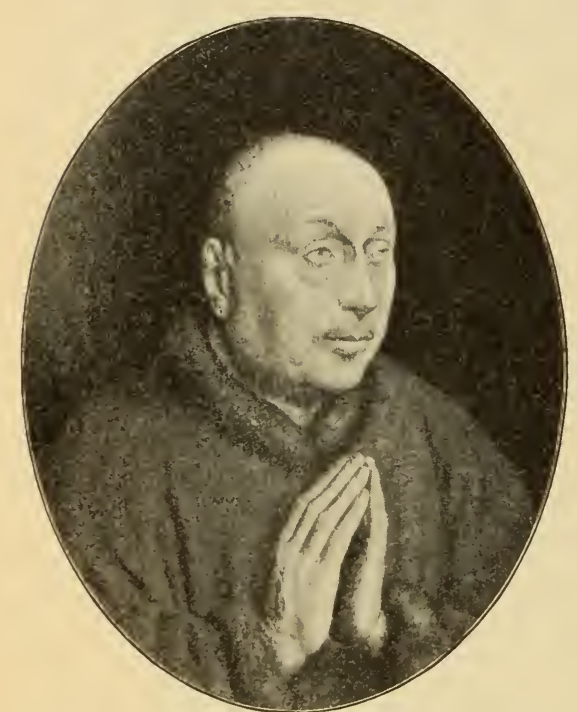

3bb. 13. Jodok 11 L Dyd. Dom Genter Ultar. (Berlin.)

\section{ФAIKT \\ A. MONL \\ ПАР ГTГQ \\ $\triangle \mathrm{A}$ BITNE}

2lls im Jalpre 1615 die peft in 2lions whitete, münfhte das Kapitel der ḩl. WWaltrudis die Reliquien des hl. Riacarins ju erhalten, und befant fie auch. Lachdem die Sendie erlofhen war, wurde diefer Sdyreit als (⿹) eidyen der DanfEarkeit der Kathedrale vout St. Bavo gefpendet.

Ju der Krippta gelangt ntan surd?

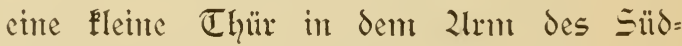
tranfepts auf der rechten Seite des Chors. Dieje urfprïngliche, int 10. Jahrhundert ges weihte IGirdhe wurde nad, unt nad ver=

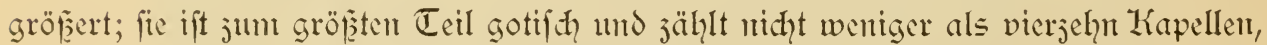
die unt den Raum, den der Chor Der Dberfirdhe cimtmmt, ftrahlenförmig herum: lanfen. Sie ift die Begräbuisftätte der Bifhöfe, deren zranloleen mit der Deforation der Ifirche wetteifern; dody erhielt fie and bis jum Ende des 18. Jahuhumberts die fterblidgen Güllen etmer 2lnjahl von 2ritgliedern hervorräende familien. Daher die jahlreidyen Grabiteme, die in die Zlianem eingelaffen find. Die meiften zlltäre find mit Gemälden gefduntiaft. Eintige find intereffant, insbejondere das 2lltar= blatt mit der (5eburt Chrifti vout D. Dourbus.

Lluter den (5rabmälent hat das der 2liargarethe von Ghiftelles, 1431 geftorben, cintigen Zunftwert, obwohl es der. Statue der Derftorbenen beraubt ift. Dorjüglid gearbeitete Statuetten von "Trauernden" füllen de Lififdyen der Seitenwände.

Die freilegutrg von St. Bavo ift ein Teil des gewaltigent Projefts, das auf einem Plaze die Zathedrale St. Bavo, die St. Zícolansfirdye mo fogar die

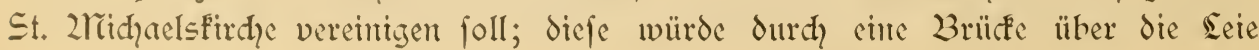


mit dem Kormmarft verbunden werden. Dies wäre der größ̨te Plaţ Europas, wem niḑt der Welt. ZKan verfäume nidht, beim Derlaffen von Et. 23avo einen Blick auf die Dratorien ju werfen, die auren an Sdifi angebradyt fund und deren enger Raum faum ausreidyt, die figurengruppen aus dem 15. Jahrhuntert ju faffen, die auf der einen wie der andern Seite die Trablegung darftellen. Zlian giebt ihnen Wilhelm Lughe als Lrheber. Lriprünglidy waren fie in der Krypta aufgeftellt und befinden fid erft feit 1764 an ihrem gegenwärtigen Platze. Da fie mit Gpfergaben und 23lumen behängt und mit einer dicken Sdjid̨t Gelfarbe über= jogent fint, fam man fie mur fdywer ftubierent.

Die durdh die Sdqaffung des St. Johanm=Platzes notwendig gewordenen Zriederlegungen haben die Seitenanfitht der Tudhhalle freigemacht, von der man bisher mur die Gauptantitht fehen Fonnte (215b. 16). Es ift ein Bau des 15. Jahr= hunderts, der den 2raḑiteften Simon van

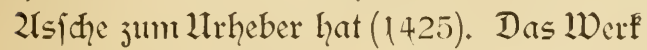
ift nicht ohne 2lülänge an das 2liechelner Sdÿffenhaus. Es hat eime vorgelagerte

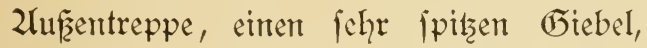

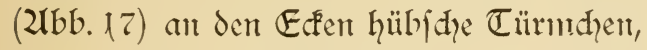
deren Balfone durḑbrodyen find, gleid, denen des Brïffeler Rathaufes, und ferner fialen, die mit Zrabben verfehen find; ohne Jweifel war es aud auf dem gegenüberliegenden äužerften Ende nit gleichen Türmthert verfehert. Seitlid mit mädhtigen Strebepfeilern beferzt, weift die Tudhalle jwei fenterreihen von je jedys Stük auf, die unteren fpirzbogig und houte vermauert, die oberen reḑtwintlig und jiemlid, niedrig*). Lleber dent (5efims jieht fid clegant eine gemeifselte Balerie

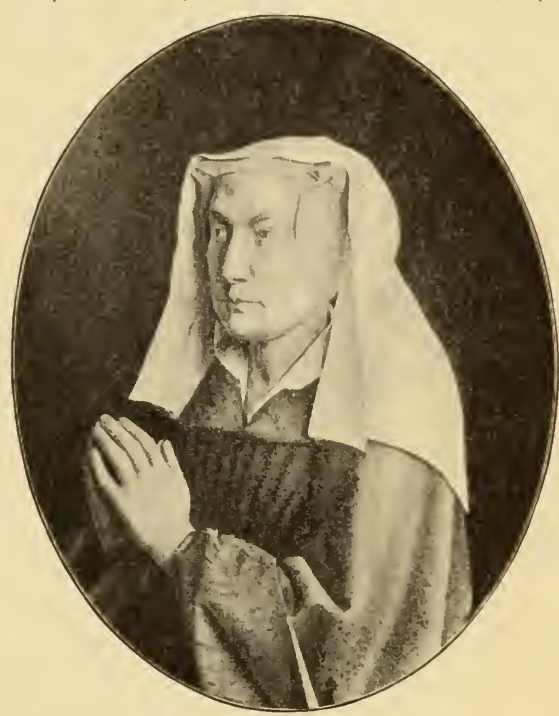

Ubb. 14. Jfabella Borlunt. Dom Gerter Zltar. (Berlitr.) him, die die Enftürmahen verbindet. Da dic Tuḑinduptrie im 16. Jahrhundert durch Llnruhen, Kriege und religiofe Derfolgungen gefährdet war, blicb die Lalle unbenutzt; fie wurde der St. 2riidhaels=23rüderfhaft oder der der fedhter überwiefer und hat, was wohl einjig in Belgien ift, feitdent unnuterbrodyen jener Gejelliḑaft als Derjammlungslof́al gedient.

Das Imtere ift nidyt ohne Intereffe: die gropen Steintreppen, der Der=

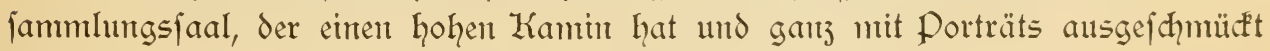
ift, unter denen die von 2rlbredyt und Jiabella nad, Rubens den Reigen eröfintur.

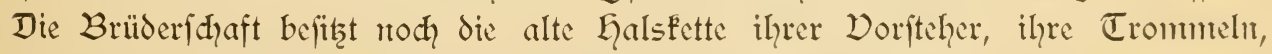
die Koptüme des Erjengels, ihres Shutzpatrons, und des Teufels mit der fupjernen 2raske; alles Dinge, die bei den jährliḑen llmjügen benuţt worden fund. Fin merḱkürdiges Gemälde hängt über dem Kantin des Derfanmlungsfaales: es

*) Das Gebäıde wiro gegenwärtig vergröf́pert und foll elf fenjter hauben. 


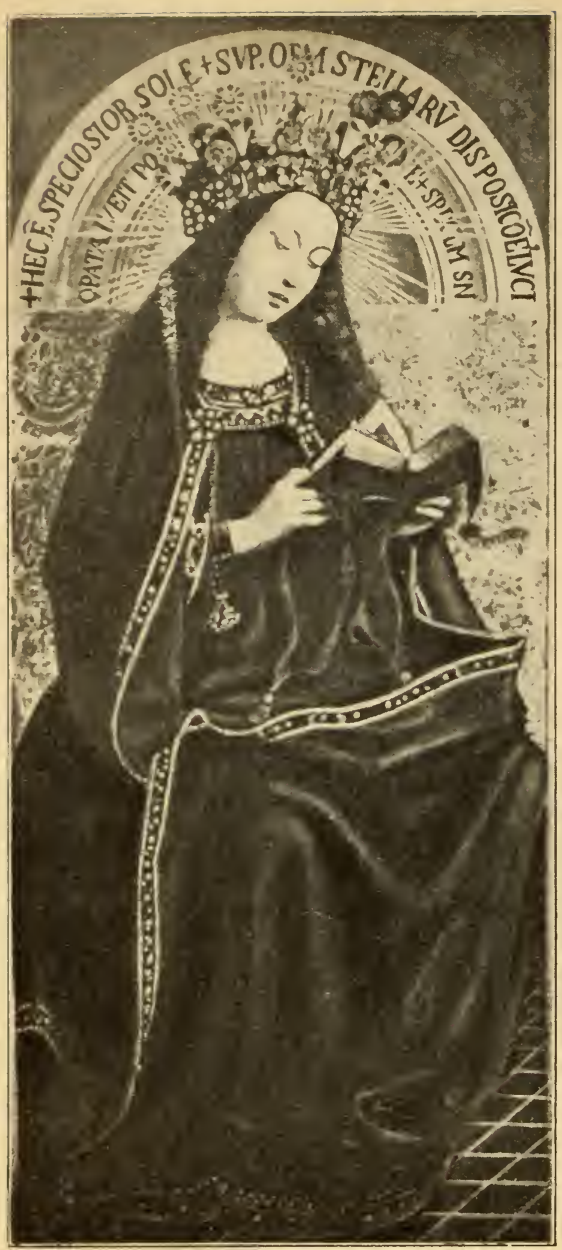

Ubb. 15. Maria voll der oberen Scite des (5enter Ultars.

ftellt eill Individum dar, das int Begriff ift, vor dem Tribumal cinen 2leineid ju leiften, und vom Tenfel geholt wird.

Sent bejitzt fonderbarerweife Feinen eigentlichen Lauptplatz. Der Buttermarkt, an dent fidh das Rathaus und der Belfried erheben, hat nidyt den mindeften monumen= talen Charafter und fteht in Feinem Derhältnis ju der Widhtigkeit und Größze der beident 5ebäude. Wir glauben nidat, da zies dies ju deren 2rachteil gereiḑt; die holhe und ftrenge Silhoutte des Belfrieds erfheint größerer, wenn biefer fich auf entgem Raume befindet, und went cimmal die bereits begomenen Zlrbeiten ifln freilegen, wird das (Gebäude an zrajeftät nur verlieren fömen (2lbb. 16).

2lls mehr dem jedhshundertjähriger Jenge von freud und Seid der Stadt, und crwadyen aus der Befreiung der Gemeinden ift von feiner Spifze oftmals der Ruf $j^{u}$ den Waffen erflungen und an den Tagen des Sieges lief das $\mathbb{E}_{\mathrm{r}}$ oft feime frohen Schwingungen ertönen. Roland, die groķe (5)locke, 1524 aufgejogen, wog nicht weniger als 12000 Pfund und ihre Infhrift that felbit ihre Rolle Pund:

Dese clocke die gheheeten is Roelant, Als men se luut ist storm int land.

Roland ift der Rame jentes fagenhaften Paladins Karls des Groken, deffen Klorn meilenmeit über Berg und Thal erflang.

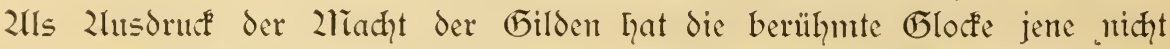
überleben dürfert. Es heirst, daris fie durdh eine Kanonenfugel jum Sdqweigen gebraḑt worden jei; 1659 wurde fie als blofeses 2rietall verfauft, und aus ihren Crümmern entitand das Glockentpiel, das fie heute erfetst. Wenn die Sache fid fo verhält, fo fehlt es ihl nidgt an Poefie.

Der Belfried ift auf rechtefigem (5rundrif erbaut, $1 / 83$ entworfen, aber erjt

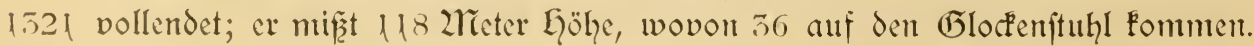
23is 1831 war der Glod"enftubl von Golj; dann faut die Stadt ju dem Entfdyluffe, ihn durh eine endgültige Befröntung ju erfekzen, und jwar entfhied man fid, was

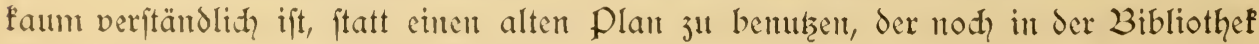

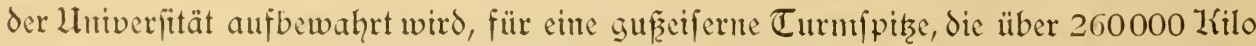
wiegt! Seit 185.5 hat der 33 an diefer enormen Belafturg widerftanden, deren ver= 
antwortlicher llrheber merfwürdigerweife ein 2lrḑiteft Laments Roclandt ift. $\mathfrak{Z}_{n}$ jeder feiner Seiten hat der Tum drei Reihen von lanjettförmigen fentern; fie bezeiḑnen die Stockwerke, deren jedes ein Jimmer bildet. Das mittlere diente, wie immer, jur 2lufbewahrung der Privilegien und Ltanden, die in 'einer Eruhe

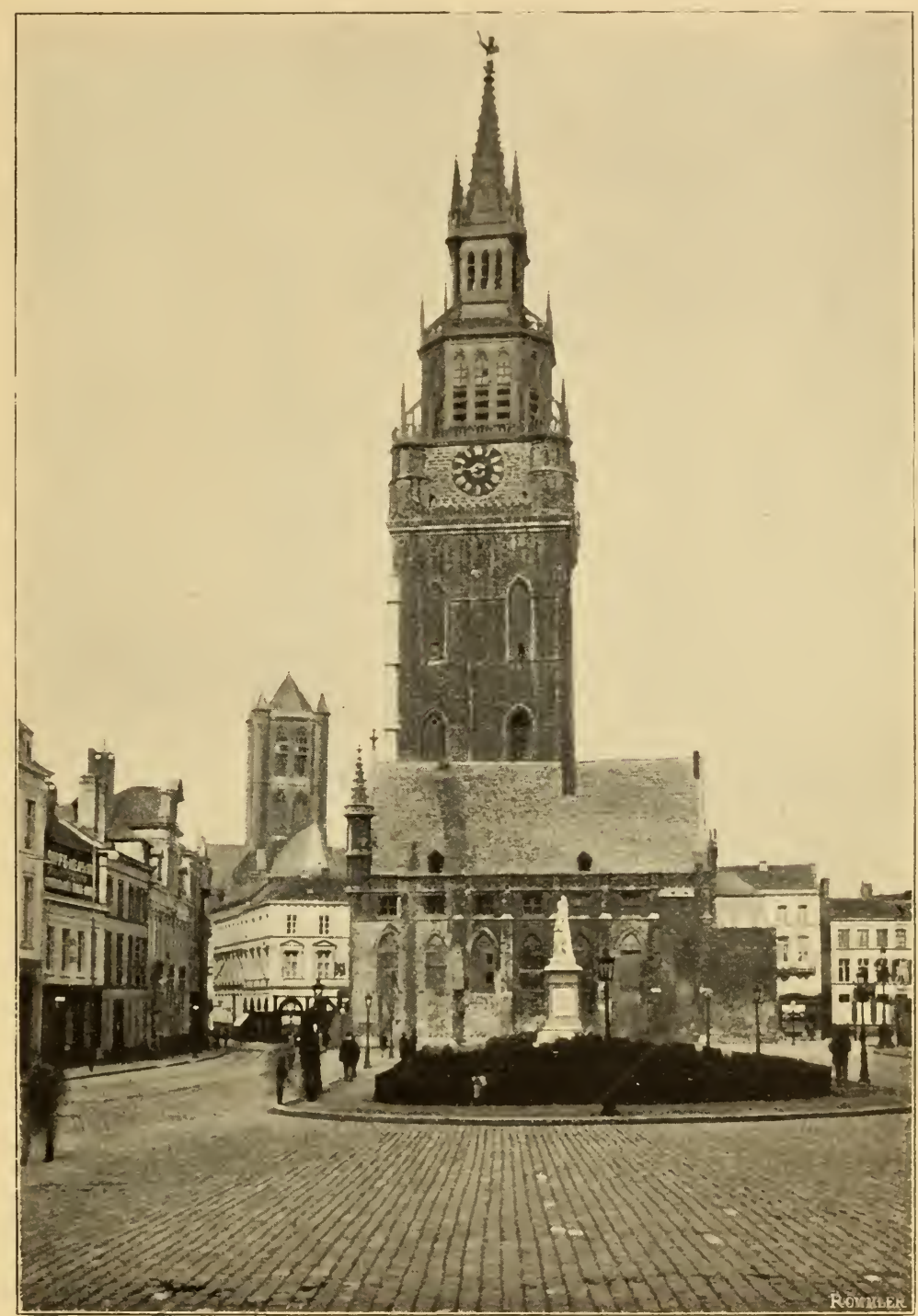

2ubb. 16. Der Belfried und Seitenanfițt der Endịalle.

mit vielen Sḑlöffern ruhten. Die fenfter find auf der ganjen Lö̆he des Turms jugemauert; es ift öfter davou die Rede gewefent, fie wieder ju öfinett. Zíluger: weife ift man davon jurücigefommen, und wem man fich doch eines Tages daju entfhliefzen follte, diejen Derfud ju madhen, fo wäre es das Bufte, juerft den eifernen Gelm abjunehmen, der den Bau belaftet. 
Zuf der Gähe hielten đag und Laaht die Wähter LImifhau. Der Dradpe von vergoldetem Kupfer, der die Spizze frönt, wiegt 180 Kilo. Sange Jeit bes trachtete man nach. Annahme von Sanderus und anderen Chroniften diefes Sinn= bild der bürgerlidhen freiheit als eine durd die Krenjfahrer aus den Grient mit= gebradyte Trophäe, die nach Brügge gefommen und erft fpäter, 1382 von den

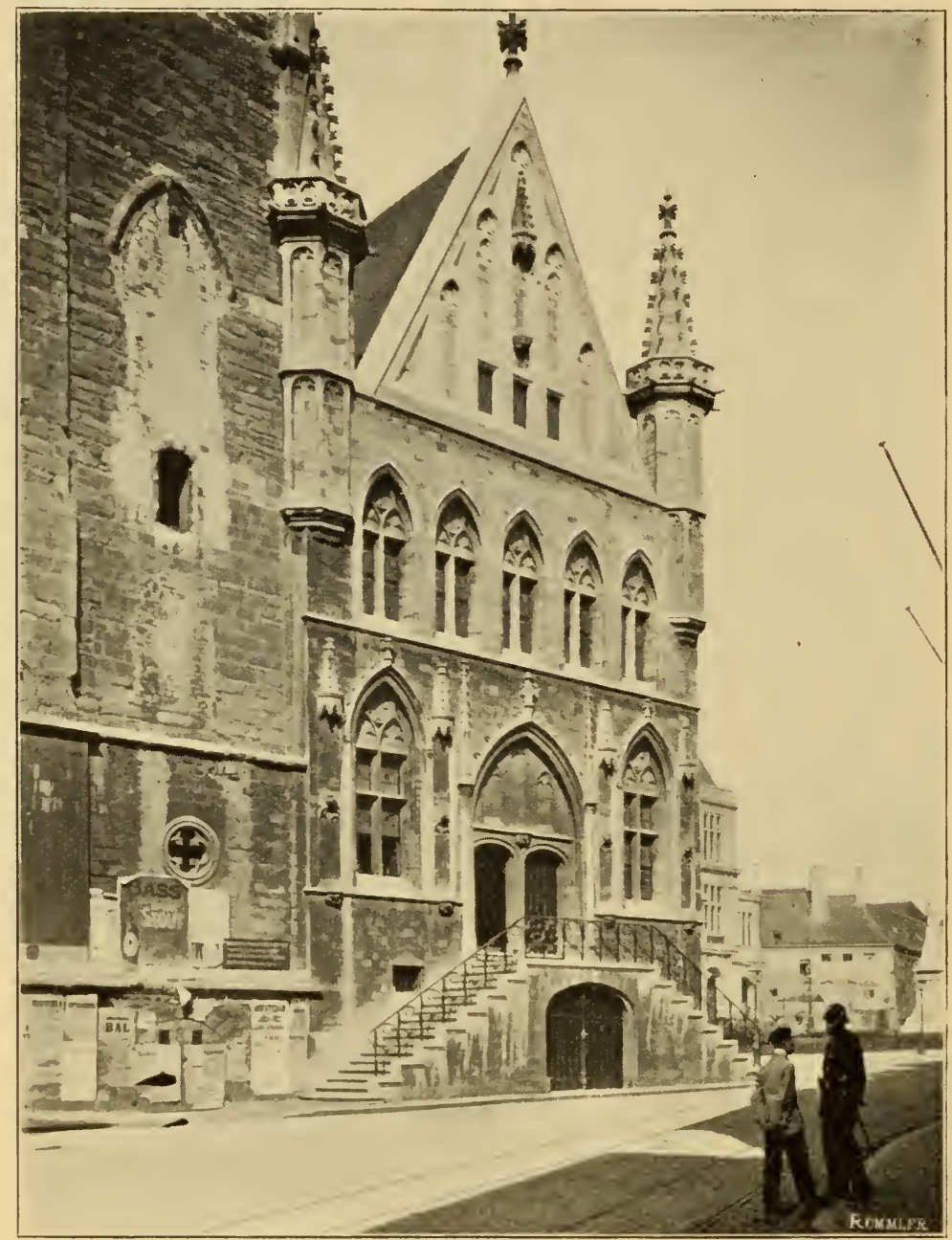

Ubb. 17. Die Tudhalle, vordere Seite.

Gentern als neues Siegeszeidhen weggefhleppt worden fei. 2ridhts von alledem ift wahr. Die Rechmungen der Stadt ftellen feft, da zer Draḑe in Gent felbit im 14. Jahrhundert angefertigt worden ift. Ebenfo hat man damals die Edfen der $23 e=$ frönungsgalerie mit vier fteinernen Kŕriegern gejiert, von denen nut einer den 21 tubilden der Jeit widerftanden lqat. Wir finden ihı im Zruffée lapidaire wieder (2lbb. 53). Er bildet bei einer bjöhe von naheju jwei 2leteten ein wertvolles Doḱument für die militärif hhe Befchichte von flandern in 2littelalter, obwohl er in Wirflichéeit fid wertig von den Typent der gleidhen Epodye entfernt, die man anderswo findet. 
Der fur des Belfrieds libut fich an die Tuchlalle an und heide ftimmen vortreffich ju einander. Dagegen würde es fdiwer feit, in gattj Europa cine fo auseintanderfallende Derbindunt - die Worte Lejeiḑnen fhon den 2lïip̌elang ju funden, wie die faffade des ziathaufes, das fidf auf einer ganjen Seite des

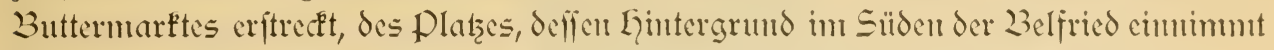
(2Abb. 1). Ljier redet alles von den widerfpredjenden Tendenjen und liefert uns das fhlagendefte Beifpiel der (5ejhmad'swanthung, die fid in saufe des 10. Jahr: humberts auf dem Gebiete der 2liḑiteftur volljog. Sdyrofi, olpue Llebergang ftellt

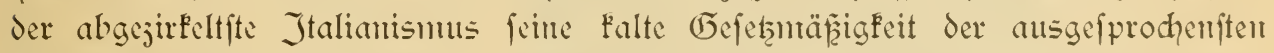
flamboyant=-5otif gegentiber; fo befteht das Rathaus gleidyfant aus jwei (5)ebäuden.

Das älere ift, wie faft alle Werfe der Zlrdyitefter Rombout Keldermans und German de Waghemafere, unvollendet geblieben. Der Plan der beiden vortrefflidyen 2lieifter, der nod anf der Lluiverijtätsbibliothee aufbewahrt wird, ift vont Jahre 1517 datiert; er ift faum $3_{\text {ul einem }}$ Diertel ansgeführt und feltfanterweife fteht diefer Teil niḑt all dem Plakze, wo der Belfried fich erhebt, fondern rechtwinflig daju nad, der Rue Gaut=Port. 2rod, daju fint hier mur 15 fenter front aus=

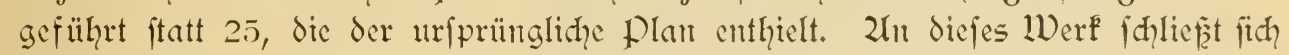
nad) dem Platze ju cine flafitifitifhe faffade von dre Stodwerfen an. Zln diefer felben Seite fund nur vier fenfter ftatt fiebjehn von dem gotifden Ban ausgeführt worden. Es ift gewir werfe vertrug; dic Wirfung wäre cinte blendinde gewefen. Die ausgefülyrte Partic ift ilhres grofen Rufes würdig. Das Efftürmdhill, der (5ang, voll wo man bie

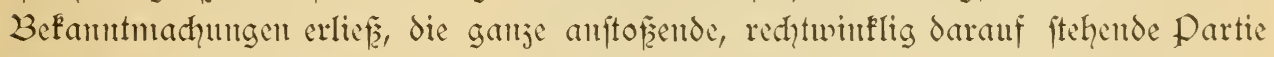
mit ihren. 2iifdyen (deren Statuen verfḑwunden find), mit ihren Spiz̧türmḑen und त) auserlefener Dinge in 2liechehn, Zhutwerpen und 2litidelburg (216b. 19).

Im Jahre 1555 wurden die 2lrbeiten mit einem Sḑlage wegen der in Gent ansgebrodyenten Unruhen unterbrodhen. 2lls man fie nadh fechjig Jahren wieder aufnahm, hatte der mene Fefdymad den Stil von Keldermans und Waghemakere als barbarifh verfdrieen. Es ift ein (5lïl, daf unter der Gerr:

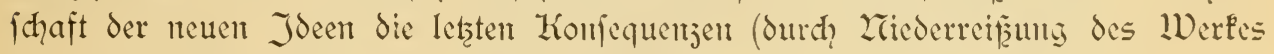
der groféen 2rrchiteften) niđht gejogen wurdent.

Die nene faffade mady dem Buttemarft $j$, die von Sdynafe mit dem Palajjo Contaro in Denedig verglidenen worden ift, erfachnt als das Widerfpiel des urfprüng= lichen Entwurfs (21bb. 18). Wie das Stadthaus in Zlntwerpent hat fie ihre nad? Drdmungen übereinandergeftellten cingelaffenen $\Xi$ änlen, ganj nad den Theorien von Sebaftian Serlio, die Pieter Coect unt Dredeman de Dries in den Zriedcrlanden populär gemtaḑt hatten. Jmmrerhin faum man, trotz der Lälte, die aus der llicberholung dicfer neunzehn fenfter in brei Etagen hervorweht, niḑt fagen, dar dicfer Teil des Banes ohme Derdienft wäre. Wir find fogar verfudt, in biefont vormelymen llerke die Lrheberidhaft von Dredentan de Dries felbft ju erfemen, was gar niḑt io übel wäre. Die Dadfenfter, die ganj bejonders an den genanten 2lrdhiteften

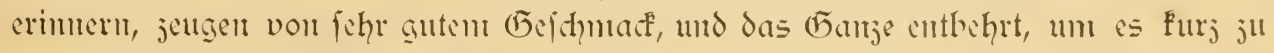

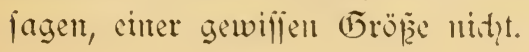




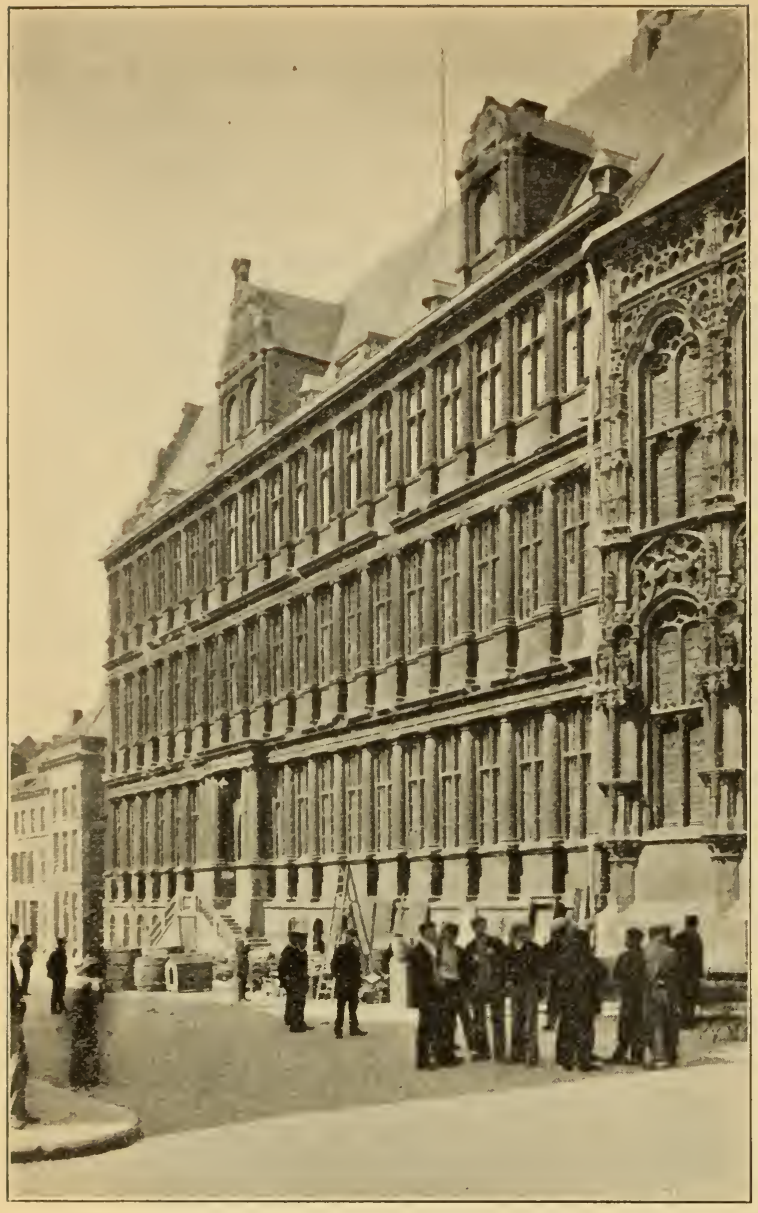

Ubb. 18. Das Stadthaus. Renaiffanteteil.

Diefer Teil des Ratlquifes wurde 1602 beendigt. Die Jeit hat ein wentig das 2rbito żende gemildert, das in dent 2lufein= andertreffer jweier fo diametral entgegengefetzter Stile gelegen ift.

Beiläufig wollen wir be $=$ merken, daf das Rathaus Feine hintere faffade hat, und dañ die im newen Stile gehaltene feitlidhe, nad dem Eeflügelnarft ju, plöhlich abbriḑt.

Das Innere trägt die unt= leugbaren Spuren der im Saufe der Jahrhunderte eingetretenen Deränderungen, fowie des 2lian= gels an cinheitlicher Seitumg bei dem fortgang der 2lrbeiten. In cinem der interen Қ̆̈̈fe ftammen bie vier Scitent aus vier ver= đdiedenen Jahrhunderten.

Llufere eెeit hat fid nit lobenswertem Eifer bemüht, die 2rizizhandlungen jeder 2urt ju fühnen, denen das verehrungs= würdige (5ebäude ausgejełzt ge= wejen war, nicht allein durd fahrläffigleteit, fondern aud durd dic Llufemutuis früherer (5ejhledyter in Sachen der Baufunjt des 16. Jahrhunderts. 2lit diefer Wieder= herftellungsarbeit hat Diollet=le= Due cinen erhebliden 2lnteil. 2liangels ciner durchaus beftimmten Erfentnis der lokalen Erforderniffe hat fie wentigftens das Derdienft gefhntackoller Jurn̈ßhaltung.

Der bemerkenswertefte Teil des Rathaujes ift die alte Treppe mit durd)= brodhenent Steingeländer, die ntan jweifellos mit Grund den uriprüngliḑen Zrdhiteften des Baues jufhreibt. Die geräumigen Säle, die Wandelhalle, der fogenanute Saal des 2urjenals, find mit ilgren majeftätifhen proportionen fehr wohl die eines 2liunicipalpalajtes. Die alte Kapelle, die ju ciner 2lrt Thronfaal geworden, ift intereffanter wegen der Eingelheiten, vornelymlidh des (5ewölbes, als in Zufehung des Gefamtemdructs. Der Beratungsfaal ift niedrig und dïfter; der chemalige Derfammlungsfaal des flandrifden Rats, heute Sdioffen=

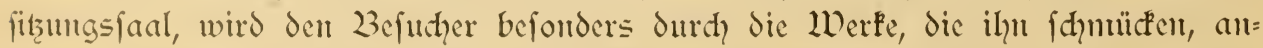
jiehen. 2lueser den Büfen chemaliger 2liagiftratsperfonen finden fidh hier Bild= niffe mehrerer Souveräte, die über Belgien geherrjht haben, befonders aus der 
öfterreidyifhen Epodze. 2liaria Therefita ift fitzend dargeftellt, befleidet mit einer

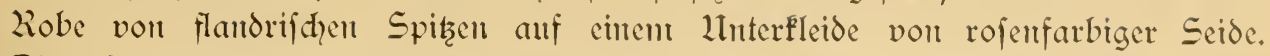
Dies Porträt wurde, wie man fagt, vou der Kaiferin illerer lieben Stadt (5ent überfandt, aus Erfentutliḑêt für die Schenfung eben diefes Spifzenfleides, das

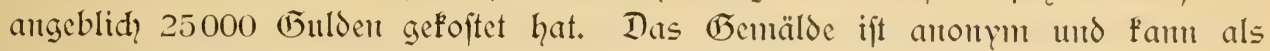

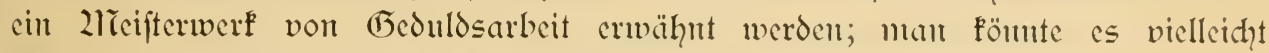
2liartiu volt 2lieytens juf dreiben (2lbb. 20).

Ein Zebengebände des Rathanjes, das nad, dem Eeflingelmarft zu liegt, 2rr. ?, unt früher vou der ftädtifḑen Wohlthätigfeits= Dermaltung benutzt wurde, befitzt einten beaḑtenswerten Saal, der wohl verdient, befanter ju werden. Er ift weder gro hod; er nimmt int Erdgejdyof cinen Ziaum von fedhs ju aḑt 2lietern ein; feine Goljfḑnitzereient tragen das Datum 1689. Eidhentes Getäfel lüuft rings um die Wände und der Raum hat einte Balfendecfe. Ein felpr fdïnter Ifantin von ge=

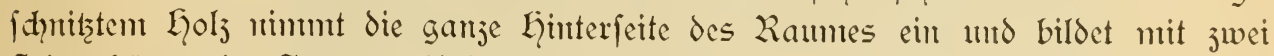
Seitenthüren eit Gantjes. Ueber diejen Thüren befinden fid beiderfeits gejdunitzte 2liedaillons von 2llbreḑt nuld Jiabella, währent das des Kaifers Karl V., vout

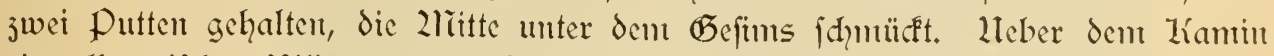
ein allegorifdes Bild von van cleef $(1646-1216)$, worauf der Kaifer throntend dargeftellt ift als Lelfer der Bedürftigen und 2lrmten, für die die Jungfran mit dem Zubjeichen der Stadt fürbitte leiftet. 2lu den Seiten find ge= iduniţte figuren von Waifen= Findern angebracht und in den Eteren fonderbare Guirlanden, gebildet von Klleidungsftïden der Waifen beiderlei (toe $=$ f̧̧leḑts: Gqüten, Strüntpfen, Schuhen u. f.w. Rings um den Saal über dent Gefims jieht fich eine Serie von (5)e mälden hin, die dic Werke Jer Barmtherjigkeit darjtellen, von Egidius Seplat. Eines davon ift datiert vort 1691. Seplat war ein zlĩaler ge= wöhnlidyen Sḑlages. Die Ljoljarbeiten merdelt Lorbert Sanvage jugefdrieben. Das Galtze ift fehr merfwürdig.

Die Gaut=Portitraze, an der ein Teil des alten Rathaus= gebändes fid hinjieht, verdanft diefent Llmitande cinen imtpo= nierenden 2ripelt, der Eindrud"

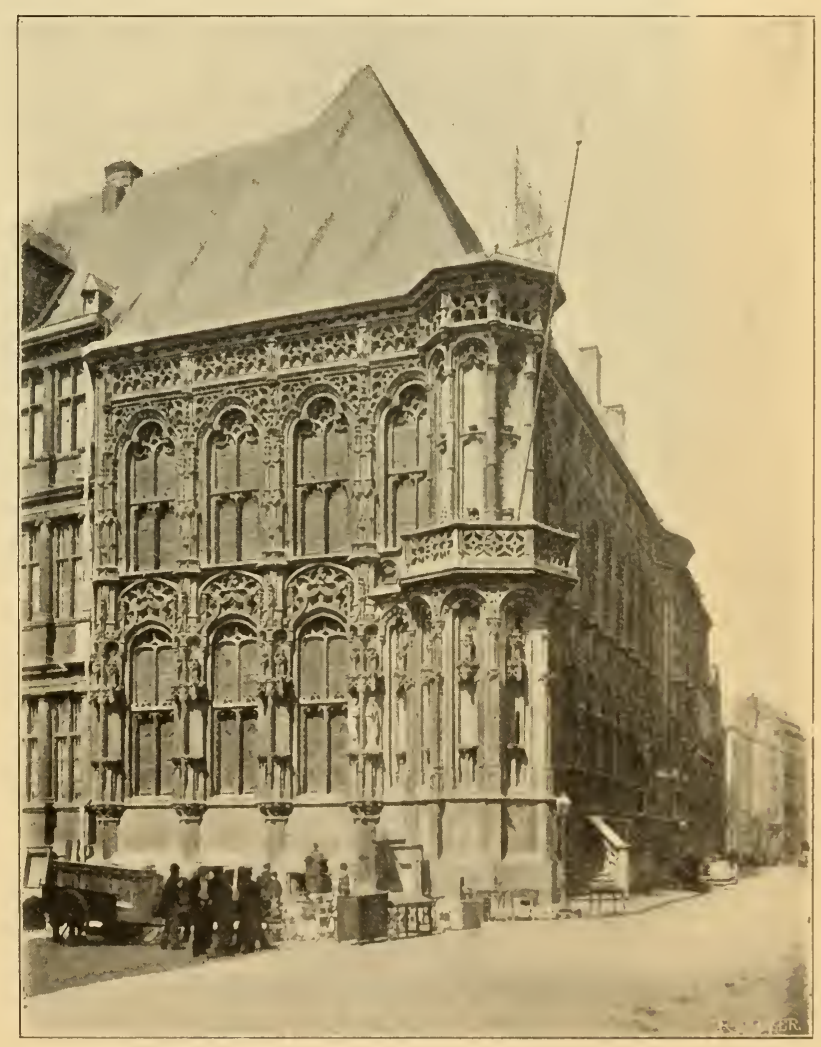

2ubb. 19. Das Stadthaus. Botifher Eeil. 


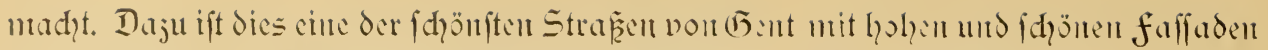
aus verfhicdenten öziten und unter ihnen cintige, bie als dic mommentulften gentant

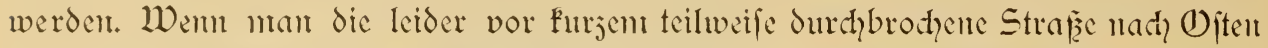

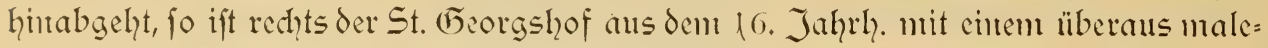
rifhen L Zir. 52, der Wafferverforgung der Stadt gewidmet, mit feitem David, cine fhönte faffade des 16. Jahyrh.; 2ir. 56, das Konfervatorium der zlüufif; "La Faucille" ", die

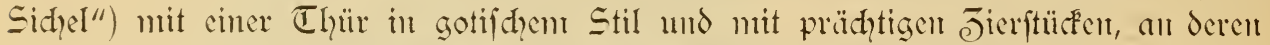

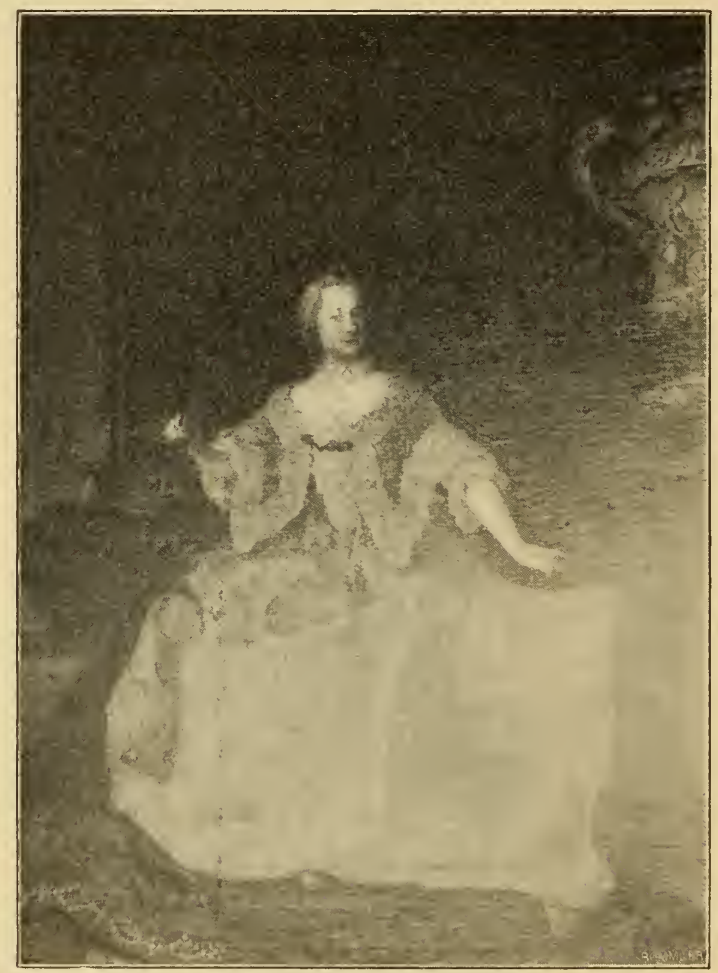

2ubb. 20. 2iathaus. Die Kaijerin Mraria Therefia.

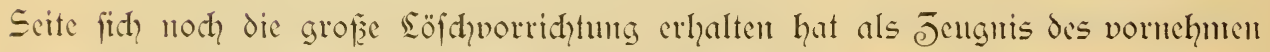
Llriprumgs des 23anes. Diefe fackelfödger, die heute fehr felten geworden fintoman kent deren nody zwei an den Thüren vornchnter Wohnthäufer in der Savaen= ftrußse -, dienten jum 2luslöfhen der fadpeln der kegleitenden Diener, fobalo dic

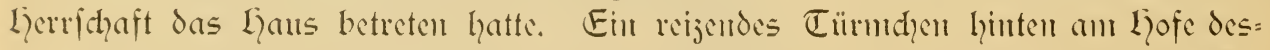
felben Lerrenhaules, cinft Palais der Thiemes und Simburgs Stirum, foll früher

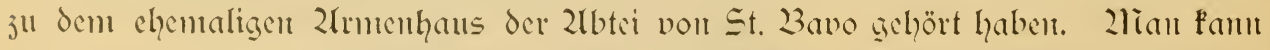

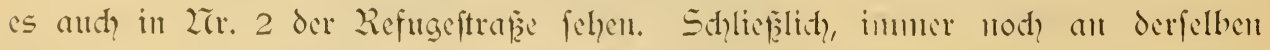

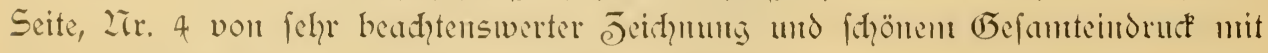

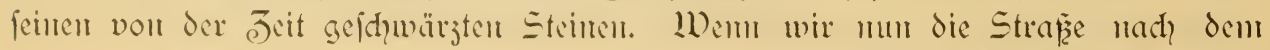
Rathans ju wieder hinaugachen, mu nath dem Lormmartf ju fommen, verfehlen 
wir niḑt, dill Teil des 2limnicipalgehändes im Stil des 16. Jahthunderts mit

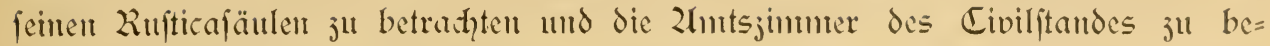
fintigent. Don der Rute de (5rainters (Jaad=Stege), die an und für fidh ju den intereffanteften jählt, oder von dem nidht weniger malerifḑen อెwirnfadengärishen (ruelle du fill Tors) aus ift diefer Teil des Rathaujes volt unuberbarer Wirkung. Wem man den Kormmarft betritt, ift man vor allem frappiert vou

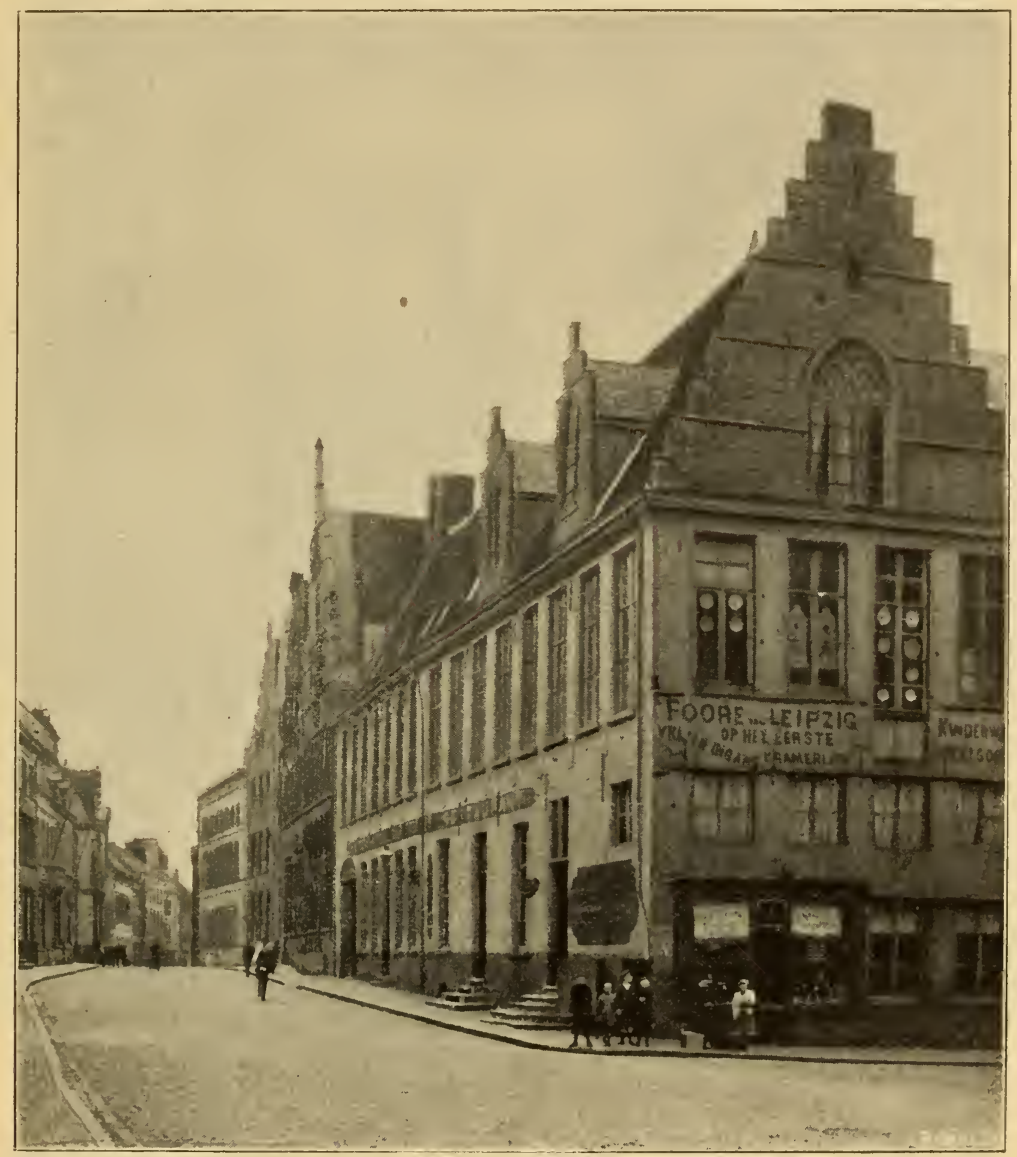

21bb. 21. Die Gant=portfrabe, der fogenamute St. Georgshof.

feiner eigenartigen Erfheinung der fhönen fluḑt von Gqäufern mit deforativen faffaden, die man vor fith hat (2fbb. 23). Sie nehmen die gante Weftecite des

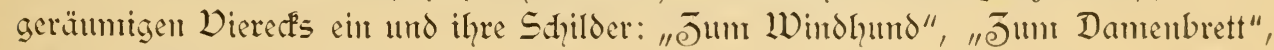
"ड̄um Wuapen vor Seeland" (1702) mit der ftoljen Devife: Dry Lquys, vry Erve (frei Laus, frei Erbe) giebt ihnen etwas von dent alten Wirtshansleben, ein 2lu= blick, der nodh veritärft wird durd die zahlreidyen Wagen, die an dent 2litattagen

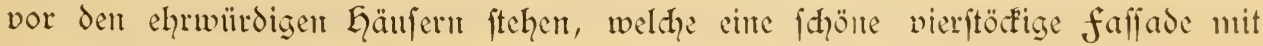
hohem (5iebel, vort 1652 datiert, beherriht.

Die Etudt Gent beabithtigt, die Zrifolatfirdye freijulegen, die wir jur Sinfen, 


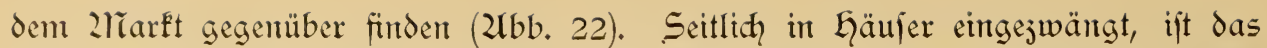
Shifï der Kirdhe den Blicken völlig entjogen. Die diiftere und graue faffade erinnert mehr an eine feftung mit ihrem maffiven rechtedfigen Turm, deffen Edfen mit Seitentürmḑen befef̧t find. Das Dortal, urfprünglid romanifh, mit abge=

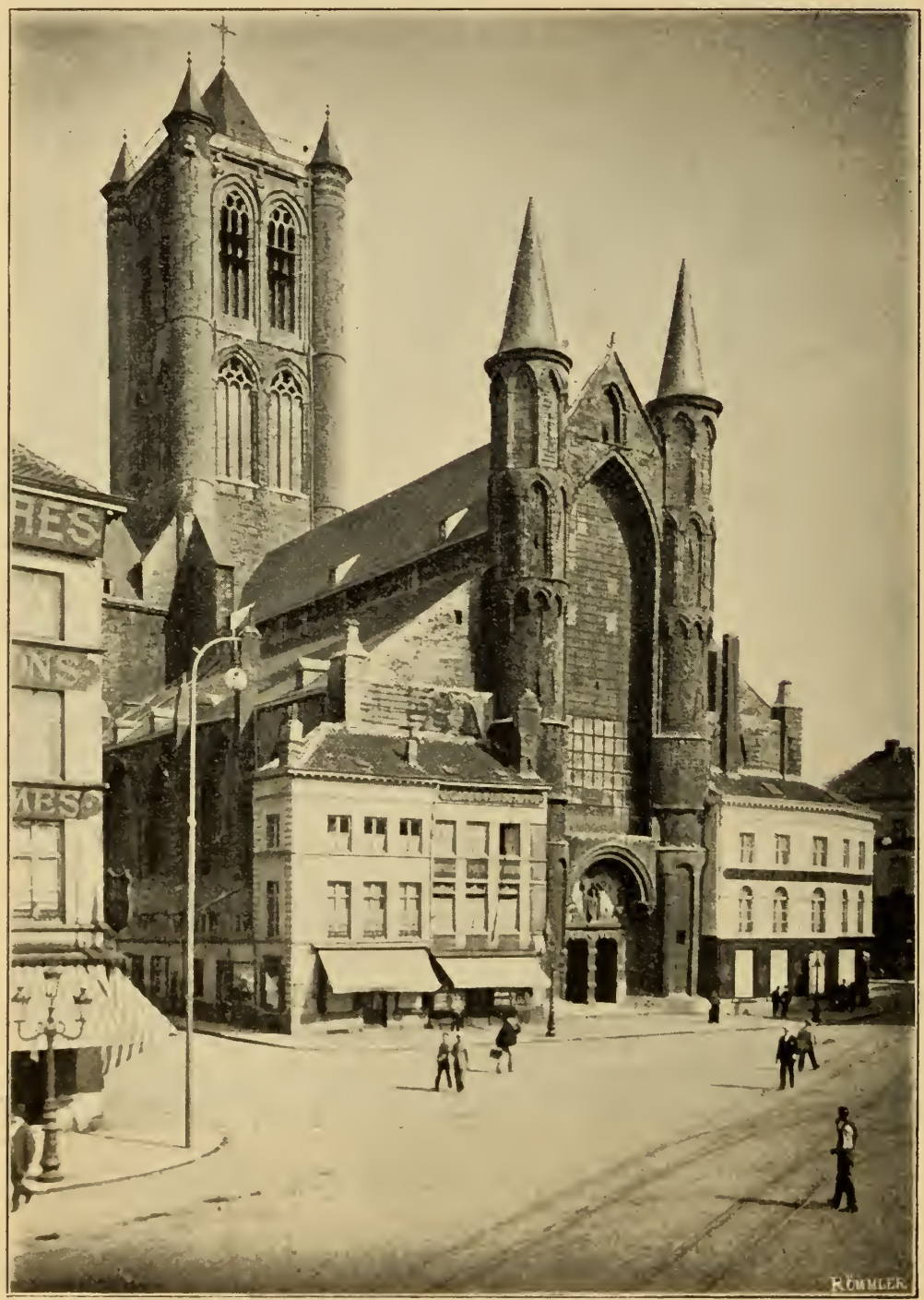

21bb, 22. Die 2rifolaifirḑe.

fetzten Wülften, ift wie übrigens der kejt der Kirdhe infolge von partiellen Re= fonftruftionen verdorben. Die faffade hat aber trokzden viel Charafter bewahrt

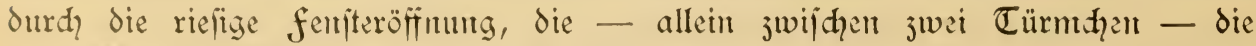
architeftonifhe (Grutdinte bildet. Der Dierungsturm datiert erft aus dem 15. Jahr=

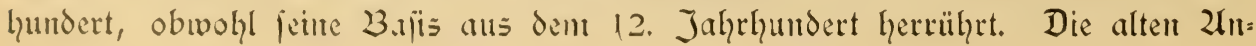




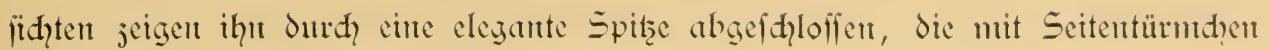
verfehen ift.

Das Jumere diefes Turms ift jehr intereffant; es enthält in der älteften Partie einen geräuntigen Saal, 12 2lieter hod und 9 2lieter 15 Centimeter breit mit 3 wei tibereinandergeftellten Reihen von Säuldhen, die mit der Zlianer verbunden find; die unteren biefer faljhen 2 refaden find in rommifhem $\subseteq$ til, bie oberen gotifd und jeigen fo die Bauperioden an.") Im Jumern ift die Kirdie entfellt und die

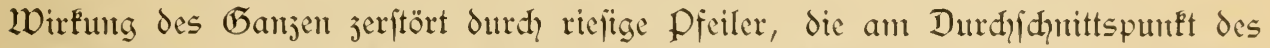

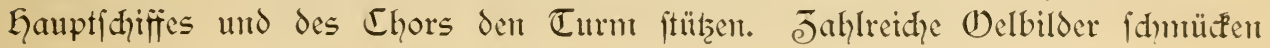

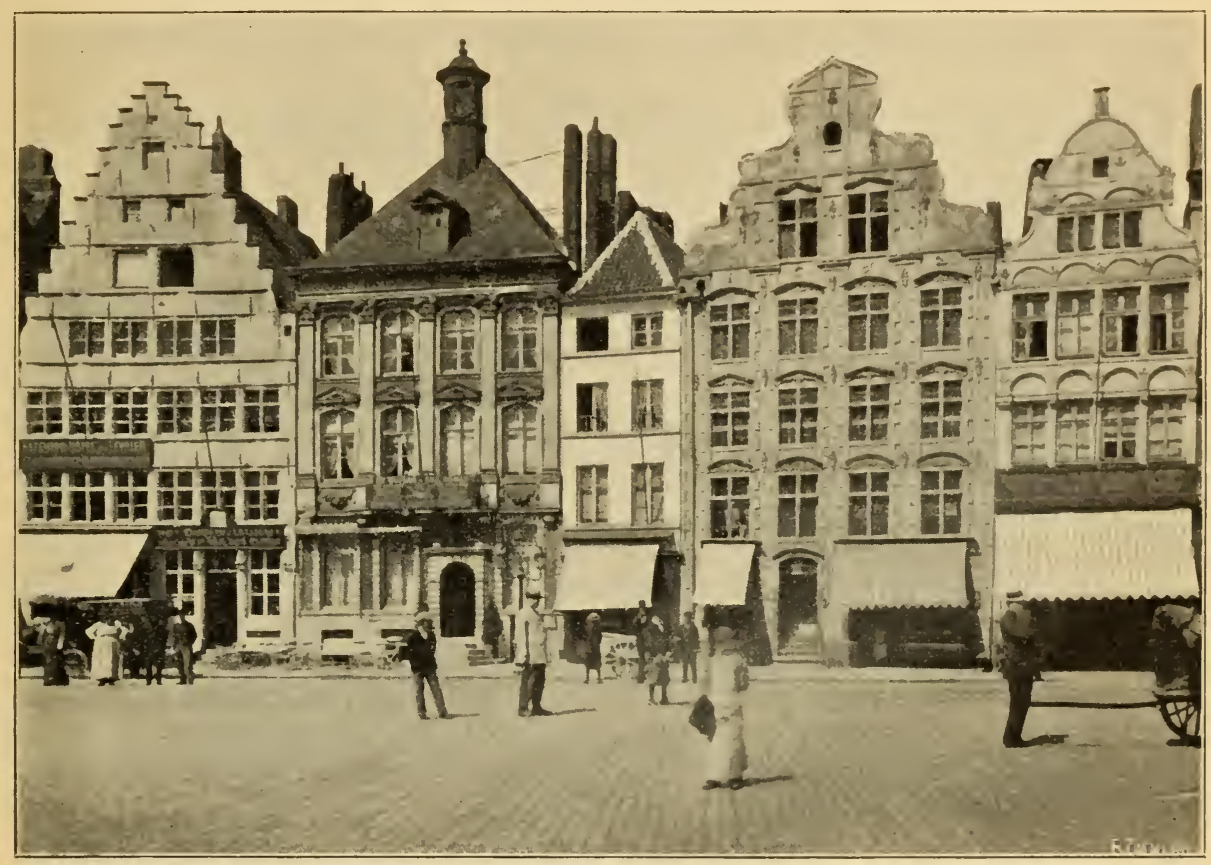

2lbb. 23. Der Kormmarft.

Sie Kapellen, feines davon ift aber erften Ranges. Die beften, aus dem 17. Jahre humbert, rühren von einem (5enter, ziifolaus de Siemafere, genamt Roofe (1601 bis 1646) her, der ebenjo wie Sinbens ein Sdüller des (I)tto Denins war, und von

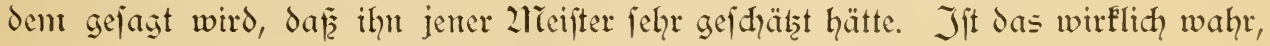

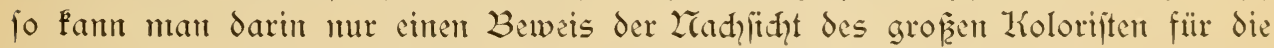
Urbeiten femer (Jenoffen fehen, die die Zatur wentiger verfdqwenderifd mit ihren Gaben allsgeftattet hatte.

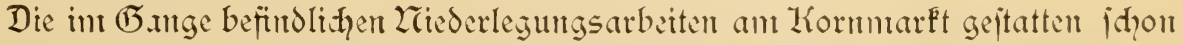
die hintere falfade des S.tiifierhaules ju betradyten; es genïgt, die Sternjtrake jull verfolgen, die eben verbreitert wird, unt an das 2 fir der seie ju gelangen.

*) Dyl. die Reproduftion diejes (5amahes im Messager des Sciences historiques 1852 5. 308. 


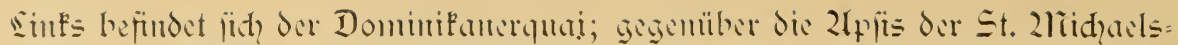

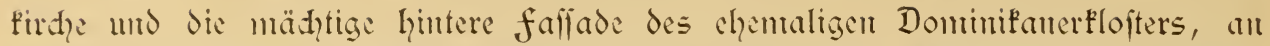
deffen fure beftändig Sdriffe feftäemad\}t jumb (2fbb. 24). Ein Bild von fdyönfer Eigenart. Jur Red̨ten befindet fïd der Zreäuterquai, der allgenteine Berülymtheit geniefit und tumfendmal abgebildet ift.

Es wäre wohl etwas gewagt, ju behaupten, da ż micre Dorfahren nitht im geringften an die Sdhönheit der Diforation gedaḑt hätten, als fie hier dicje ans= crlefenen falfaden häuften; democh wird man angefidyts diefer präḑtigen Gäujer= flucht verfudt, ju fagen, da die Bammeifter geleitet ju haben fheint. Jutem find die Bauepodhen aud verfdieden. Das Sagerhaus (Etapelhuis) datiert aus dem 15. Jahrhundert; feine



2tbb 24. Das ehemalige Dominifanertlojer mit der 2tpjis non Et. MTidquel.

falfade ift dank der Dicke der 2lünern aufreht ftehen geblieben, während das ganje Jumere in der 2Tad)t vom 24. jum 25. Fibruar 1896 cilt Shaub der flammen

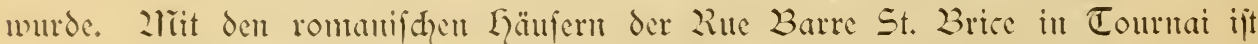
es eine der ältejten Profanhanten, die es in 23clgien giebt. 2hit femen abwedhelnd vierectigen und rundbogizen fenftirn, feinem hohen Gicbs, feinem Dorban ant

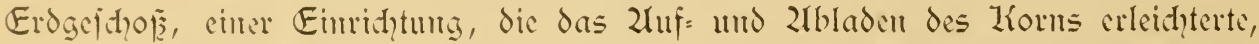

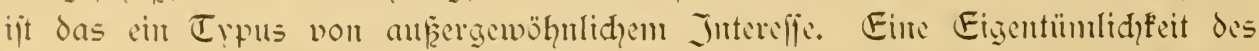
Sagerhaules ift, daf es rie Treppen gehabt hat; alle Sto fiverfe waren mit seitern werfehen. Das arfe Etodwerk war mu von der Stralic aus anf die angegebente Weife ju erreitiut.

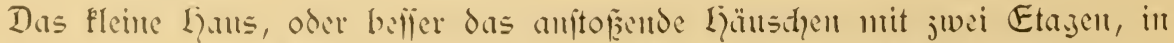

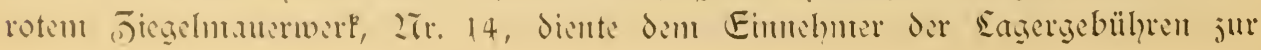




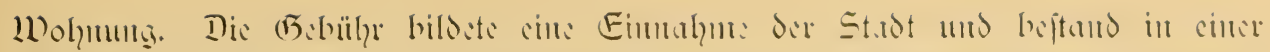

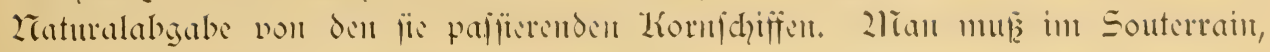
wo fid) cin Eaben mit früd)ten bef̈ndet, die maffiuen Säulen mit den romanifisen Zapitälen anfehen, dic das (bebände tragen.")

Es folgt mut das baus der Kormmeffer. Die falfade ift ftark werwittert,

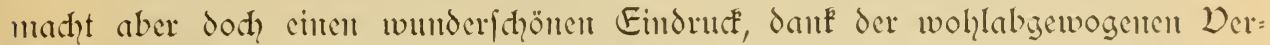
bälniffe. Es ift ein ansgejeidlueter đypus des vlämifdien loaules aus dem 17. Jahrhumbert ( 1098$)$ mit feinem Stufengicbel, feinen fünf $\subseteq$ tocfuerfen und feinen anf= einamderfolgenden Tranfleiften. Zllle (Drnamente, fo jalliteid) fie waren, fund verftumpft.

Dutd) das Windlpundgäpden getrennt und an den Kormmarlt angrenjend,

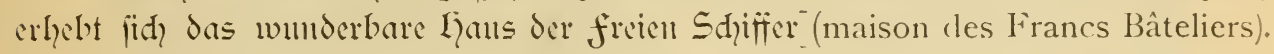

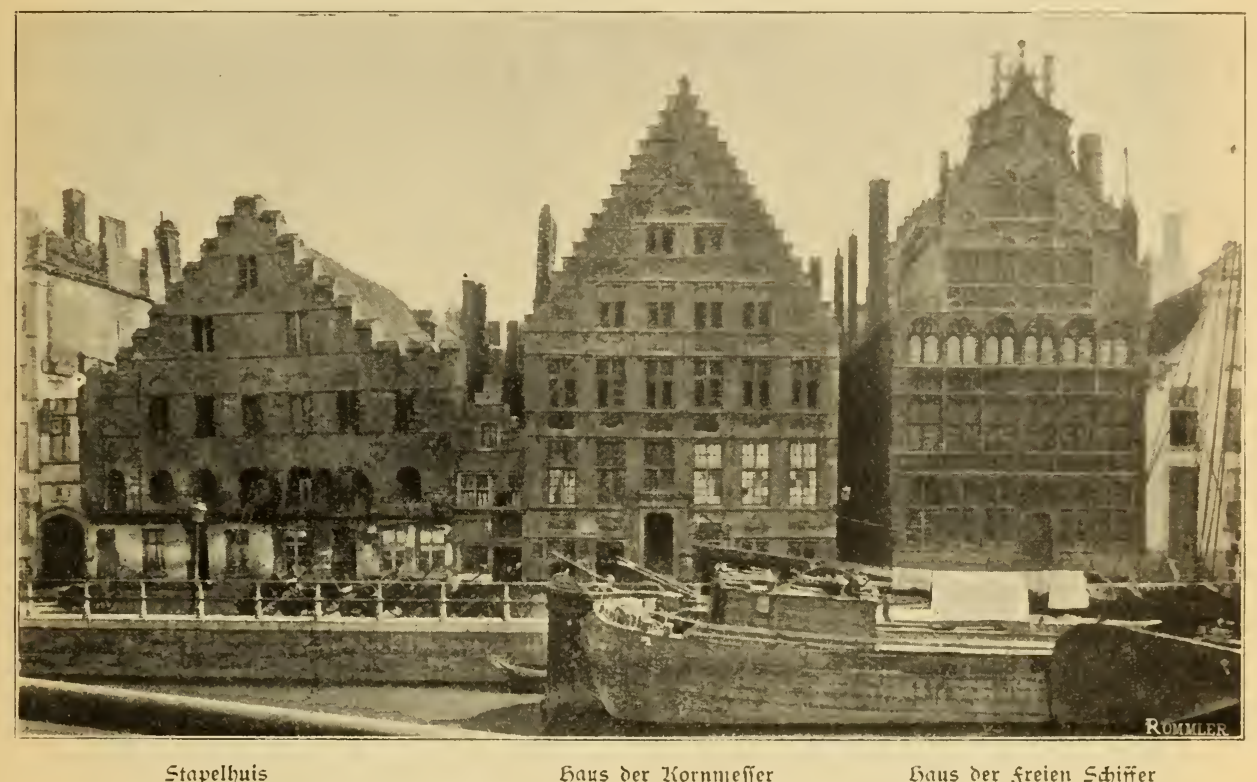

21bb. 25. Der Kräuterquai.

Es ftammut ans dem Jahr 1551, wie das Datum ïber der Thür anjeight, die

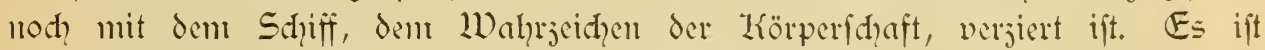
im Stile der flamboyantgotif gehalten. Die fenfter ser vier Stodfwerfe find

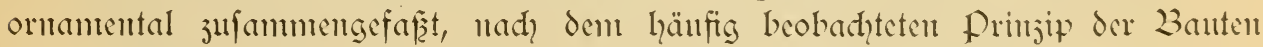

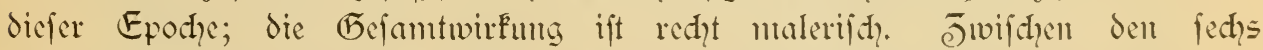
fenftern der erften und dar jweiten Etage befindet fidt cine Serie von Edjildern,

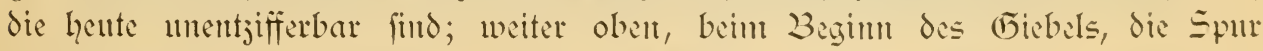
anderer Sfulpturen, wälprend man in der Lähe der vierten Etuge die gefrenjtent Etäbe nut den fenerftein des goldenen Drieses arüt, mas, mit den Sänlân, die auf den Dorfprïngen des Giebels ïberentander ftehen, auf Karl V. Bejug haben

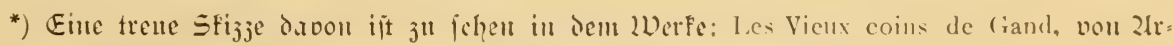
mand beills, 1898-1899. 


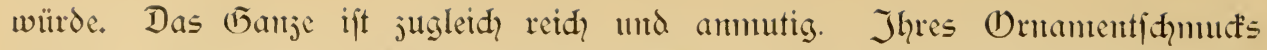

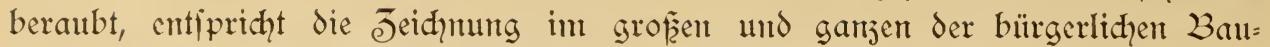
weife während eines guten Teiles des 17. Jahrhunterts.

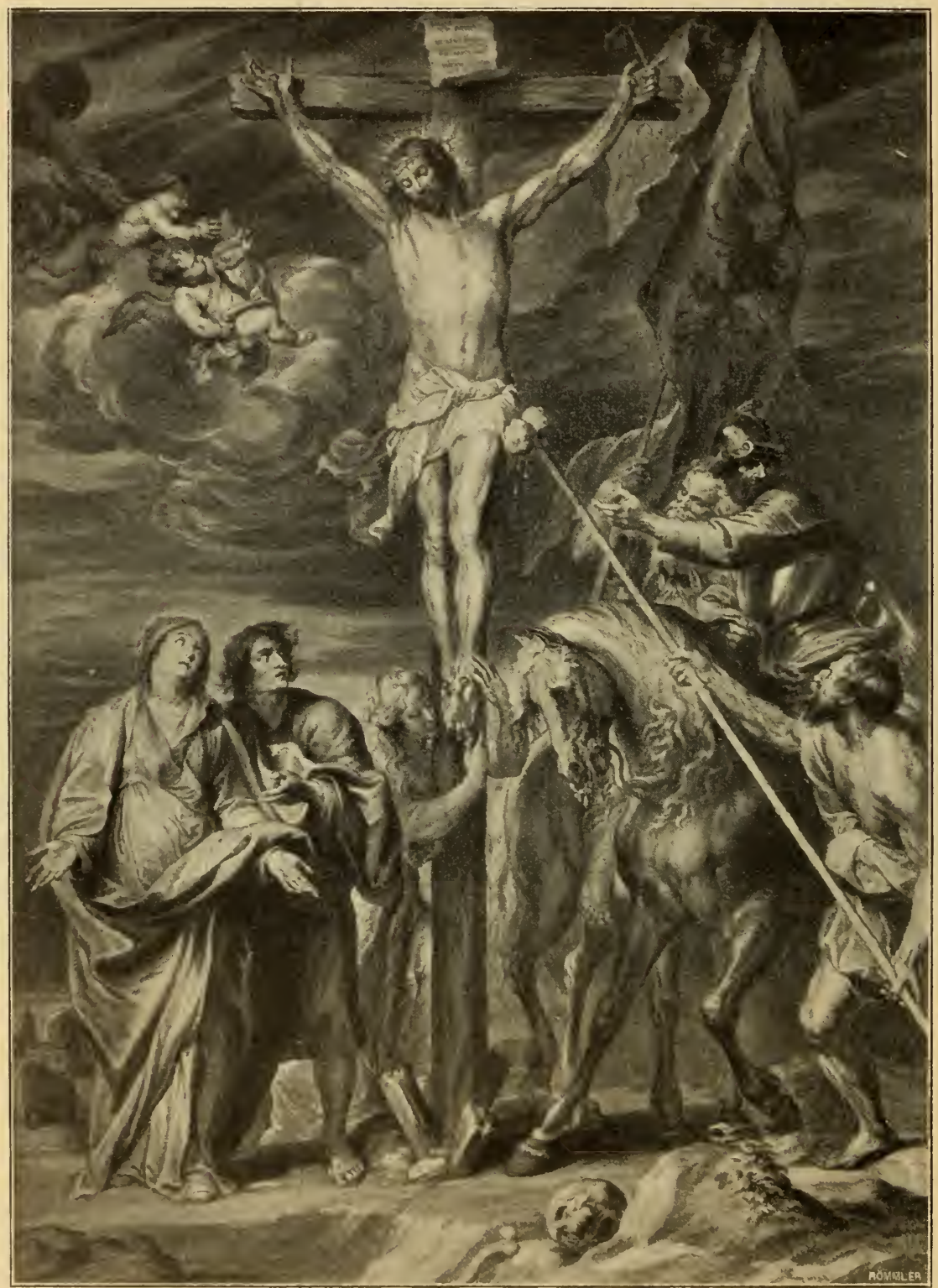

21bb. 26. St. Midqael. 2ut. van Dycf: Der fogentante Chriftus mit dem Sḩwamm.

(5ent ift cine Stast, bie man vorjugsweife freitags, ant 2liarftage, be= fidftigen follte; die Straken und Zais find dam den ganjen 2lorgen von der Zraffe der Zäufer und Derf̈üuer entzenommen, was den malerifden Reiz verdoppelt.

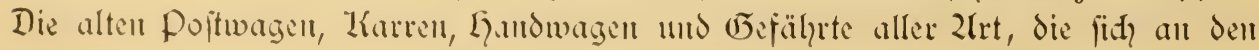


Straf̧enfreujungen häufen, geben der fonft fo ruhigen Stadt ein reiches Eeben. Der Eetreidefai, wem and von minderem Jntereffe als der gegenüber= liegende Irränterfai jeigt demtody eintige intereffante Gebände, j. 23. 2ir. 8, das Kaus der "unfreien Sḑiffer" aus dem 17. Jahrhumdert, mit einem Göicbel,

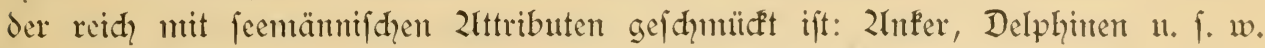

St. Zirichael, deffen $\mathfrak{I}_{p}$ fits wir vom Domintfanterfai aus fahen, ift cin Bau von duifterem 2lnblicf nit abgeftumpftent Curm. Die republifantifdze Regienung hatte ihn einft jum Tempel der Dermunft gentaḑt. Der Turm follte vierhundert fur hod werden; das 2rodell ift nod in ardyäologifhen 2lüneum ju jehen.

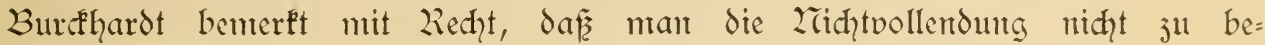
danern brandyt.

St. 21riḑael wurde 1445 begonten und ift niḑt ohne Grofzartigkeit. Eylindrifdhe Säulen von weifem Stein teilen den Raum in drei Schiffe; die Jiegelwölbuntg ift von fä̈ner Wirfung. Die Chor F́apellen jeigen Eemälde, deren ältefte niḑt über das 17. Jahrhundert jurücFigehent. Das bedeutendfte ift die berühmte Krenzigung von van Dyck, unter dem zamen "le Christ à l'éponge" befannt, wonad Bolswert uns einen bewundernswerten Stich Ginter: laffert hat (2fbb.26). Das 2lufueumi in Brilfel bejtizt die SFijze der Kompofition. Das Gemälde hat fehr gelitten und ift feit dent lekzten Jahrhundert mur nod eine Ruine. Bolswert war genötigt, nachdem die erften Zubjüge des Stiḑs gemaḑt waren, ein Detail, das in den Zlugen der Kirdhenworfteher jiemlid, widhtig war, abjuändern: die Land des hl. Johannes, die bei van Dyck auf die Sdyulter der hl. Jungfran gelegt war, was von der Eeiftliḑfeit als defpeftierlich angefehen wurde.

Die (5eifzelung, von Gerhard Jెeghers, in der neutten Kapelle unten an der Seite verdient Erwähnung als 2Meifterwerf des 2lialers. Es ift ein Werf groken Stils, von fđ̆̈nem Kolorit, dem man mur den Dorwurf jut reiḑer fülle in den formen des Chriftus maḩen fant. 2Tah dem Bilde eriftiert ein fhöner Stid von Dorfternatr.

Wir ïbergehen einen heiligen franj de Paula, der Ribera jugefdriehen woird, aber diefes berïhnten fpanifhent llialers unwïrdig wäre.

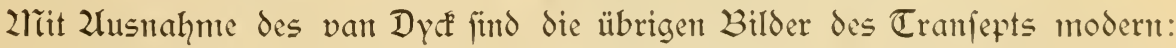
die Krenfindung von J. Paelint $(1781-1839)$, die Eimmelfahrt 2liariä von P. J. C. françois (1759-1851), endiđh die "Derkündigung" von 2. C. Sens (1793-1822).

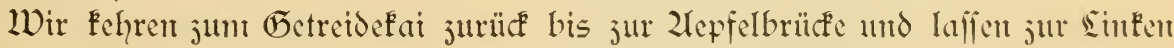

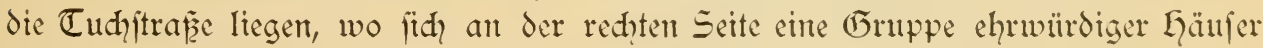
erhebt, deren Dadfinfte fidh unter der Sajt des zllters ju bengen fdyeinent. Die freunde malerifder Punte werden ihre kechmung finden, went fie auf dem Pont ant

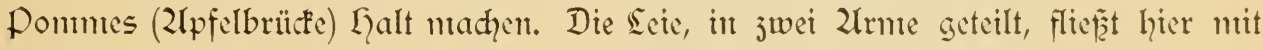
der Sieve jufammen; die Brüße überfhreitet dintgemär drei Wafferläufe und bietet nadh den verfhiedenen Ridhtungen intereffante 2lufiḑten dar. Don dem Durdeinander der Banwerke rechts löft fich die alte fleifhhalle ab, deren faffade wir auf der Derlängerung des (5emtijemarftes finden (2lbb. 2i). 
Lente dem Poftdicnjt gewionte, bildet die gerämuige, int Jaḩ 1404 er=

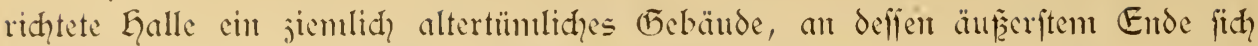
cin Pleines Café, la Potence, "in't Ealgenhuis" bejdildet, erhebt. Dieje feltame Bejeidunumg rührt volt dem llmitand her, da man didht bei demt (5)bände nodh

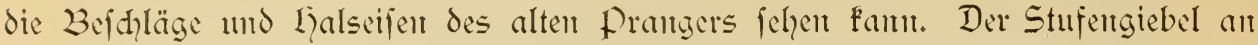
der 2rordicite mit feinen fenftern in Dreiftidhgewölben, feiner 2rifhe mit ciner

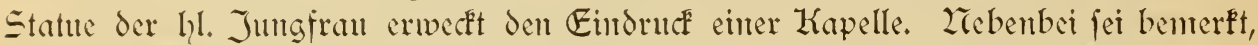
dar die 2labomtentigum ein Tintenfar hält, in weldhes das Chriftusfind eine feder einjutanthen fich anfhicft. Die 2lrchäologen haben bis heute dicfes Rätfel nidht ju löjen vermtodyt. Die fleifdhalle hatte wirflid ihre Kapelle, aber dicje

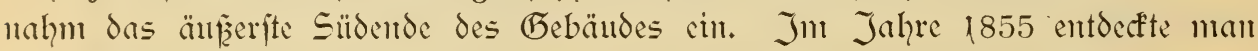

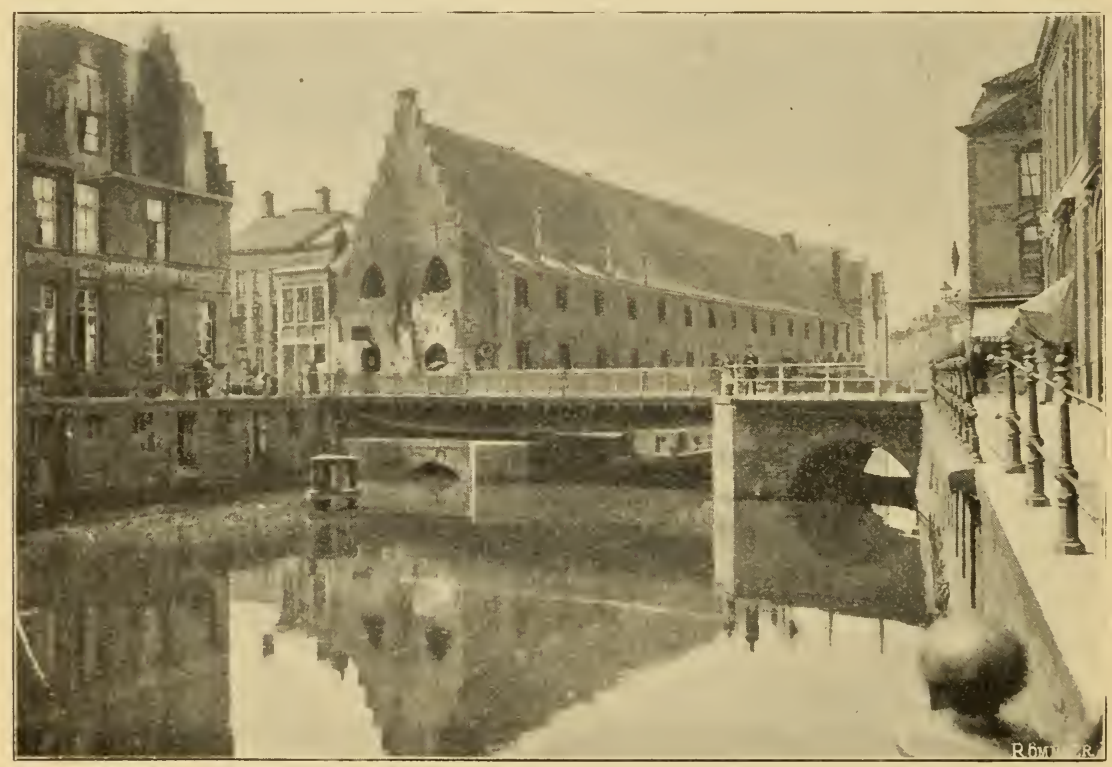

abb. 2\%. Die alte fleifhballe.

unter dem Put an der Wand, ohne Jumeifel an der Stelle, wo früher der Zlltar geftanden hatte, eine $\mathfrak{W}$ andmalerei in fđöncm Stil mo jicntlid gut crhalten; man hat geglaubt, fie dent (5)enter 2laler Labudyodonofor (2iabur) 2liartins ( $\dagger$ 1454) jufhreiben zu follen. Diejes Bild ift in (Del ausgeführt, mit der Jahresjahl 1448 bejeidunct, hat dic form cines Epiz̧bogens und ftellt die Geburt Chrifti dar. (1) ben jawebt (5ott Dater; unten futeen un das Jejusfind die Jungfrau, der hl. Jojeph und dic Jübin อ̈elevia (von der Sic apofryphen Evangelien fpredhen) und mehrere Engel. Jm Dordergrunde endid, betend Philipp der (5ute und feine frau Jiabella von Dortugal, deren Sohn, der (5̃raf von Charolais mo der jumbe 21 dolf von Eleve, Lerr von Ravenftein, alle erfembar an ilyren Wappen. Die Jufdyrift lehert, da diefes Dotivbild der Iforporation von Jacob von Ietelbuetere,

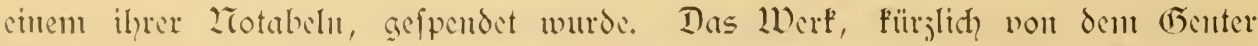

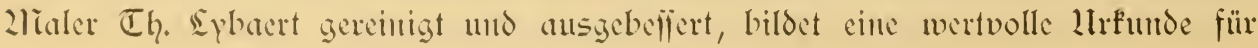




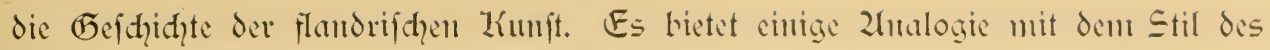
fogenamten zleifters von flemalle**).

Lum find wir an dem intereffanteften funfte unferes Spajierganges angelangt (21bb.29). Don der Kräuterbrüde ans jeigen fid, wohin man aud ben Blice rid)tet, die verfdjedenartigften Perfpeftiven, die faprijiöfen Sinien verbinden der länjer fid) mit dent wunderbaren Dordergrutd, den die Wafferfläche der Kanäle abgiebt.

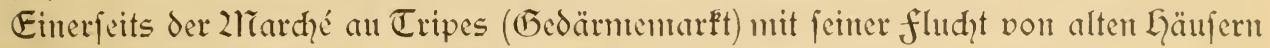
mit niedrigen fenftern; redhts der Iranthquai mit feinten Eçhäufern von ganj verfditedentent Stil und auf der anderen Seite die 2runmtern 5, 7, 9 und 11, die

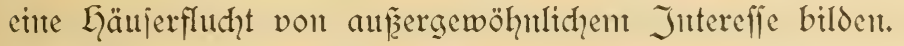

Der St. Pharalildemplat, an deffen Sïdweftede fid der an Rubens erimernde Portifus des fifdmarktes crhebt, der mit figuren des 2reptun, der Schelde und der sys deforiert ift (an Stelle der 1872 durd fener jerftörten) (2ubb. 28), jeigt uns

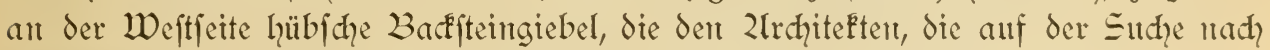
zlüftern des alten vlämifhen Stils fund, jum Studium empfohlen feten. Sie ver= dienen den hentigen $\mathcal{B}$ edürfuiffen angepafizt ju werden.

Zlber der Lquptanzielungspunft des St. Pharahildemplazes ift heute das padende zild des Grafenfhlolles, 's Gravenfteen, das die ganje 2rordeite bildet und

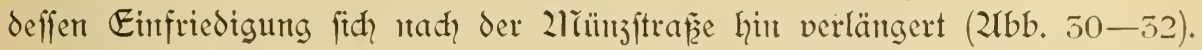

Es ift Fanm einige Jahre her, dafí mant in den fülhrern über diefes mädhtige Erimterungsjetchen der flandrifhen Dergangenheit lefen Fomnte: "2rur das Ein= gangsthor ift davon übrig geblieben." Wirklid, vermutetelt mur wenige, daĩ linter den Gäujern des Plakzes, die gewiffermafen in feine Krïmmmugen eingebettet waren, nod der alte Kern vorhanden war, den jene gleidham ïber= wudpert hatten.

Erft in Jahre 1887 fajzte die Genter Stadtverwaltung den löblidyen Entfdlufiz, ju erwerben, was man eine Ruine jut nerment fidh fhent, unt dell gewaltigften Reft der fendalen Epodie flanderns aus Sidht ju jiehen. Sanderus (Flandria Illustrata) jeigt ılts auf einem fetiter Stidhe das ganje Sḑlofiz, äuñerlid? faum verfhieden davon, wie es vor werigen Jahren nod war. Sdyritt vor Shritt war es int Sallfe der Jahr hunderte fojufagen gefangen gejetzt vou

*) Die angefïhrte "fresfe" ijt im Llınrif́" ftich, ïbrigens jiemlich verätıcrt, im M essager des sciences historiques (5ent 1859), S. 105) reprodtijiert.

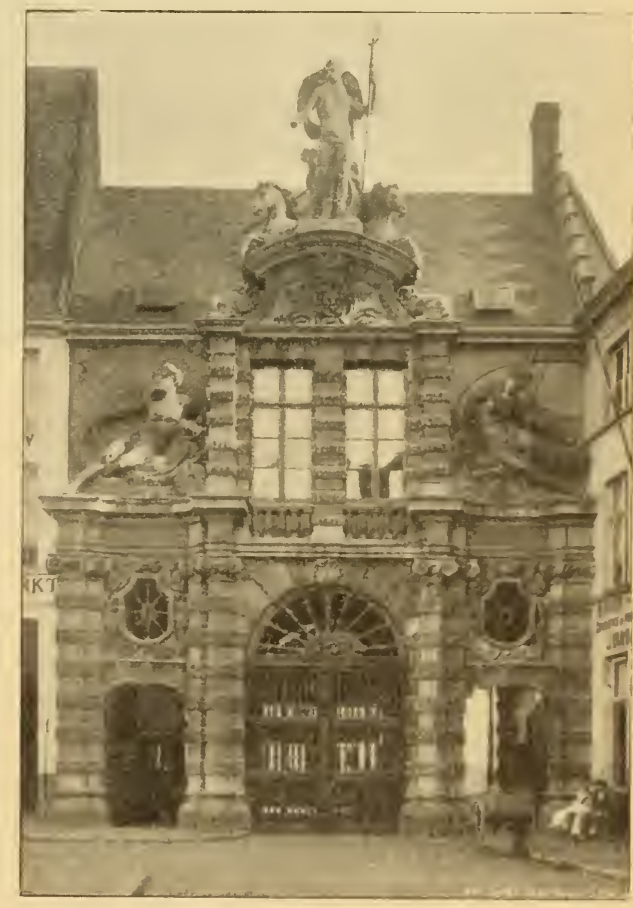

2ubb. 28. fallade des fifdimarftes. (2lus demt "Inventaire Arehéologique de (rand".) 
modernen Bauten, bis es fhliefilid niḑt viel mehr als eine Segende ward. Llian Fannte mur fein Eingangsthor, weiter nidhts. Das Innere war ju Werfítätten umgewandelt und es hatten fid unbejdreibliche Wohnhöhlen feiner bentädtitigt, wahrhaftige Kloafen, etwas, wie jene Ruinen, in denen die Llferbewohner des Tiber in der ewigen Stadt nifteten. Es iff ein wahres $\mathfrak{W}_{\mathfrak{s}}$ under, daf nidht cine feuersbrunft fhon lange den ZTachfonmten das foptbare Erbftilce nationaler Dergangenheit geraubt hat.

Don hier aus haben Johama von Konftantinopel, (5uy von Dampierre und Robert von Béthume Ltrunden datiert. Gier vielleiḑt hatte Zrrtevelde Unter= redungen mit Ednard III., hier wurde Jä̌baea von Baiern gefangen gehalten. Im 2liittelalter Centrum der Stadt, wurde das Sḑlofiz, das im 9. Jahrhundert erridhtet worden ijt, im 12. von Philipp von Elfar vergröferent und trägt die Spur

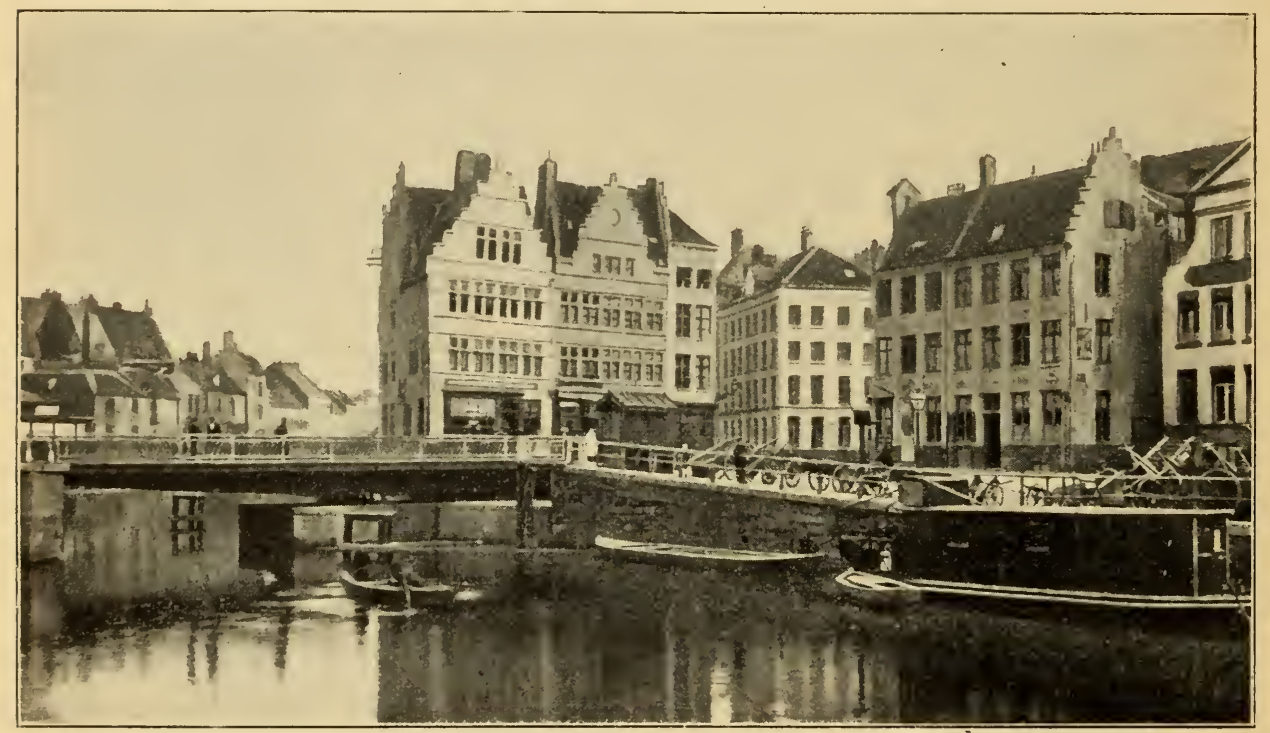

2৮bb. 29. Die Kräuterbriicłe.

franko=fyrifher Einflinffe, die ans Paläftina ftammen. 2lls Sitz des Rates von flandern bis in die Regierungsjeit 2raria Therefias, war es feit 1353 niḑt mehr, Refidenz der Sonveräne. Es war, (Eefängnis und feudaler Eeriḑtshof; unter feinent Bemölben find viele Ltuglüéliche der folter unterworfan worden. 2fls es 1729 verkauft wurde, überwies man es privater Bemulzultg.

"Ein Sdyild der entftehenden Stadt unter Z3alduin, dem fagenthaften Lielden

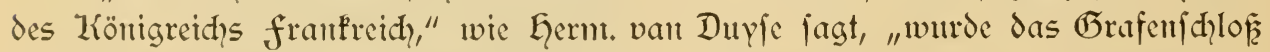
in 12. Jaḩrhutdert eine 2lrt 23aftille, eine Sḑuţweḩ für die argwöhnifa das

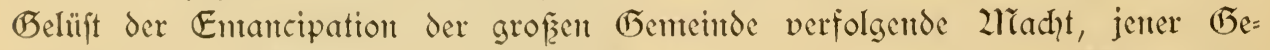
meinde, die die Ehre hatte, die ewige Dorfämpferin der freiheit im 2liittelpuntte des freieften Santes der Welt ju feir."

So wie es heute erdheint, ift das Sdylor fojnlagen cine Zuferitehung. Imt zorden und Weften ijt feine Lmfriedigung von den (5ewäffern der Sieve unfpült. 


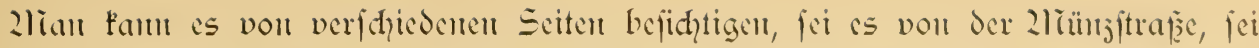

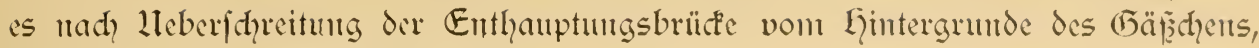
Detit (5ewat genanut (2)bb. 32).

(Dhue andere Virbindung mit der Zluzenuelt, als cinem gedecten Dorbau,

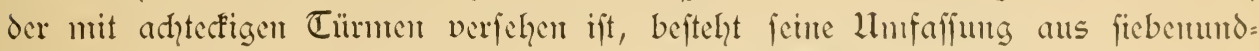

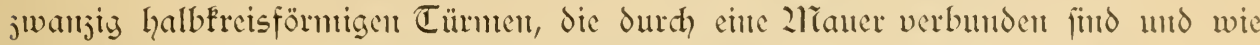

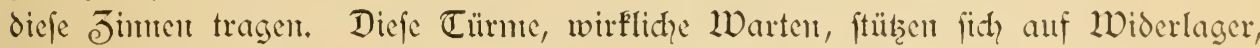
die vont Boden aufiteigen, und diefent Llmitande ift ohne Jెweifel das Wumber jujuf dreiben, da hat trotzen fömten. Die Wiederherftellungsarbeiten, die mit Einfiḑt unter der

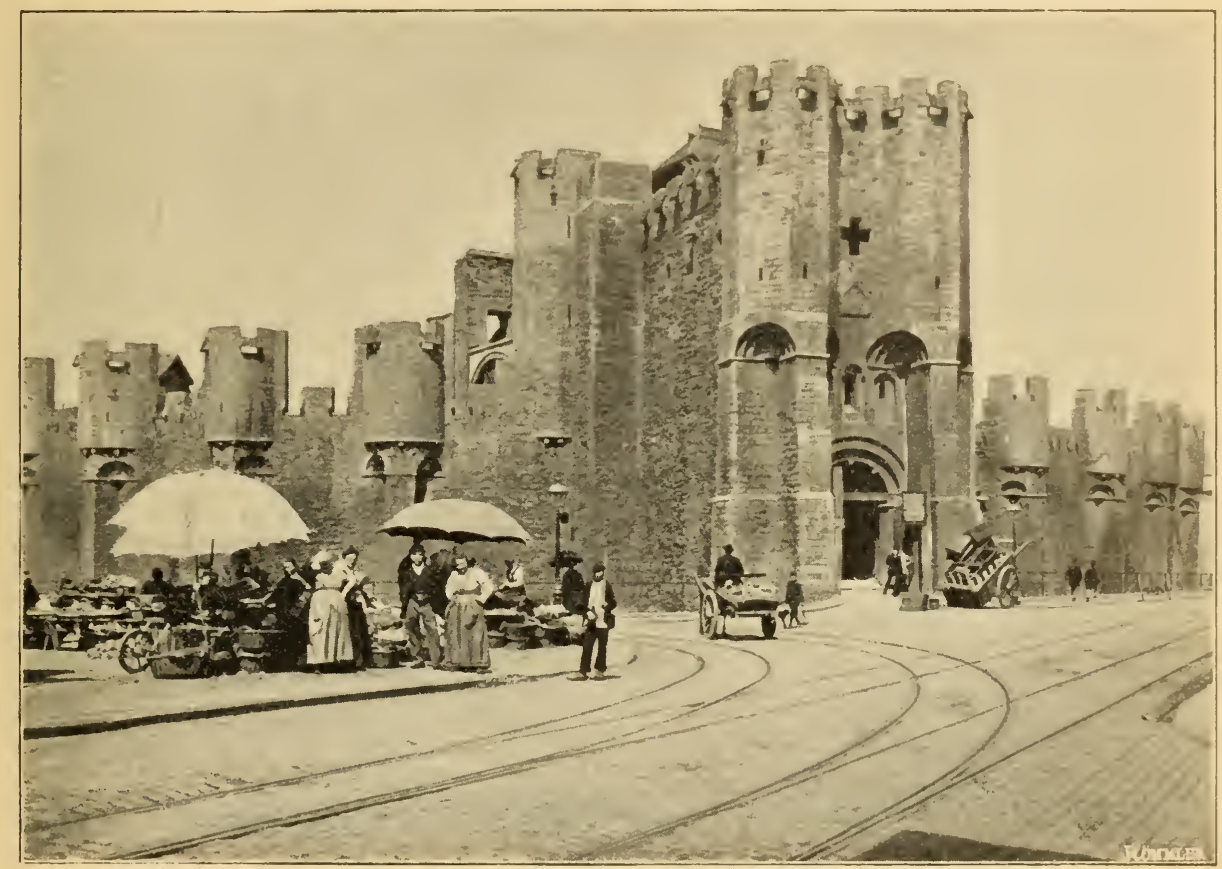

2ubb. 30. Das Brafenfitlofi.

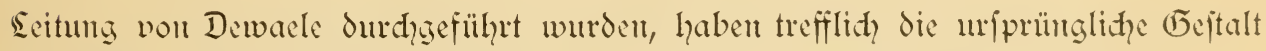

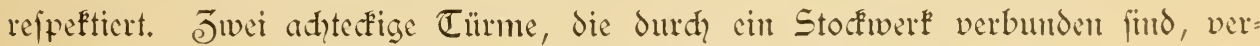
teidigen das romanifhe Thor, worniber fith in entem vierteilizen Schilde die Jn= idrift befindet:

$$
\begin{aligned}
& \text { M } \cdot \mathrm{C} \cdot \mathrm{L} \cdot \mathrm{XXX} \\
& \text { I'HIL. COMES FLAND. \& VI } \\
& \text { ROM } \cdot \text { FILI' THIRICI COIS } \\
& \text { \& CIBHLIE } \\
& \text { FEC } \cdot \text { H C CAS } \\
& \text { TELL O PONI. }
\end{aligned}
$$

Was ntait fo übirträgt:

I 80 Philippus comes Flandriae et Viromandiae, filius

Theodorici comitis et Cibilie, fecit hoc castellum componi. 
Die breiten Scharten finto rod mit Eifenthafen verjehen, die jur Landohabung

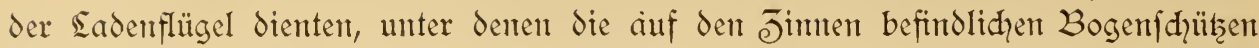
Sdyut fanden. Ziehrere davon find wieder alt Ort und Stelle angebracht wordent, ebenfo wie die ZMauen, die den Derteidigern geftatteten, die Belagerer am fukze der Burg ju treffen. Don der fogenannten Enthauptungsbrücfe aus macht das Eanze eituen padFenden Eindrut?.

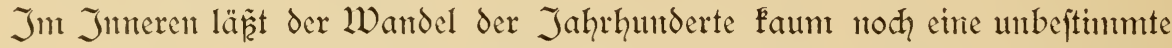

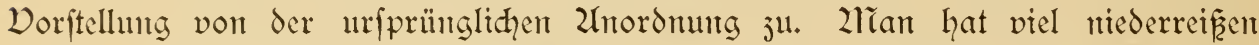
müffen, um die Spuren des früheften 2 aues wieder aufufinden, und man wei nicht redht, worauf man die Teile jurïlfführen foll. Es jeigen fich dabei beträdht=

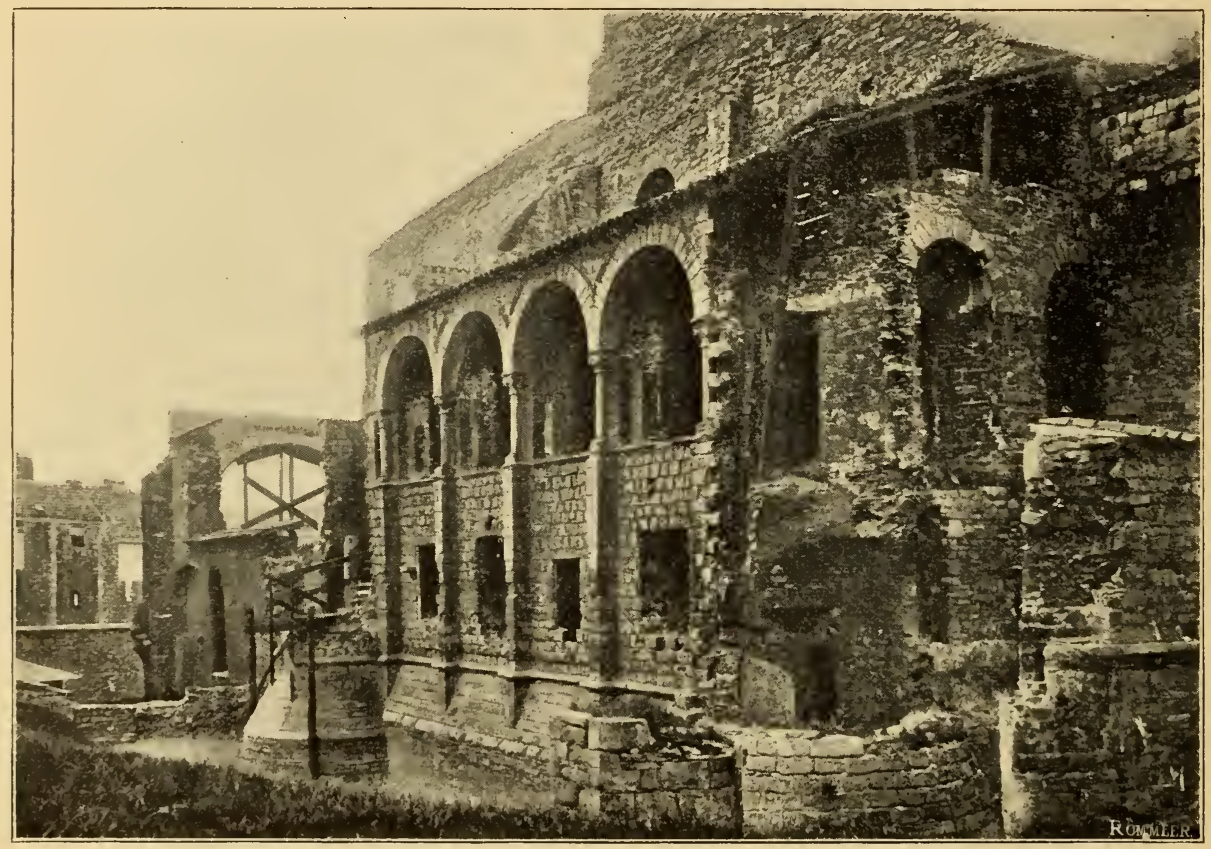

2bb. 31. Romanifhe Galerie an Grafenfhloñ.

liche Lluterfhiede der Bodenerhebung, Wölbungen find eingeftüryt und auf die 2/1n=

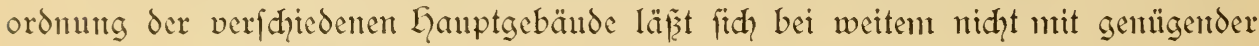

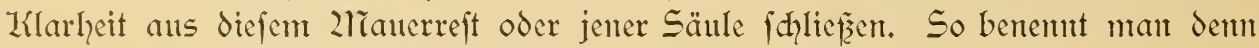

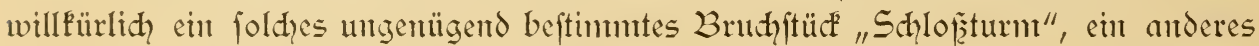
"Kapelle". Es war ein unterer und ein oberer $L$ - 0 o vorhandent; Sanderus giebt deren Plats ant. Der fḑmale Eang, der über der Eingangsthür fith erhebt, bildet cine Partie von rein romanifhem Stil mit frengfömmiger fenfteröffunng und

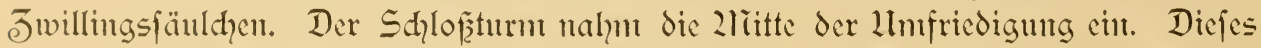

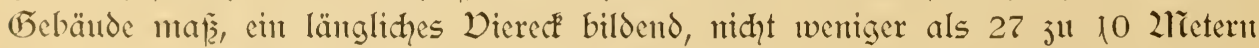
und war 30 2lieter hod. Die Zurt des zlianerwer's erlaubt die Jeet feiner $\mathbb{E}_{\mathbf{r}}=$ ridhtung zu beftimmen, nänlid das 10., weun nid)t das 9. Jahrhundert. So be= ftätigt fich die Entftelyung des Sdyloffes, die auf 23alduin Eifenam jurüd'yefülynt 
wird, deffen $\mathcal{B} u r g$ Philipp von Elfafiz bei feiner Riüffehr aus dem heiligen Sante

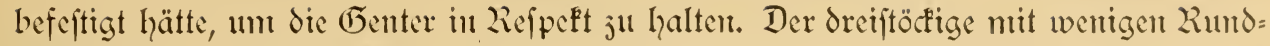
bogenfenftern verfehene Turm endigt im Sanderus in ciner jumengefrönten Plattform.

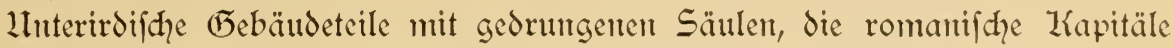
haben, Fömten als aus dem 12. Jahrhundert ftammend angefehen werden. Die "Kapelle", die an die Wefteeite der Einfaffungsmaner angelehnt ift, jeigt fhon gotifḑe Eewölbe, deren romantifhe Säulen bie Bogen auffangen. Wohl erhalten ift cine Ealerie im fdiönften romanifden Stil, deren Beftimmung nod, Flarjuftellen ift. 2ln jedem ihrer Endpunfte ift cin Turm mit ciner Treppe darin, wovon nod, ein paar Stufen vorhanden find (2lbb. 5l).

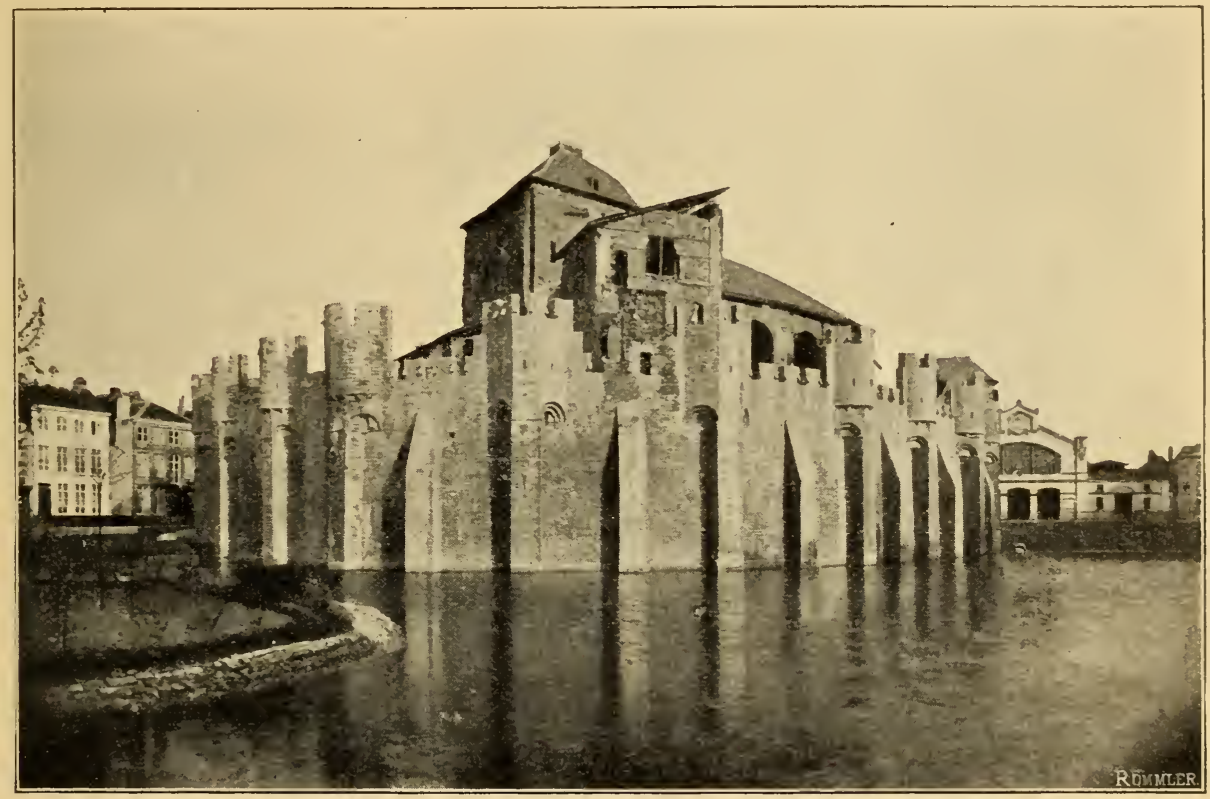

21bb. 32. Das Grajertịloñ.

2lian hat vom Rundgang einen fehr merfwürdigen Blid anf cinen Teil der Stadt, und niḑts ift anjiehender, als eine Promenade auf den J̈imen. Der allgemeine Befuch des Jnmeren ift freilid nod midht geftattet.

Die in Gent fehr eingemurzelte Dolfsüberlieferung, der jufolge cin unter= irdifher Gang das Sdylof mit dem freien felde verband, um fo den Jitfaffen ju geftatten ju entweidhen oder Eilfsfeäfte herbeijuziehen, hat fid durd feine

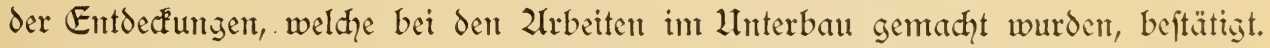

Die Brüggerftraf̧e, die uns gegenüber liegt, enthält einige hübidhe alte Lqüujer; wern wir fie bis jur Pfefferftrafe verfolgen, fo bieten fich bei der Zrenjung diefer mit der Gohen Straje cine Reihe von faffaden des 17. Jahrhunderts von an= mutiger 2Unordmung dar. 2ln der EdFe ebent diefer Gohen Strafe und der Pieffer=

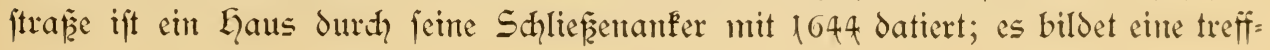




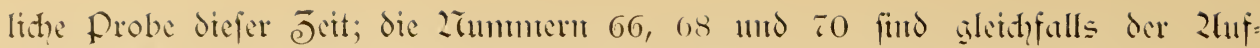
merfiankett des Zlltertumisforjhers würdig (2lbb. 53).

Wern der Küurftler oder der fremde es nidht eilig hat, follte er vorziehen, einen Unweg durd die än "2lbrahan" benant find, ju madhen. 2fuch hier werden ihn Gäufer von dharafte= riftifher Erfheimung anjiehert. Ein fdyönes Eejantbild liefert in der Zubraham=

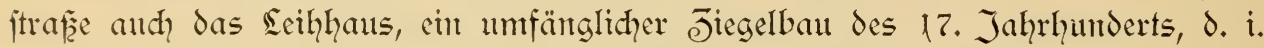
aus der Periode, da diefe fegensreichen Inftitute entftanden. "Hier leent men den aermen oock sonder interest" (hier leiht man den 2lrmen aud ohne Jinfent) verfündet eme Jnfdrrift über der Thür. Das Wappen des Bifdofs Trieft ijt niḑt weit davon, und jweifellos danft man ihm ebenfalls diefe hilfreidye ön= fluhtfitätte. Wenjel Coebergher, der 2raler, Stifter der Seihhäujer in Belgien, ift 1621 der Banmeifter von dicfem typifhen Bau gewejen.

In gerader Sinte for zen wir Jurch die Zlbrahamgaffe anf den "fürftenlyof" ("Cour du Prince"), faum etwas mehr als eine Erimmerumg. Ein Fürjlich wieder hergeridteter Thorbogen, das ift alles. Gier hatten feit dem 14. Jahrhundert die Lerrfher ihren Sith und Karl V. erblidß̈te an diefer Stelle das widht der Welt. Es gab hier in 2rittelalter einen Sömenzwinger; Zflbreḑt Dürer jeidntete eines diefer Tiere mit der Bemerfung "jull Gent".*)

Wie durch eitren Jauber haben unfere Sthritte uns in eine ideale LImgebung geführt, etwas, wie die vergänglichen Stadtviertel, die unter dem Kramen "2llt= 2lntwerpen", "2ult=Dresden" bei den 2lusftellungen ins Seben gerufen worden find: zum ehemaligen Grożen Beguinenhof, der jeţt verlaffen ift. Darin maltet nod?

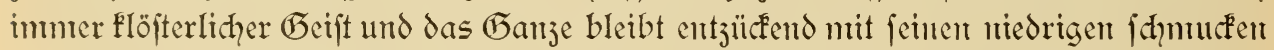
und lachenden Wohmungen, bald mit einem Dorgärthen verfehen, bald in eimem (5ärtchen eingefhlofien, mit niedrigen Thüren, die mit Thürłlopfern verjehen find. zhan fonm hier felten vorbei; es ift wie eine fleine Stadt für fidh, die ilyren baumbepflanjten Plak, ihre Kirche, nein ihre Kirchen, ihren gewöhnlichen Pumtp: brummen hat - an der Frenze der tojenden Stadt ein Ort der Ruhe und Samm= lung, ein Plaalanftire (2ubb. 54).

Kein frenter, der vorübergeht, follte verfäumten, dies ganj reizvolle unto

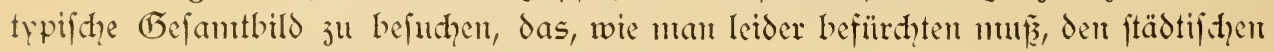
Bedürfuifien bald gartz jum (1)pfer gefallen feitr wird. *:)

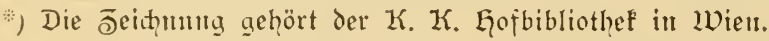

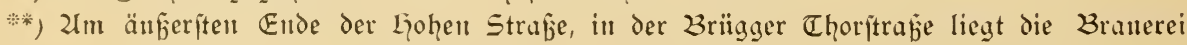

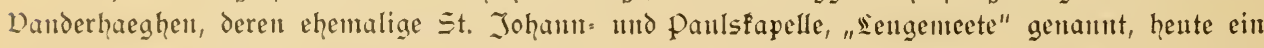
Zlebengebände bildet. In diefer Kapelle, die hente als Bierniederlage dient, wurden 1845 unter den Manerputs von felir De Digne Wandmalereien gefunden, die militürifhe 2ufjïge des 13. oder des 14. Jahrhunderts darftellten und in detten der genannte Alltertumsforfher Genter Kor:

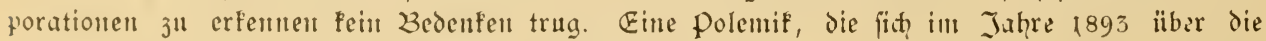
form des Goedendag, der Waffe der Genter Iltilijen erhob, eine polentif, in deren Derlaufe

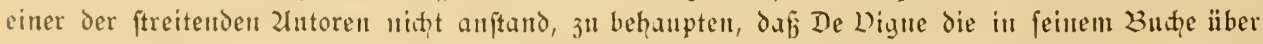
die Benter ZKorporationen reprodujierten Malereien entwader felbft gemant, oder wenigitens ge:

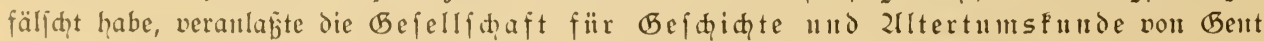
3n einer durhgreifenden Unterfuhung der ehemaligen Kapelle. Die Beridte der Kommiffare, die in Jaḩre 1899 neröffentliht wurden, ergaben, dafj jedz Spur der in Jaḩr $18+5$ entdecten fresfen

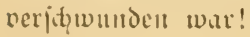


Wir rerlaffen dicfe Einöde, unt junt Boulevard ju gelangent, wo uns das intpojante Profil desliabot entgegentritt; int Dorüber= gehen grüfen wir das Stand= bild eines Wohlthäters der 2lenfdhheit, des berühmten Jrmenarjtes Jofeph Guis= lain, ein Werf von $\mathfrak{G} a n=$ burfin, 1887 erriḑtet. Gatis= lain war der Reformator der Jrrenpflege; die Zrranfen waren, wie man weir, bis dahin wahrhaften Peint= gurgen ausgefetzt gewejen.

Der Rabot, befonders malerifd gelegen, ift eines der f̧önen Lleberbleibjel der Kriegsbaufunft des Zlittel= alters in Belgien. $\mathbb{E}_{r}$ ïber: brüfft die Sieve und ift ein Feftungswerḱ, das die Genter errichteten jum (5edädhtuis an ilyren Widerjtand gegen den Kaifer friedrid, III. unt gegen den römilichen Iröntg 2líarimtilian im Jahre 14.88.

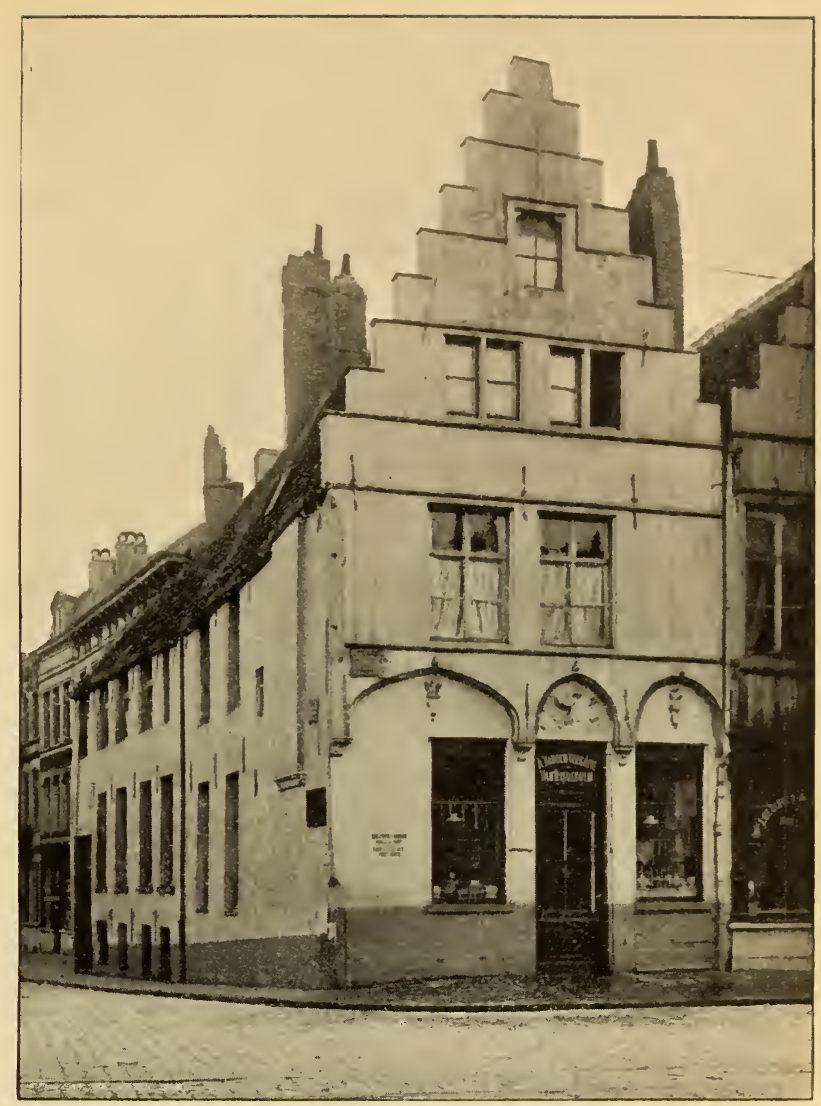

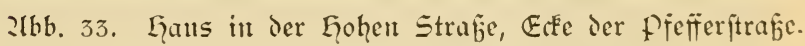
(?us dcul "I Iuventaire Archéologique de Gant".)

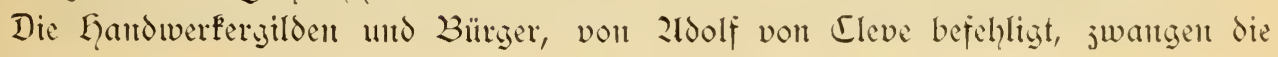
Z3elagerer, naḑdent diefe viermal nergeblid, geftürmt hatten, jum kiückjuge. Der (5rundftein wurde am 13. Juni 1489 gelegt, wie uns eine Jnfdyrift mit fdönen

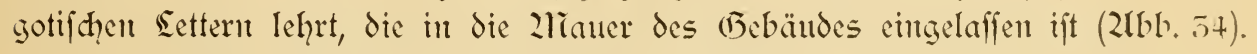

Der Liabot, 1860 etwas abgeändert, befteht aus jwei runden Türmen nit

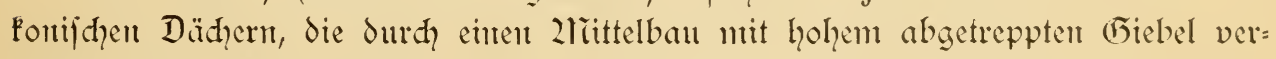
bunden find. Er beherridht die Sieve vollftündig und Fonnte ihren Sauf durd fall=

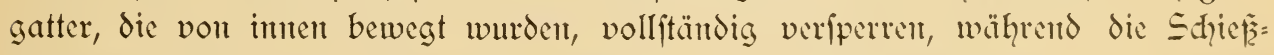
fharten, die in die Türme eingefhntten fint, die 2luftürmenden in sicfpeft hielten. Das Ganje wirft monumental nub jehr deforativ.

Dor Eteg über die Sieve, von dent aus der Blicf auf den Rabot ant günftigften ift, führt uns auf den malerifhen Et. 2lutoniusquai hinab, wo fid int cinem (5arten nodh das Soḱal der ehemaligent 2lrmbruftfdyützengilde vont hl. 2lutonius befindet, mit einer faffade, die die Wahrjeidjen der 23rü̈erfhaft mit dem Datum 1645 trägt. Dann erreiḑen wir in gerader Sinte, die 2lFadentebrïffe paffïerent, die Gentäldegalerie. 
Das Genter 2linfenm, aus alten und neuen Werfen beftehend, von denen feines erften Ranges ift, reijt niđhtsdeftomentiger die 2lufmerffamfeit wegen des Jutereffes, das es in lokaler Eimfiḑt bietet. Es wädyjt übrigens jiemtidy regel=

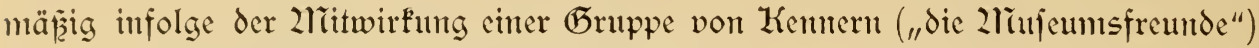
an, die feiner 2 ereidherung Zufnterf́fantfeit wionten und deren Erwerbungen einen einfirhtsvollen Eifer befunden. Ein Katalog, der vor dreiß̧ig Jahren von 21. P. Sunaert redigiert wurde, ift natïlich heute veraltet, bietet aber darum dod, 2đuţen wegen der Liaḑweife, die er über die Lerfunft der Gemälde giebt.

Wir geben die Lquptwerłe nady der 2unfitellung. Im Treppenhaufe find cinige Werfe olne Jutereffe. Eingangsjaal: 2rr. 94: J. Dourbus, Triptydhon: der Prophet Jefaias veripriḑt dent Gefefias deffen demmächitige Geilung. Redhter

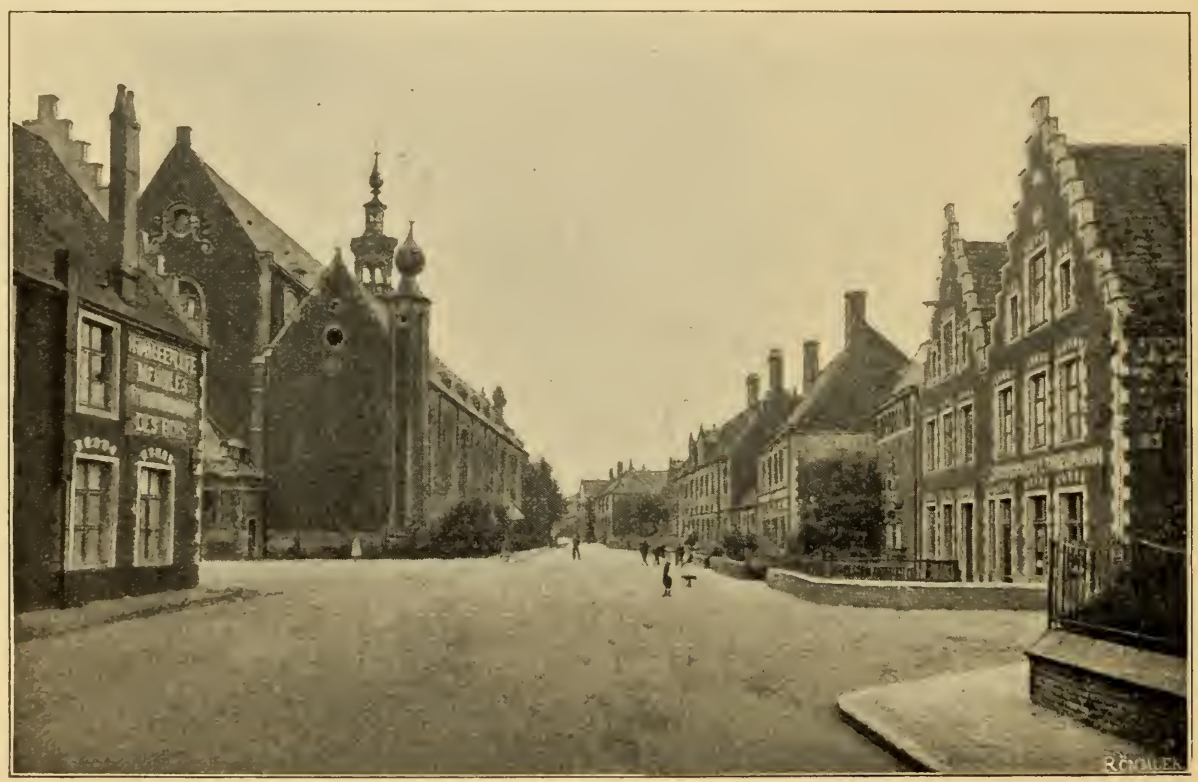

2ubb. 34. Strafje in dem ehemaligen grofjen Begntmenhof.

flügel: ausgejeidnutes Bildnis des Jafob del Rito, 2lbtes von 23andeloo, betend; hinter ihmm fein Sdquţheiliger. Sinfer flügel: Chriftus am Zrenj. 2(r. 86: Jan van Gemeffen, die Berufung des heiligen 2läatthäus, ein von dem 2lieifter oft be= handelter Gegenftand. Das erwähute Eremplar fann niḑt ju den befferen der= artigen Darftellungen gejählt werden. 2Unf einem der Papierbündel, die anf dem

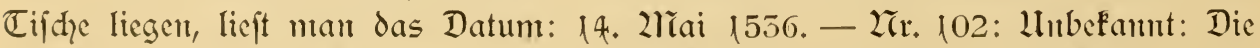

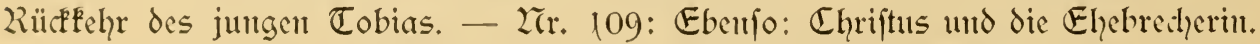

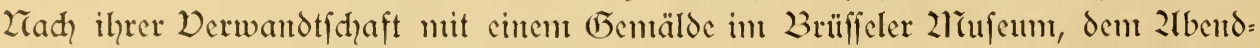
mahl, fdyeinen uns diefe beiden Bilder, die offenbar von demfellen 2lialer fint, dem Peter Coeck anjugehören. - Llubefannt: Zetender 2liönd, weis gefleidet, nor: jügliḑes fleines Bild, das gelitten hat. Diefelbe Perfönliḑßeit (vielleiḑt der Stifter) findet fich auf dem grofien 2lltarbild vou fr. Dourbus, das 2lbendmahl, 2ir. 95,

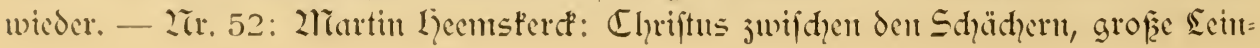


wand aus dent Zilofter der "Reidyen Clairiffen" ftammend. - 2ir. 5.3: Derfelbe: Toter Chriftus, dem Engel die Dormentrone abnehmen (15.32), jwei ansgejeidnete 23eifpiele

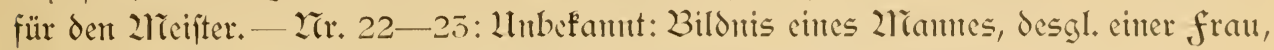

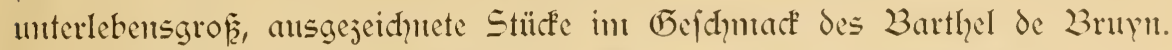

Jum grofen Saal mit (Dberlid)t, 2(r. 4, 5, 6: Jordaens: St. 2lmbrofus; die Derföhunng; die Ehebredperin; Werfe nou minderem Werte - 2rr.91: Jacob vou 2Irtois: gute Sandfhaft; 2ir. 86: Dantel Seghers: 23lumen um eine leere 2rifhe, \{dönes Stücf des 2lieifters. - 2ir. 112: "2Tatoire“ (Jacob de Wit): Kindergruppe. 2ir. 113: 2homym (2iubens ober nad ifmm): Die Jungfrau mit dent Jefusfinde, eine Kompofition, die S. a Bolswert geftodyen lyat, wo die Jungfran gefrönt wird und das

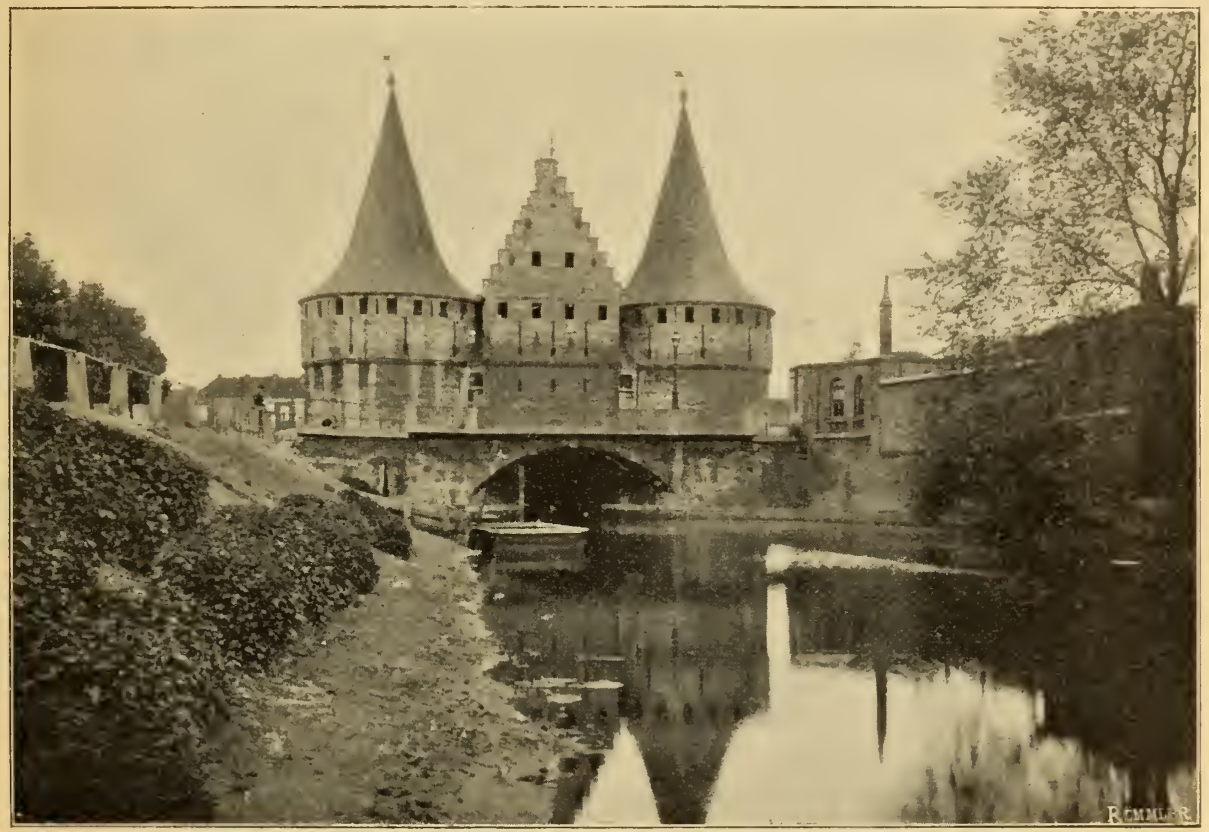

2lbb. 35. Der fogenannte "Rabot" (Giobel).

IKind das Sjepter hält. Das Bild ift vielleiḑt ein durd Retondyen entftelltes (1)riginal.2ir. 9: Rubens: Stigntatifation des hl. franj; berïhunte Darftellung, von Dorfterman geftodyen, ein Werf von grozer Eigentart, verumftaltet durd, unglüeflidye Llebermalungen. - 2ri. 24: Dan Dyw (Peter Thys?): Samion und Dalila; - 2ir. 45: desgl. Dorträt, (5rau in (5rau, des Zndreas van Stalbent (apofryph). - 2ir. 55: 23. D. Zkaunind:

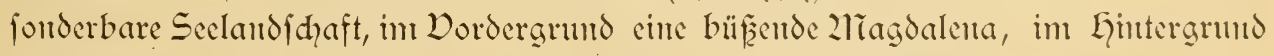
cin Gewitterfturm, wo alle Elentente entfeffelt find; fehr merfun̈rdiges fleines $23 i l d$. 2rr. 26: Th. Rontbouts: Der Traum des hl. Jofeph; 2ir. 69: derfelbe: Die fünf Sinne, reife Kompofitionen, eines wie das andere, und Werke eines guten Praftifers. 2rr. 11: franc. Dudhaftel, 1668: feier der Eimfeţung Taris II., Zänigs non Spanten, jun Grafen von flandern, cint Krompofition mit cinter 2lienge figuren

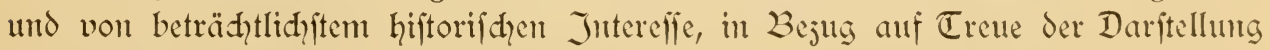
des freitagsmarktes, der Perfönlid̨̧eiten, von denen viele Porträts find, und der 
Koptüme. Ein in jeder Bejiehung ausgejeidhnetes Werḱ. - 2Cr. 12: Peter Joleph Derhaeghen, 176\%: Darfellumg im Tempel, gutes Bild, mit gewandtem Pinfel ausgeführt. - 2rr. 90: Robert von 2ludenaerde: Die Geiftlidhen der 2lbtei von Bandeloo junt Kapitel vereinigt; intereffantes Bild eines feltenen 2lieifters, der als

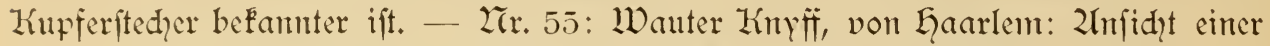

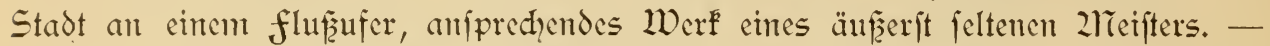
2rr. 82: Peter van den 2loont: Feil. familie in ciner Sandidhaft, ausgejeidhnetes flemes (5emtälde, das feinen 2 trheber als cinen der feinften Koloriften und als 2rad)= ciferer van Dyef's in feinen Fleinen Kindergeftalten Fennen lehrt. - 2ri. 58: Deter Thys: El. Sebaftian. - 2läan hält Peter Thys für eimen Sḑüler van Dyd's; das gegen=

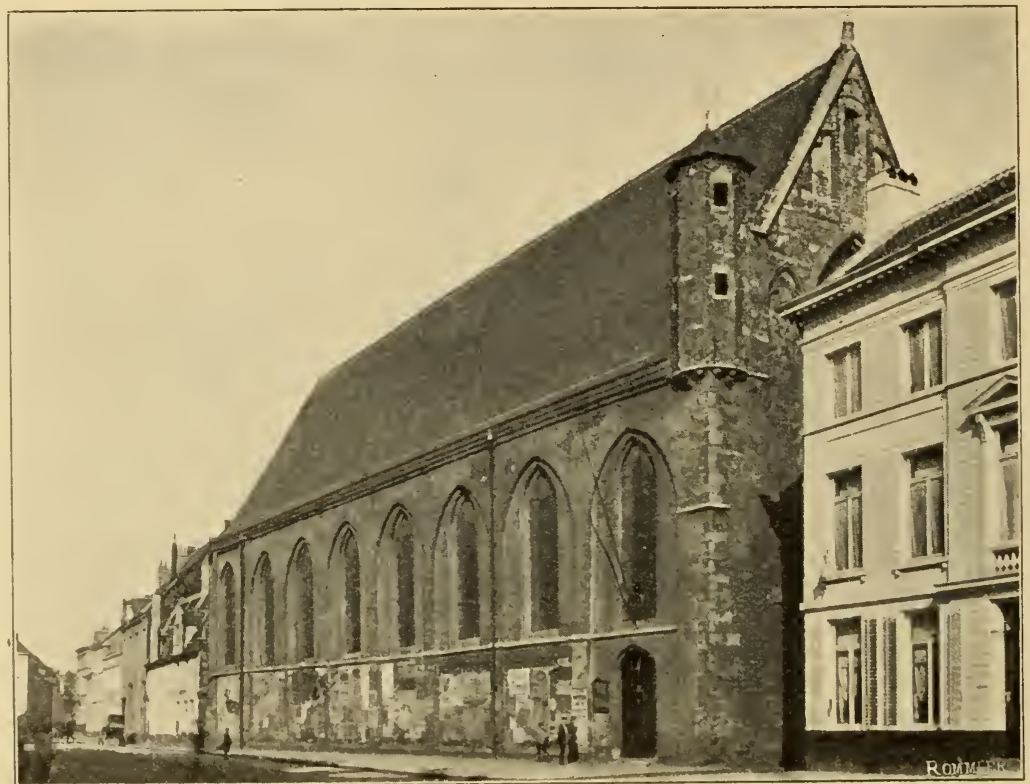

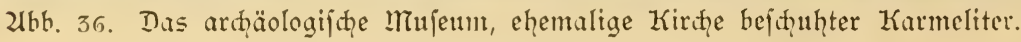

märtige (5emälde jeigt ihn unter dem ganj direften Einflup diefes berïhnten 2lieifers.

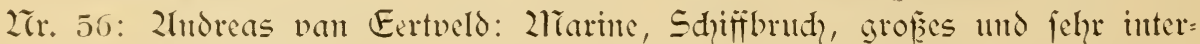
clfantes (5emälde $(3,15 \mathrm{~m}$ betit, $1,70 \mathrm{~m}$ hodh). - (5̃afp. de Crayer (?): Bildnis

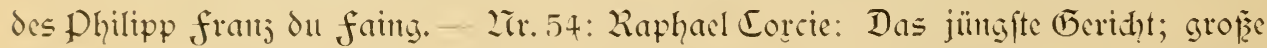
Zompofition mit jallreiden Perfonen, aus dent Rathans herrïhrent, durth Lleber= malungen entftellt. - 2ir. 124: 21. T. Tiey: 23ruftbild cines 2rannes, ausgejeidhnetes

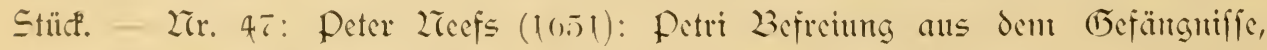
mit fehr intereffantem Sidfteffeft. - 2ir. 8б: Jacob van Es: Stilleben, 2ruftern,

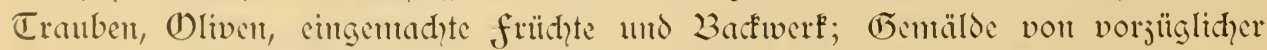

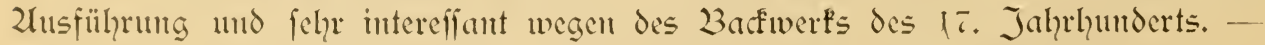
2rr. 46: D. Z3renghel (nad) ilqu): 23anernhodjeit, Lopie des Wiener 23ildes. 2rr. 79: C. 2lialpue (1615-1689): Stilleben, bejeidynet. Die Werfe dicfes 2lut=

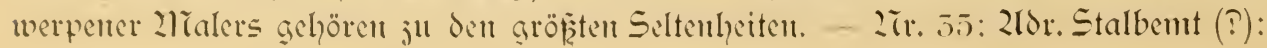


Der hl. 2lartin in einer Sandfhaft. - 2ir. 95: frans Gals: 23ruftbild einer frau (Sammlung Kunns) (2rbb. 37). - 2ri. 42: 2ric. Berghem: (5ruppe von 2Rindern

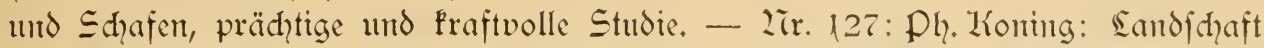
mit Turnt auf einem felfen urd weitem Ljorizont, pöptlidyes Werk.

2Cummehr Fonmt ein ganjer Saal mit Bildern von Caspard de Erayer und von de Siemaedfer, gent. Roofe. Das Zlitueum befitzt mehre als jwanjig Gemrälde des erfteren und aḑt des lef̧teren. Das 2liartprim des hl. 23lafus, 1668

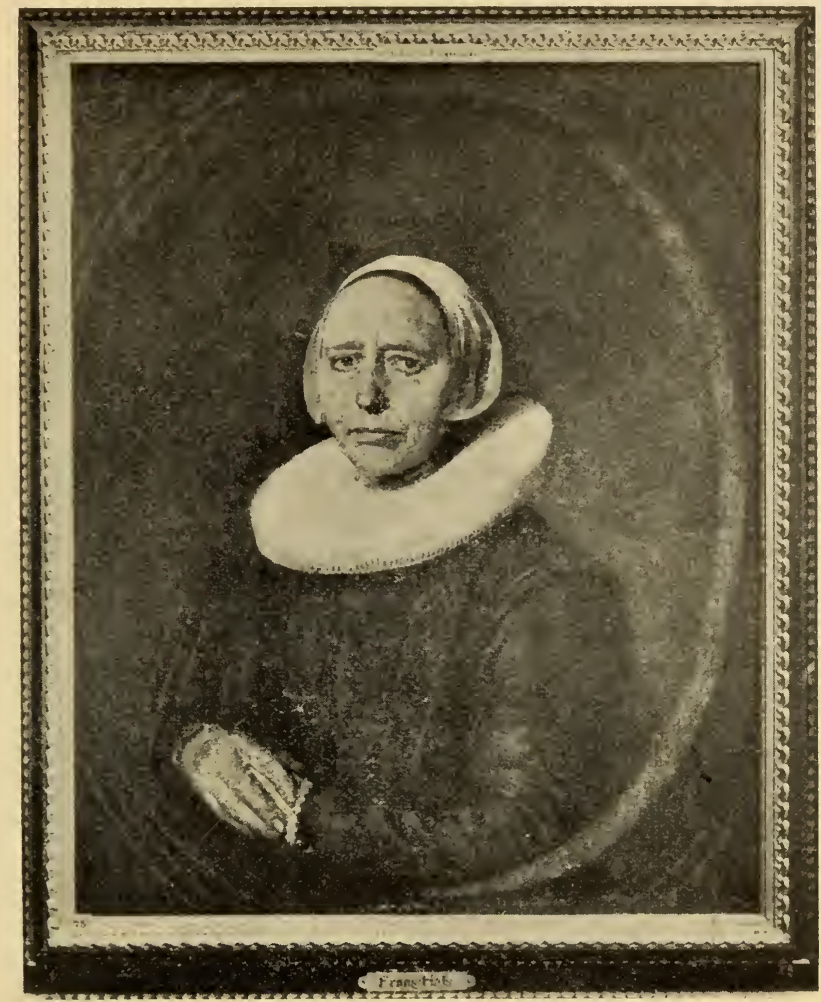

2lbb. 37. UF́ademie=MTufenm: frans Gals, franenporträt (2lus dem ., Inventaire Archéologique de Gand".)

von Crayer für die (jeţt abgetragene) Zitrche der Dontutífanter gemalt, wo der 2lialer beigefek̨t wurde, ijt das Werk eines 86 jährigen (5reifes!

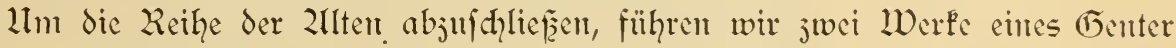

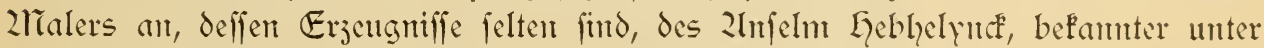
dem Zimmen Zlufelm van Lqulle (1594-1608), eines guten Porträtiften, von dent die

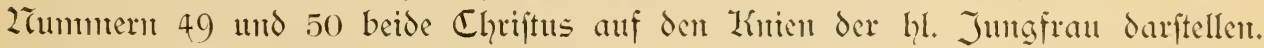
Dan Gqulle ift der 2lăaler, der die Bildniffe der 23evollntïhtigten des friedens= pongreffes volt zlüufter ausfïlyrte.

Die moderne 2lbteilung der (5)enter (5alerie nimmt unfer Jutereffe wegen

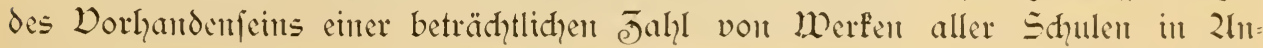
iprud, die bejonders in den dreijährigen Salons gefanmelt wurden, die int Fent 


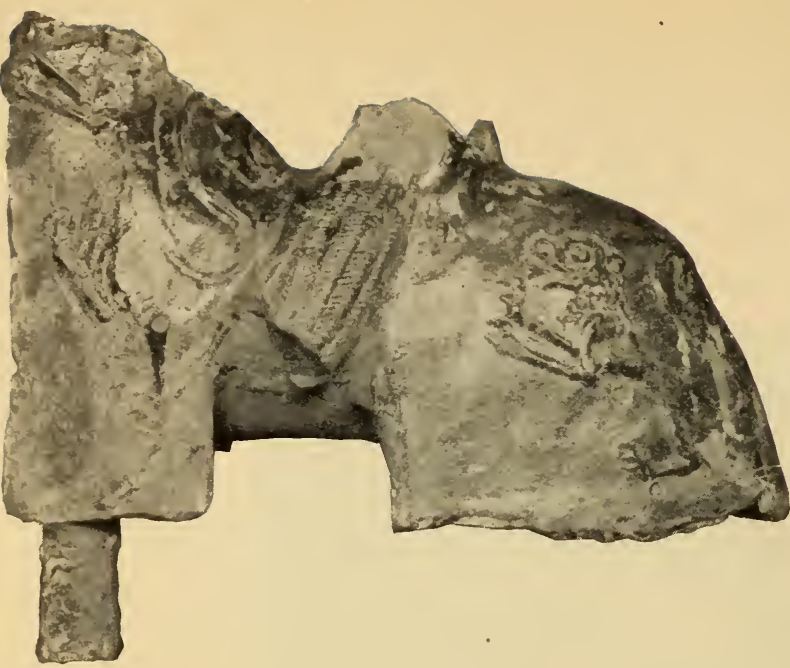

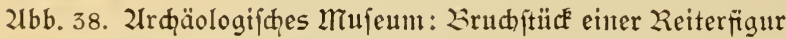
aus glafterter Terracotta. 12. Jahrhundert. faft immer gern von den aus= wärtigen Kürfflern befdicft worden futd. Wir begnügen uns, die Zramen der haupt= [äd)lid)ften hier vertretenen 2lieifter anjufübren: Belgier: Gallait - Feiu erftes (5emälde, der Jinsgrofhen (1832); c. 2leunier, der hl. Stephan; Zllfr. Derwée; Séon frédéric; E. Clans. franjofen: $23 o u=$ guereau; Roll; Peloule; E’her: mitte. Deutfhe 2c.: Senbad; Kroyer; Gronvald; van 2lüu= den. Endlich entige Bildhauer: Rude, Paul De Digne, Dinçotte, Gippolyte Se Roy.

Reidher als die Gemälde: galerie, verdient das ein paar Sdritte davon entfernte 2lltertuntsmufeum in der Sangen

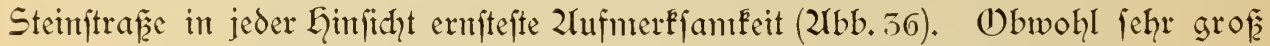
und mit 2liethode aufgeftellt, erfdheint es it der gerüunigen ehentaligen Zirche be: fhuhter Karmeliter fhon beengt. Seme Jufammenfeţung ift fehr verfąidenartig. Der Befucher gewimt einen 21 eberblid über alle Epodhen; einige fund durd be= trädtliche Serien vertreten, wie j. B3. die des Sdimiedceifens und der Keramif, die für fid) allein tanfend Lummern umfajt, bei etwa jweitanfend, die die ganje Sammlıntg zählt. Der Katalog, ein WerF von herman van Duyfe, des verftorbenten Komfervators, ift fehr gut bearbeitet, leider datiert er non dem Jahre 1886. Die Zufmerkfamfeit des zefuders foll ant enige befonders be= merfenswerte Stüdi gelenft werden. 2ir. 628: figur cines (5enter Irriegers aus dent 12. Jahuthutdert, Trümmer, die man 1864 ant freitags= markt ausgegrabent hat. Die Rethe der Etandarten enthält die Iriegsftardarte der Benter in 16. Jahr: lumbert mit der ent= blematifden Jung=

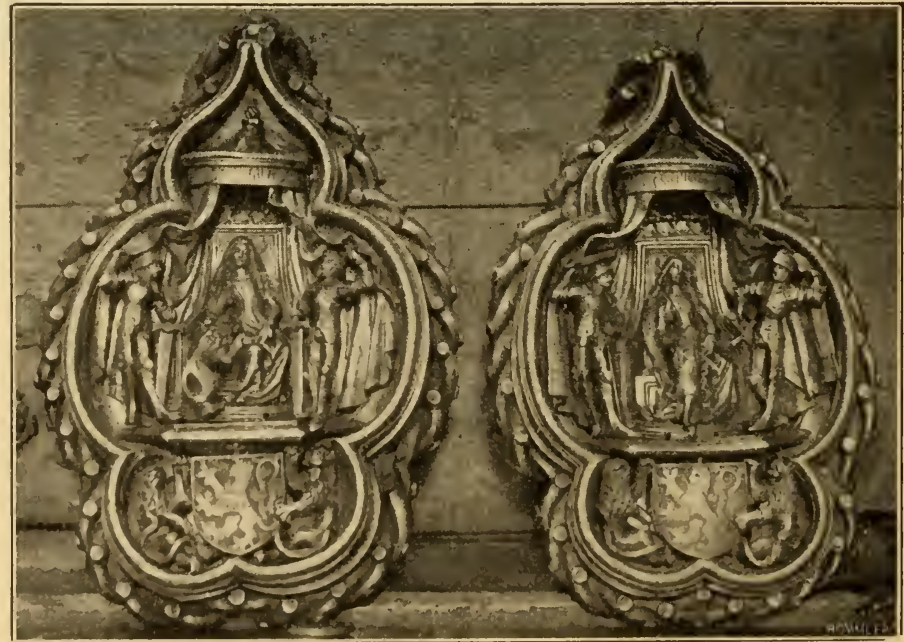

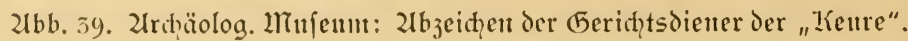


frau der Stadt (2ir. 765). - 2ir. 871: Das Sthild cintes 23aders des 1\%. Jahre hunderts, wo man den 3 arbier cinen Gammel fderen fieht, cine Darfellung, von der ein alter Stich vorhanden ift. - 2er. 8бis: 2flte Truhe für die Privilegien der Gantwerfergilden, aus dem 14. Jahrhundert ftammend und ehentals in Belfried aufbemahrt.

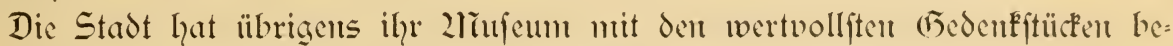
reidhert, von weldher 2 ret fie and immer fein mögen. So finden wir j. 23. hier

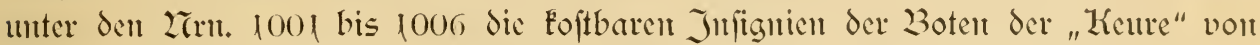
(5ent (216h. 59), Spielleute des Belfrieds, (5oldfdhmiedarbeitent des 15. Jahrhumberts, die von Corntelus de 23 ont ausgeführt fint, in hübidgen Sederfutteralen. Dor

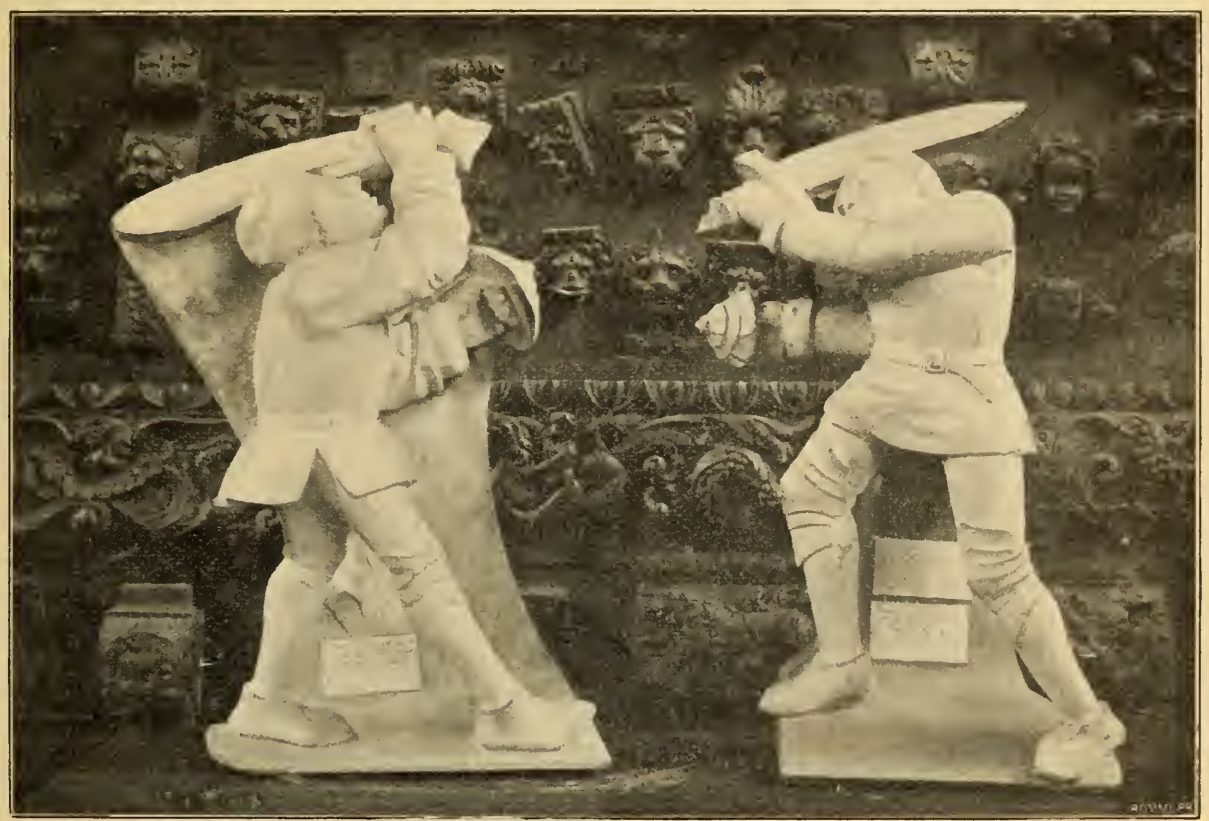

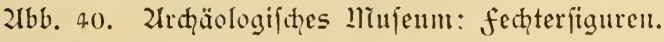

einigen Jahren wurde der Stadt (5)ent für einen diefer Gegenftäıde von einem grofizen Parifer Sammler eine enorme Summe geboter. - Der Stab der (5̃eridhts= diener der "Kente" unter Dhilipp II., bemerFenswerte cifelierte 2rrbeit; die Gals= kette des Dorjtehers der 2lrmbruft fhühenengilde, von Gold, mit translucidem Email ver=

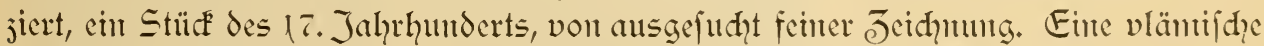
eglomifierte Glasmalerei des 15. Jahrhumberts, dic Dreifaltigfeit, cine jweite von

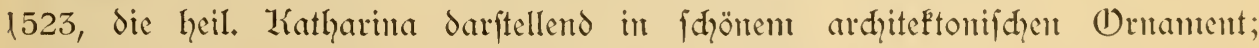

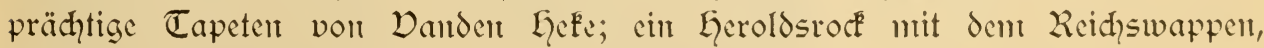
jufolge des Kataloges aus dem 16. Jahthundert, aber, wie wir glauben, aus

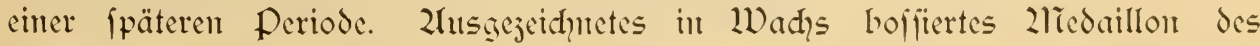
Sorenj Dubois, etra 1581. Eine 2lizahl merfwürdiger Traḑten und darunter

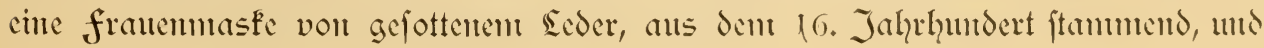


in eintem Brumten an Fürftenhof gefunden; - cinc andere frauemmaspe von fhwarzent Sammet, 1\%. Jahrhundert, eir Beweisftück aus der Gerid̨tsfanzlei des Rats von flandern ftanmtend. Wunderfḑöne liturgifhe Erefäre aus graviertem Liupfer, dem 14. Jahrhundert entftummend, in flų̈hett der unteren Schelde aufgefunden. Eines weift in der 2litte Eott $\mathcal{D}$ ater auf, ungeben von Köppien mit Keiligen= fheinem. Eerrlide Grabplatten aus graviertem Lupfer. 2ir. 1900 ift die des Wilhelm

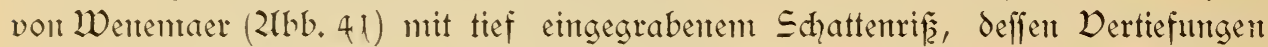
mit fhwarzem Email ausgefüllt find, nit einem Worte ein wirflidhes Zriello. Die genannte Perfönlichlêt, 1325 in einem Kampfe getötet, ift in natürlidher Größ̨e wiedergegeben, barhaupt, ganj bewaffnet, vor fith den Schild mit dem emaillierten Wappen tragent und in der Gand das blanke Schwert haltend, das die Worte auf der Klinge fühtt: horrebant dudum reprobi me cernere nudum (die Böfen haben ftets gejittert, midh blant zu fehen). In jeder Bejiehung ein Werte erften Ranges.

Zridht wentiger fhön ift die Platte der 2rargarethe von Brume, der Gattin des Wilhelm von Wenemtaer (2זr. 1901), gleidhfalls graviert und nielliert, mit ge= falteten Gänden dargeftellt und von bewunderungswürdiger 2lrbeit.

2ir. 1909, Grabplatte in vergoldetent unt nielliertent Kupfer des infulierten 2lbtes Seonard 23ette, geftorben 1607, ein fehr bemerFenswertes Stür", bejeidhnet: Libert van Eghem me fecit Mechliniae. Sie wiegt niḑt wentiger als 100 Kílo.

Linter den ziöbeln fint einige befonderer Beaðhtung würdig, die 2rr. 922, die der Zufbewahrung der Zrdhive der Weinhändergenoffenfdajt gedient hat, vom Jahre 1640, und der 2lrbeit wegen der Schrant in Rofofoptil, 2rr. 924.

त) figuren aus dem 14. Jahrhut = dert, die aus dir Jacobsfirche herrühren (2lbb.40); cin ricjelt= groper Eduh, der mit Fold gefüllt ill Jahle 1 - 8 .5 dem Siat von flandern won der Korporation der Sdullffliter dargebradyt wurde. Es finden fith hier auch einige (5emtälde, cines (20. 1895), figniert P. Eeclant, bejicht fich auf

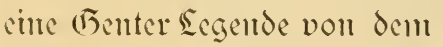
Sohu, der der Sdirarfiditer icines Vaters war, dic man im Sanderus auf der loge= uanten Enthauptumgsbrürac dargeftellt findet. Ein Water und ein Solyn haben beide ju= gleidh den Zopf ueruinft. Der zlägiftrat wollte dent begllat= diagelt, der delt anderent ent=

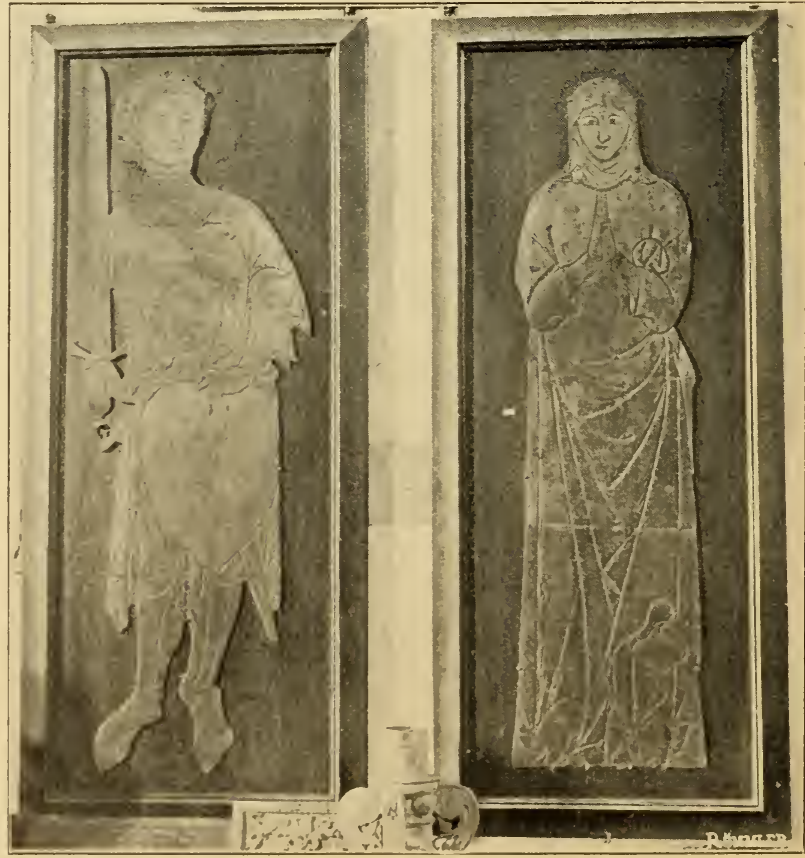

21bb, 41. 2trţäologifąes MTnfeul1. Srabplatte des

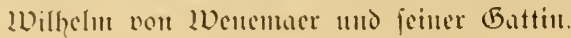


haupten wolle. Dent Sohn, der anf inftündige 23 itten feines Daters eingemilligt hatte, an

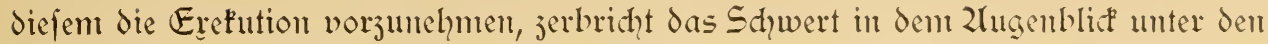
Gänden, da er fidh anfhidft, feine frevelthat ausjuführen. - 2ir. 1889: J. 23. van Dolrfom: froher Einjug des Kaifers Karl VI. in Gent und deffen Jirauguration auf dem freitagsmarkt; hödhft intereffantes Bild, das früher den Etändefaal int Rathaus gefdmmüft hat. Der Ifaifer durdh zliarquis Prié vorgeftellt.

Z3eim Derlaffen des 2lltertumsmufeums und linfs durch das 23ötthergärchen gehent, deffen Ecke es bildet, haben wir umittelbar auf derfelben Ecite den fortifus der den อ̈ugang bildet zu dem chentaligen Kreuzgang des Kilofters der befduhten Karnteliter, ein Grunditüd", deffen Jufaffen fich heute über Gundert (103) beziffern. Dort giebt es unabfehbare Korridore und eine monumentale höljerne Treppe des 17. Jahrhunderts mit Baluftrade von fehr hyilbfher (5efantwirfung. *)

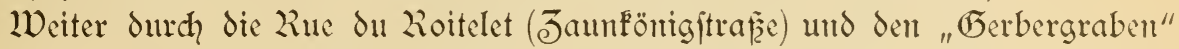
(Fossé des Corroyeurs) ftofen wir auf die 2llte 23urgftra ze und ftehent dem Pont du Eaitage gegenïber. für den freund von 2ultertümern wimmelt diefes Diertel von intereffanten DbjeFten, Gefantbildern und Einjelheiten.

Die jwei Қäufer gegenüber der 2lïldhpeifen=Brücke an der Ecke der Zllten 23urg=

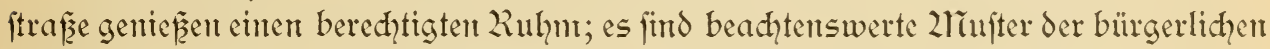
2lrdyiteftur des 17. Jahrhunderts (2lbb. 42). Die faffaden find mit einer fülle won Ernamenten deforiert, die eitre holge Dorftellung von dem Reichtum ihrer Eigentünter erwecker. Das erfte, vom Jahre 1669 datiert und "jum fliegenden Girfdhen" (den vliegenden Ģert) befdyildet, hat einen Giebel von eleganter und gefiunftelter

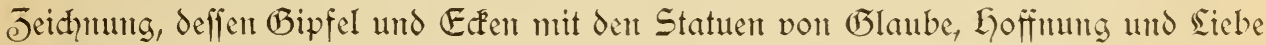
gefhunüft fint. In der 21 ritte fpringt ans ciner Sünette das Bruftbild eines flöten= fpielers fräftig vor. Lleber den fenftern des Erdgefhoffes - einer Trödelbude und des (Iberftodes finden fid Basreliefs mit liegenden allegorifhen figuren. Das anfto zende Gaus ift fehre ährtich, aber mit niedrigerem Giebel; es hat als 3 as= reliefs fechs von den fieben Werfen der Barmherzigkeit. Durd ene feine 2luf=

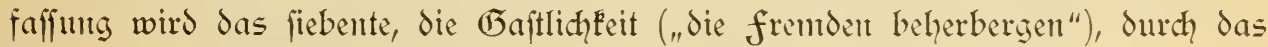
Gaus felbjt dargeftellt.

Weiterhin in der Zllten 23 ugftraje war bis in die nenfte Jeit ein Laus mit Reliefs verjiert, wo dirurgifhe (Dperationen dargeftellt warent; es follte die ehentalige Wohnung des berühuten Palfyn fein, einer der Ecudhten der dqururgifaten Kunft, der 1650 in Eourtrai geboren und der Erfinder der Felurtsjange war. Das Gaus ift vor einigen 2lionaten von dem 23 efitzer ahgehrodyen morden! Die Gqüner, die an den pont du saitage grenjen, geben ein föftlidhes $23 i l d$ ab nit ihren niedrigen vornehm gejeidyteten faffaden.

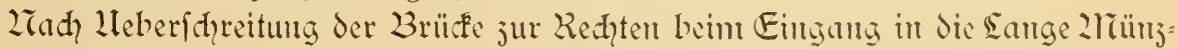

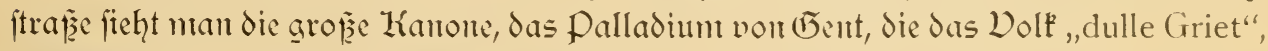

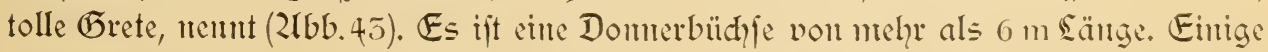
Zutoren haben ihre volfstünlidg: Bejeidinumg auf 2liargarethe von Kontantinopel jurücfführen wollen; das geht aber niḑt an, dem andere Stüde berjelben 2trt in England 
und Shottland heifien and 2hargarete: "2lions 2lieg", "Roaring 2lieg". Joleph

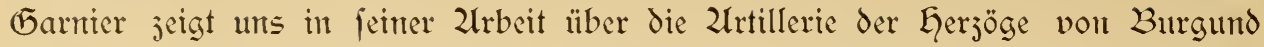
Stïcke, die diefen fürften gehörten und gleidffalls "Friette" genannt wurden. Int zrufeum von Bafel fahen wir ein foldyes Stür" von gleiḑem Typus aber von

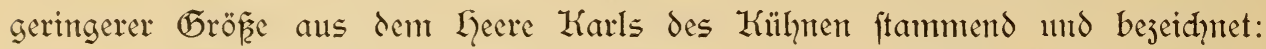

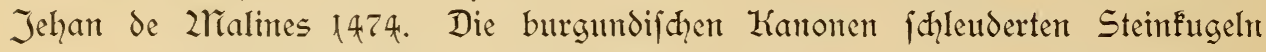
bis ju 400 Pfund Gewidht und bedurften einer $\mathfrak{S a d u n g}$ von 70 Pfund Pulver. Das Genter Exemplar wird für die Trophäe entes Sieges der. Fenter über die

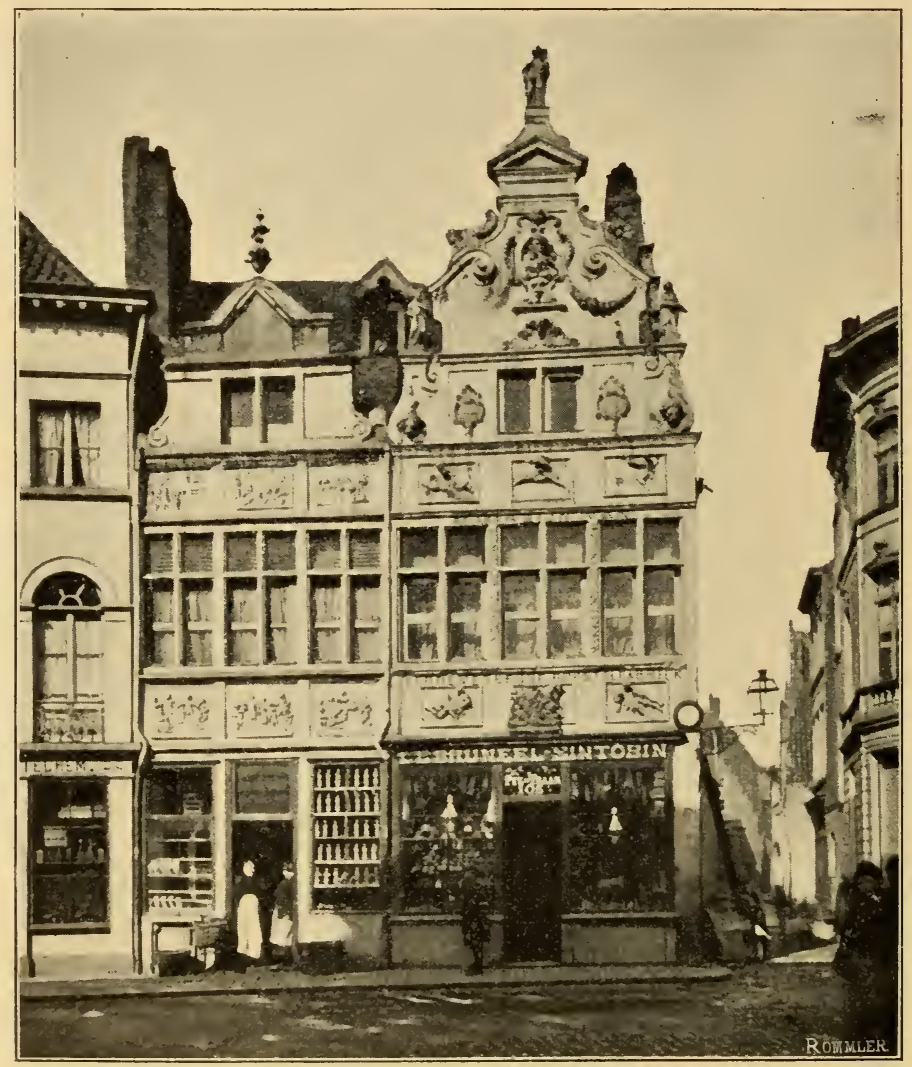

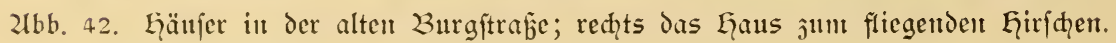

Burgutder gehalten; wo wurde fie erbeutet? 2ran dirfte es nidht genau angeben

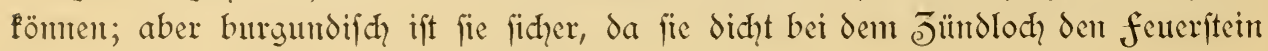
des goldenen Dlief̧es eintgraviert trägt.

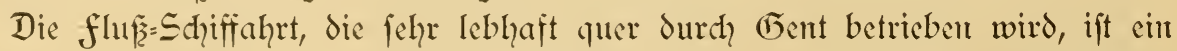

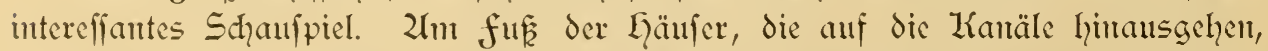
und faft in gleidher 5 göhe mit diefen bemerft man ein Goljtrottoir mit Dorfpringen

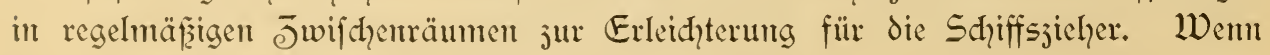
fie an einem Punfte anlangen, wo j. B. Die Pfeiler ciner Brütpe ilyren $W_{e g}$ unter= brechen, erkllettern die Jicher cine Seiter, überfhreiten das 23 rett der Breite nad, 
un dann wieder jum Liivean ihres improvifierten Kais hinabjufteigen und die mülyame fahrt fortjufetzen.

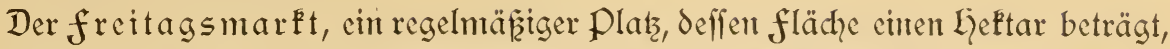
Fanm als das (5enter forum bejeidhnet werden. Im 2lïttelpunft erhebt fidh ein Foloffales Standbild des Jafob von Zrtevelde (1290-1345), cin Werk von De Digne= Qupo, des Vaters volt Paul De Digne, volt dent die Gruppe Brepdel und de Coninc in 23rïgge herrührt. Die etwas theatralifhe Kqaltung des Dolfsmannes erflärt und rechtfertigt fïh aus ver hintei fzenden 2liadht feines Wortes, das mehr als einmal auf dent gleichen Platze widerhallte, wo fidh hente fein Bild erhebt.

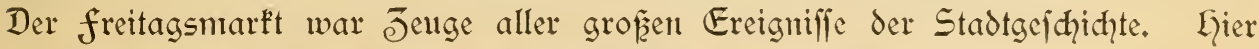

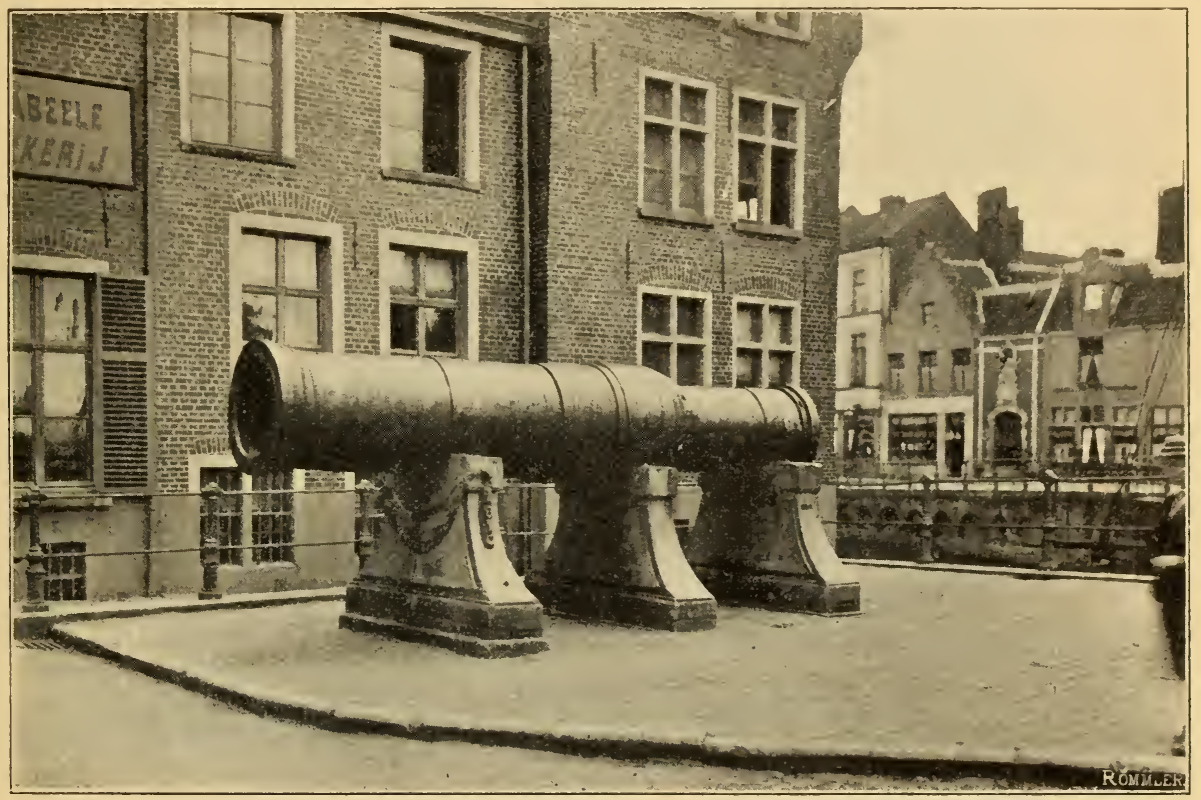

2lbb. 43. Die grof́e Kanone: "Dulle Griete".

war es, wo in Jahre $13 \not 0$ Eduard III. vont England, von Zrtevelde herbei= gerufert, đąwur, die Saḩe der flamläıder nie ju verlaffen; hier war es, wo wenige Jahre fpäter an 2. 2liai 1345 die Webor und Walker fich jenten bruder= mörderijhen Kampf lieferten, von dent die Solalgefḑid̨te die Erinnerunti unter dent 2ramen des "böfen 2rontags" bewahnt hat; hier ferner fammelte 1382 Philipp von Zlrtevelde das Dolf, un gegen Brilgge ju marfhieren; hier endlich war es, wo in Perfon oder durd Bevollmtädthtigte dic Souveräne dic Eide leifteten, wo fid, fefte und Turniere abjpielten, wo bis in die neueften Jeiten fich der 2lusdruc der Dolfsentpfindung in oftmals ftürmifhen Jujammentünften Fund gab. Dor wenigen 2lionaten hat die fojialiftifde 2lrbeiterpartei, die unter dem Zaamen Doornit (Dorwärts) gegründet wurde, auf demfelben freitagsmark̂t= plaţ das gerüuntige Soḱal feiner politifhen Derfanmtumgen und feiner Der= brüderungsfefte eingeweiht. 


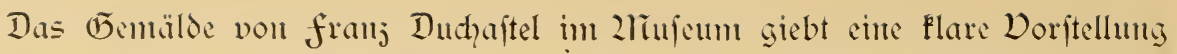
des Platzes im Sḑmunt der hohen fefttage; es beweift überdies, daf er im all= gemeinen nodh an Ente des 17. Jahrhunderts nur wenig Gänfer von momumen= taler Erfdyeinung hatte; die meiften waren niedrig und von ganj geringer $\mathfrak{W}$ idh tigfeit; mehrere fogar hatten Goljfaffaden. Eleute noch als 2lrittelpunft eines Dolfsviertels, entlehnt er dzm Ifleinthandel feine lebendige und fo auszefproḑen dqarafteriftifdge Phyfiognomie. 2lm freitag bietet der "freitagsmarft", befeţ̧

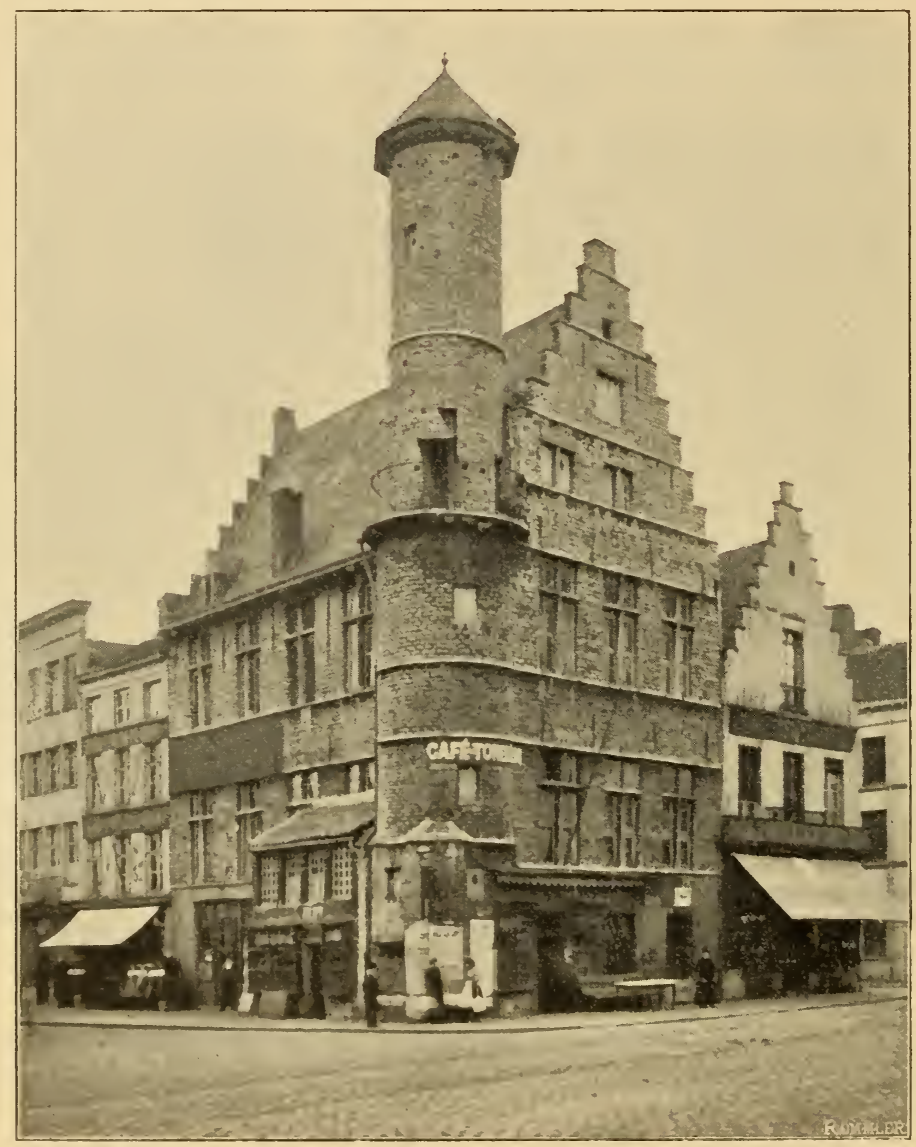

21bb. 44. Das "שorefen".

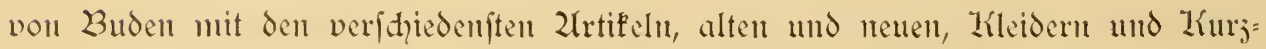

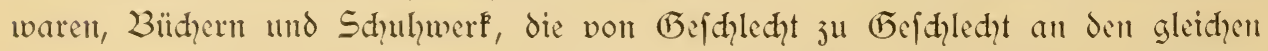
Stellen aufemander folgen, das Sthanfpiel ciner Eeizziger zleffe in fleinem Riallmen.

Einige 23anten des 18. Jahrhunderts ftehen nod hie und da rundhermu ant Plaţe, befonders an der Siidfeite; aber mit 2lusnahme jentes Gibändes, das unter dem Zamen Toreken (Türmdhen) befannt ift und aus dem 15. Jahrhundert ju ftammen fdpeint, bietet feines davon ernfthaftes Intereffe. Llulälsift fprady man 
dent Toreken einen wiḑtigen $\mathbf{L r j p r u n g} 3$; man maḑte daraus ein Leberbleibfel des ehemaligen Rathaules. Geute ift erwiefen, dafiz der Bau dem früheren Junft= gebände der Sohgerber angehörte. Das "Türmḑen" in diefer, an grofizartigen Erimterungen fo reiden 2lmgebung mit dem Eiebelhaule, an das es angelehnt ift, und das wentiger alt jul fein jheint, bejd\}wört die Eeifter vergangener Jeiten.

Im (1) fert, faft mit dem freitagsmarft jufammenfliepend, liegt der grofize St. Jacobsplaţ, chemals der friedhof der gleidhuantigen Kirdhe, der älteften von Gent, im 12. Jahrthundert gegründet, mit f̧̧önen romanifłen Türmen, aber zum grofen Teil, im Sanfe der Jahre 1870-73 durd den 2lrḑiteften van 2lsfhe

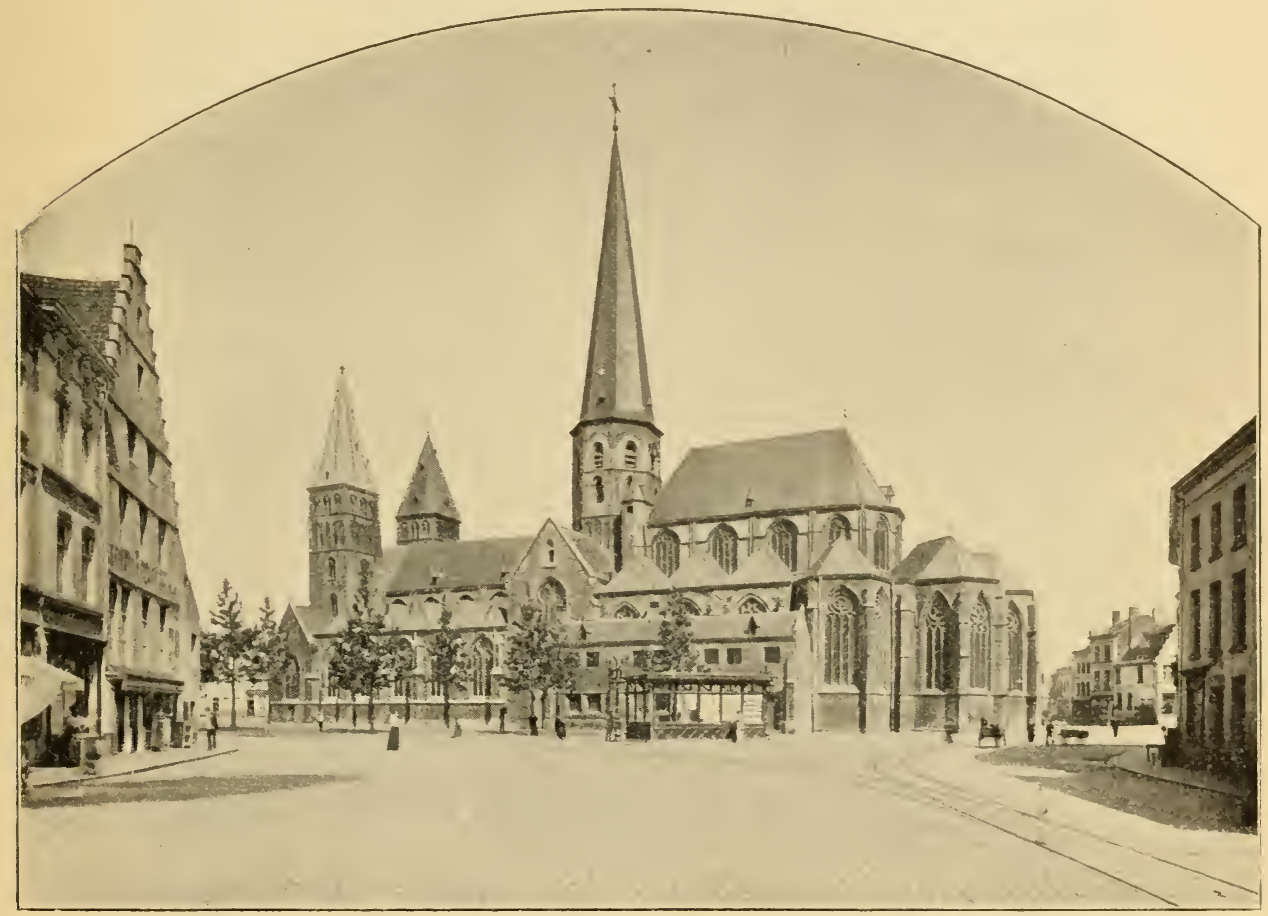

2ubb. 45. Die Jafobsfirche.

ernenert. Diefe 2lrbeit ift trefflidy ausgeführt worden und man Eam fagen, da St. Jacob die fhönfte Zirthe von trent ift. Die beiden romanifhen Türme der faffade find merfwürdig; der nördliḑe hat cin vierfeitiges Dad, der andere trägt eine pyramidal geformte Spitze mit gotifhen Krabben. 2us Stein von

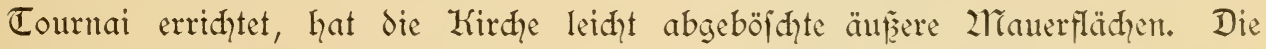
Kapellen ans demt 15. Jahrhundert find dem Werḱe mur äuperlidy angefetz̧.

Das Inmere, aus vier Sdyiffen beftehend, hat midhts Eharafteriftifhes. Der füzboden der Kirthe liegt unter dem Ziivean des Platzes. Jhr Fünftlerifdyer

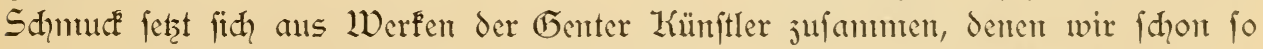
oft begegnet find: (5. de Crayer, van Cleef, Roofe und anderer. Jü Reḑten im Chor aus dem 17. Jahrhundert ein figönes Tabernakel aus 2liarmor, lehr hodh 
mit durchbrohenen fupferten Thüren, darïher der frmbolifhe Pelifan. Diefe fehr intereffante 2ledicula ift 1593 datiert, fdyeint aber von fpäter 3 ll fein. Desgleidhen in Chor das Grab des Wilhelm von Brondhorft und feiner fran 2liarie von WWarlujel,

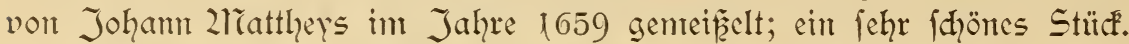

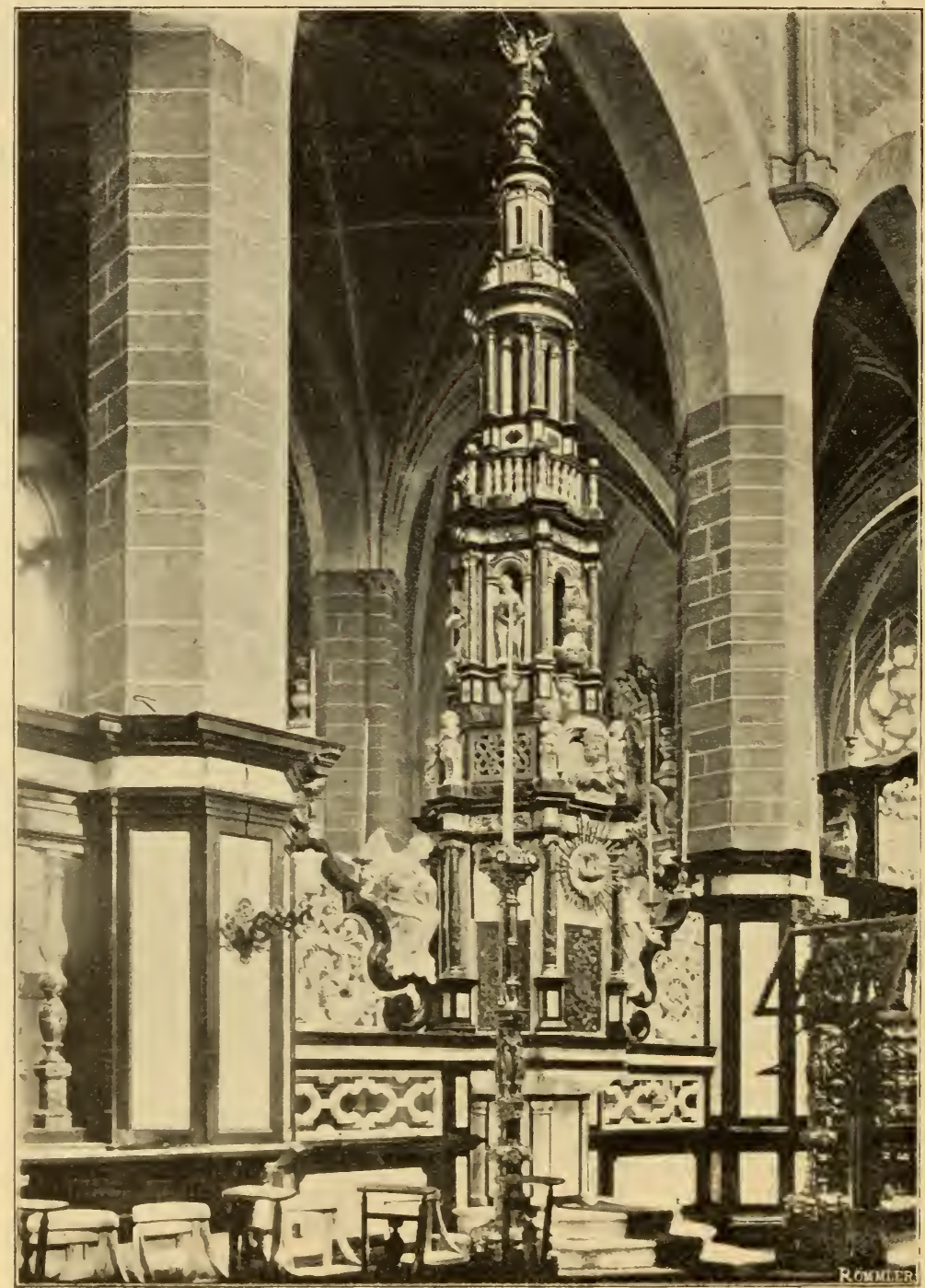

2lbb. 46. Tabernafel in der Jafobsfirtic.

Der Predigtfulyl, woran 2liamtor und Golj verfhneljen, ift von Karel van Poucle, dem Sdïpper des 1784 erriḑteten 2lommentes für Joh. Palfyn, vom 2lerjte=Ifollegium geftiftet und im grofen Sdiff, leider fehr hod, aufgeftellt. Die

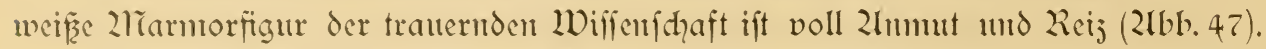

Einte der Glocten von St. Johami, Salvator genamt und vom Jahre 
1628 datiert, jeigt in ihrem (1)berteil cinen Totentanj in Relief. Fin Jünglintg und ein (5reis, von Code geführt, führent eine wilde Sarabante auf.")

Die (5enter Bibliothek, in der nahen Zaadybarfhaft von St. Jacob gelegen, nimmt dic Räume der chemaligen Zlbtei von Baudeloo cin, die äußzerlich mit Zustahnte eines hübfhent Türmdyens der chemaligen Zitrdqe ohne Jntereffe find. Ein merfwürdiger Umitand ift, das die (5enter Bibliotheł mehre als dreif̧ig Jahre älter ift als die Fründung Belgiens felbft. Jut der That wurde jur Jeit der 2lufhebungder Klöpter, 1797, dan den Bemtïhungen des beriihnten Bibliophilen van Ghulthem, der Stod" der mönthifhen Bühercien in der Zlbtei von Bandeloo vereinigt. Int folgenden Jahke wurde die Bibliothe" dem Publifum jugänglidy gemadyt und hat feitdent immer dicjelben ziäume ime gehabt, obwohl fie fid durd Sthenfungen und 2lnfäufe bedcutend entwidfelt hat. In $\mathfrak{B}_{\mathrm{ejug}}$ anf litterarifde und hiftorifdye

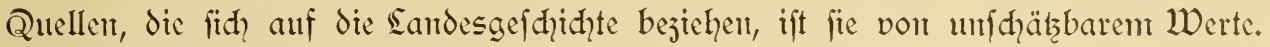
Die Dofumente der graphifhen Kunft find nidht wentiger wertvoll; dic gantze Der= gangenheit von (5ent ift darit durd Jeidymutgen, die nad, mtehreren Taufenden jählen, vertreten, und dieje bilden cinte Quelle widhtigfter Zraḑweifungen. Die che= malige Kapelle von Bandeloo, die jeţt als Bühergaleric dient, ift von fehr malerifher Wirfung.

Das fal. 2lthenacum verbunden nut der 23ibliothep nimmt einen Teil des alten Klojters cir. Das Gemadh des Zlbtes hat nod das alte Eetäfel im Stile Sudwigs XIV. und feine int Jahre 1656 von dent fabrifanten françois de 2roor von 2ludenarde gelieferten Tapifferien. Zlud von ihrent sinftigen Elantz haben diefe cin gut Teil bewahrt, mur dic fleifd?= tönc find ins Sđ̧wärjliḑe übergegangent, es fint mythologif he Scenem*:) dargeftellt.

Die alten und chrwärdigen (5ärten von Baudeloo bildent den Botanifhen Farten der Stadt (5ent, der in der gartenfreundliden Welt fo beriihnt ift. 2lran findet den Eingang, went man rechtwinflig von der Eeorgftrafe abjweigt, die wir mut verfolgen, unt uns nad dent Rituen der 2lbtei vou St. $23 a v o j u$ wertden, jenent Sapidar:2liufeum, vou dem in saufe unferer Befartibung fhout mehr als cimmal dic kede gewefen ift (2rbb. 48 u. 49).

Der $\mathfrak{W}_{e g}$, den wir nehmten, führt uns mitten in cint maritintes Diertel - dent bent ift aud Lafenftadt. Sängs des Rotenturmfais

*) Dgl. die äeihnung diejes Streifens in Kervyn de Dolfaersbeeff, Les Eglises de Gand, Bo. II, S. 36.

**) Siehe das Inventaire archéologielue de Gand 1899, Э. 129.

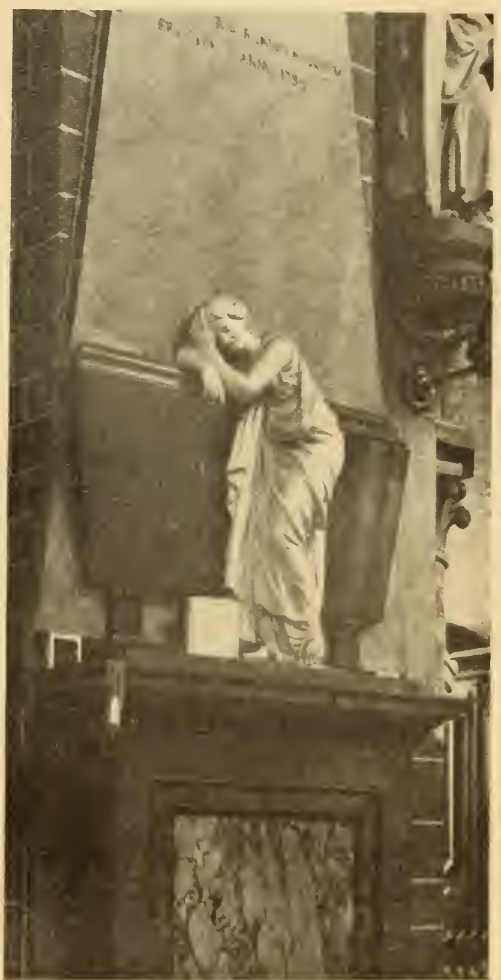

2ubb. 47. Jafobsfirche: Grabmal von Toham folfyn. 1784. (2fus de!n »I.A.d.G. ) 
weiterwandernd überfhreiten wir die De pauw:Brücke und bald jeigen fich die 2lianerrefte deffen, was cinft bis jum 16. Jahrhundert cine der reidhiten Zubteien flanderns war und in Gent die "Stadt" des hl. Bavo bildete.

2lbfeits vom ftäbtifhen Getriebe entlehnen diefe Runten felbft von ihrer Ein=

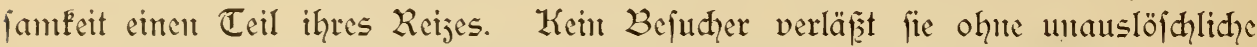
Eindrïße, er mag Zlltertumsforfher, Künjtler oder aud mur Sd auluftiger fein.

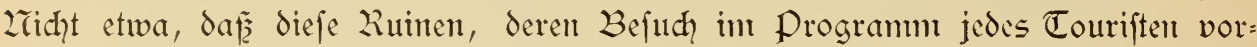
gejehen ift, in irgend welcher Weife iḩer neuen Beftinmung angepafzet worden wären; man hat fie weder in poetifhes oder dramtatifhes Eewand gefleidet; fie find geblieben, was jeit und Llmitände ans ihnen gemadyt haben.

Eine wunderlidhe und felten vorfommende Thatfadye - einjig fogar in der

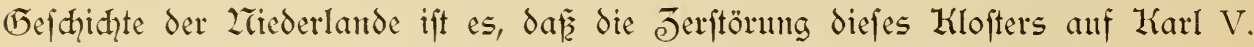
jurüç̧uführen ift. Der Kaifer, willents, infolge der Erhebung von 1539 cine

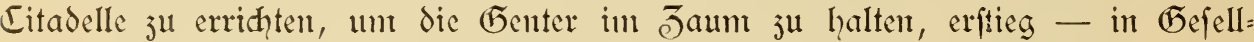
Ghaft feines Butbers ferditand und, wie man fagt, des Kerjogs von 2llba - den Turm vou St. Joham, heute St. Bavo, und wählte als Stätte feiner feftung juft den (Drt, wo feit nem Jahthunderten die 2riöndqe fid ihren frommen llebungen friedidy lingegeben hatter.

Das Klofter wurde fait ganj niedergelegt und fein Baumaterial diente jur Errichtung der nenen feftung. LIm das Kapitel jul entfhädigen, verlegte es der Zaifer mit feinen Redhten und Privilegien nad der Johannisfirdhe, die feit jener Jeit den Zamen St. Bavo amtahnt.

Zur ans Gemälden und Kupferftidhen fentuen wir einigermasen die alte 2lbtei; was davon übrig geblieben, ift faft nidhts als cintige 2lanerrefte, cintige Bogen, ein paar Stücle eines Irreujgangs, Zkellerräume und weiter unten, für fich

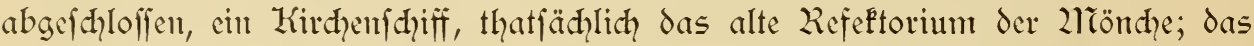
(5anze ïberwudhert von Sdhnuroherpflanjen, Brombeerfträudhern, Epheu, Stein= bred, gemifht mit launif̧en öweigen von anderem Gefträud, die in voller Lleppigkeit treiben.

Der Eindruce ift ergreifend. Diefe 2fbzefhiedenheit, wo der Säm der 2 uzen= welt erfitirbt, hat etwas von den Galerien des Campo Santo in Pifa. Fier wie dort fpriḑt alles von der Liiḑtigfeit der Dinge, und es fheint dent Eindringling, went er über die gelosferten Steinplatten hin wandelt, als wenn muter feinen Sdyritten die 2radhe der Toten, von denen der Diḑter fpridht, fid erhöbe.

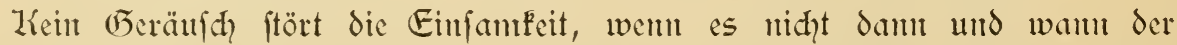

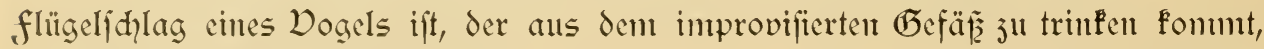
das ihm das Regenwaffer in der Kählung irgent weldhen phantaftifhen Sfultptur= ftüctes liefert.

Went man gewiffen forfhern Glanben fhenft, hat die Zlbtei, dic im 7. Jahrhundert von dent hl. 2lmandus gegründet wurde, als 2łrḑiteften Eginhard in cigenter Perfon gehabt. Der 2lianerverbant und die Zkutsbogeturfaturen, die nodh aufred)t ftehen, fdyeinen die angegebene Erbanungsjeit jul beftätigen.

Die gewölbte (5alerie des Irrenjganges, volt dem 2lbt de 2liercatel erriḑtet, ju der man gelangt, wem man die Lmrfriedigung durdhfdyritten hat, datiert erft 


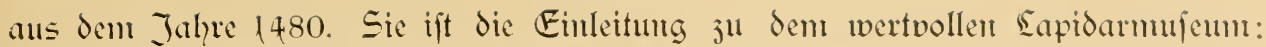

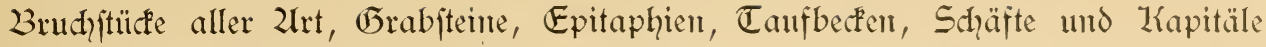
von Säulen, Brudyitüle von figuren, liegend oder an die 2rauter gelehnt, häufig von höchftem Wert. อ̄u erwähnen find unter diefen elyrwürdigen Reften die SFulp= turen des portals der 2fbtei felbft, 1852 entbecft. Sie zeigen, dem 11. oder 12. Jahrhundert angehörend, die Reliquien von St. 23avo, wie fie 1058 aus= geftellt waren und die Wunder, die fie wirftent.

Der fogenannte Kapitelfaal, oder aud Krypta der hl. Jung jrai betitelt, unter

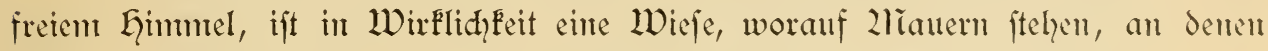
fich ZIetterpflanjen breit maḑen, und dod, ift er von gropem Jutereffe; man hat hier 21 Gräber in form von 2lünmienfärgen gefunden, die im 23oden ausgehöhlt waren. Wunderbare Rundbogenfenfter öfinen fich nath der (ñalerie hin, die wir eben verlafien habent. Die mittelfte Deffinutg dient als Thür; wie die anderen hat fie Säulenbündel als Pfoften und gedoppelte 230 gen eingejeidntet, die fith auf gepaarte Säulen von jierlidjter Jెeichnung ftïtzen.

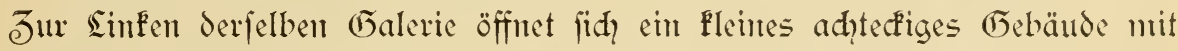
Etagen=2lufbau, Baptifterium des hl. 2liacarius genamt, und 1179 geweiht. Es

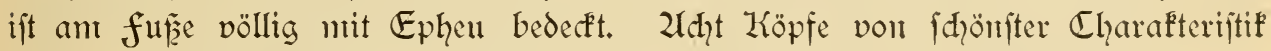
find an den zlianerfanten fithtbar. Der (D) berban diefes Türmdhens ift von romanifdyen fenftern erlendytet.

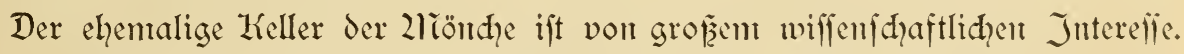
Die ganje Wölbung ift von ciner Centralfänle geftütst, gegen die alle Rippan dis (5auzen jufantmenlaufen.

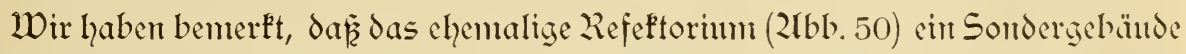
in dem Garten bildet; das genilgt, unt eite Dorftellung von der Bedeutung diefes Klofters jul geben, deffen Gejamtheit, nad, dem Plane von 1534, von einer fanm glaublichen Größze ift. Bis jum Jahl 1882 diente dies 2röndhsrefeftortum als Paroḑialfirche, nahdem es von 1534-1830 das Gotteshans des Shlofies der Spantier gewefen war. Es ift eill fehr geräumiges Schiff mit fiḑtbarem Ljolj= werk, feitlich von adhtundjwanjig Runbbogenfenftern erhellt, das Ganje jiemlids jerfallen. 2lian hat auf der 2lbfhrägung der ferifter Spuren von Polychromie, figuren von nid̨t näher beftintment Geiligen gefunden; fie fdyeinen dem 11 . oder 12. Jahrhundert ju entiftammen. Der orientalifhe (Giebel wird von dret parallelen fenftern durḑbrodhen.

Das Sdyiff, aus dent alles, was beweglid war, entfernt ift, bildet den Laupt=

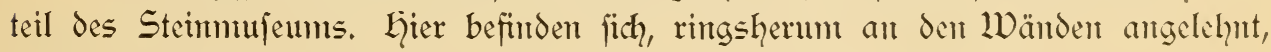
die merfwürdigen Frabplatten, die 1885 bei der Zriederlegutg der 2hïhlle und der Braentgaten=Shleuje gefammelt woudden, deren Bettung fie gebildet hatten. Dicje erftaunliche und unerwartete Entbeckung hat aus dem Stemmufeum cines dir erften der Welt gemadyt. Die in Stein gegrabenen Bildutiffe der Derftorbentu ftamment jumteift aus dent 13. Jahrhundert. 2lian förnte von dent Platten, die förmlid geftodhen fint, fehr wohl Drutłabjüge maḑen. 2ubgejehen von ihrem

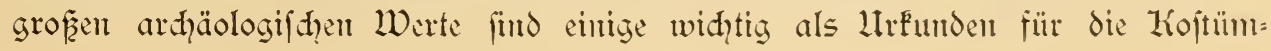




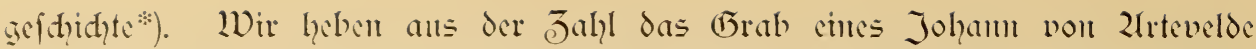
$(\dagger 1260), 23$ moer des Genter Dolpsmamies, heraus. E E giebt welthe darunter,

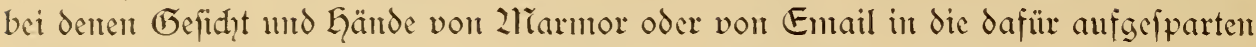

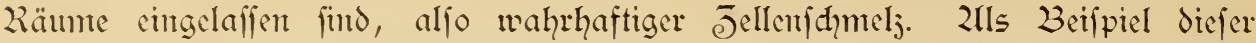

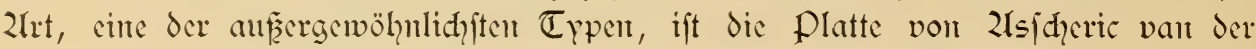
Conderbord anjuführen. Sie befteht aus fdywarjem 2liarmor und ftellt cin befejtigtes Sdylof oder vielleidyt ein Stadthor dar, in rotent und weisent Entail

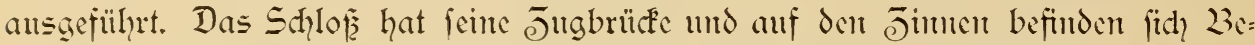
waffirte. Das (5anje ijt von merfwürdiger 3 eftimmtheit. Dic Platte mur ans der erften Gälfte des 13. Jahrhunderts firn. Zaidht weniger intereffant ift cin

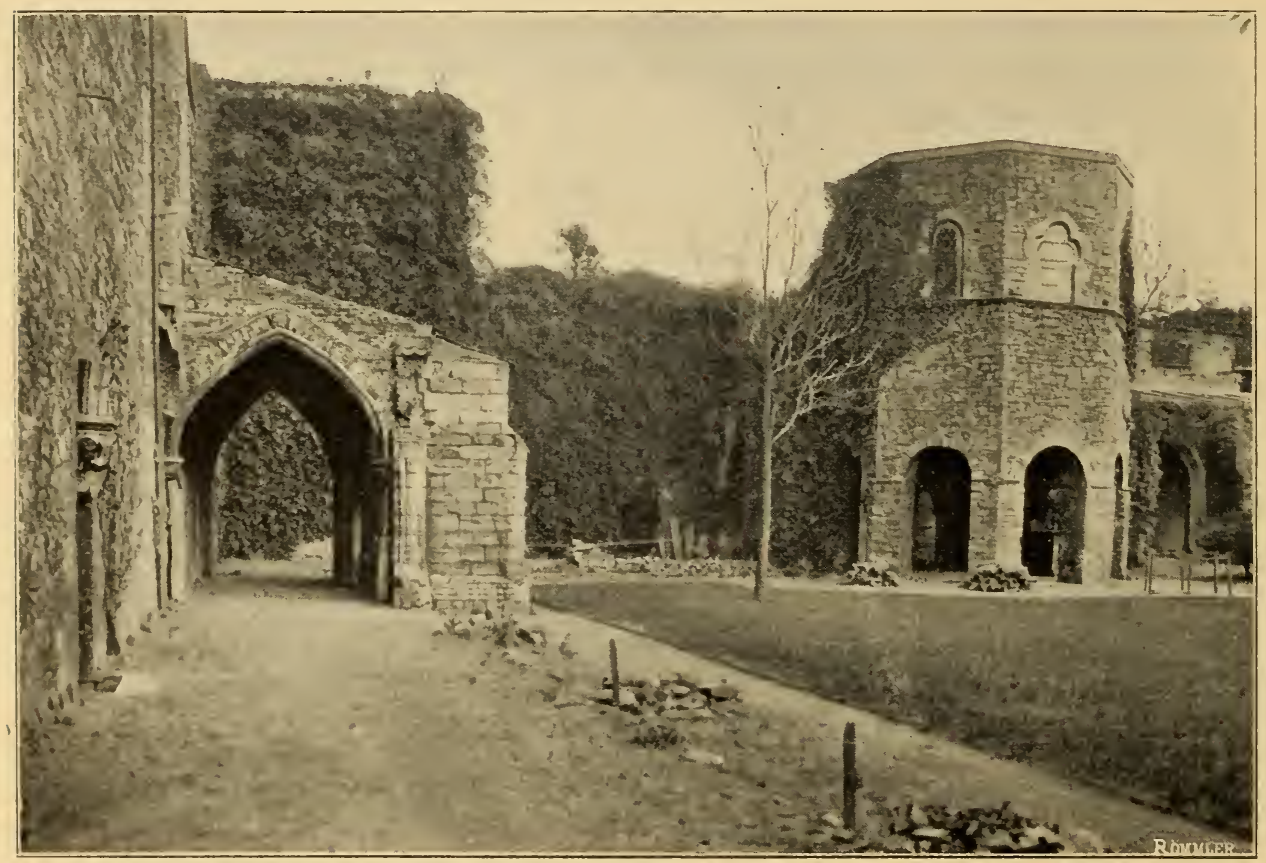

21bb. 48. Ruiten der 2ubtei 5t. 23avo ([apidar=!lTufeum).

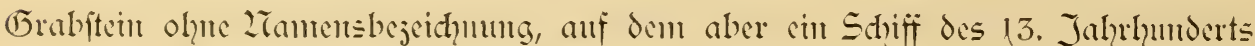
cingraviert ift, mit fintem 2liafterb, dem Pavillon, dem gropen 2liaft und dem Zunfer; der (5rabftein des 23ruders Wilhelm von 2lünde († 1272), won fhönftem Stil. Jan 23lome beriđhtet uns: "Jal wurde int Jahre 1290 getötet".

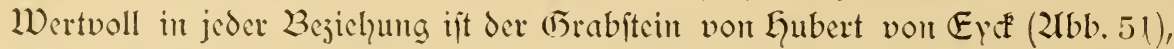
der 1426 in Gent verforben ift und in der Irrppta der Zirdye St. Johant, hente St. 23avo, heigeferzt wutrde, wofelbit man 1892 dic Platte wieder anffand, dic durch Eerm Et. 2liorticr beftimmt worden ift. Sie ift 2,08 2lieter hodh und 1,19 2licter breit und ftellt, verticft, eir Spelett dar, das vor fid, ebenfalls vertieft,

*) Eiche: licthune de Villers, Anciennes peintures murales anx ruines de St. Bavon. Rerue

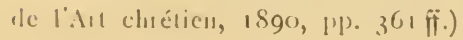


ein redytefiges feld von 66 ju 45 Sentmuetern trägt, beftimmut jur 2lufuahme einter Platte mit der (ñrabfdrift in Derfen, wie fie van zliander giebt.

Jn einer Ecke ift die Bildfäule cines Bunter Lriegers anfgeftellt, eintes jener vier, die 1358 an den Ecken des Belfrieds angebraht worden waren, und jwar die cinjige, die uns mur erhalten ift. Sie mißzt jwei zlieter in der $\mathfrak{h}$ öhe mid fheint

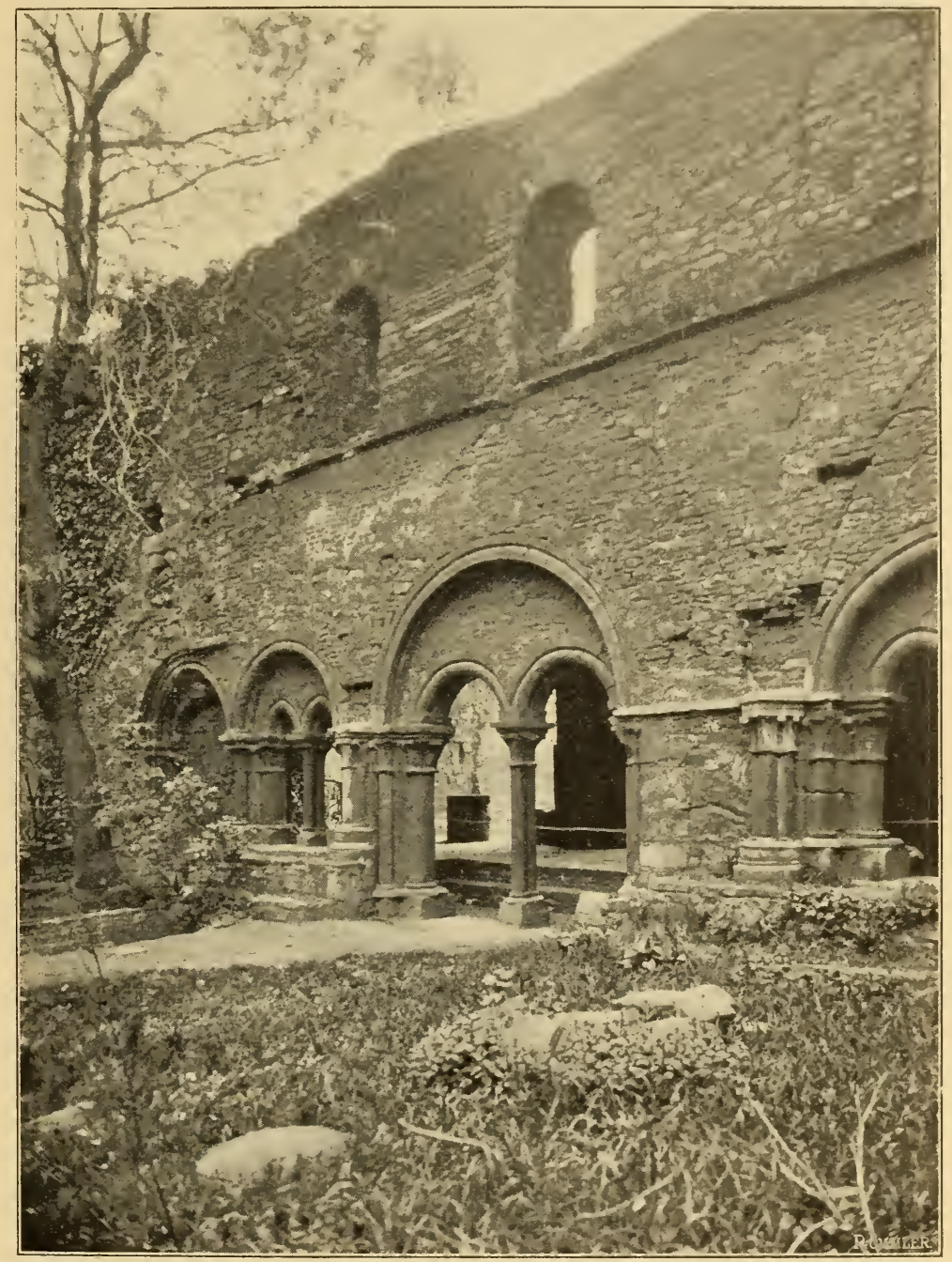

Ubb. 49. Ruiten der 2lbtei St. Zavo (Iapidar=MTufeum).

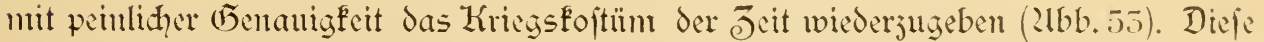
figur wurde erft 1869 von Belfried herabgenommen. Ein entjüféender Elener Ultar, in Stein gemeifielt, ans dem 15. Jahrhundert und der SAlule von Tommai fammend:

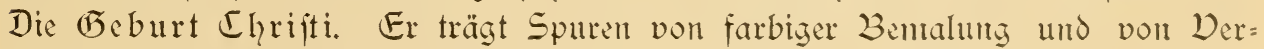
goldung und die Lintergrundandihaft ift in Del gemalt. Es ijt ein Stüd von

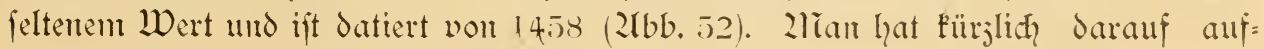




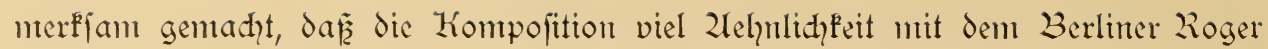
van der Weyden hat.*)

27ierfen wir noch das beadhtenswerte Wahrzeichen der Genter Weilljapfer an, eine SFulptur des 16. Jahrhunderts von grofent Intereffe, aber leider ftark

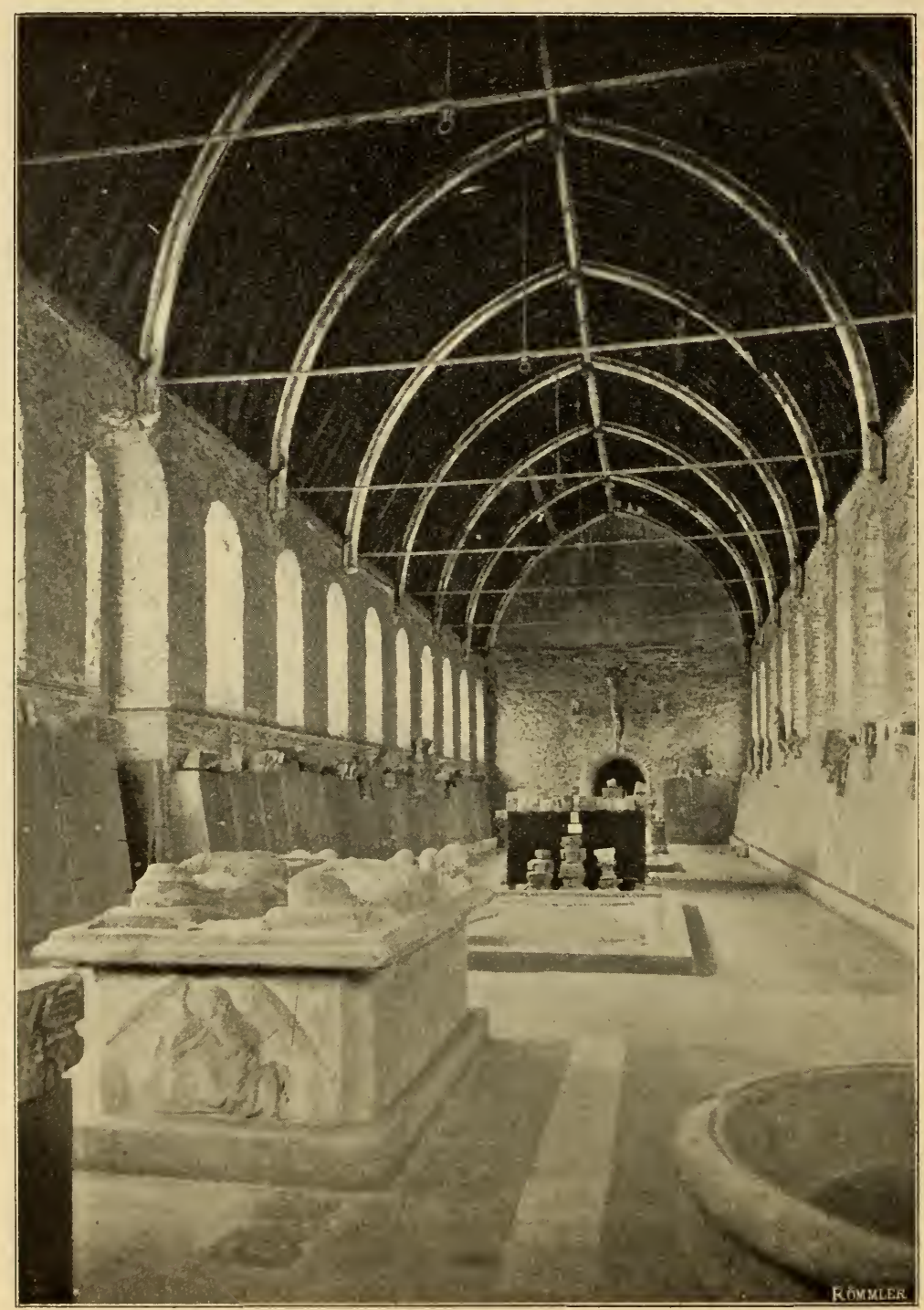

2ubb. 50. Das Steimmufenm, friiheres Refeftorium.

bef ḑäbigt; endlid, das präđhtige (Grabmal Johanmes, Baftards von Cleve, und

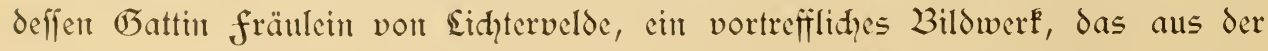
Kirhte volt Rouffelacre ftanmt und das unglanblither Weife die Zitrifenvorfteher

*) L. Llacterlint(F: Roger von der Weyden et les Yinaigiers de Tournai. Bruxelles Igoo. 
dem Grafen Thiennes 1840 abtraten. Der Ritter ift in Waffen dargeftellt, ntit

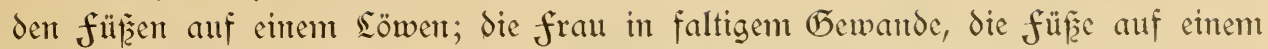
Gqunde. Eine Gruppe von jwei Zindern, die fith friffen, ift cine ausgezeidhntete Sfulptur des 17. Jahrhunderts.

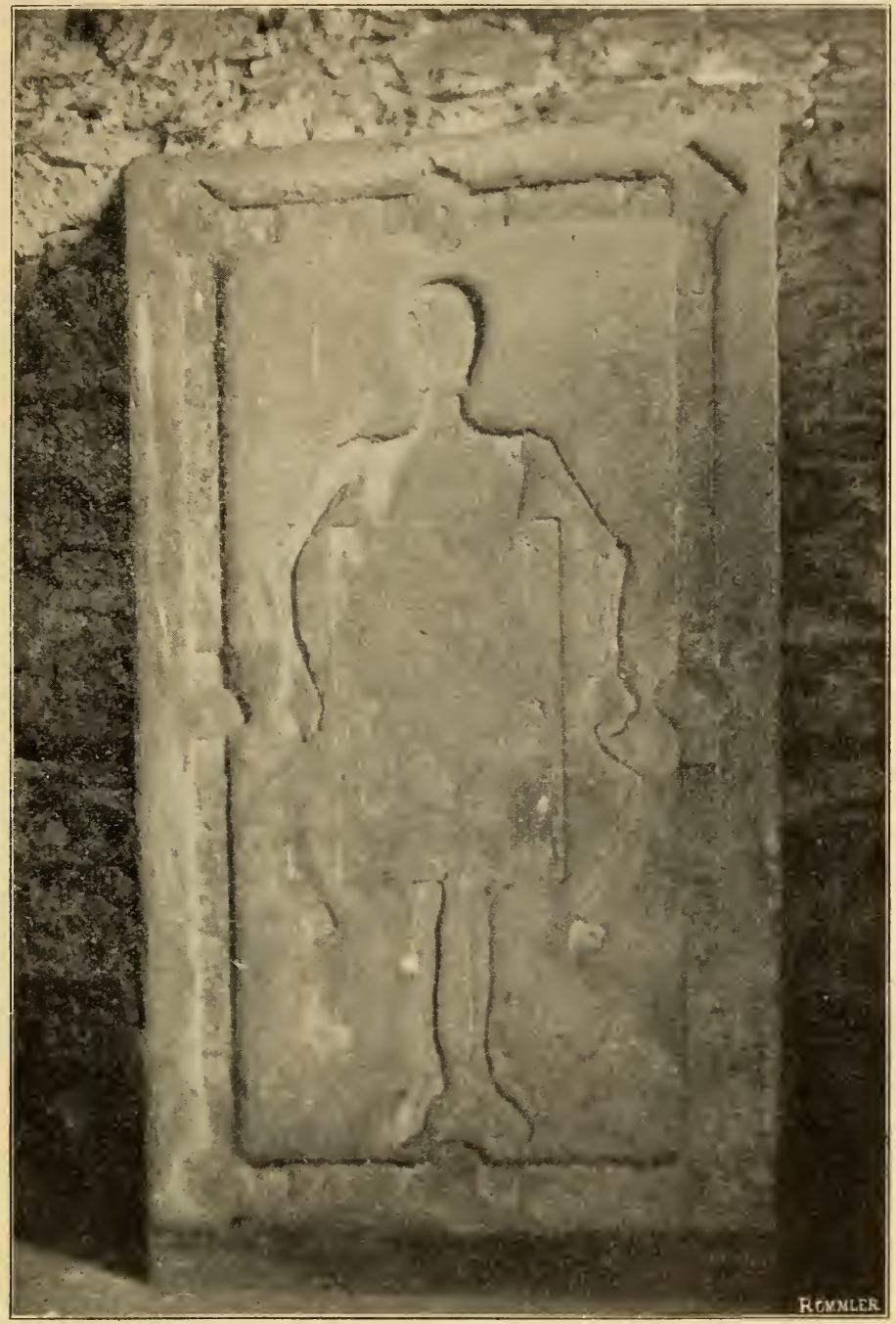

2ubb. 51. Equbert van Eyd's Grabjtein im Lapidar=Mujeum.

Jumitten der Kapelle ift ein fđöntes 2rojaifpplafter des 13. Jahrhunderts teilweife wieder hergeftellt worden.

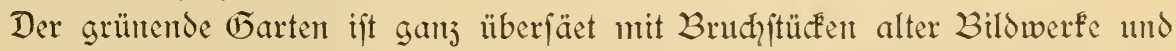
bietet bei jedem Sdyritte intereffante Einzelheiten. Fegent die Wand gelehnt fehen wir ein grofes Relicf, eine ehemalige Sopraporte der Waifenfdulle, cin wohl= gelungentes Stück. In der 2littte thront die Jungfrau von Erent, von jwei Engeln 


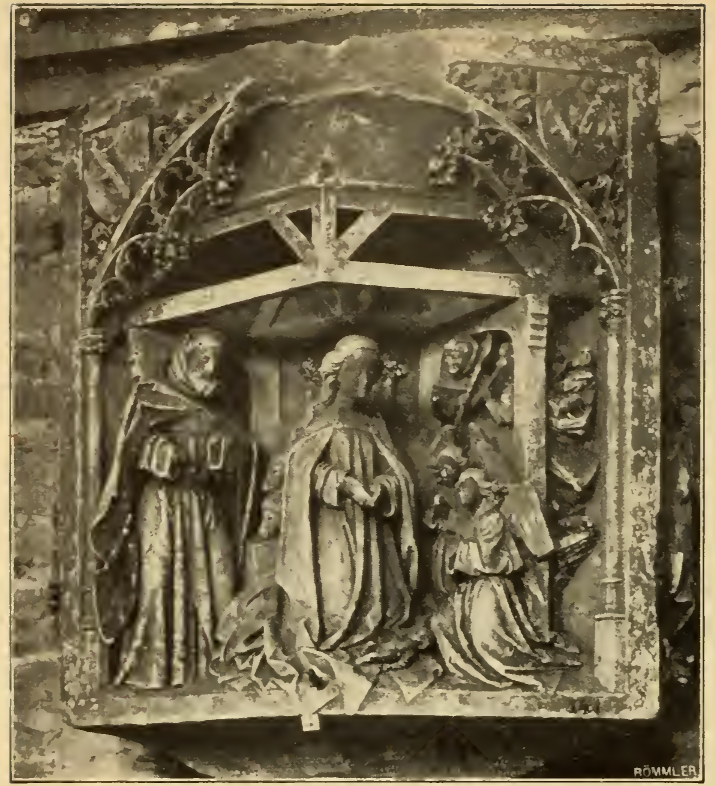

2łbb. 52. Steinmufenm: Zelief mit der (5eburt Chrijti. 1458.

verelprt; an jeder Site mit bem L)ute in der Land eincr Denfionäre der Shule in malerifduen Tradyt. Die Infarift lautet:

\section{PIETATIS GANDA SCHOLA PAVPERI'M*).}

2lan fapeidet mur mit $23 e=$ dauem von diefer Stätte, die fo voll von feffelnden Erinterungen ift.

Zelqmen wir den $W_{e g}$ jur Stadt ïber die van Eyd 23 rïlle und die gleidnamige Strapic, an deren Ende der Turm volt $S t$. Bavo fid abjeidunet, wieder allf, fo fehen wir int Dorübergehen einige Banten vou hübfdem, male= rifdien Zublick: an der Ecke des Platzes und der Straje, 2rr. 21, ein miedriges $\mathfrak{L}$ aus mit Doppel= giebel, ohne J̄weifel ans dem Begint des 16. Jahrhunderts herrührend (2lbb. 54);

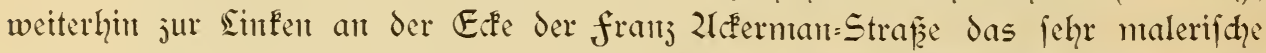
Gefamtbild eines Gaufes mit niedriger 2lianer und Lébenbanten. Sdyreiten wir quer über die "Karls V. Strake" und den "Lluteren Sdheldekai" entlang, die Stelle, die im 1.j. Jahrhuntdert die (5renze jwifdhen franfreid und dent deutfden Reidge bildete, grüzen im Dorbeigehen den Steen voll (5erhard dent Tenfel, fo erreiden wir in

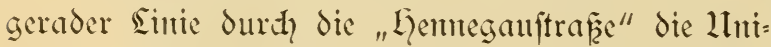
verfität, deren adytfäulige falfade von foritthifdyer (V) dmung fid gegen die kue de foulons (WValfer: ftrafies) jul erhebt. Sie ift ein Wert von Roclandt, 1826 erbaut, und nad, 2unfidt von 3 urcthardt, 1846, eine der glänjendften llniverfitätsbauten, die es damals gab; diefe Würdigung ift and hente nod geredhtfertigt trotz den Lluiverfitätspaläften von Wien und Straf̧burg. Die "Ealle des Pas Perdus" und der afademiifhe Saal madhen cinen vornehnten Ein: oruck. (I) ben in Treppenhaufe ftellen die fresken vou $\mathfrak{E}$. de Tacye und 2U. Cluyjenaar die grofien Phafen des menfdyliden Wiffens dyarapteriftifd dar und endigen mit der franjëfiften SRenolution.

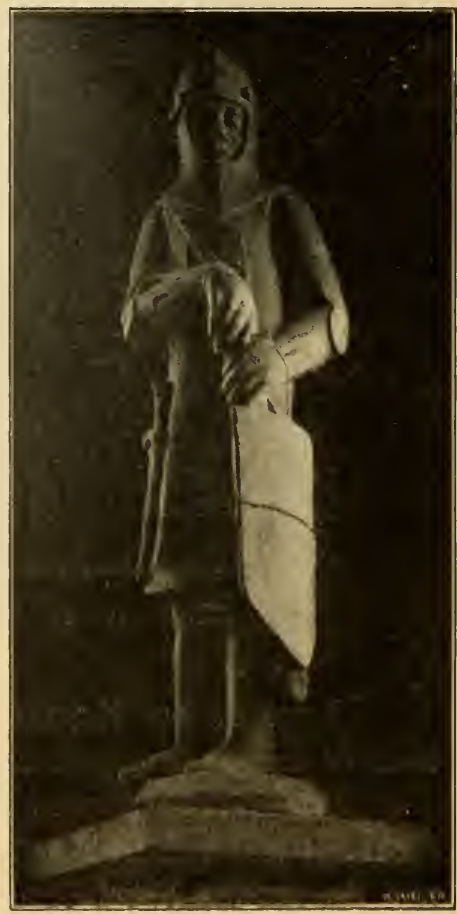

*) 1662.

21bb. 53. Etcimunfeum: Trieger vom 23elfried. 


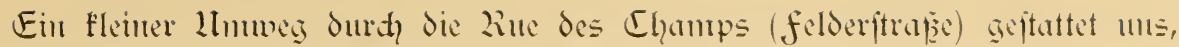
das grofe und gewaltige (5ebände im Stile Sudwigs XV. ju betradłten, das ehemalige Wohnhans von hante Steenthuyfe, wo sudwig XVIII. während der ëeit,

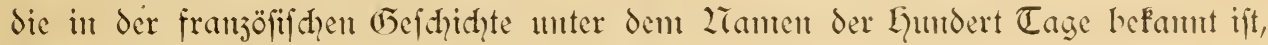
Kof ļiclt.

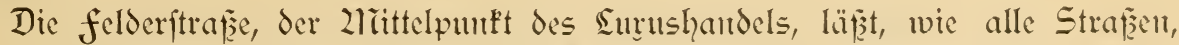
die in der Ziähe der Place d'zlrmes (Waffen=flatz) liegent, etwas volt der Dor=

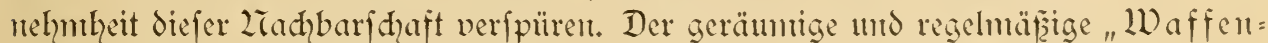

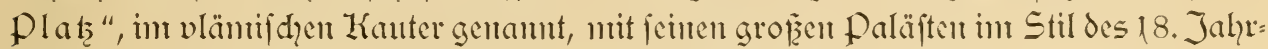
hunderts, feiner fdyönen Launtwadhe und felbft aud den 2llmen, mit denen er bepflangt ift, hat etwas Dormärjlides in feinem ganzen Wejen. Er ift mit einem Worte der Dereinigungspunft der vornehment und adeligen Welt, wie der freitags= marft der llittelpunft des Dol'swerkehrs ift.

Durh die Sontent oder durd dic Theaterftraze, dic beide von den Exten des Platzes ausgehen, erreidht man den Juftijpalaft, eit hedentendes (5ebände vor: nehmen Charafters, von Roelandt 1846 erbaut, für das die Seie und die Schelde cinen felgr vorteilhaften Zahhment bilden. Dor dem Palaft eine fḑöne Statue des berïhnten 21bvofaten 2lietbepentingen (1399-1881) von Julian Dillens (216b. 55).

2lian betritt den Juftijpalajt von der (Ditfeite aus, die der Theaterftraßze gegentiber liegt. Eine grofe Treppe führt jur "Salle des pas Perdns", die mit cinigen, meift modernen Gemtälden gefhmülft ift, unter denten man angenthm

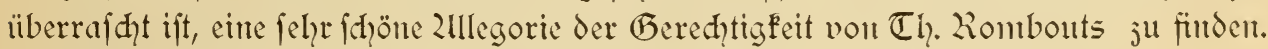
Ein (5emälde von Suvé ans 23rügge (174.5-1807), dem Direftor der franjöfit đ̧en IKunft=2lkadentie in Ront, die Bildniffe in ganjer figur volt Bonaparte als

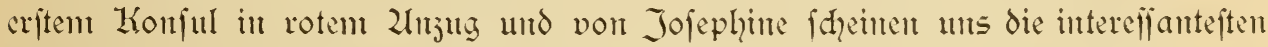

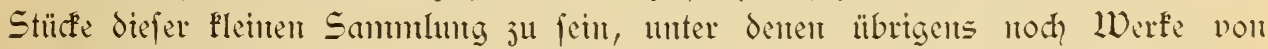

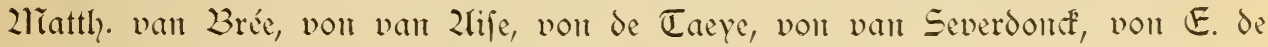
Pratere, von $P$. van de $\mathcal{D}$ in unt von zliontald figutrieren.

In jüblidher Ridhtung, d. i. in der der hinteren falfad des Juftijpalaftes,

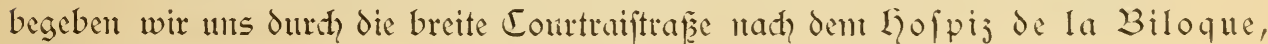
deffer 3 efud fid jedent Zltertumsfreutde empriehlt (2lbb. 56 u. 57).

Wir erfteigen hier den 2liont Blandin, wo die berïlymte 2rbtri St. Peter "ant Blandin:Berge" lag; der 2⿰亻bt verwaltete einen Teil des (5enter Territorinms die "Stadt" St. Deter, cbenfo wie es eirre "Stadt" St. Bawo gab. Das Diertel

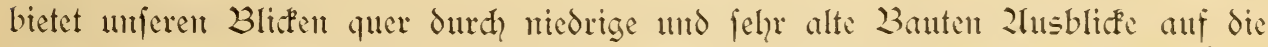

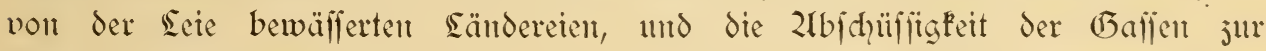
Reditent ift auffallend in diejer Stadt, wo fidh forft wentg Terrainfduwanfungen zeigen.

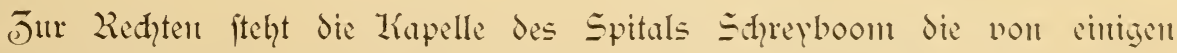
Zlutoren crwähnt, aber von minterem Jntereffe ift; ihve Befonderheit, mit porträts

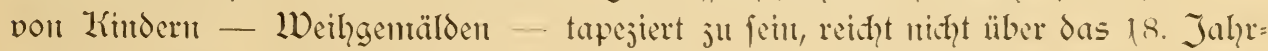

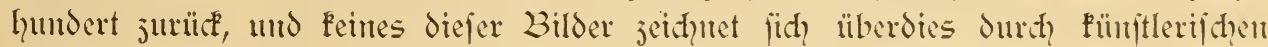
Wert aus.

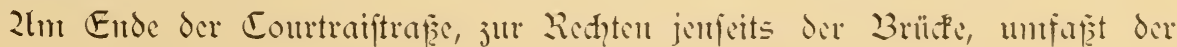




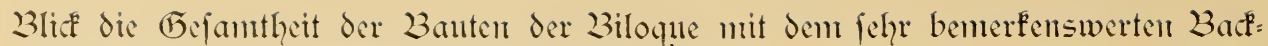
fteingiebel aus dem 13. Jahrlhundert, dem des Ereifenhofpizes, deffen Jnteres reḑt intereffant ift (2lbb, 56).

Wem wir durch 2ir. 3 des Biloque=Kais eintreten, dringen wir in das riefige Gebiet, das die Genter Spitäler cintehmen, deren durd weite Rajenfläḑen getrente

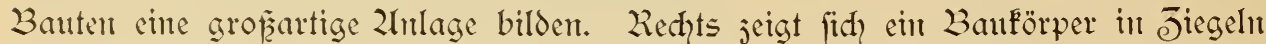
unt Lqufteit ausgeführt ans dem 17. Jahprhundert, der als Bäkerei dient; es ift ein eleganter Typus jenter Epodhe und fieht wie ein Lebengebände eines Sdylofies aus. Zluf dem grofent Lofe redyts erftrecft fid die faffade der ehemaligen Ziapelle,

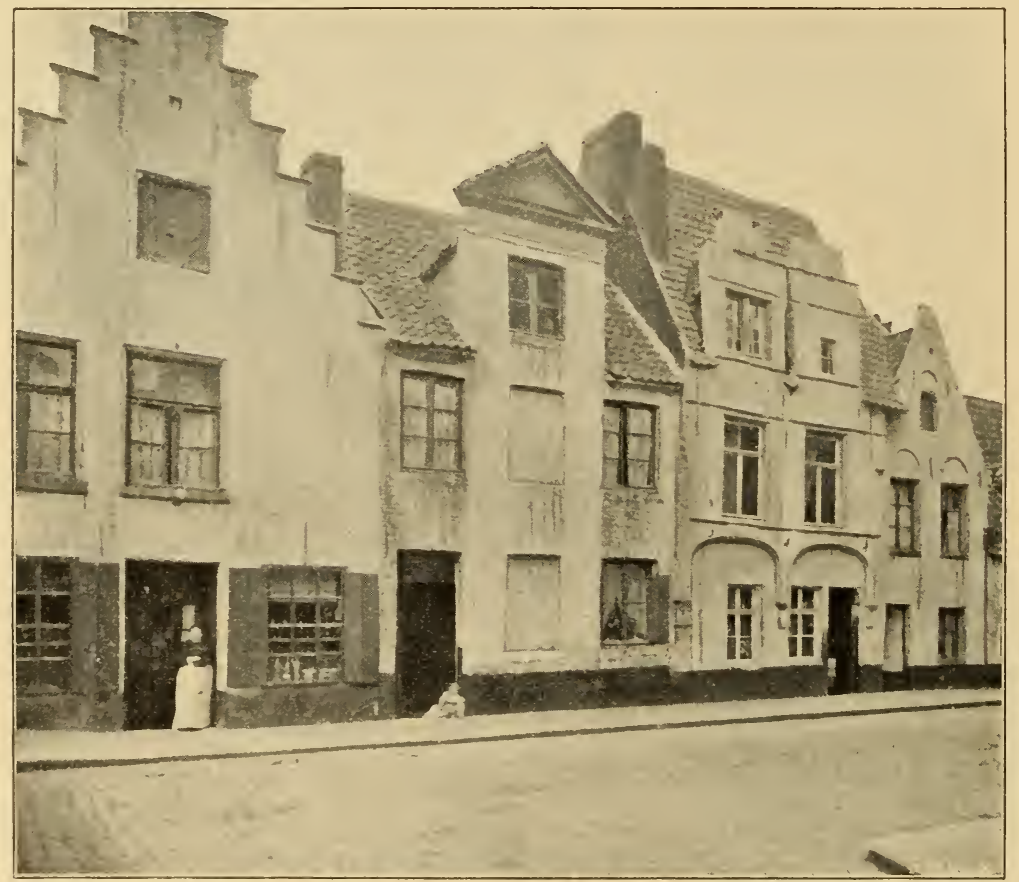

2łbb. 54. Die van Eyck=Straje 2ir. 21.

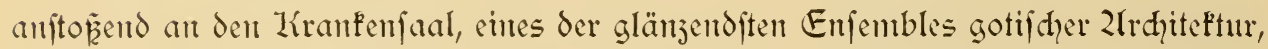
die Z3elgien befitzt.

"Lätte die Stadt (5ent den Reifenden nithts anderes als fein altes Loopital der Biloque zu zeigen," fagt $\mathfrak{U}$. Derlaegen, "fo würden fie Feinesfalls den

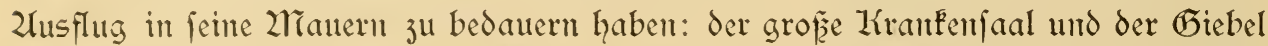
des Zapitelfaales find wirflid 2lionumente, einjig in ZBelgien und nur fehr felten ill Europa anjutreffen."

Zus Stein von Tournai erbant, find die beiden faffaden, bis jum Beginn der (5iebel vereinigt (21bb.5z). Der Lluterban ift mit einer Reile von Bogen verfehen, die von dünnen, Prabbenbeferzten Säuldyen geftütz̧t wirden; ihre $3 a j e n$ ruhzu auf ciner durḑlaufenden Lluterlage. Jwwei frühgotifdye Dorlqallen mit jtar" voripringenden

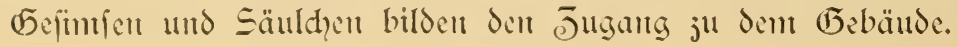


Die ehemalige Kapelle hat ein (vermauertes) feniter mit hübjhen Fleeblatt=

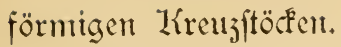

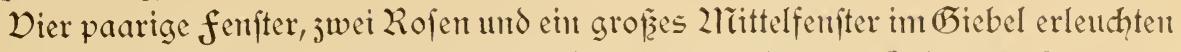

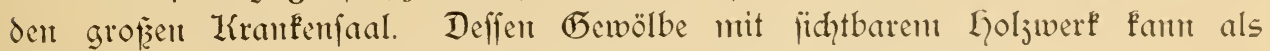
vortrefflid bejeidynet werden. ES ftanmt aus demt 2lufang des 15. Jaḩrhutderts.

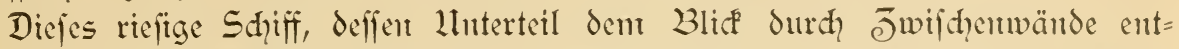
3ogen ift, die einen 2littelgang bilden, hat eine Tiefe von 5521 reter bei 1621 teter 23reite. Die Wölluntg ift 18 2lieter hod und jerfällt in einzelne 2lbteilungen. Dic

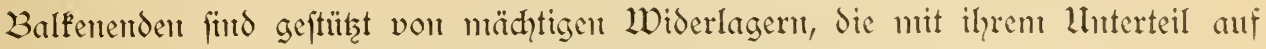

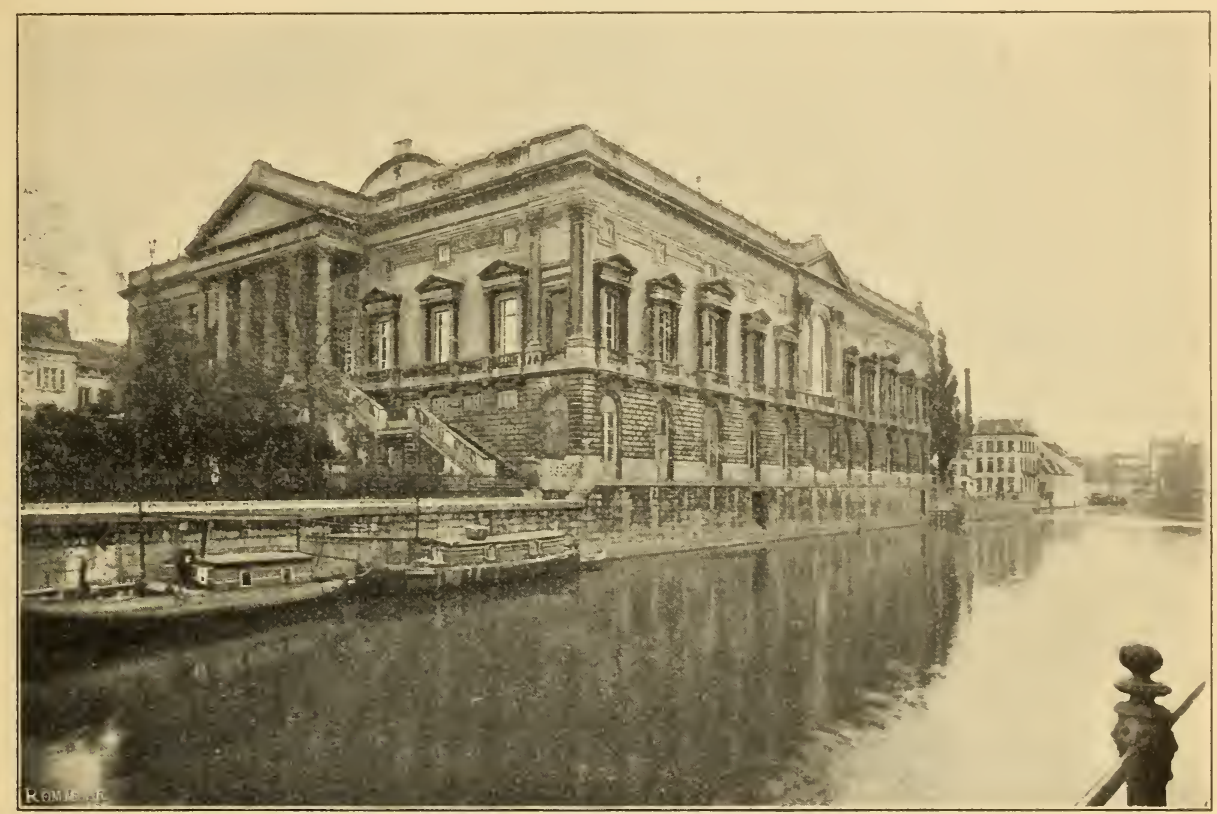

Ubb. 55. Der Iujtijpalajt.

Sdywellen ruhen. Die Zufeinanderfolge diefer gejdwwngenen Sinten bringt cintu multderbarent Effeft hervor (2łbb. 58).

Weiter nad vorn, imterhalb der Einfriedigung, verdient das (5)eifenthofpij feinerfeits Zupmerffamfeit, obwohl es ein Jahrhundert jünger ift. 2luenen ift der

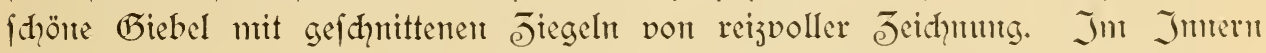
gelangt man $j^{\text {hl }}$ dejem Teil des 23anes durch ein Sabyrinth non Korriboren, nadidem man das Refeftorium der Greife, cinen fehr intereffanten 23au des 1\%. Jahr=

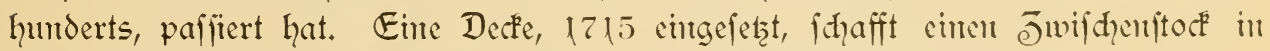

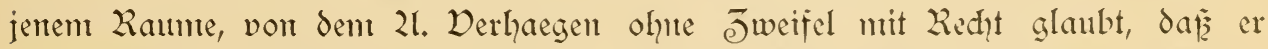
das chemalige Refeftorium gewefen fein milffe. Ein Riamin mit grofent 2lintel

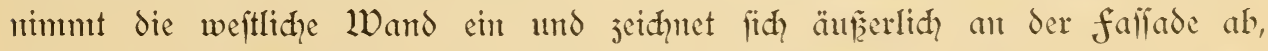
indem feine 2lusmündung deren Giebel bildet (2lbb. 56). Diefer Saal ftammut aus dent 14. Jahrhundert.

Int Interen fint die $\mathfrak{W a ̈ r d e}$ des Eates von widhtigut 2läalereien einge: 
nomment, die mit Wafferfarben auf rotem. Frumb gentalt fints; fie ftellen auf der Weftwant den hl. Johannes und den hl. Chriftoph, auf der öftlichen wand Shriftus und die Jungfran auf dem Throne dar. Diefe Ecmälde find von

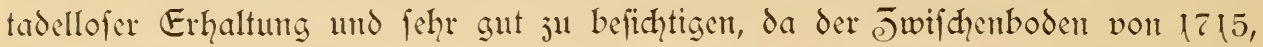
von dem eben die kiede war, fajt bis ju ihrer Göhe hinaufreidht. Es verfteht

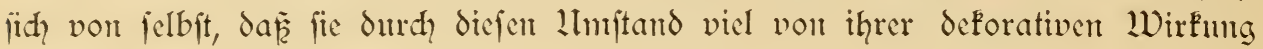
cinbuïzert.

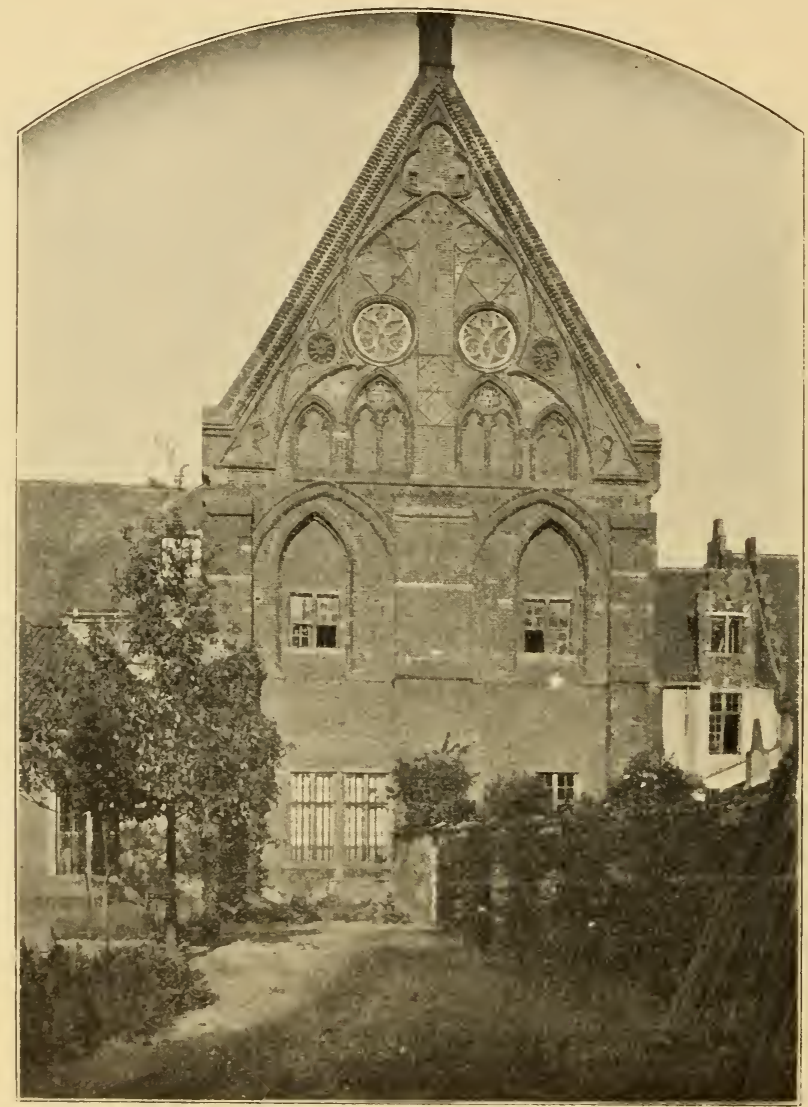

3lbb. 5h. Giebel der: Biloque.

Das Sdqudelgewölbe diefes Sales ift chenfalls hemunderungsmürdig. Es lqat mäḑtige polydromierte Rippen, die anf dünten Säulḑen mhen; diefe werden wieder von Konfolen gehalten, dic die feltamften fratzen bilden.

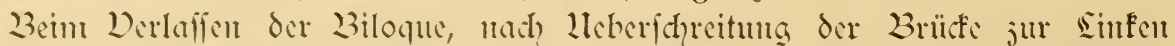
werfolgen wir den 23onlevard der Citadelle und gehen den erft Fürjlid gefdhaffenen

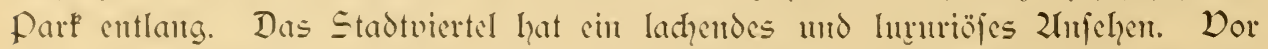

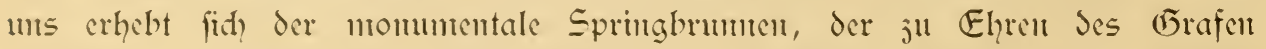

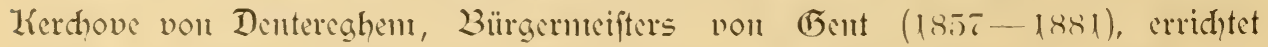

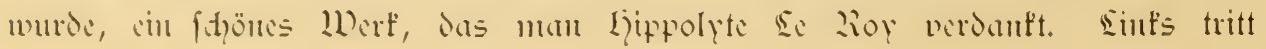


fogleidh die Kunpel der Petersfirche hervor, auf dem Platze, wo die chemalige

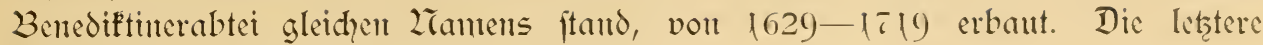
Jahresjahl ift auf der faffade angebradyt.

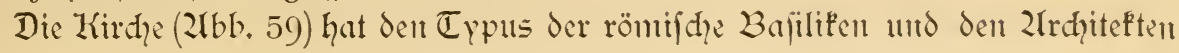

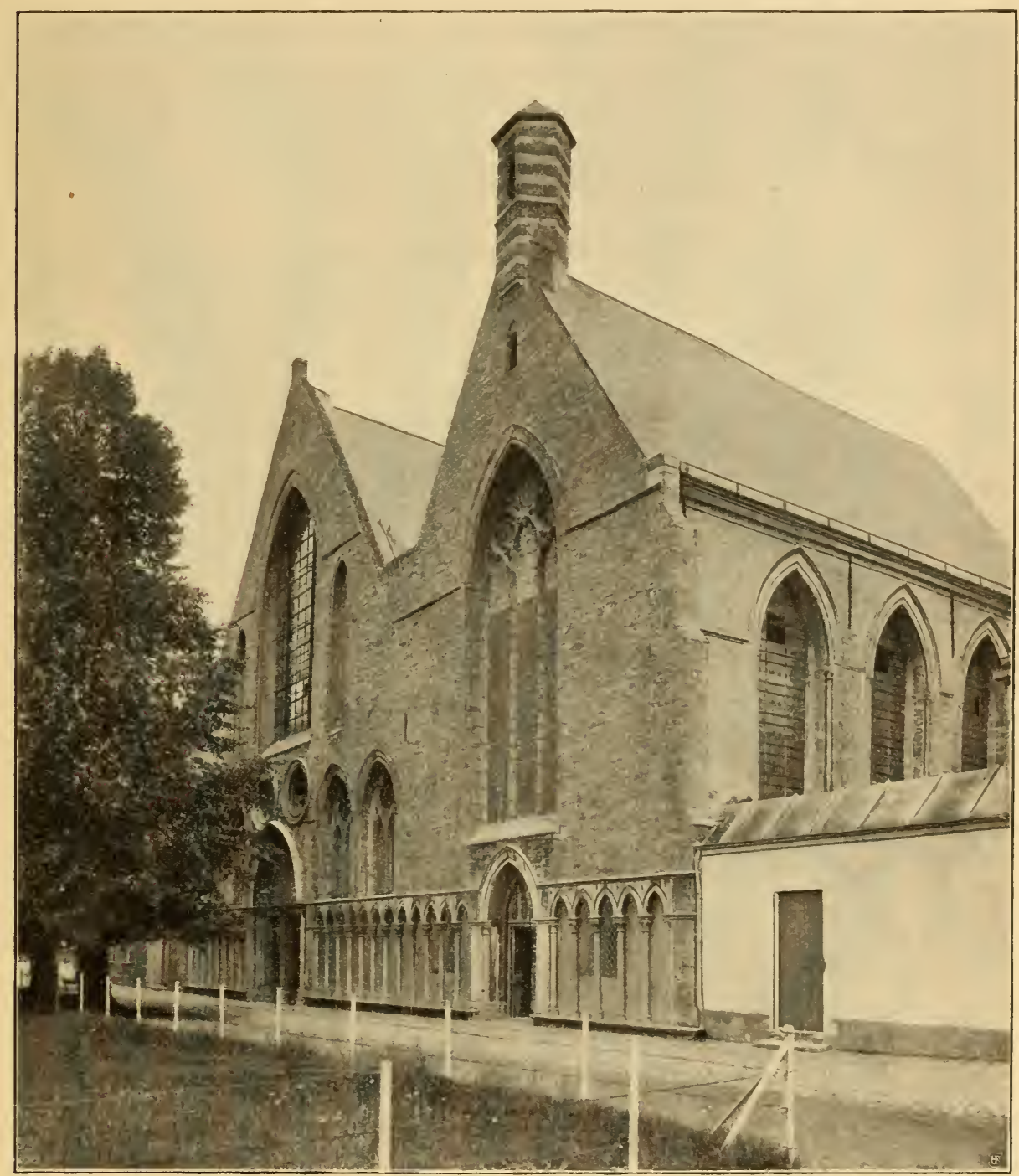

2lbb. 57. Die Biloque. falfade der Kapelle und des Eientienhaufes.

(5Tionamui Dajanjio (j. van Santen) lag angenfdzeinlid St. Peter in Sime. Der all=

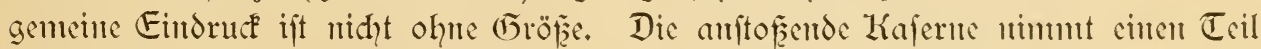
der Räume des ehemaligen Klofters ein und man fieht dort, was nodh von dem alten Irreujgang in gotifhen Stil übrig geblicben ift. Im Jumeren ift der 2Inbliff

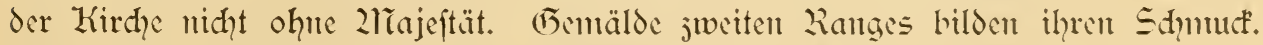

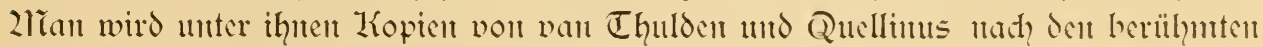


Bildern von Rubens dem Triumph der Religion und dem Triumph der Kirche finden, dic für Dlivarez in Tapeten ausgeführt worden fintd.

Was man Eaum erwarten würde - in diejer modernen Kirche ruhten bis 1883 die fterblichen Rejte der Jiabella von Wejterreid, der Sđhwejter Karls V. und Gattin Chriftians II. von Dänemark, die, Eaum 25 Jahre alt, im Exil ju J)wynaerde, nahe bei (5ent, 1526 geftorben ift. Die unglüfliche fürftin war in der ehemaligen St. Petersfirche unter einem Ziaufoleum beigefetzt worden, deffen Edhöpfer der Bildhauer Jan de Geere war, der nad̆ den Jeidunumgen des 2lĭabufe arbeitete. Ladhdem diefes $5 r a b$ von den Bilderftürmern 1578 vernichtet worden war, wurden die volt dent 2lbt von St. Peter gejanmelten Febeinte in ein nenes

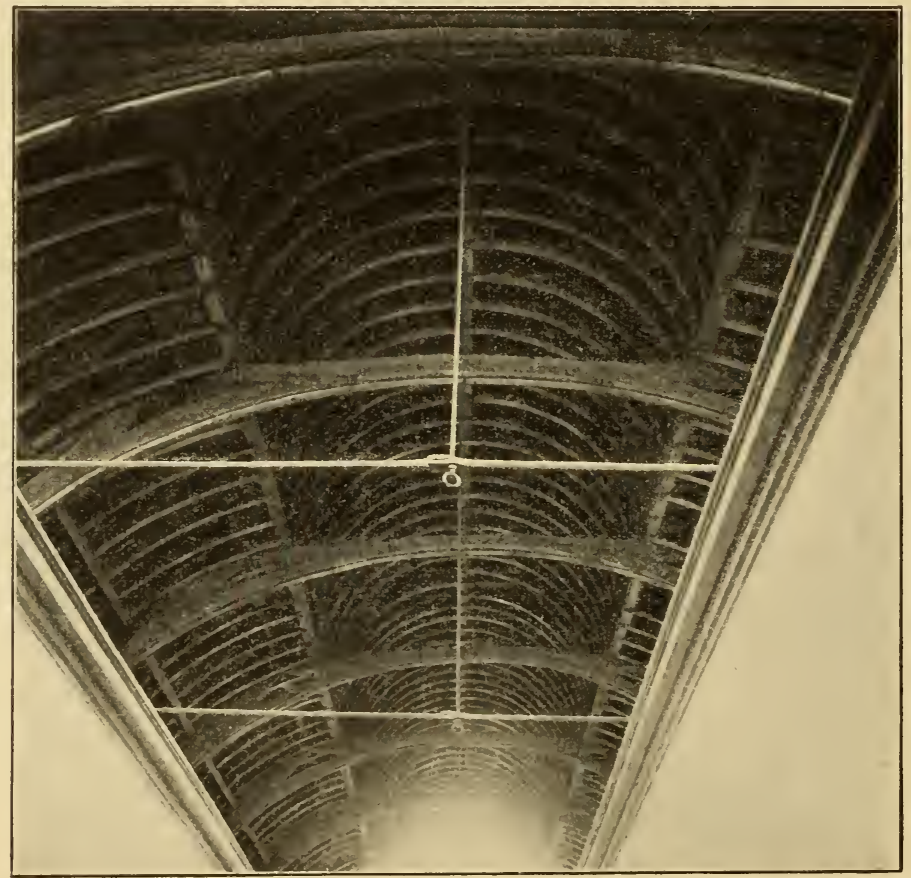

2ubb. 58. Dedfe des Kranfertaales in der 23iloque.

Kenotaphium eingefargt, dem fie 1883 wieder entronmen und auf $W_{\text {unf }}$ d der Liegierung nađ Dänentark gebracht wurden.

Uleber die 2lïndhsbrücte gelangen wir ju dem Kai gleichen Ziamens; ein hübfder Spajiergang, der in gerader Sinte nad, dem 23ahnhof füll?t.

Don hier aus gefehen, bieten bie Jugänge ju der Ikirḑe mit den (Ëärten,

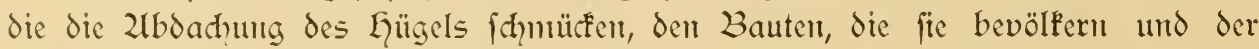
Shelde, die fie befpillt, ein entjülfendes $23 i l d$.

Lhufere lange Wanderung hat dem Sefer erlanbt, die Gefantheit der fünft= lerifden Sdjäze der Stadt Gent zu betradten. Es bleibt indeffent nody ein mer" würdiges (I)bjeft übrig, wohin uns unfer $\mathfrak{W}$ eg nidht gefühtht hat und das doch nod einen fleinen Llmweg lohnt. Das ift der Pleine 3 eginenhof, nod bewohnt 
volt ciner jahlreidhen Bevölferung von gottesfürdhtigen framen und feit jwei Jahr= hunderten befantr.

Durh die Bahnhofftrafe unt über den Zrteveldeplaţ, wo fid die St. Zlnment= firdhe erhebt, die 1853 von dem verftorbenen Profeffor Canneel im byjantinif hen Stil deforiert worden ift, erreidht man die Sange Deildhenftrafe (Songue rue des Diolettes), wo in $\tilde{L}_{\mathfrak{r}} .65$ fich der Eingang $j^{u}$ dem Beginenhofe findet. Er ift auf ciner regel=

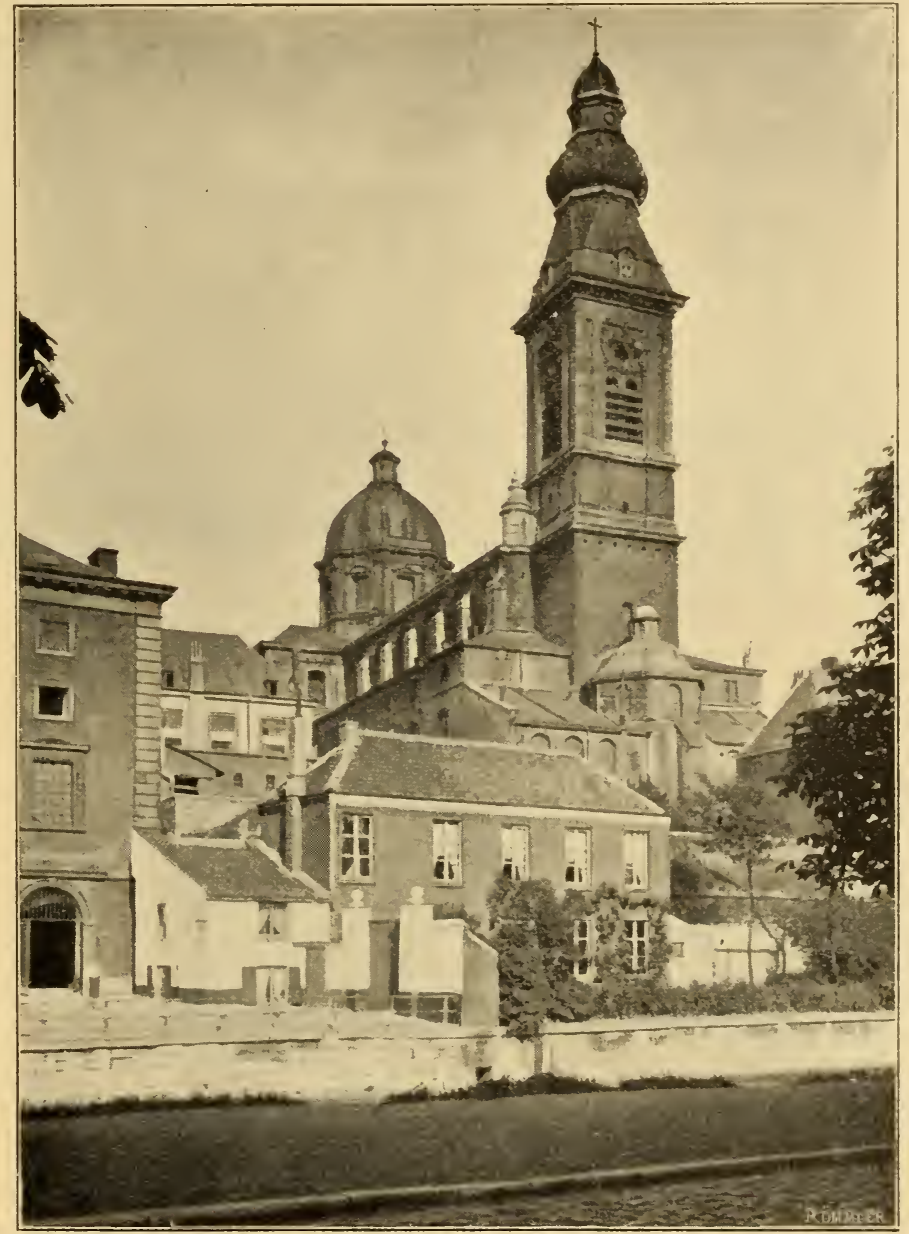

2lbb. 59. Die Petersfirthe vom Kai gefeher.

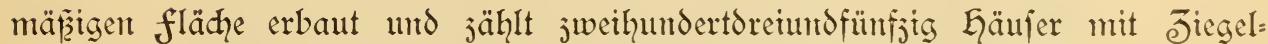
faffaden und flemen Dierec'sfenftern, die eitren weiten Rajenplats einrahmen, worauf fïh eine geräumige Kirḑe des 17. Jahrhunderts erhebt.

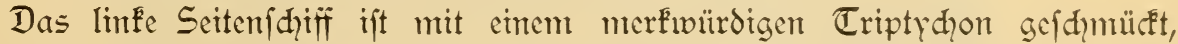
figniert 5 . S. Gorenbault und mit der Jahresjahl 1596 verjehen. Dies ift, wie eine Injhrift des Rahmens Fundthut, ein Leberblick über die h. Kirdye unt die Ge= meinfhaft der Eeiligen: Een teeken van de eenighe heilige Catolieke en Apostolieke Kerck en Gemeenschap der Heiligen. 
Dem Gedanfen nadh Enüpft es an jente Gattung von myftifhen Darftellungen an, deren Gauptwerk der Triumph des heil. 'Sammes ift. Die Dreieinigkeit nimmt den oberften Teil der Kompofition ein; Geilige beiderlei Fefhleḑts fommen, um aus dem Beffen eines prädytigen Brumens, der von dem aus Chrifti Wunden

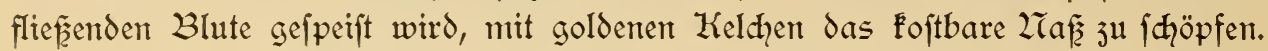
Im Dordergrunt linfs ftehent die Erlöften, rechts fehen wir cine $B_{11}$ e mit Teufeln,

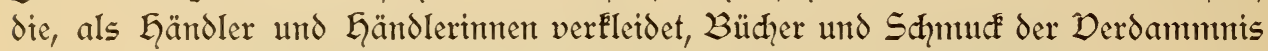
verÉaufen. Jhre Kundfḩaft ift zahlreich und gewählt; man fieḩt darunter nicht mur fürften, fondern felbft Eeiftliche, ja auch Bifhöfe!! Das Eemälde ift ju ftark verpukzt und hat fither an feinem uriprünglidhen Werte verloren, ift aber nidhtsdefto: weniger fehre intereffant.

Unter den zahlreiḑen Künftlern des Zramens Ggorenbault, die in Gent ge: arbeitet haben, Fonnten wir niḑt genau den LItheber des Werkes beftimmen, auf

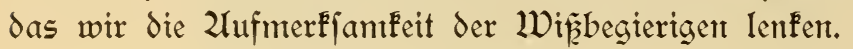

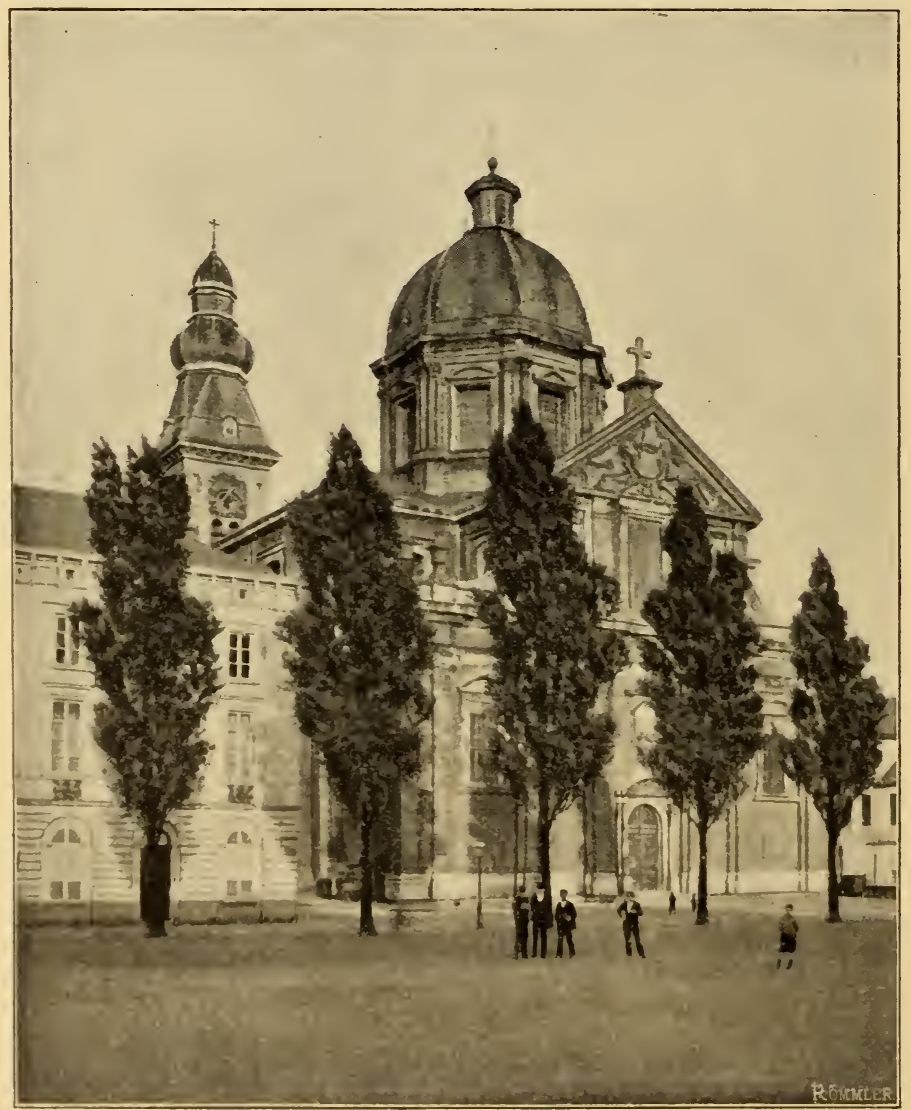

2bb. 60. Die Petersfirḑe. 


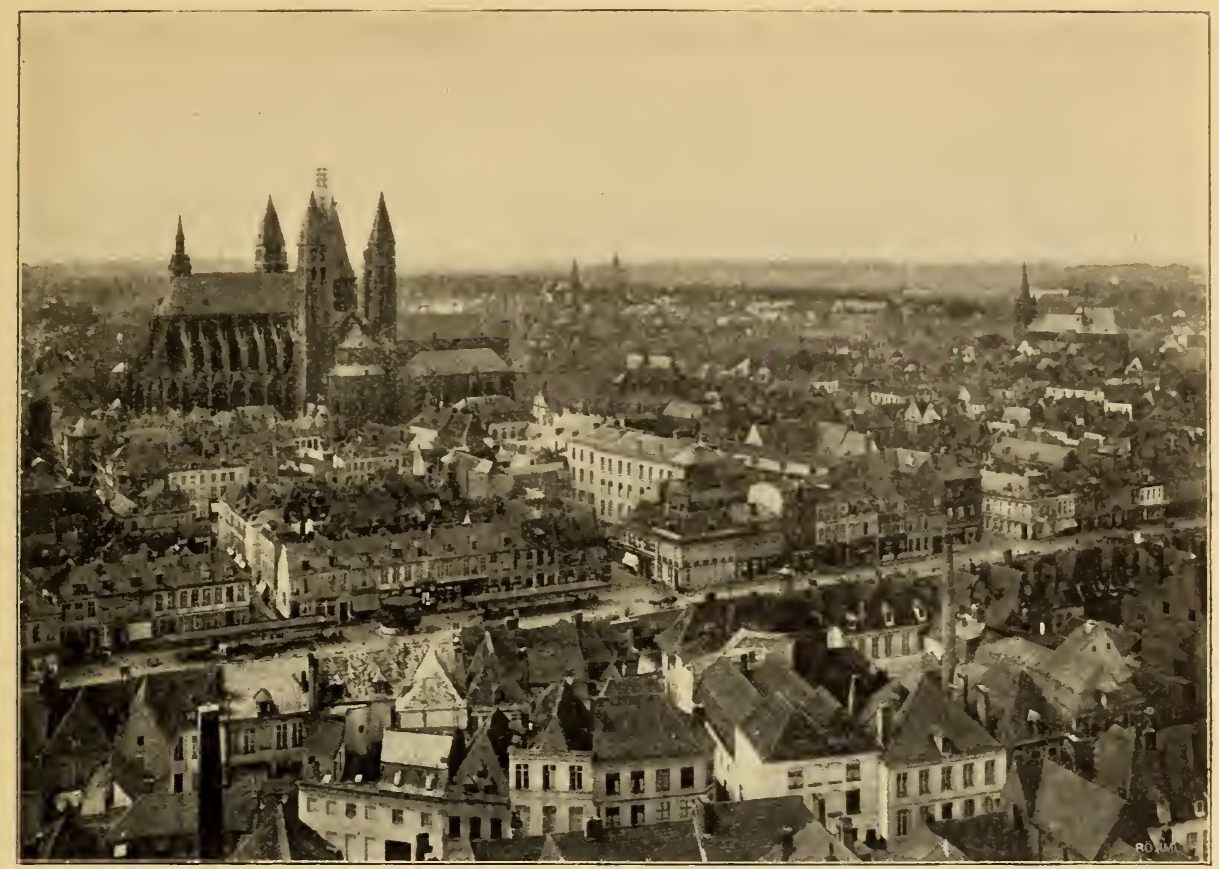

2bb. 61. Befamtanfid̨t von Tournai.

\section{Twurnai.}

Teine Stadt in Belgien jieht die Zufmerffaméeit des Kunftforfhers fo gleidy. mäpëig durdh ihr Zltter und durch die Bedentung einzelner Bantenf́mäler an wie Tournat. E Es bietet jwar niḑt wie die vlämifḩen Städte eine reidhe 2lienge von malerif̧hen Bauwerf́en dar, die den öffentliḑen Gebäuden profanter und Firḑlicher Zrert als Rahmen dienen, und dody lebt die Dergangenheit hier in intpojanten Bau= reften, die in der herrliḑen Kathedrale gipfeln, auf die niḑt nur die BevölFerung von Tournai, fondern and das ganze Sant mit Redht ftolj ift.

Zrit den Gallen von 2)pern fant man auf dent Gebiete der Firḑliḑen Bauten mur Zotre=Dame von Coumai vergleidhen; beide von ausnahmsweifer Bedeutung, rufen fie in glänjendfter Weije den Eindruc mittelalterlicher Banfunft auf belgifhem Boden wadt.

Ziidhts verrät dem 2Hnfommenden in Tournat auf den crften 3 lid die $B_{e}=$ deutung der Stadt für die Vergangenheit. Kein mädytiges Stadtthor wird durdh= fhritten; da, wo einft die von Subwig XIV. erdaḑte und von Dauban entworfene furdhtbare Befeftigungsmauer fidh erhob, jichen fich breite, ftille Boulevards litr. Dom Bahnhof laufen gerade, regelmäżige Strafen von modernem 2lusjehen in das Stadtimmere, und wenn fie nidht die weite Perfpeftive auf die Kathedrale mit iḩren fünf Türmen, den ,choncq clotiers", wie der Dol'́sntumb fie nennt, eröffneten, 


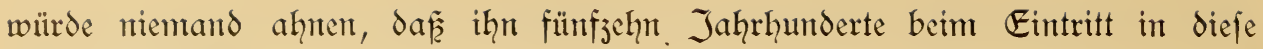
Stadt begrüręen.

In feinem Grundrif hat fid Tournai feit dem 21rittelalter niḑt wefentlid verändert; fein Sbebiet hat fidh nicht erweitert. Die Shelde, die die Stadt von

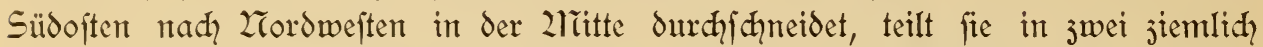

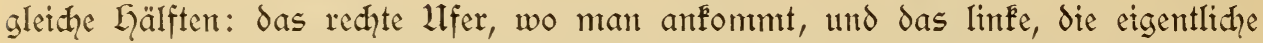
Stadt mit Kathedrale, Belfried, Rathaus und 2rupeum. Der leţtere Teil fenFt iich leidht.

Don den alten, fo malerifḑen Stadthoren ift feins mehr vorhanden. ZTod heute, wie im 13. Jahrhundert, bildet die alte Brücle, „Pont des trous", die äurerite Grenje des Stadtgebietes int 2rordweften und nod immer offnen fich ihre

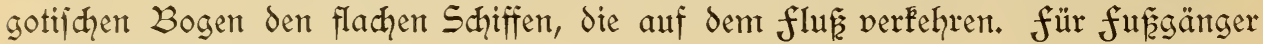
ift fie nicht geöffinet.

(Ubwohl das reḑte 11 fer nidht fo reich an bedeutenden Baudenfmälern ift, wie das linke, hat es dodh ein wirfliches hiftorifhes Intereffe. Der fremte darf fidh aljo nidyt durdh den berechtigten Wunfh, vor allem die Kathedrale ju jehen,

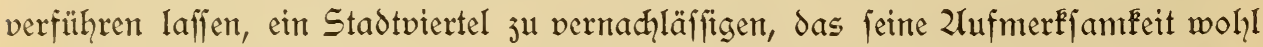
verdient und das in uns die Erimterung an die fernfte Dergangenheit der Stadt wahhruft, einen Stadtteil, der Königen aus dent älteften Eefhleḑ̧t als Refidenz diente und wovon ein Teil noch heute der "Bourg" genannt wird, während man eimen anderen auch noch immer mit dem Kanten "Château" bejeiḍnet.

Tournai, ein Writtelpunft regen, geiftigen Sebens, hat ftets begeifterte 2ulter= tumsforfher und Eelehrte gehabt, und hat fie nodh heute. Ulm fo befremolidher wirft es, da fi man beinahe bei jedem Sdyritt die Verwüftungen Fonftatieren Fann, die ein wahrhaft fieberhafter Drang nadh Lmbildung verjduld het hat. Während die neuen Baudenf̈mäler, gelinde gejagt, nur ein feF́undäres Intereffe bieten, waren die, die abgetragen und veriḩwunden find, oft von wirfliḑer Bedentung für Zkunjt und Eefhichte.

Schon Bojière, der widhtigfte Sofalhiftorifer, der 1864 fein bedentendes Werk: "Das alte und das neue Tournai" veröffentlid?te, fprad, fith mit tiefer Bitter= Feit darüber aus.

"Die f̧̧̈nen und alten Gebäude, worauf Tournai mit vollem kieḑt ftolz jein Fonnte," fagt er, "find verfhwunden. Die 2renthen find in Bejug anf fie

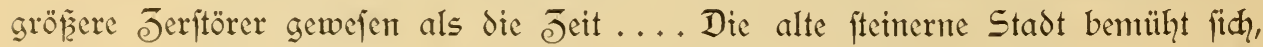
modern ju werden, Fo kett, vergipft, übertünḑt, wie eire Stadt von geftern!" Es ift ihr mur ju gut gelungen!

Toumai hatte im 2litttelalter jur Grafichaft flandern gehört, war dant unter franzöfif he Gerrfhaft gefommen, von Philipp 2luguft bis auf franj I.; eine Eurze Dberherrfhaft Englands unter Eeintrid VIII. ausgentonmen, hatte Toumai feit 1521 ju Spanien gehört.

Kadhdem das Gebiet von Tournai von Karl V. und deffen Kadfolgern bis $3 u$ feiner Eroberung durch Eubwig XIV. (1668) beherriḑt worden war, gelangte es an die Dereinigten Provinjen, an Kaifer Karl VI., um unter Snowig XV. nadh der Sdyladyt von fontentop (1745) wieder franzöfith ju werden; unter 2liaria 


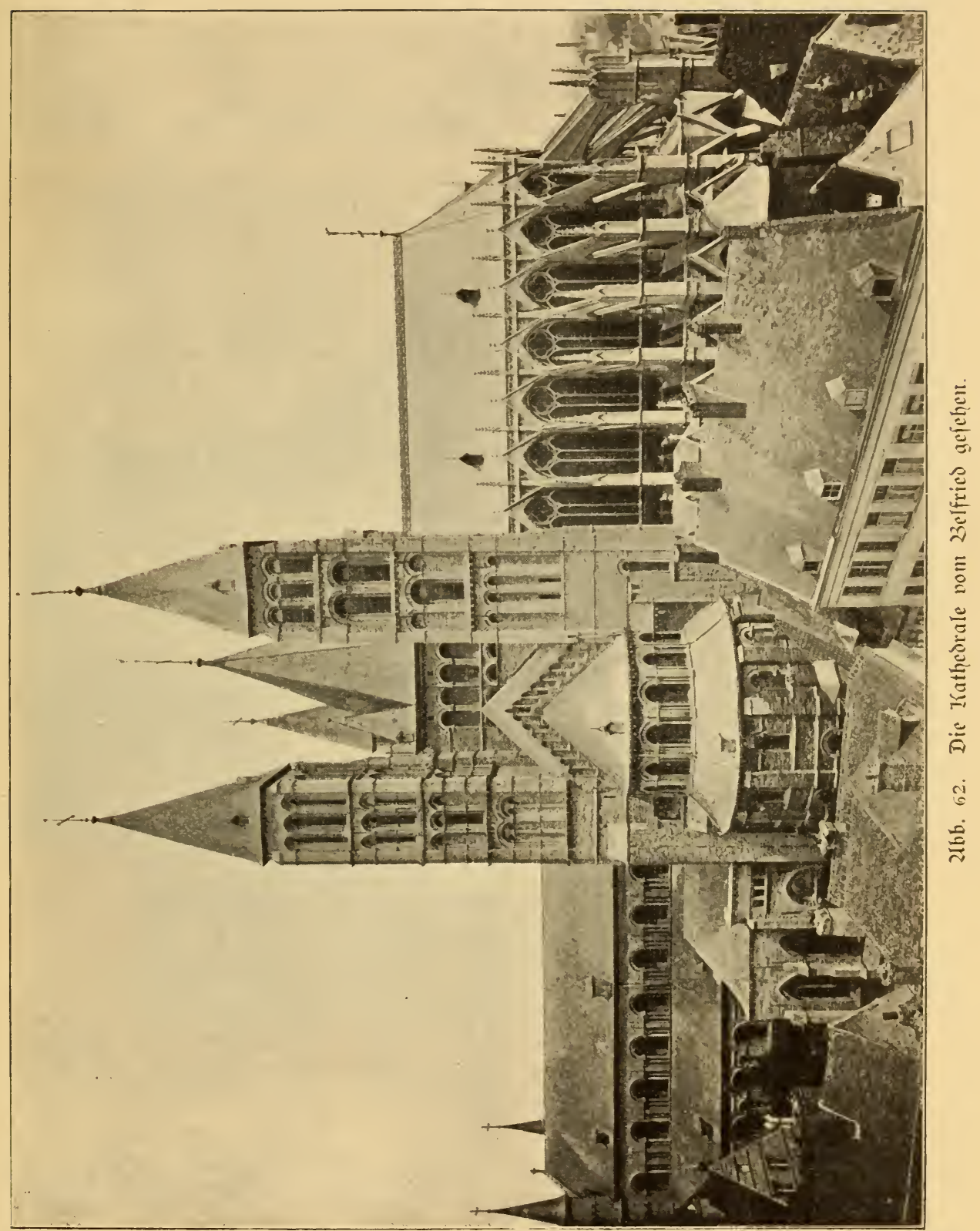


Therefta und Jofeph II. bildete es einen Teil der öfterreidifhen Ziiederlande, dann

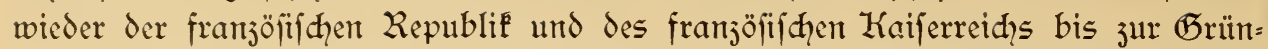
dung des Königreidhs der Ziiederlande 1815 . Zllle diefe aufeinander folgenden 2räd̆te haben dort ihre Spuren hinterlaffen.

2ran fann fith fehr gut über das Zusfehen der Stadt in den erjten Jahren

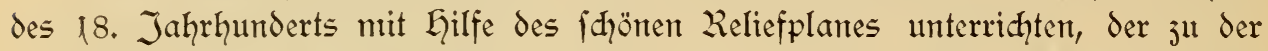
im Parifer Gotel des Juwalides veremigten Sammlung gehört. Eug. Soil fagt darüber in feiner dem fojtbaren Informationsmittel gewiometen intereffanten Stubie:

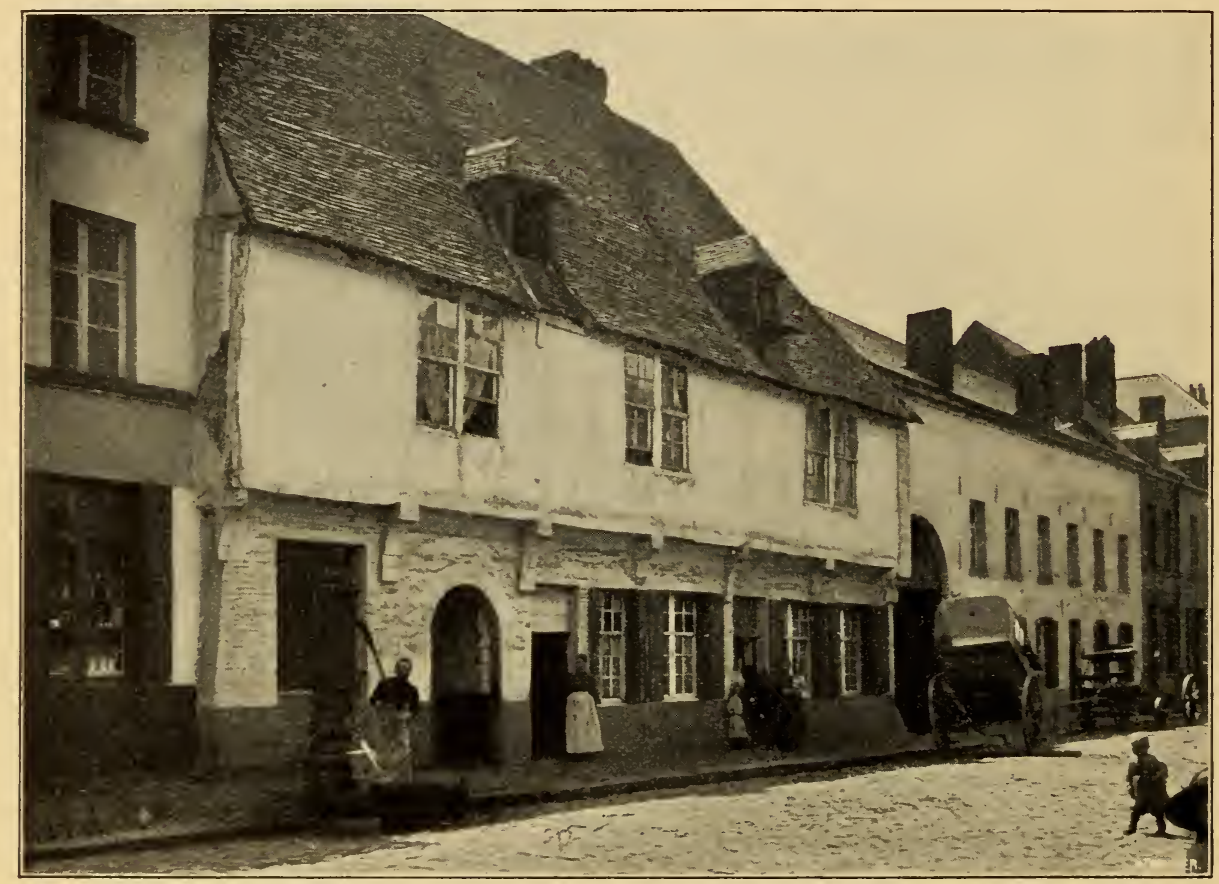

2abb. 63. Rue des Croifters.

"Es ift ein Dofument allererften Ranges, das einen unj dhäß̨baren Wert für bic Zenntnis der Stadt, fo wie fie ehemals eriftiterte, befitzt." $\left.{ }^{*}\right)$

Zluęer feinen firḑliḑen Baudenf̈nälern und befonders anęer der Kathedrale, die von den angejehenften Gelehrten als ein 21 hufter, als der 2 husgangspunft einer wirflidgen Kunftbewegung auf dem (Eebiete der Firdhlidhen Zrdhiteftur angefehen wird, alfo auserer den Banten aus dem frühen 2rittelalter bietet Tournai Beifpiele der Renaiffance, aus dem 17. und dem 18. Jahrhundert, und bewahrt fehr deut= lich die Spuren der aufeinander folgenden vlämifhen, brabantifhen und fran= zöfifchen Einflüffe. 2łber während die alten 2lnfithten uns eine Stadt mit jahl= reiḑen malerifḑen Läujerfaffaden, mit ausgezacten Giebeln jeigen, unterbrechen

*) Soil, Tournai en I 70I; d'après un plan en relief conservé à l'Hotel des Invalides à Paris. 1897. 
heute faum hie und da einige foldher Bauten die Eleidhförmigfett des Stadtbildes, das uns befonders häufer aus der Jeit Subwigs XIV. bietet und das infolge= deffen nodh fehr ausgefprodhen den Charafter einer franzöfifdyen feftung hat.

Liedrige Läujer, an denen weifere oder blaner Stein mit Jiegeln abwedyjelt und deren hohe und enge fenfter nahe an den fark voripringenden, von zahl=

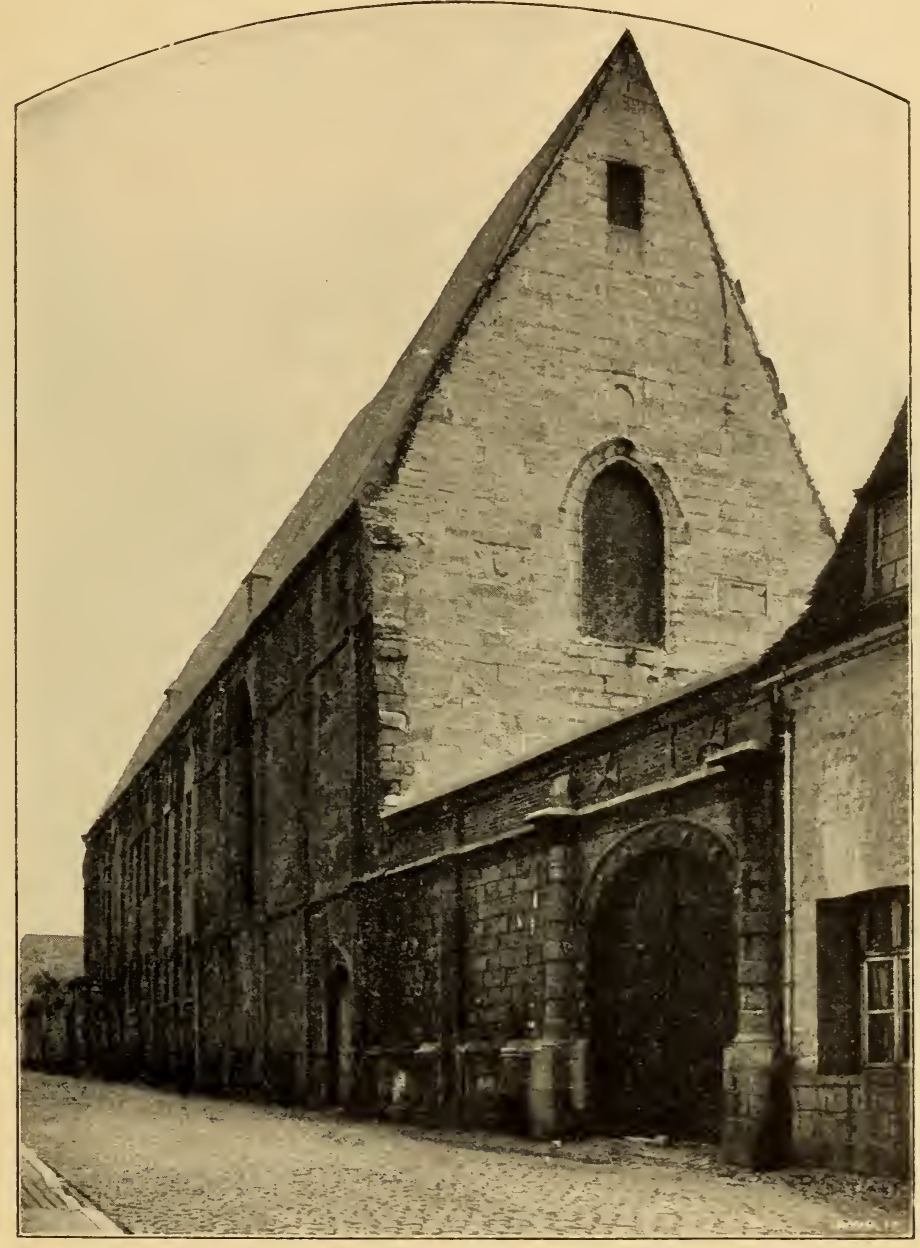

2lbb. 64. Klojter der Kreujträger (Croifiters).

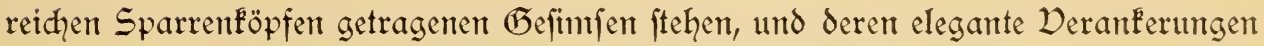
die hauptfächliche Derjierung bilden - das ift der häufigite Typus des Gaules von Tournai. Er findet fid befonders häufig im Stadtimern und auf den Kais.

Eine größzere 2rannigfaltigkeit bemerf́t man in den Stadtvierteln des reḑten

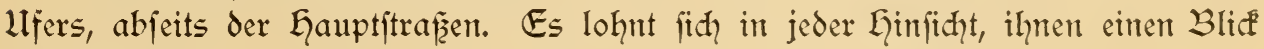
ju qhenéen.

Wenn wir beim Derlaffen des Bahnhofes den fđhmalen Wafferlauf, den 
man hier "petite rivière" nennt, überfąrittẹn haben und linfs dem Boulevard des Zerviens folgen, erreidhen wir bald den Plaţ, der Jurh das Jujammenftopen der Strafen "Rue de zliarvis" und "Rue des Croifiers" gebildet wird. 2ln der Ecfe der leţtgenanten ift eine Gäujergruppe aus dem 16. Jahrlqundert, 2itr. 43, 41 und 39 - in diefer Reihenfolge jeigt fie fidh —, die mit ihren überhänaenden

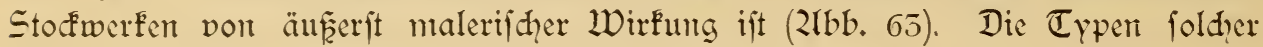
Zrt find jeţt in Tournai fehr felten.

Das Klofter der Kreujträger (Croisiers), oder beffer gejagt, die Rejte, die davon übrig geblieben find, nämlid das Sđiff der ehemaligen Kirdhe, erhebt fïh linfs.

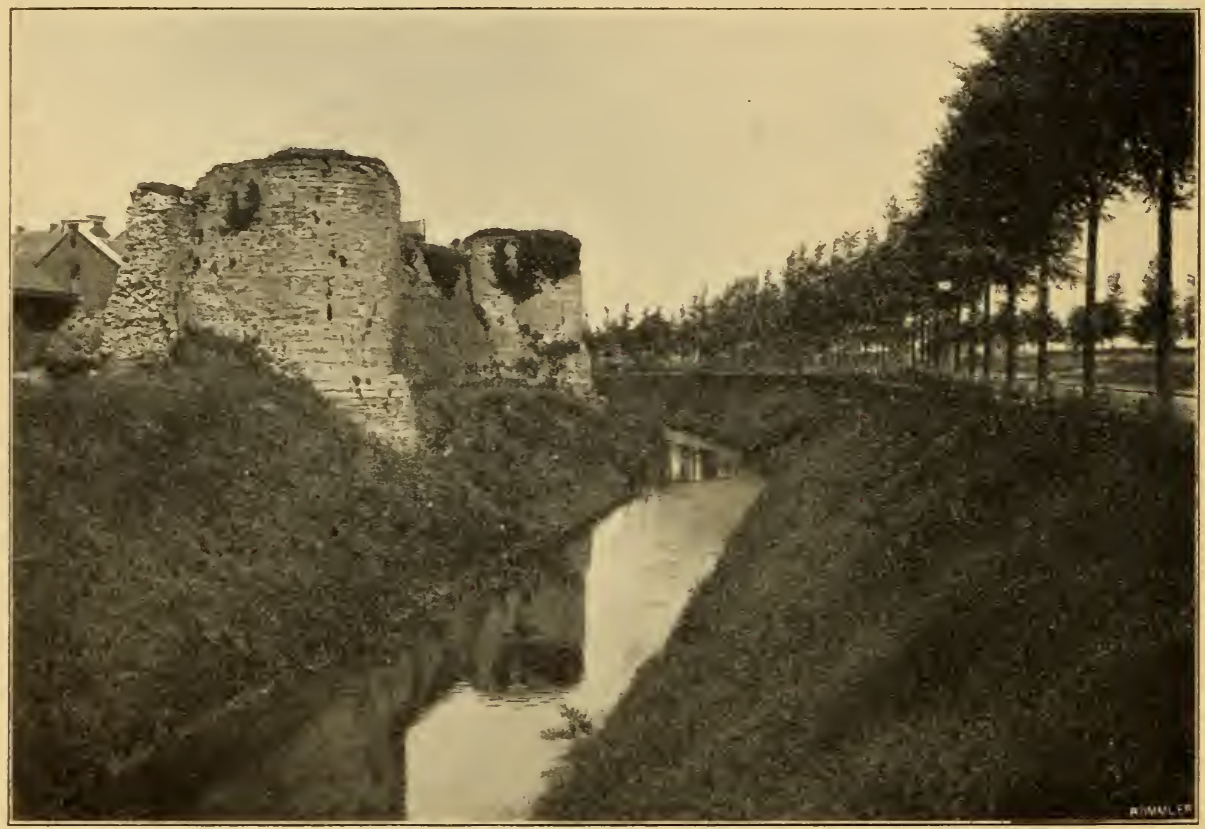

21bb. 65. 2IIter Stadtwall.

Der gotifhe Bau, mit fehr mädtigen Strebepfeilern verfehen, ftammt ans dem 15. Jahrhundert. Das portal aus dem 17. Jahrhundert ift dyarafteriftifd; es ift überdies nod mit dem Zrreuj des Drdens gef́rönt. Das Eantje ift in die IKa= vallerickajerne, bie unter $\mathfrak{L}$ towig XIV. crbaut wurde, cinbejogen (2lbb. 64).

Wenn man die Johannesfirḑe jur Reḑten liegen läß̈t, deren von ciner hohen und eleganten Frabbenbefetzten Spitze geFrönter Turm - der einjige Teil aus alter Jeit - aus dem 14. Jahrhundert ftammt, fo erreidyt man den aller= malerifditen Dunft, den unfere Wanderung uns veridhaffen Fann: die chemalige feptungsmauer ober, um es genauer ausjudrüléen, das, was nod, vont der britten feftungsmauer übrig geblieben ift - ein Banwerf des 15. Jahrhunderts. Der Znıblid" ift überwältigend.

Sebendiger fels und mähtige aufgemanerte Stemfdhiḑten fḑieben fid in= cinander, allenthalben von (Eeirbart und Windhafer überwudhert, fo fheinen diefe 


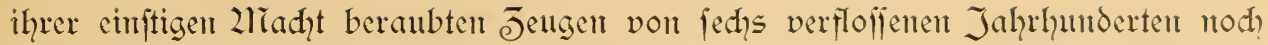
Irraft genug ju befitzen, um mandher Belagerung trotzen jul fömten. Wie oft haben fie von f́riegerifdyent Kanonendonner oder den Triumphfalven wiedergehallt, die den Einjng der füriten begrürten, die nach cinander Tournai zum Sitz ihrer Gerridhaft gemadht haben.

Durdh das jetzt verfhmundene Thor von 2larvis find Philipp IV., der Shöne, Sudwig XIV. von franfreich und Karl voll Spanien in die Stadt gejogen. Ein Zugenjenge, Ealvete de Eitrella, hat uns ein zauberhaftes 3 ild von dem grop = artigen Empfang hinterlaffen, den die Stadt Tontuai Karl V. und feinem Solpte bereitet hat.

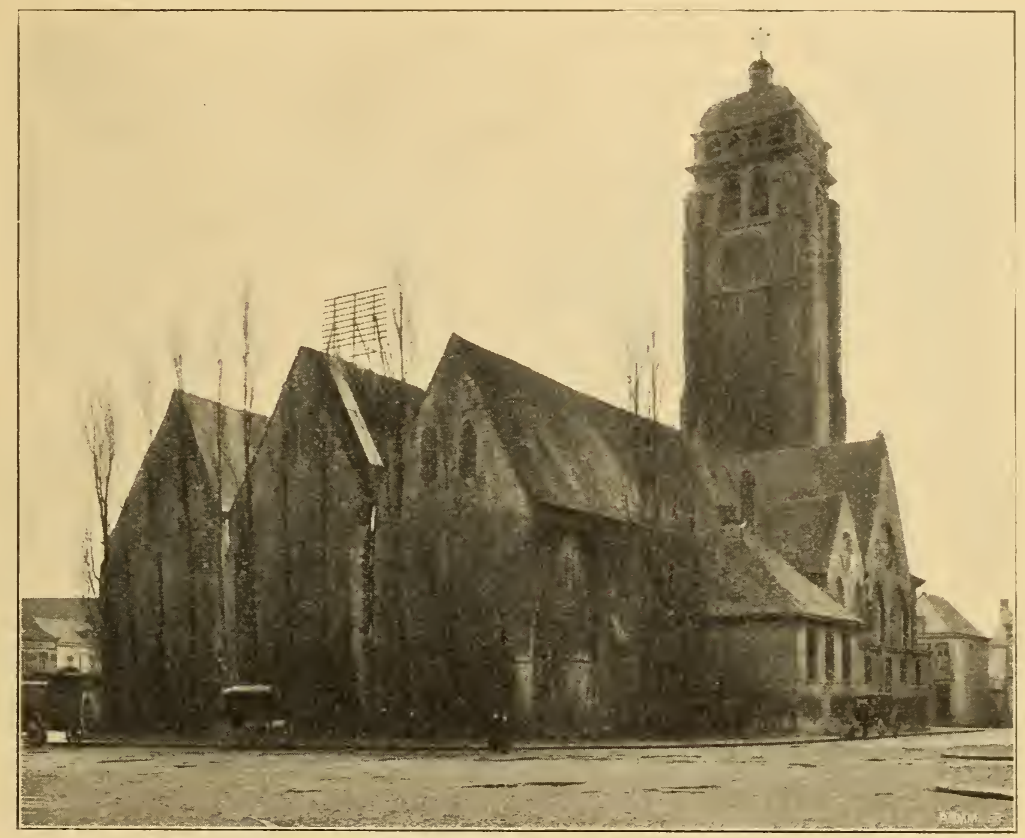

21bb. 66. St. Brice. begrü位.

freilich hatten fie audh mit ihren Jumufen Leinridh VIII. von England

$\mathfrak{W}_{\text {enn }}$ wir die Brefhe überfḑritten haben, die uns ju dem Klofter der "Kreujträger" jurülf̧ührt, folgen wir der engen und frummen "Stra官e der fads

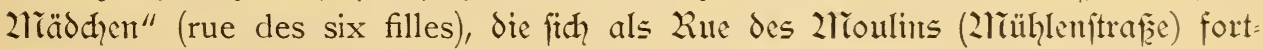

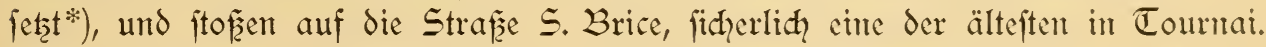
Redyts der grofe und maffine Turm von S. Brice, beinahe gerade gegenüber dic berühnte Gäujergruppe aus dem 12. Jahrhundert, das cinjige Beifpiel in Belgien von Privatbanten diefer fernen Jeit.

Die Kirdhe S. Brice, ein fehr alter $3 a u$, hat im Verlauf der Jahrhutderte

*) In Cournai ändern die Strab̧en bei iḩrer Derlängernng oft den Ziamen. 
unzählige Derättderungen erfahren, fowohl int Jntern, als an der 2luzenfeite; fie ift fo entftellt, da man verfhitedene 2liale die frage erörtert hat, ob man fie nidht abtragen folle. Da fie ganj frei fteht, faum man ihr jedod, eine gewiffe malerifhe Wirfung niđgt abiprechen.

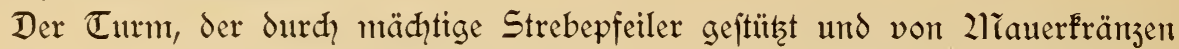
durdqquert wird, ift von einer đḑwerfälligen metallenten Turmhaube bedect', die aus dem Jahre 1822 ftammt. Don dort oben hat man den fhönften Ueberblick ïber die Kathedrale, wie er fith nirgends anderswo bietet.

Der im übrigen unintereffante Turm, der dem Shiffe vorgelagert ift, hat

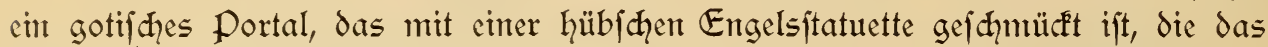
Wappen von franferch hält. Eine ähnliche figur befindet fich im Minleum.

Uriprünglich in Bafilifenform mit rundem Chorabjhluf erbaut, dheint S. Brice feit dem 12. Jahrhundert in der Tiefe fajt verdoppelt worden ju fein. Zluzen verrät nichts das hohe Zllter der Kirche. Ein Dach ohne befondere Eigenart, eine flaḑe Chorhaube, mit vermauerten gotifhen fenftern, unbedeutende Seitenj diiffe.

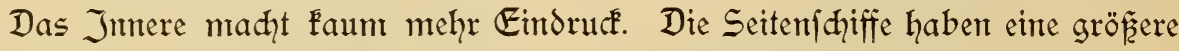
Breite als das Gauptichiff, wo man am Choreingang riefige Pfeiler bemerft, die früher den romanifhen Turm trugen.

Das moderne Tonnengewölbe hat im 2lnfang des 19. Jahrnunderts die flaḑe Deçe verdrängt.

Zicht weit vont Eingang zeigen fich in demt Lqauptfhiff die urfprüngliḑen romanifhen Gewölbejodhe.

Der Chor mit feinen Seitenfhiffen zeigt eine gewiffe Dorneḩmheit und feine Gewölberippen und Sänlenfapitäle verdienen das Intereffe des Kunftforfhers.

Der Gauptaltar ift mit einer Kreuzabnahme gefhnülft, von Jacob van Dojt aus Brügge; die 2rialereien der Seitenaltäre find von der L̨and eimes einhei= mifhen Künftlers, des 2lïihel Bouillon, eines jiemlidh unbeFannten Zaahtreters

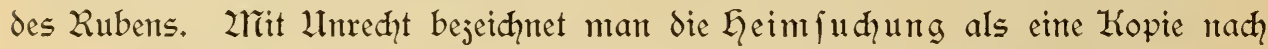
dem berühmten Gqaupte der Zntwerpener Sduule; es ift dies ein OriginalmerÉ des Bouillon, der als Selqrer des Philipp von Chammagne gilt.

Eine Fupferne (Erabplatte, die im Chor jur Erinmerung alt Jean de Dour, feine frau, Katharina von Garlebecque, und deren Kinder aufgeftellt worden ift, bietet ein merfwürdiges Beifpiel von der Stecherfunft des 15. Jahrhunderts; leider ift fie reftauriert. Ein hübihes 2riarmordenf́nal des Parlamentspräfidenten Jacques 2liartin volt Polinchove - denn Tournai hatte fein Parlament unter Subwig XIV. - hat gleidfalls im Chor feinen Plak.

Der Zitrchenfdhat von S. Brice enthält liturgifḑe ëiergegenftände von grofent

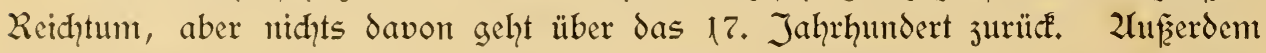
wird dort eine Zlgraffe vout vergoldetem Sillber aufbewahrt, die aus dem Sḑaţ von Ehilderidh I. herftammen foll.

Zidut weit von der Zitrhe fand man 1653 an der Stelle, wo jez̧t das Gqaus 2ir. 8 an der Terraffe von S. Z3rice fteht, in einer Tiefe von 8 fuf die berïhntent merowingifhen Waffen und Sdynutfadhen, die unter dem Lamen des Sdhatzes childeridys I. $(\dagger$ 481) befaunt find. 
2liehr als 100 Goldmünjen byjantinifher Kaifer, Gunderte von goldenten Bienen und Silberftücken, faft alle aus der frïhen Jeit des römifdyen Kaiferreidhes, Waffen, 2rgraffen und Ringe fanden fidh jwifhen menfdylidgen Grebeinen. Ein goldener Ring jeigte das Bruftbild eines langhaarigen 2lanmes, der eine Sanje hielt, und wies die Bejeidhung: Childerici Regis auf.

Diefe fehr Foftbaren, übrigens fhon oft befdriebenten Eegenfüände hatten zu= erft Seopold Willyelm von Defterreich gehört, der zur Jeit ilgrer Zuffürdung Statt= halter der Ziederlande war. Sie gingen dann in den Befit Zaifer Seopolds über, der fie 1664 $\mathfrak{S u b w i g ~ X I V . ~ f h e n f t e . ~ S p a ̈ t e r ~ i n ~ d e r ~ K a ̈ n i g l i c h e n ~ B i b l i o t h e ~ a u f = ~}$ bewahrt, wurden fie 1831 jum größżten Teil geftohlen. Die Diebe wurden ver=

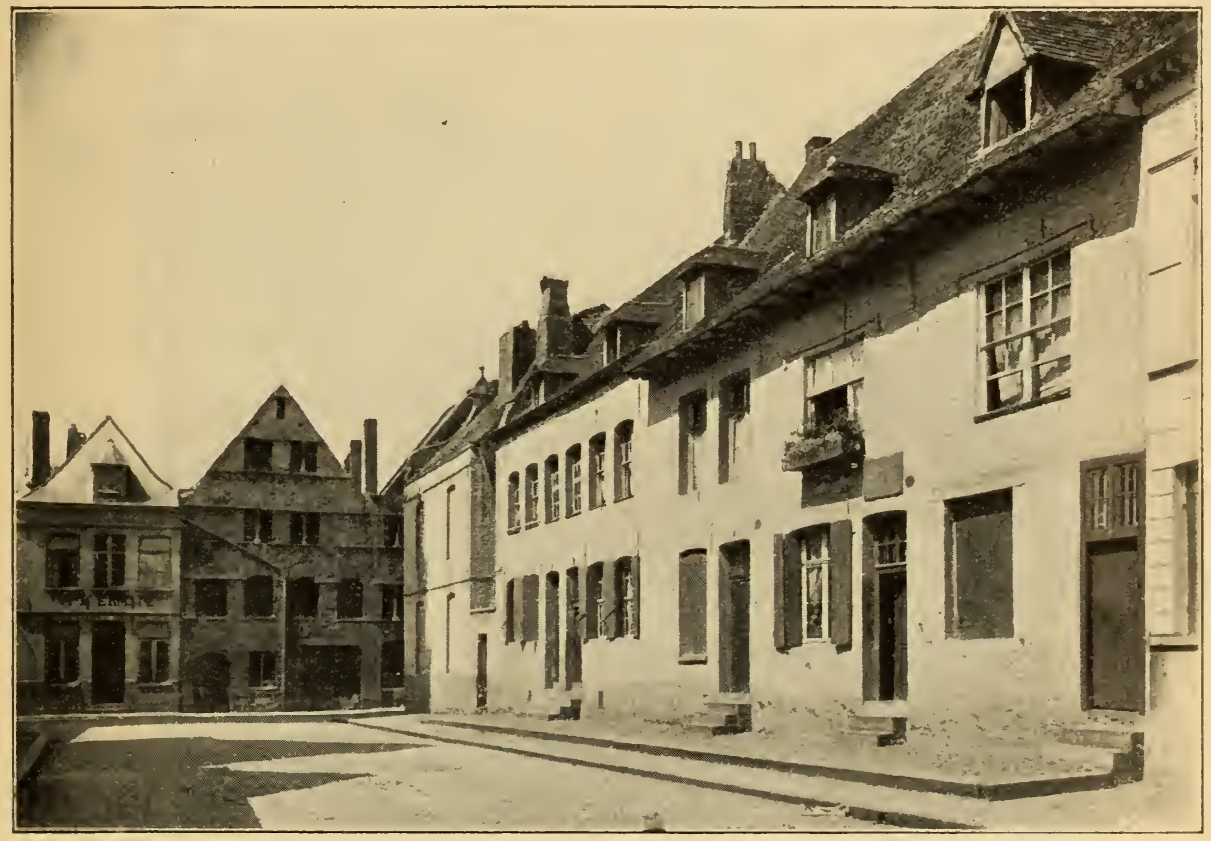

Zlbb. 67. 区erraffe von St. Brice.

(Im Gintergrunde die romanifäen Eäufer.)

folgt und entledigten fich ihrer Beute, indem fie fie in die Seine warfen, mur einen ganj geringen Teil hat man davon wieder erlangt, der heute int Zlünz"abinett der Lationalbibliothe ju paris aufbewahrt wird.

Die romanifhen Eäujer Lir. 8 und 10 an der "Liue Barre=S. Brice" bejeugen jur Genüge das 2flter diejes Diertels. Beide $\mathfrak{G}$ äufer haben je drei Stoct" werke mit grofenen j̄wifhenräumen; durch Steinbänder find dic Reihen der vier= ecfigen fenfter getrennt, die je durch ein elegantes Säuldhen geteilt find. Die Thüren find rundbogig. Das 2rawerwere befteht aus Kauftein und das Gefamt= bild ruft ganj ummittelbar die Erinnerung an das "Stapelhaus" in Eent wach. Rüçwärts wie im Imtern find beide Ģäufer ganj und gar modernifitert (Zlbb. 68).

Irr. 18 an der Edpe der "Rue des Bondhers S. Brice" ift der Typus eines eleganten Lqaufes des 17. Jaḩrhunderts mit breiten und wohl proportionierten 
fenftern und cinem eleganten Giebel (2łbb. 69). Während diefes Flaus, das 1660 datiert ift, älter fheint, jeigt ein anderes, das die Ecke der Terraffe bildet und die Jahresjahl 1559 trägt, cher den Stempel des 17. Jahrhunderts.

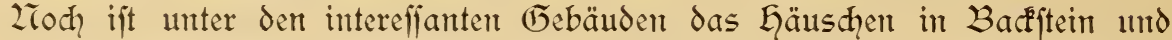
Golz 2ir. 5 hervorjuheben, an der Ecke der "Itnteren St. Brice=Strafee" und der Rue des Campeaur. In dem fhon fo arm gewordenen Tournai find das häufer= gruppen, die befonders hod, gehalten ju werden verdienen.

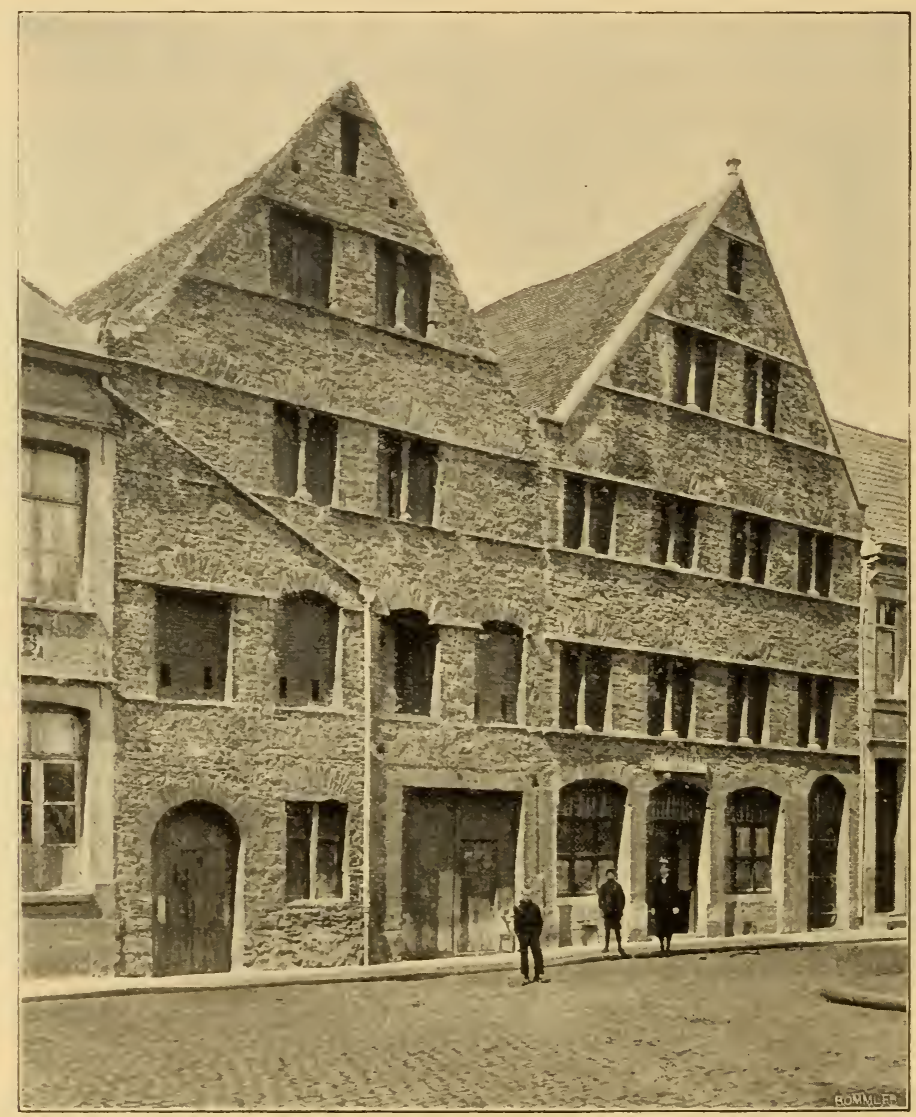

2łbb. 68. Romanifhe Gäujer in der ZRue Barre St. Brice.

Das Stadtviertel von S. Brice hat, abgefehen von den merowingifden Iflemodien, die fein 30 en barg, nod, oft durd andere funde das fehr hohe Zlter feiner Gründung bewiefen.

In der nädjten Zähbe des (Drtes, wo wir uns befinden, da wo die zlionnel= und die Childerid)=Strafe jufanmenfto

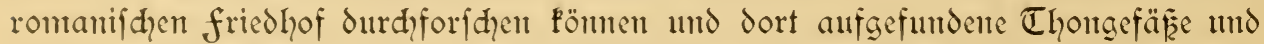
andere Bregenftände haben ju der 23ereiḑerung der ftädtifḑen Sammlumgen fehr viel beigetragert. 
Einter S. Brice offint fith die Quesnoy=Stra ze. Gier erhebt fich Ginter einem an fidh fhon altertïmlidhen und merfwürdigen Gitter die Kapelle des friiheren Zrovizenhaules der Jejuiten, heute ein Zebengebäude des Königliđhen

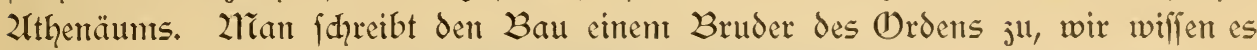
nidht, ob dem fo ift, mur eines ift fidher, nämlid, da fas bas portal der jetzt ganj

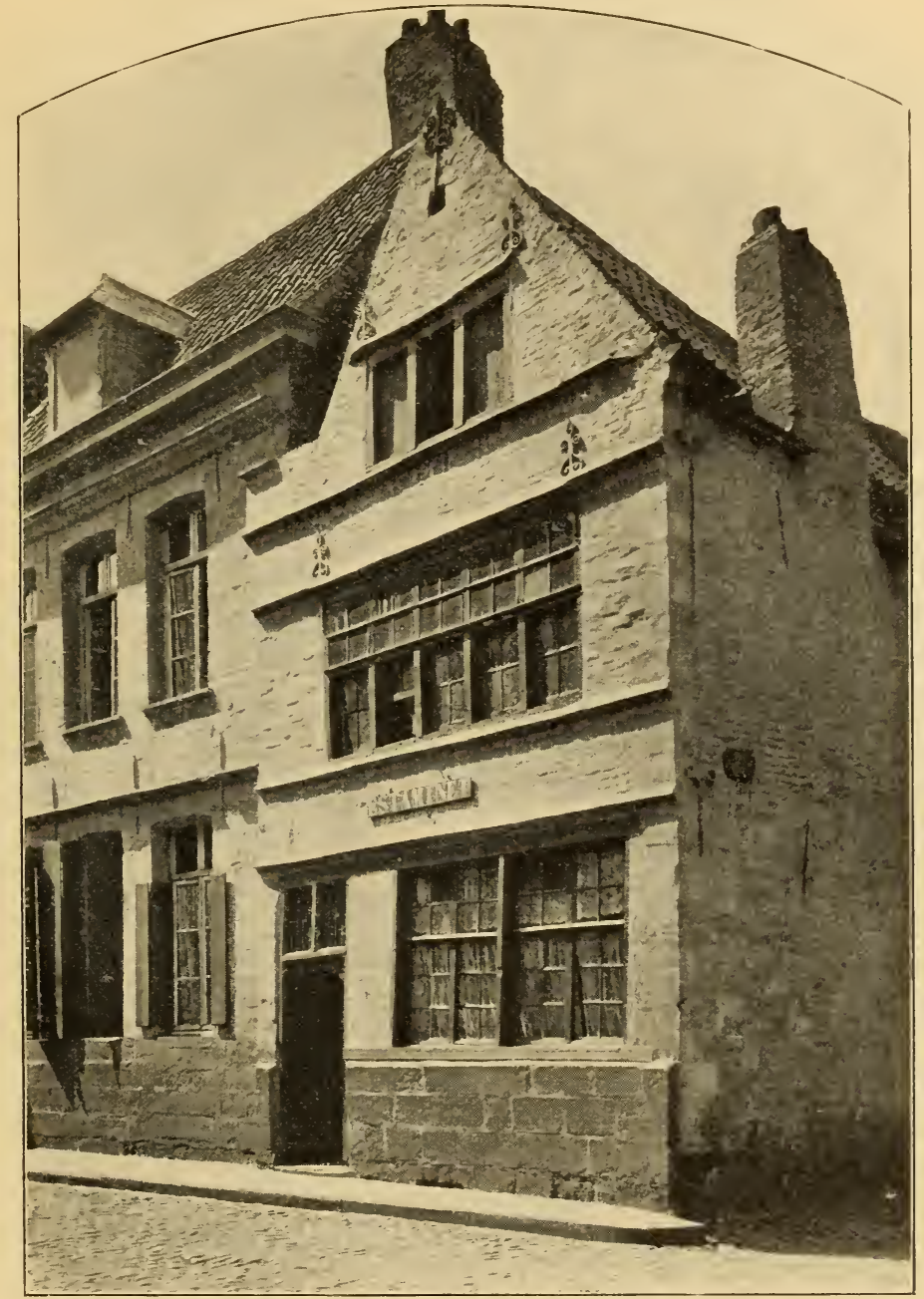

21bb. 69. Litue Barre St. Brice 2Tr. 18.

anderen כ̄weckent dienenden Kapelle eines der gelungenften Beifpiele der Spätrenaiffance

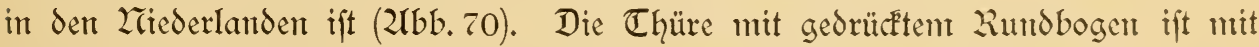

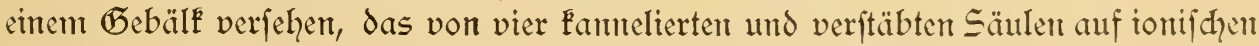
Bafen getragen wird, und deffen fries mit eleganten SFulpturen gefdqunicht ift. Darüber ift eine im GalbFreis gewölbte Zrifhe, flanfiert von Germen und Der= jierungen; thr Gefims trägt das Zronogranmm des Jefuiten, das in der erjherjögs= lichen Krone gipfelt und das von jwei vorjïglid, ausgefïhrten Engelfiguren ge= 
halten wird. Die 2liadonma, die früher in der 2rifhe ftand, ijt jeţt in 2liujeum untergebraḑ̧t. Das Ganje verdiente durch lbgur in weiteren Zreifen befannt gemaḑt jul werden.

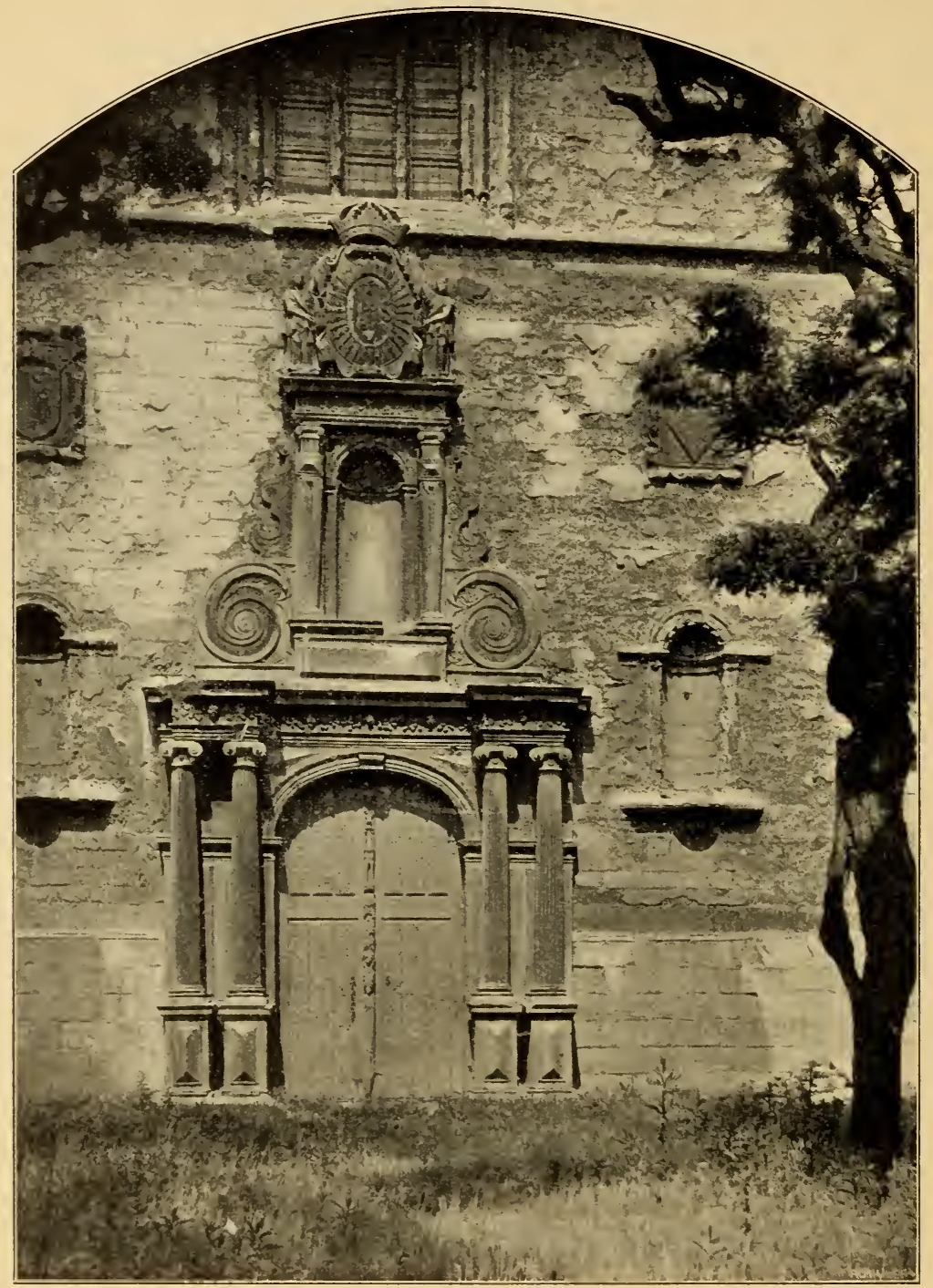

Ubb. 70. Portal der Kapelle des 21thenäums. früher Kapelle des ziovizenhaules der Jefuiten.

Wie viele andere firdlidhe Banwerfe diefer Jeit in Belgien, ift and biefe Zapelle gotifden Stiles. Sie dient als Turnhalle. Ein eleganter, fhllanfer Glockenturm fdyliefżt fie $a b$.

Die Llöfe des frïheren Zrovizenhanles gewähren durd ihre Galerien mit dorifdzen Säulen ein gewiffes Jntereffe.

Das Stadtwiertel des "Bourg" hatte bis jum 17. Jahrhundert feine eigente 


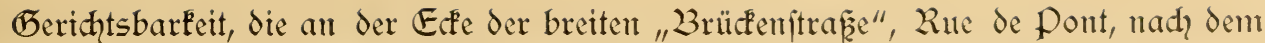
Kai zu, ihren Sitz hatte. Lleberdies bildet diefer int 14. Jahrhhundert erriḑtete Bal, der heute feine anfänglidge Beftinmung faum erfennen läpzt, drei von eitrander getrennte Wohnitättert.

Die Shlqelde ähnelt in ihrem Sauf durd Tournai dem ftillften holländifhen

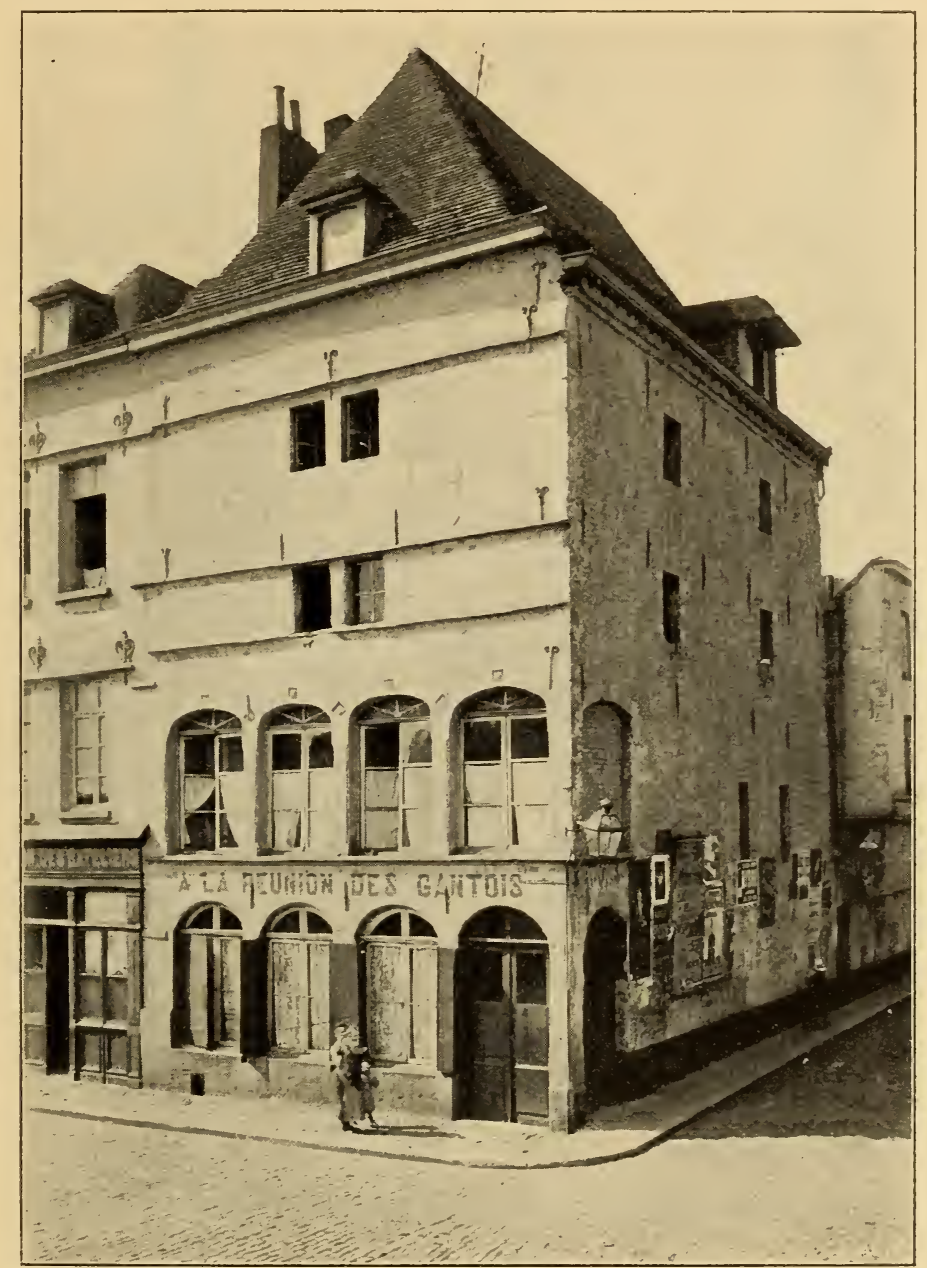

2hb. 21. Zai Taillepierre 2ir. 1.

Kanal, befonders $\delta a$, wo, wie am Kai Difquin, das Llfer mit Bäunten bejetzt ijt.

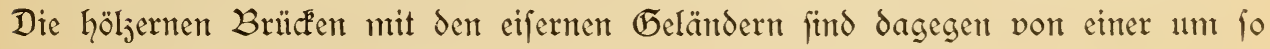
¡törenderen 2lltägliḑ̨eit für dent, der fiđ gern ihrer fteinernen Dorgänger erimtert, die von Jahrhunderten refpeftiert und nun jerftört worden find, ju maḑen (2lbb. 23).

Die meiften Gäuler, die fidh an fluz Linjiehen, tragen fehr dentlid enten

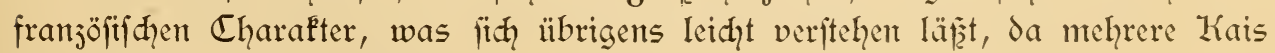
von $\mathfrak{s}$ llowig XIV. ftanment. 


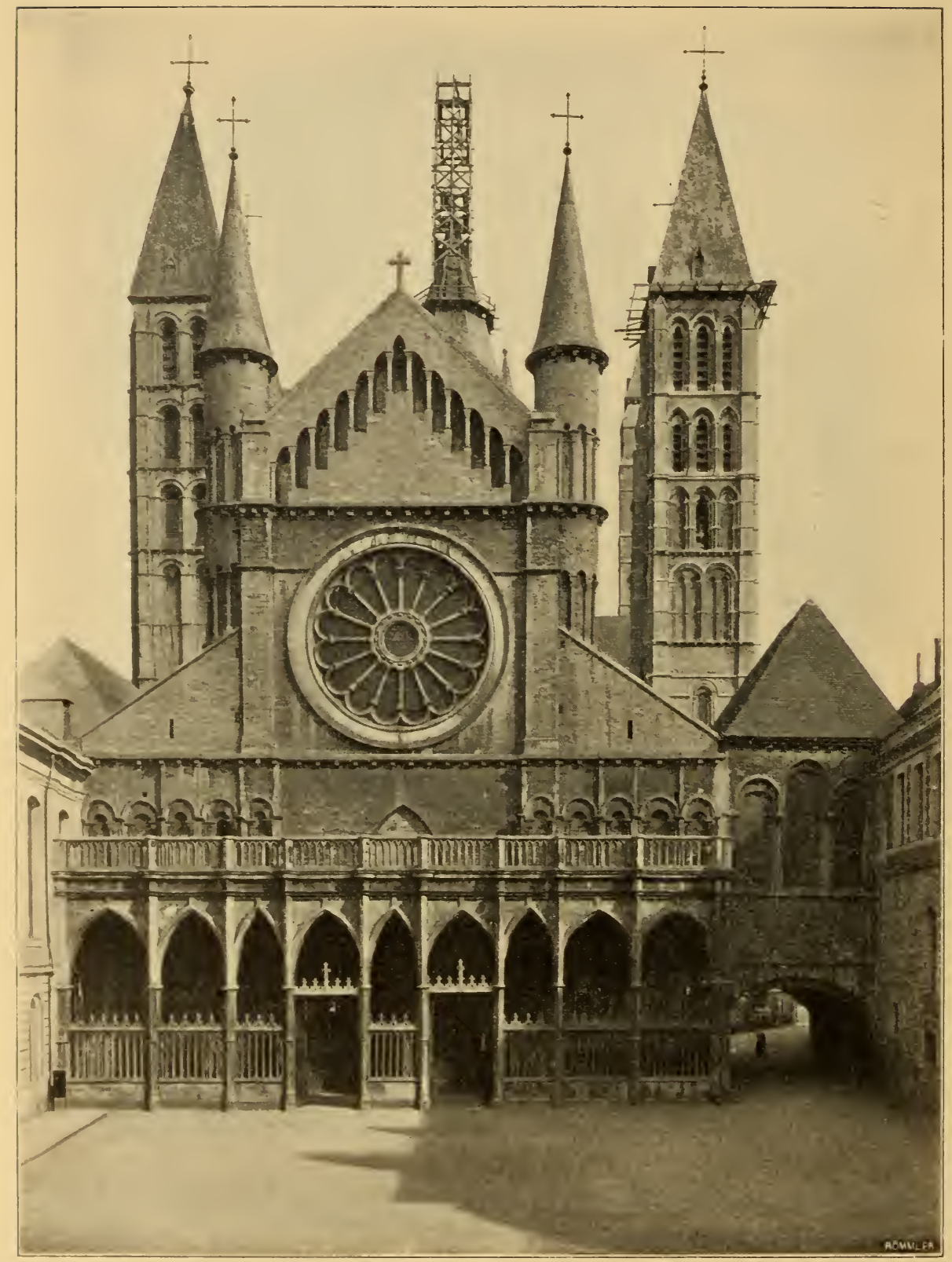

2bb. 22. Die Katheorale. Gauptfront. 
Wenn man jedod den "Pont à pont" (Pont aux pommes) überfdyritten hat,

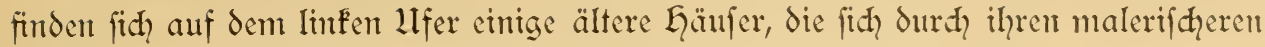
Charafter ausjeidquen.

Zramentlid ift an Lai Taillepière 2ir. I cin fehr intereffantes Lqaus mit drei Etagen, die beiden oberen mux zu je cinem fenfter, und von einer 21ulage, die man mur felten antrifft. Der 23 au fheint aus dem Ende des 16. Jaḩrḩunderts

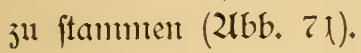

2ir. 26 am Lai des Poiffonceaur zeigt eine elegante faffade aus dem 17. Jahrhundert in Stein und J̈iegeln nit jierlichen Derankerungen.

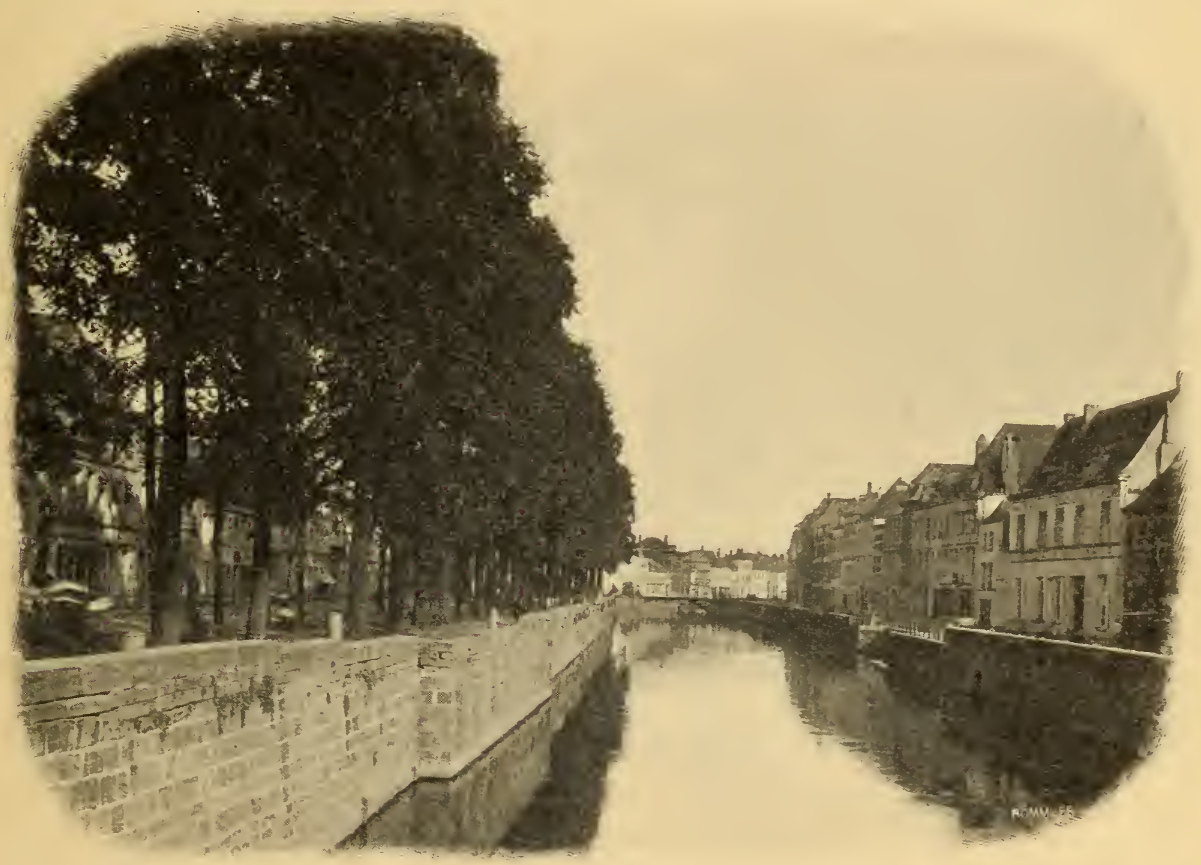

2bb. 33. Kai Difquin.

Wern wir den Weg über den "fifḑmarkt" fortfetzen, erfheint uns plötz= lidh durdh den Durdhbruch der Kue de Ia Santerne lint's die herrliche Turmeruppe nut dem nördliden Queriḑiff der Kathedrale.

Die Rue de l'Ģôpital 2rotre Dame, wo wir über der Thür der Zláadentie (des früheren Gofpitals) im Dorübergehen cin hübjdhes Relief mit der 21radonna fehen, von 2T. Se Creux $(1233-1299)$, führt uns in gerader Sinie nady der Place

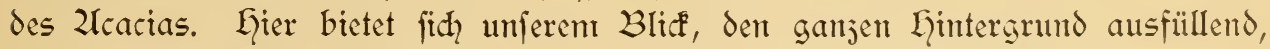
die impojante 2liaffe der Kathedrale, der Chor, das Querfhifi und vor uns die Treppe, die ju der berühymten „Porte mantille" führt - das Ganje von bejaulhernder Wirfung.

Den Bifhofsplat, von wo aus mant die Lauptfaffade überbliffent fantm, unt die Stelle, wo wir uns befinden, ausgenommen, jeigt fith dic Bafflifa, die von 
allen Seiten von Gqäufern eingefḑloffen ift, nur in engbegrenjten Teilen. Jeţt hat fidh cinte lebhafte Propaganda ju ihrer freilegung entwidelt; es würde fich unt weitgehende Expropriationen handeln, und die Derwirfliḑung diefes Inter= nehmens dürfte niḑt leiḩt fein, juntal wenn die vollftändige freilegung diefes Steinfoloffes erreitht werden foll.

Die Kathedrale von Tournai ift niđht mur das größzte und ältepte firchliche

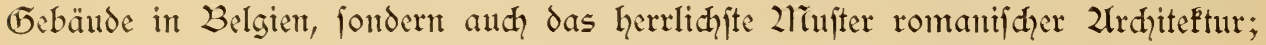
fie gehört überhaupt ju den impofanteften Firchliḑen Bauwerfen der Welt.

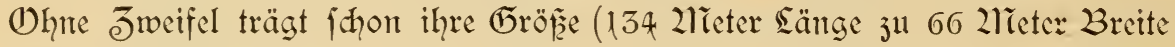

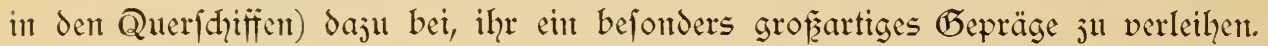
Das Junere jumal hat eitten majeftätijhhen Charafter, ber den Dergleid mit den

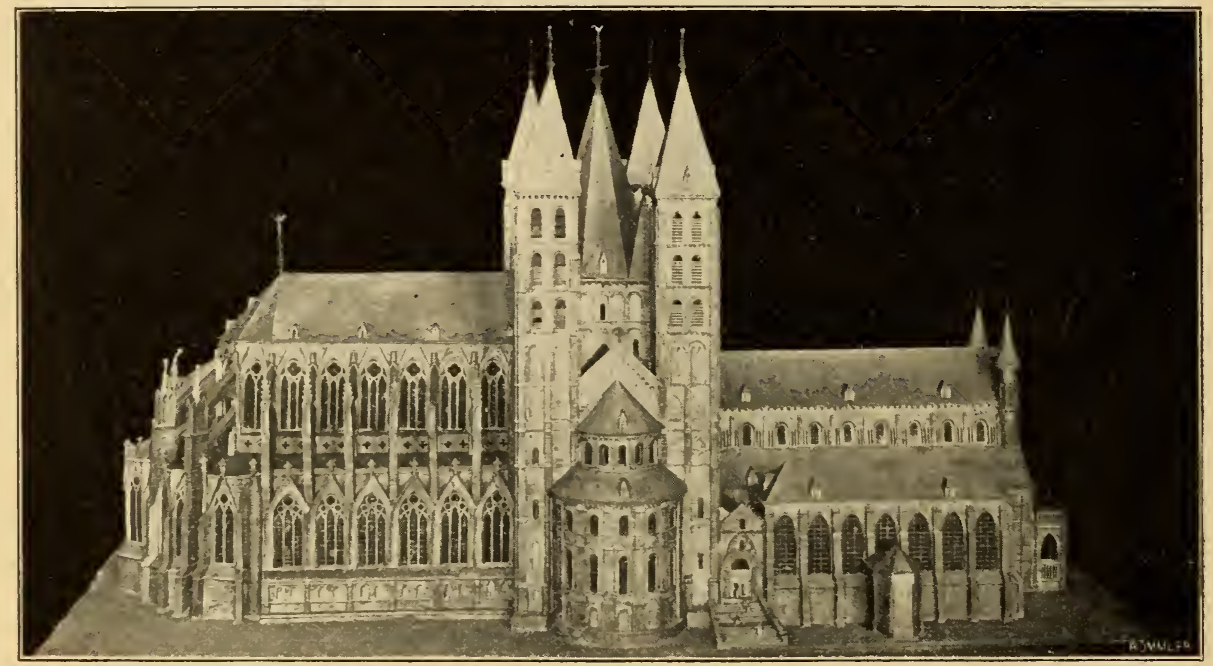

21bb. 24. Gipsmodell der Kathedrale im Mtujeum. (2rbeit des Ģerrn $\mathcal{D} a$ ffeur.)

erhabenen Kathedralen von 2Torwid, Gloncefter, Ely, Saon und Soiffonts wad?= ruft. Indes fehlt ihgr de Einheitliḑ̧eit. Wälhrend im Sanghans und dent Quer= idiffen aus demt 11. und 12. Jahrhundert der Runbbogen austahmslos herridht, ift der Chor, der 1242 angefangen und 1325 beendigt worden ift, in Gegenteil ein wundervolles Beifpiel der frühgotif. Er ift unter dem Episf̈opat des Walter

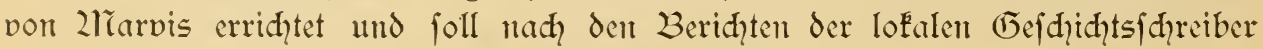
an bie Stelle cintes urfprünglid, romanifden Chors gefezzt worden fein.

Wie demt and fei, dicjer Ehor, der fidh in der 23 reite wie das Sdyiff felbjt entwidelt, übertrifft diefes um 15 2lieter an Ķöhe. für das Jumere trägt diejer

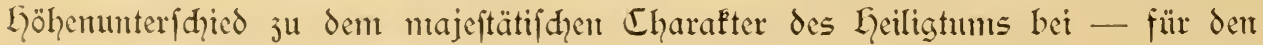
¿luseneindruc wirft er verwirrend.

Was Zotre Dame von Tournai cin befonderes und eigenartiges Eepräge giebt, ift die (5ruppiernng ihrer fünf Türme an der Derbindung des Chors mit dem

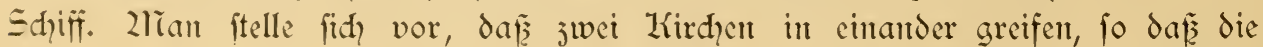


beiden präḑ̧tigen Querjhiffie die Derbitdung ausmadhen - das ift aus der Ent= fermutg betraḑtet die Wirfung diejes jauberhaften Eanjen.

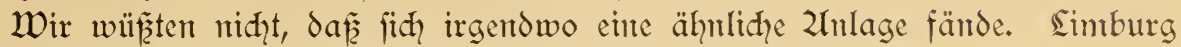

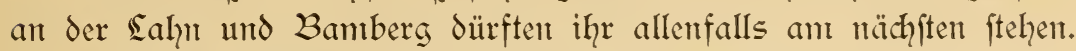

Wie fie entiftanden ift, ift fhwer ju jagen; auf alle fälle giebt fie eine hohe Joee von dem Reiḑtum und dent weiten Bliç ihrer Sḑöpfer. Stammen diefe verfdyiedenen Türme alle aus gleidher Jeit? Luiḑts beweift es, aber mehr als cin Grunt giebt 2lnla is daran ju jweifeln.

Der 2lïttelturm, der wie die vier anderen rechtecfig ift, aber maffiger unt um jwei Stockwerfe niedriger, bringt diefe Derichiedenlqeit durch die grö̈rere 5 öhe der Turmfpitze wieder ein. Dieje oftogone Spitze ijt von Esftürmthen eingefa žst.

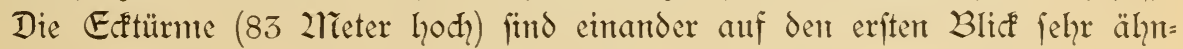
lidy und dod? find fie von einander verfhieden. 2llle haben vier StocFerwe, aber ilqre Bogenftellungen find nach Stil und Derteilung ungleidh; und während von den beiden Türmen, die dem Chor am nädften ftehen, der jur redten rein romanif h ift und der iḩm gegenüberliegende dem llebergangsftil angehört, fint die beiden anderen jüngeren Bauepochen jujuweifen und der eine ift logar rein gotifd.

Die vier Turmipitzen, die unterfdyiedslos pyramidal find, wurden im 16. Jahrhundert ernewert. Lqatten fie uriprünglich eine andere form? fajt mödhten wir es glauben, went wir uns der 2lëehrjahl der Türme aus derjelben Epoche, die wir namentlid in Deutfhland gefehen haben, erintern.

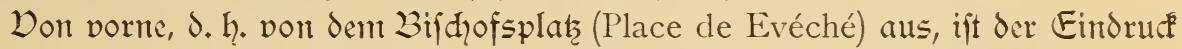
der Kathedrale weniger befriedigend. Sie fällt junähjt durd, den zliangel an llebereinftimmuntg der einjetnen Teile untereinander auf, der befonders durch bie ungeheure ftrahlenförnige Riofe hervortritt, womit man 1851 die faffade glaubte

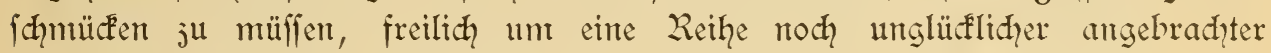
fenfteröffuntgen dadurch ju erjez̧en.

Die Reihe ungleidh breiter gotifher Bogenftellungen der Vorhalle, die den

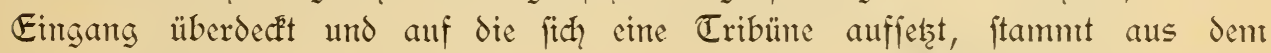

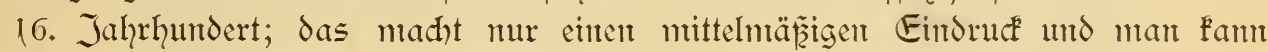
über dent Steingeländer, das diejen 2lrchitefturteil abjhliężt, die Spizen der fenjter= öfinungen in der uriprüngliden faffade hervorjpringen fehen.

Einen Gegenfats daju bildet und von wirélid malerifher Wirfung ift der gewölbte Eang, der in Tournai "Durdhgangspforte" (Fausse porte) genannt wirb, und deffen Dbergejhof mit brei fenjteröfinungen, die mit den eleganten Säuldyen

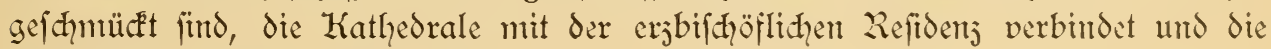
bif̧̋̈fliche Kapelle bildet (2łbb. 75).

Unter der Dorhalle find Reliefs, ja logar Godpreliefs aus verjdiedenten Epoḑen übereinander angebraḑt, die gewifferma fen cine Jujammenfaffung der Bildhauerfunft in Tournai währent jeçs Jahrhunderten geben. Diefe Werḱe verdienten die

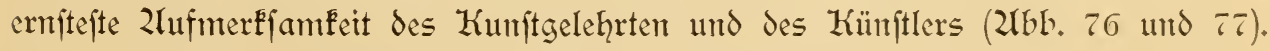
In einer bemerfenswerten 2lrbeit: "Lleber cine alte Birbhauerfdule in Tournai", einer 2lrbeit, die im Stuttgarter Kuntblatt 1848 veröffentlicht 
wurde, betont Waagen die hohe Bedentung der SFulptur von Tournat und fareibt

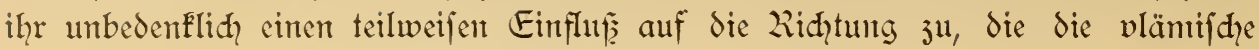
2ralerei unter den Brüdern van Eyck nehmen follte.

Zirgends in Belgien - diefe Thatjache ift niḑt ju beftreiten - fieht mant die Plaftif in fo mähligem Elanje wie in Cournai hervortreten, und das

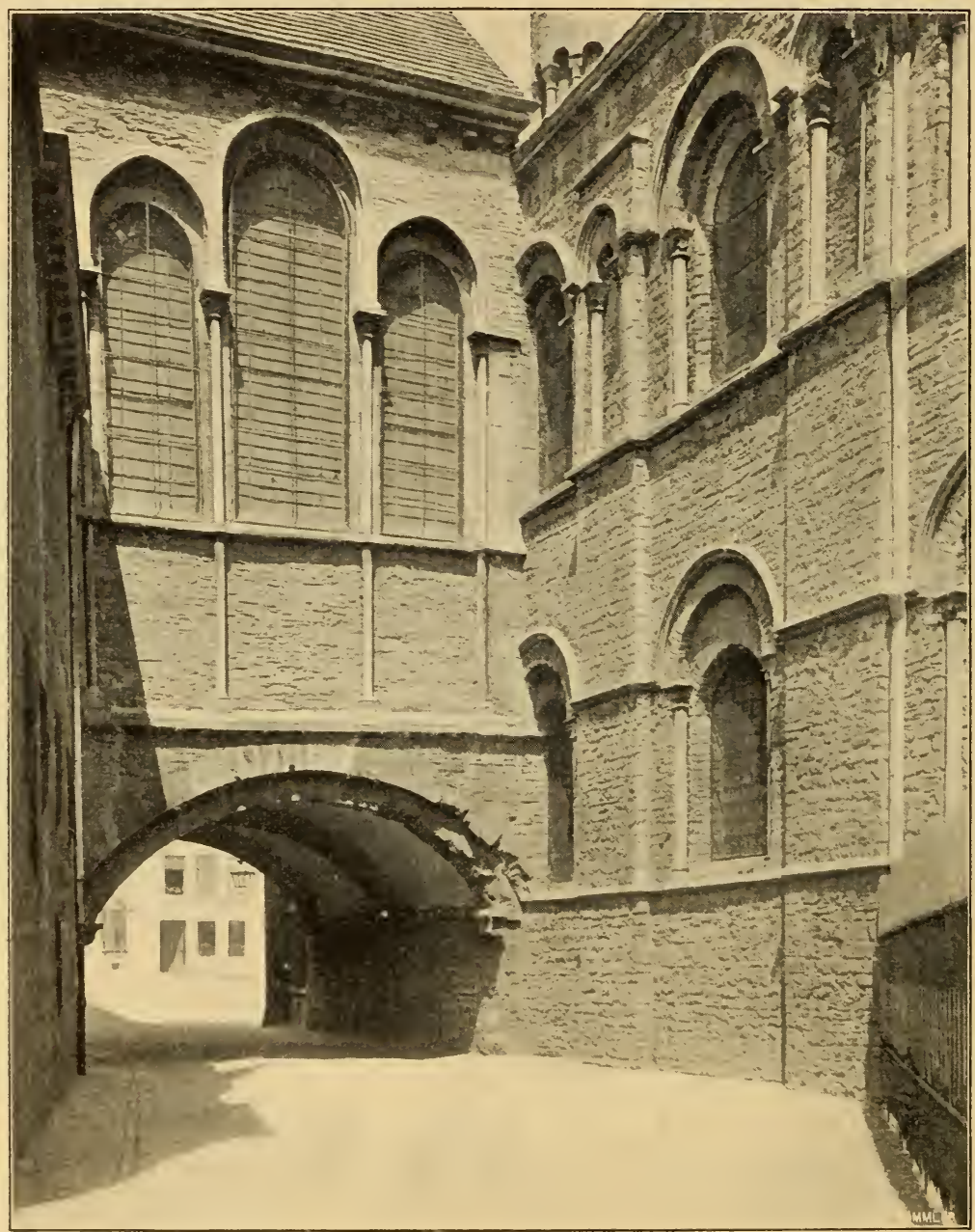

21bb. 25. Durdigangspforte jwifhen der Kathedrale und der erjbifhäflihen Ziefidenj.

in einer Epodhe, da die vläntifḑe Kunft nod, in den erften 2lnfängen war. Waagen nimmet niđht 2luftand, cin ZRelief aus dem 14. Jahrḩutdert als über den Werfen des $\mathfrak{Z}_{\text {ntdrea }}$ Difano ftehend zu bezeidnuen!

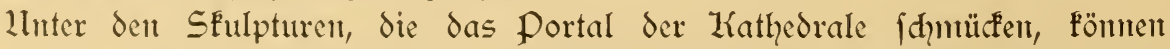

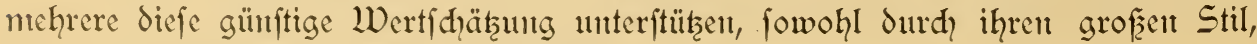
wie durch ihre genaue 2raturbeobadytung.

Zlus verfhiedenen Epodyen ftamment, teilen fie fid in drei ZReihen cin, von 
denen die unterfte, aus bem 13. Jahrhundert, befonders benterfenswert ift, und

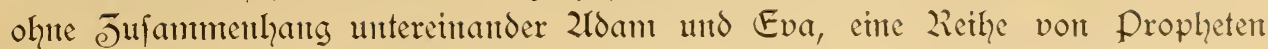
und Kirdhenvätern enthält, fladyreliefs in blauent hemeganifhen Stein, die von eitter gotifąen 2lufade befrönt find. Es fund jelyt auf jeder Seite und fie ver= dienen, ju den fḑ̋̈nfen 2lrbeiten ihrer 2lrt in Belgien gerechnet ju werden.

2leherere vout ifhen haben fehr gelittent, obwolyl in geringerent Grade als die Lodhreliefs, die fid über ihnen befinden und die leiḑter ju verderben waren. Diefe find von einem nidht bezeidneten Ifünfler ans dem 16. Jahrhundert und von gartj hervorragender 2lusführung.

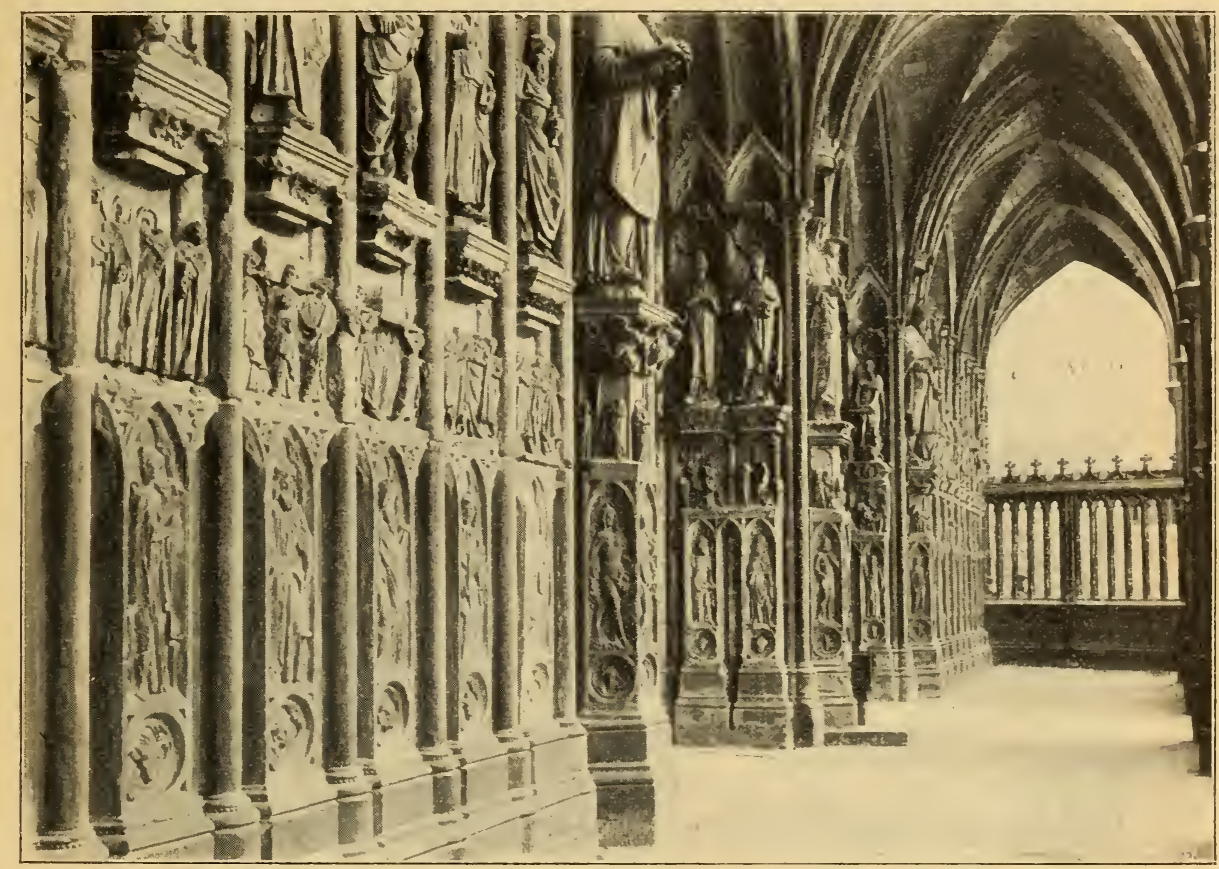

21bb. 26. SFulpturen in der Dorhalle der Kathedrale.

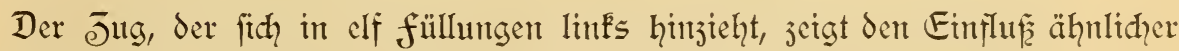
Sdyöpfungen dex italienifhen Kunft. Die in ber gleidhen Reihe redhts ftellen Scenten bar aus der Befdichte des Königs Chilperid in feinen Bejiehungen ju Tournai; fo behaupten wentgftens die Sofalgefhid)tsfhreiber. Die obere Reihe, 2lpoftelftatuen in mujhelförmigen Lithen, die Bilder der Zliabonna und der Schuthheiligen von Tournai, des heiligen Piat und des heiligen Eleutherus, bietet ein weit geringeres Fünflerifhes Jutereffe dar.

IIm die Grofzartigfeit der sinien und die harmonifhen Derhältniffe der

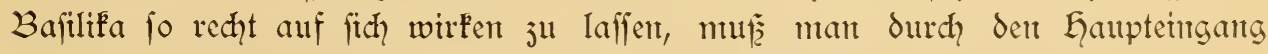
eintreten. Gier ift man auf gleicher Löhe mit ber Straže, während man jahlreiḑe Stufen erfteigen mufz, um das nördlidhe Portal zu erreichen, und im Gegenjatz daju mehrere Stufen hinabiteigen, wern man durd das fübliche Thor ein= 
treten will. Das hat nidhts Erftaunliches, da die Kathedrale auf einem Giügel= abhang liegt.

Der Eindrute, den man empfängt, wenn man eimmal die Shwelle über=

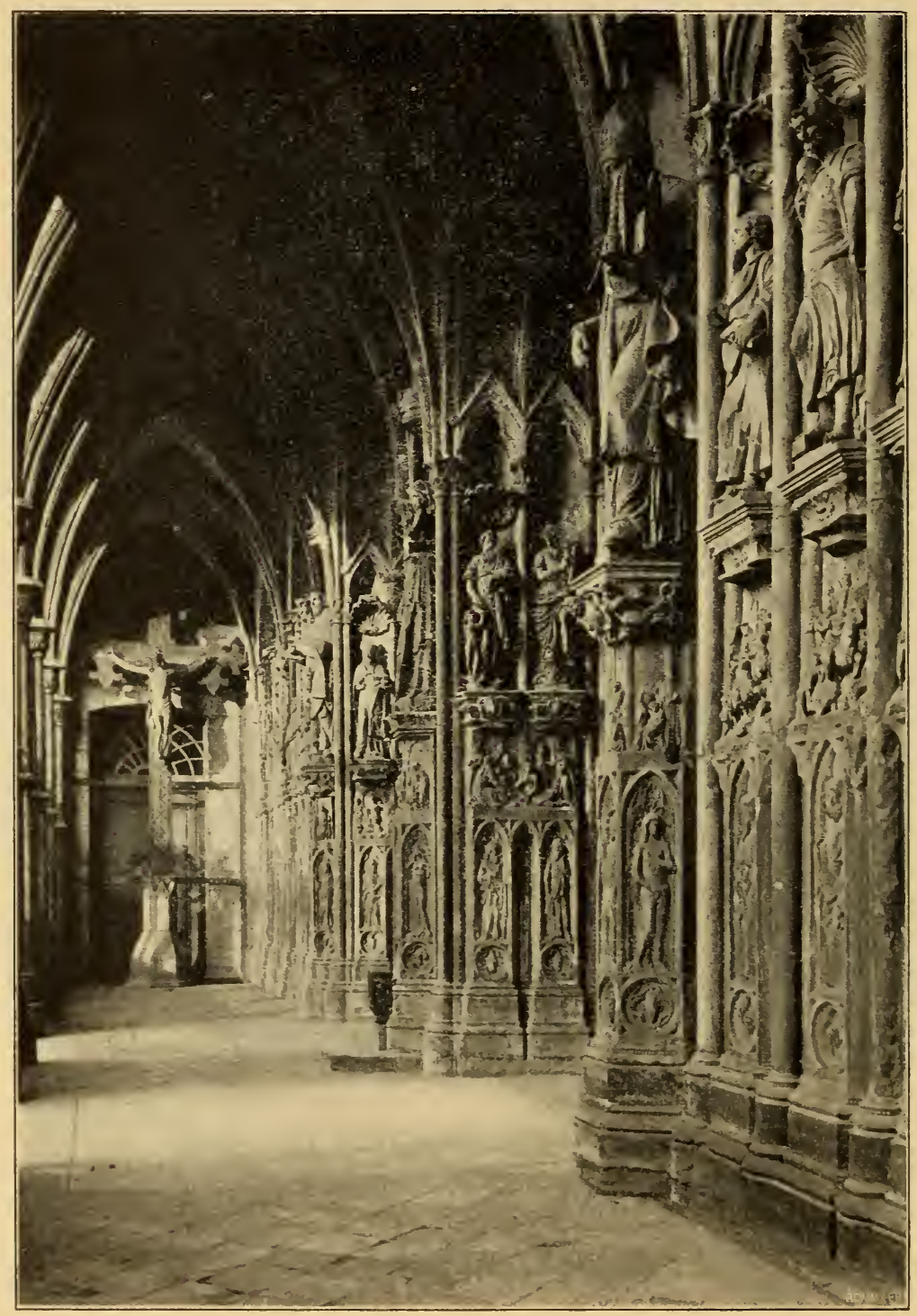

2ubb. 37. Sfulpturen in der Dorhalle der Kathedrale.

fdyritten hat, ift ein tiefer. Das Schiff, von fo gewaltiger 2lusdehnung, da nadh den Berechnungen von $230 j$ ière jwei Drittel der Bevölferung von Tournai darin Sdutr finden förnten, ift von ergreifendjter Wirfung. Die 33 zlieter hohe Wandung, wo fich vier Reihen von Zrefaden mit fdharffantigen Rundbogen und cingejogenen 2lrdhivolten überemander ftellen, fällt durd) feine vornehme Einfaḑheit auf. 
Fin Tonnengewölbe, das man lizl leider an Stelle der urfprünglichen 23alfendecke anbradhte, hat die erfte Zlnlage entftellt, unt man würde aud die fidhtharen 2rauerfhiḑten dem mildhweirent. 2liörtelverputz vorjiehen, weldher von

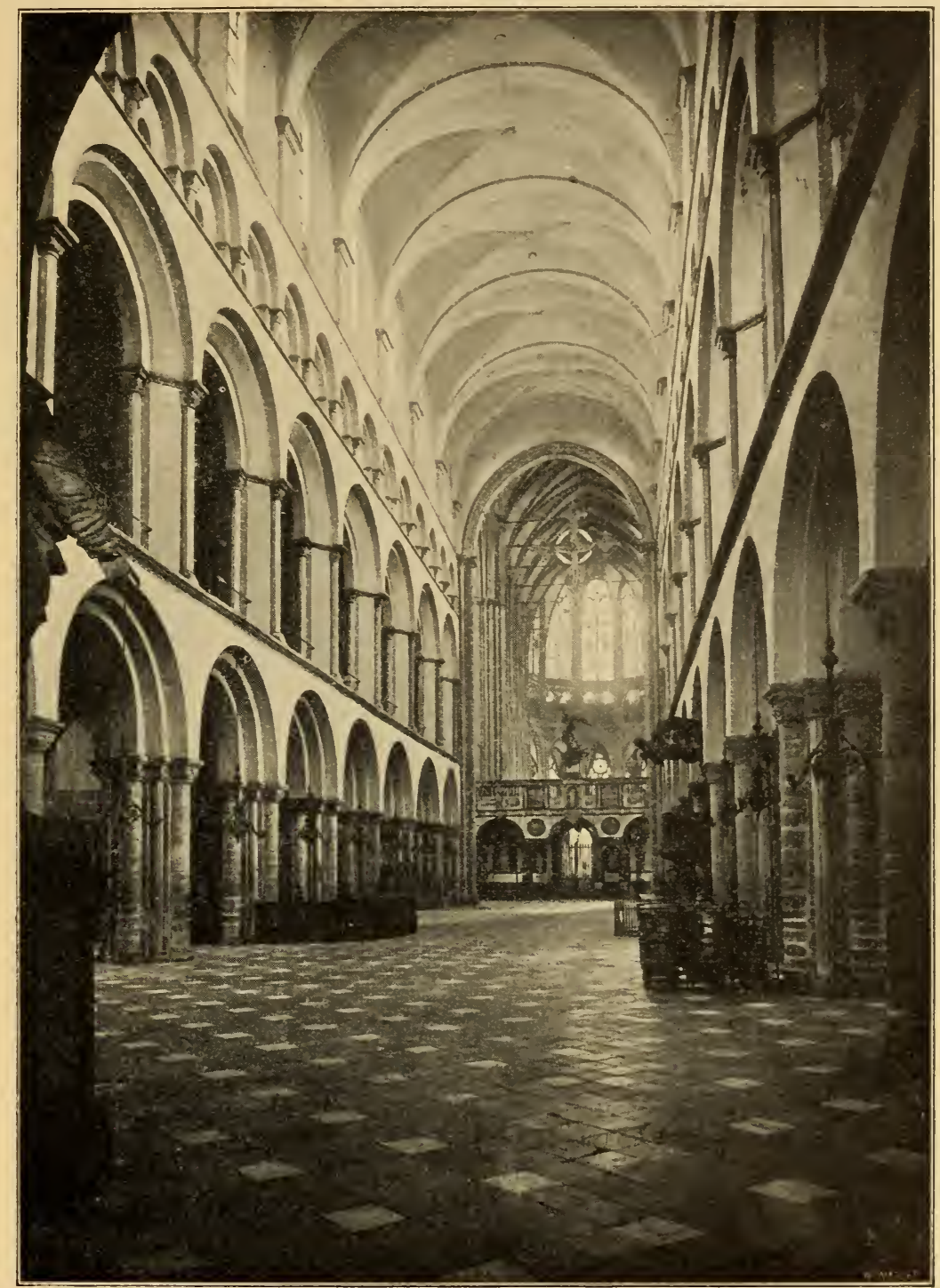

2łbb. 28. Interes des Ģauptidiffes der Kathedrale mit dem Chor. (2ufnaḩme von Eh. Daffeur in Eournai freundlidfit zur Derfügung geftellt.)

den Bogenanjätzen an die Wände bedefft. Trotzdem ift der Gefamteindrut vort überwältigender 2rajeftät.

Die maffituen Pfeiler mit ihren romanifhen Bafen, ausgejiert mit Lalb= fäulen, deren Kapitelle durd ihre deforative Phantaftif bemerkenswert find, und

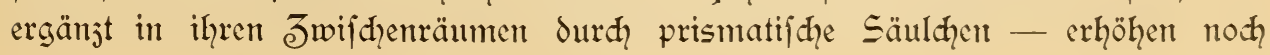




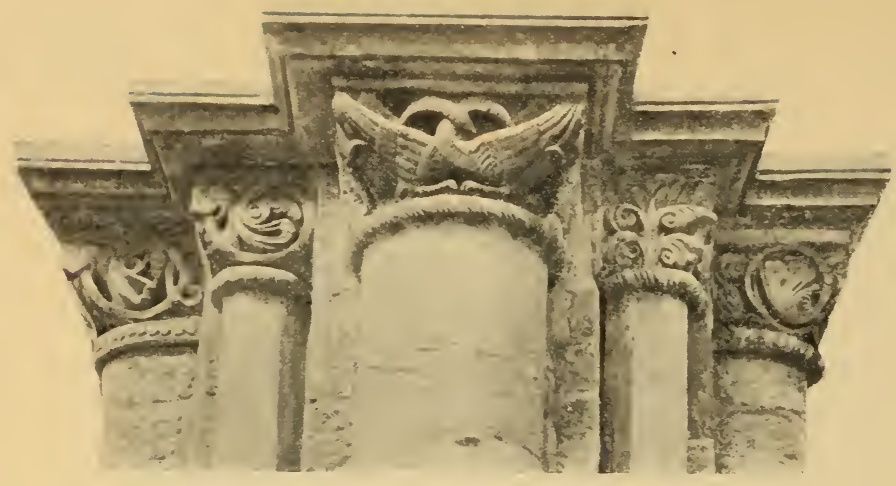

den mäđ̧tigen Eimdruck diefer Peripeftive von neun Gewölbejoḑen, jo

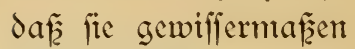
wie cime grofartige zlllee erfdyeinen, bie $\mathfrak{u}^{\mathrm{u}}$ demmajeftätif ḩen Chor hinfüllyt, der wie in Sidht getand daliegt unt deffen Eewölbe fid in das Inendidhe jut verlieren fheinen.

In form eines lateinifhen Krenjes, mit drei Sdiffen, die auf den Quer= fditfen fenfredht ftehen, wo, wie in dem Kauptjḑiffe, fich die zweite Reihe von ZreF́aden, die eben fo hod und breit wie die unteren fint, in geräumigen Galerien öfinnet.

Weit oben jieht fith das Triforium mit doppelten Fonzentrifhen 21rdhivolten hin, nod höher der Siđhtgaden ebenfalls int Kuundbogen.

Die Seitenfaiffe und die Ealerien, die fidh darüber hinjiehen, erhalten ihr Siḑ̨t durd jwei fenfterreihen.
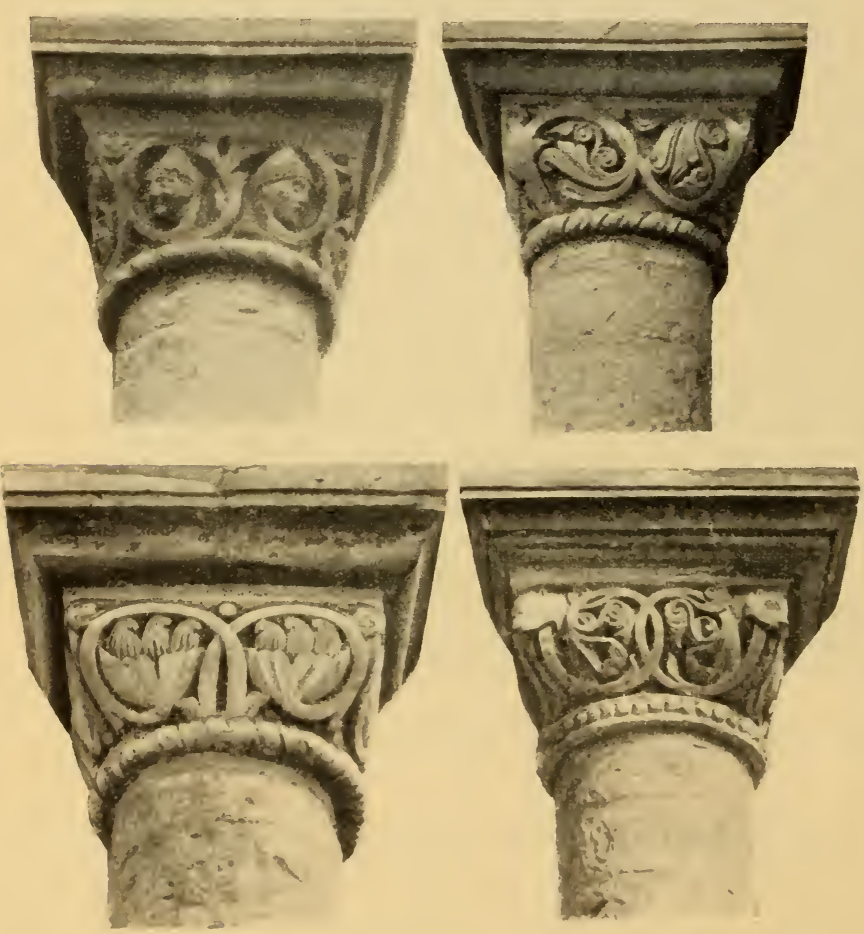

21bb. 79. Deridiedene Kapitelle aus der Kathedrale.

(mit freundr. Benehmigung des Derfaffers aus: E.' J. Soil, la Cathédrale de Tournai.)
Ebenfowentig wie das Lauptidhiff und dic $5 a=$ lerien, haben die Seiten= ¡đ̧iffe ihre uriprürgliḑe Decke, die hier durdy ein Zreujgewölbe erfetzt ift, deren Widerlager ciner= feits die Pfeiler des Kaupt= fhiffes und andrerfeits eine Reihe von Pfeilen bilden, denen die ur= fprürtglid\}e eingebundene Säule feḩlt.

Fine Eigentünlid\}= Feit, dic dem Bejudher nidyt entgehen wird, ift, dar das rechte Seitenfhitif breiter und höher ift, als das linfe; dieje Ulugleidhheit wird $\delta a=$ durdy erflärt, da jas das reḑte Seitenfduiff für die 2läunter beftimmt war. $D_{a}$, wo $\mathfrak{L a n g}=$ und 


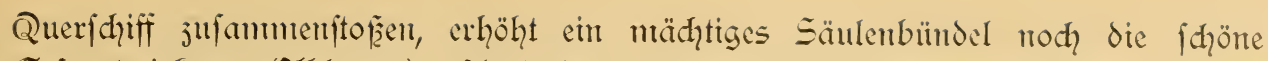

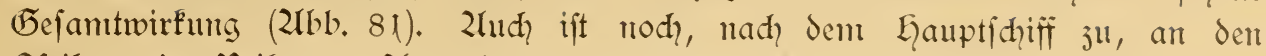

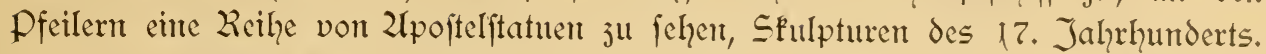
Der 3lick nadh der entgegengefetzten Seite maḑt cinen geringeren Eindruck.

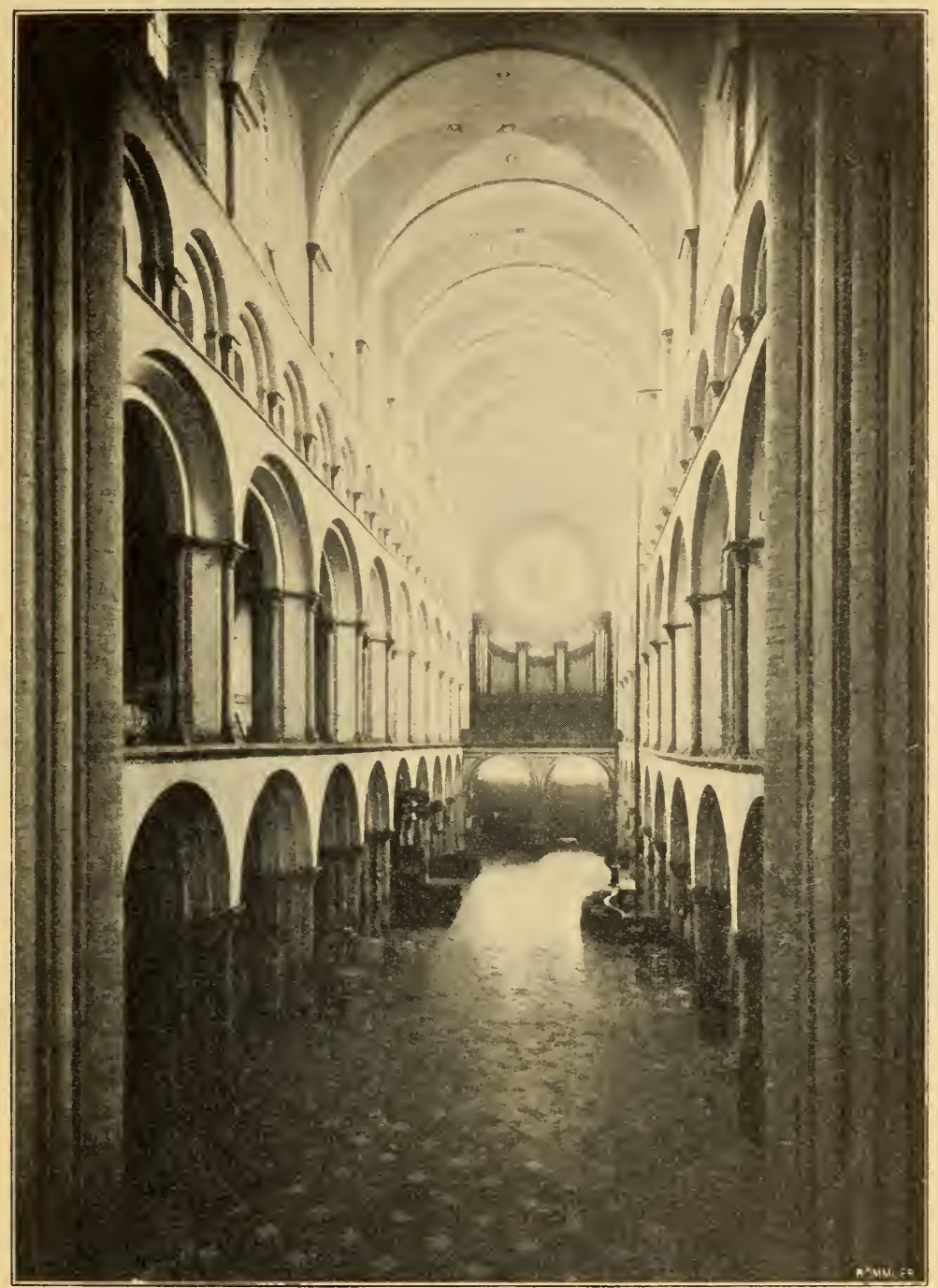

2lbb. 80. Blifk Jurd das Gquptfhiff der Kathedrale gegen das Gauptportal.

Die riefige fenfterrofe nit ihren bunten farben - es mag vielleicht fimmreich fein, ift aber keineswegs elegant, die Sinie des fenfters und die des (1)gelgehäujes in Ulebereinftimmung ju bringen - und die Drgelbühne felbłt ftimmen durळhaus nicht mit dem Stil des Бbebäudes überein.

Das Querfhiff hingegen erfüllt faft immer den Befucher mit Bewunderung, und die Bilder, die man von der Kathedrale Eennt, Gheinen mit Dorliebe diefe 


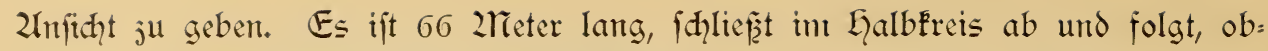
wohl es etwas jünger ift als das Sangldifif, dod überall defien Syftem.

Sieben Rundbogen, von hohen monocylindrifhen Säulen getragen, bienen

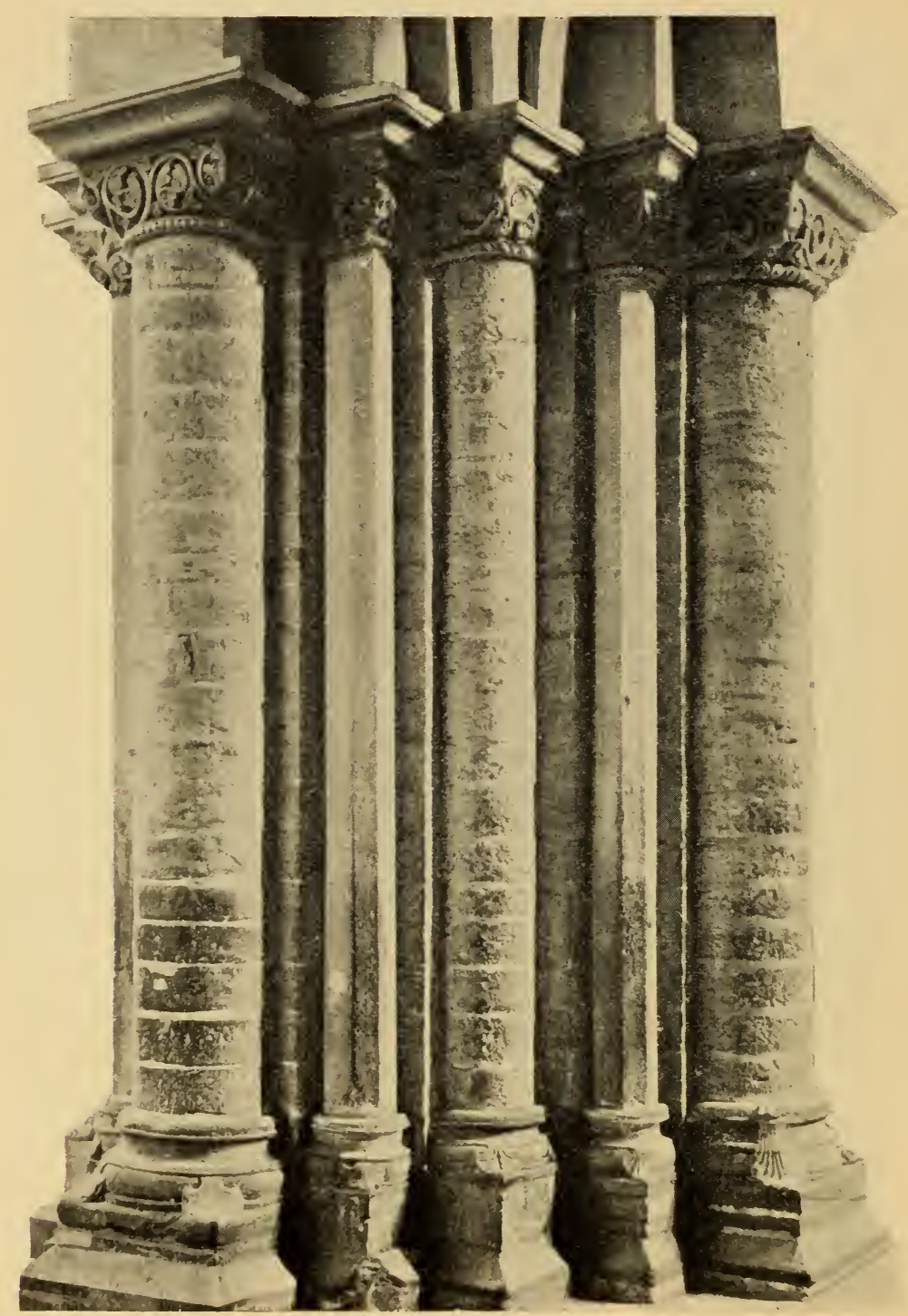

2Łbb. 81. Säulenbündel jwifhen Gqupt= und (1)erjđifï der Kathedrale. (zrach Soil, La Cathédrale de Tournai.)

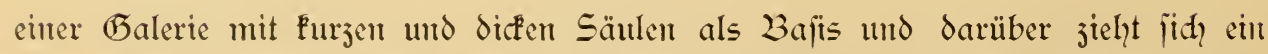
Triforium hin, von deffen mit Säuldhen eingefaßzten Pfeilern ftrahlenförmige Rippen ausgehen, in deren J̈wifdyenträunten eine keihe vout rundbogigen fenftern ausgefpart ift. 
Ein riefiger Bogen umrahmt das ganje bauliḑe 2liotiv von mähtiger Wirfung, das man jiemlid, nahe in der Kathedrale von Soiffons wiederfindet.

Sḑon jeigen fïh die Dorläufer der (5otif. Das Querfditï, das 14 2rieter breit und 38 2leter hod, ift, hat $\delta a$, wo es fid mit dem Sangldifi Ereujt, als Göhepunt die Saterne, die dem mittleren Glodenturm entipriḑt, und deren Kreuj= gewölbe auf Säulenbündeln ruht, die bis jum Boden reidhen. Die Göhe diefer saterme beträgt 48 2licter (2lbb. 83).

In gewiffer Weife den chor abjdiliefend, erhebt fid hier der berühmte

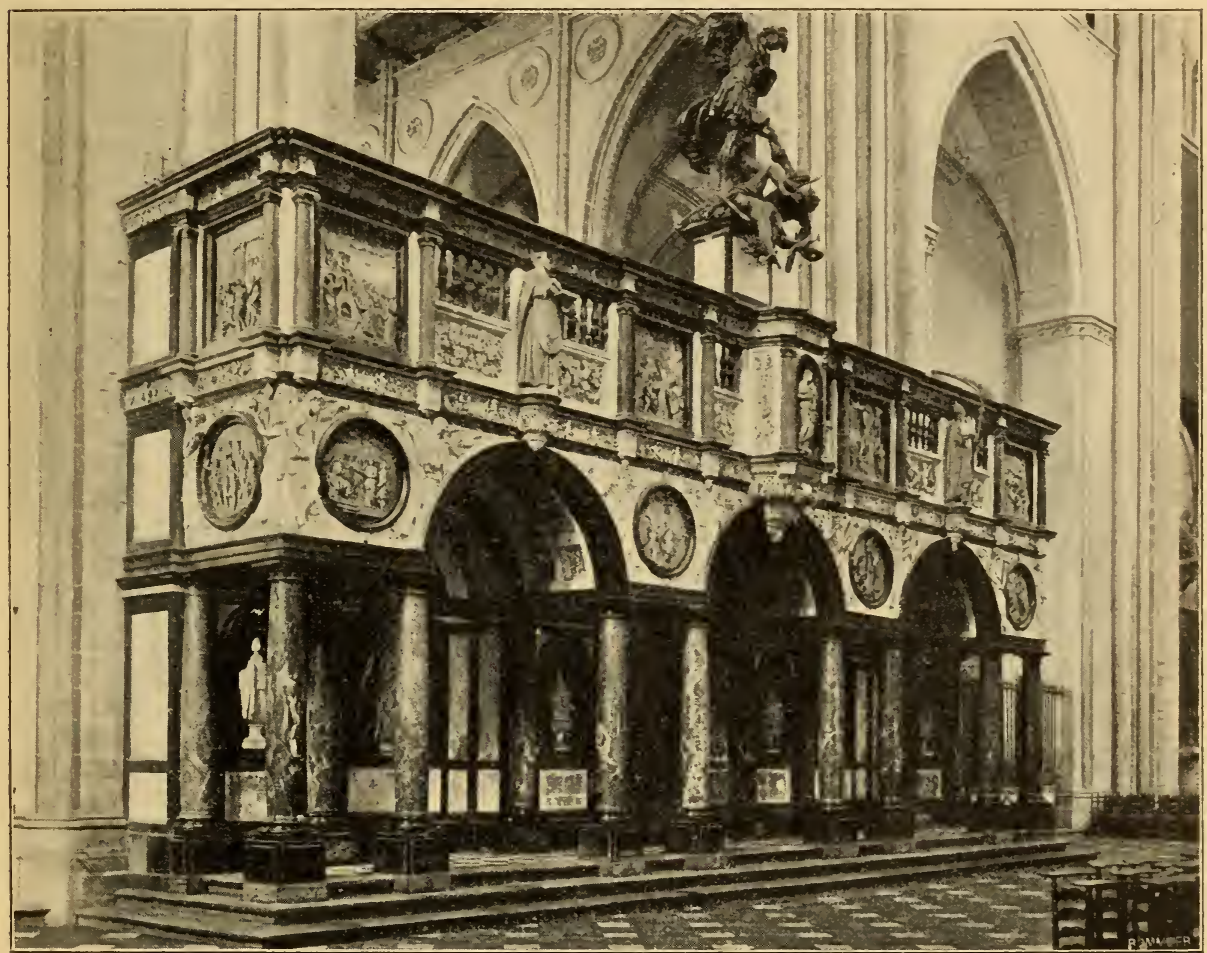

2ubb. 82. Chorbiihne von Cornelius floris in der Kathedrale.

DortiFus oder die Chorbühne, ein Werf des Cornelius floris aus 2lutwerpen, ein 2reifterwerF der Renaiffance in den Ziiederlanden. Es datiert ans dem Jahre 1572. Zlbwedhslung bringen die dorifhen Säulen aus rotem 2liarmor, der fdhwarje 2rarmor der ardhiteftonifhen Sinien und der weiše 2liarmor der 2liedaillons von hervorragender Bildhauerarbeit, deren Darjtellungen dem alten und neuen Eefta: ment entrommen find und fidh auf die Erlöjung des 2lienfhengefdyledytes bejiehen. Sehre đhöne Kragfteine mit den Statuen der 2liadomna, des hl. Elentherius und des hl. Piat vervollftändigen dies fhöne Erefantbild. (1)bwohl nadh demt Chor ju einfadyer gebildet, ift aud da die Chorbülnte nid̨tsdeftoweniger von groper Elegantz und vollf́ommenemt Eefd̨maté.

Don der unteren Partie, die -weipe zlarmorvajen und Eipsftatuen đhmüffen, 
Eamt man niḑt dasfelbe fagen. Es ift faum jweifelhaft, dar diefe Juthaten niḑt int Sinne des urfprüngliḑen Planes gelegen waren, ebenfowenig wie diefer beab: fïhtigt haben fomte, fo vollitändig den Blid auf den Chor ju verdecken.

Was die immenje figur des hll. 2lïhael betrifft, ein Werf von $\mathfrak{S e}$ Creut, die das Ganze überragt, fo ift fie eine 2rrbeit des 18. Jahrhunderts, an fidh benterf́enswert, aber fie pap̧t ntit ihrem Stil und ihren proportionen niđht hierher.

Seitwärts von der Chorbilįne, an den Wänden des Querfhiffes, hat man vor wenigen Jahren eine Reihe von fresfen blofiz gelegt, die die Segende der hll. 2rargarethe darftellen. Sie find jiemlich gut erhalten und fheinen aus dem 12. Jahrhundert ju fanmen. Бrewöhnlich find fie mit einent Dorhang bedecft.

Iln der unteren fenfterreihe des Querjhiffes find Elasfenjter angebradht, die (itđ urfprünglid im Chor befanden, wo fie jeţt durd moderne fenfter erfeţt find, deren Stil freilith nuehr dent der Kirche entipriḑt, die aber ficher von geringerent Fünftlerifhen $\mathfrak{W}_{\text {ert }}$ furd.

Daf man diefe intereffanten Beifpicle der Glasmalerei in den Ziiederlanden dem Dierç Bouts aus Söwen oder dem Sueas 2ldriaens aus 2lntwerpen ju= fhreibt, ift mur hypothetifh und aušerdem durch den Stil der Glasfenfter felbjt widerlegt, der für das 16. Jahrhundert fehr dharafteriftif if ift.

Die Darftellungen find der Só́algefdhiḑte entrommen, fehr lebendig wieder= gejeben und fehr wertvoll für das Studium der Eefhichte der Koftüme unt der Sittert. Sieben fenfter auf jeder Seite furd fo in jwei Reihen gefd̨mücţt.

Der Chor bildet durch feine edlen Derhältniffe und die Reinheit feiner Sinten

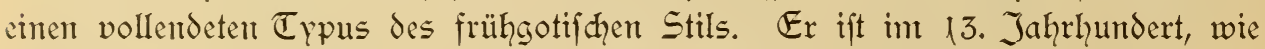
wir fhon gefagt haben, an die Stelle eines urfprünglidyen Chors getreten, der im 9. Jahrhundert durdh die 2Tormanmen jerftört worden war. Das ift wentigtens die zleinung der Gefdidhtsfhreiber von Tournai.

Die Wölbung, woran fith in wundervollen Rippent die Bündel vort jwanjig Eäulen non ganz ungewöhnlichem Sđ̆wung entfalten, ift von herrlidhiter Wirfung. כ̄wifhen den Säulen fügt die gewundene Sinie der fenfter des Wandelganges nod einen neuen Reiz ju der Wirf̈ung des Ganzen hintzh. Daju fonmut nod ein fḩ̈̈nes Triforium, worüber fich ein fehr hoher Sidhtgaden hinjteht, unt dem Eantjen den Charafter einev feltenen 2lajajeftät einjuprägen.

Der reiche unt anmutige Gauptaltar, der ans dem 18. Jalprhundert ftanmt, verbindet nicht ungef hicfit die Eleganz des Stils Souis XIV. mit der Strenge der LIntgebung, wohin ihn der Jufall verfeçt hat. Er ift das Werk des cinheimifdhen (5oldfhmieds Gafpard Sefebvre unt wurde für die 2lbtei von S. 2Tiartin gemadht. Seine 2redaillons von getriebentem Silber, peine grofen Sendhter, feine Engels= geftalten mit flatternden (5ewändern find wirflid bewundernswert. Der 2lltar lqat

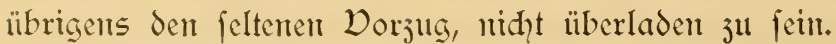

2 hr beiden Seiten des Zltars befinden fid jwei fehr reich ansgeftattete Reliquien=

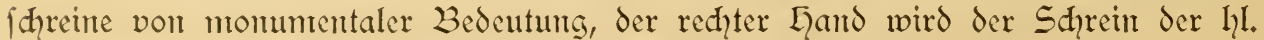
Jungfrau, der linfsftehende der des hl. Elentherius genant; beide find aus dent 13. Jahrhundert. 
Der Reliquienf hrein der 2líadontra ftammt aus demt Jahre 1205; er trägt die Signatur des Ziticolas von Derdun, des Sdyöpfers des berülymten emaillierten Zlltarauffatzes zu Klofterneuburg und 1207 Bürgers von Tournat. Der Sthrein

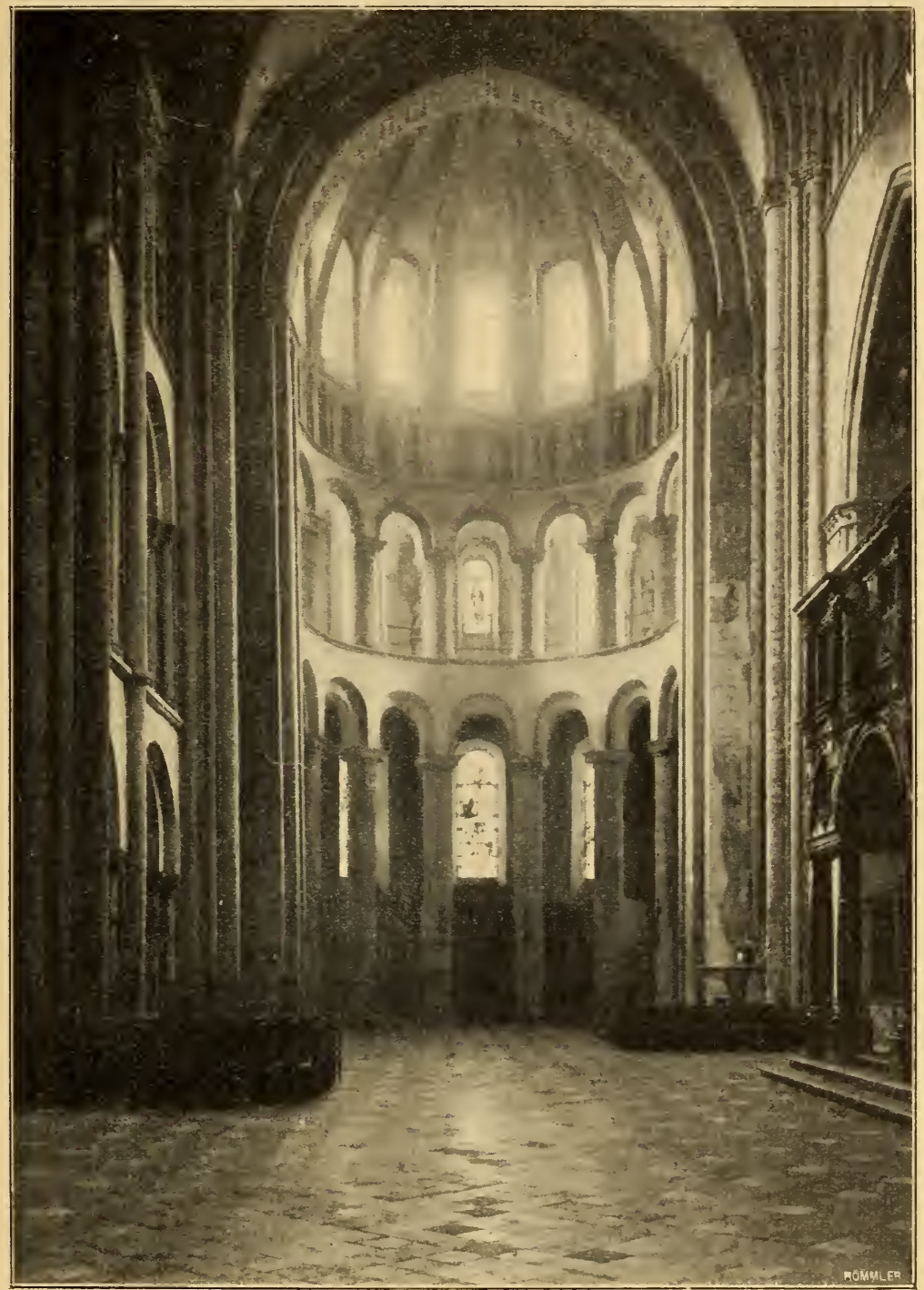

2łbb. 83. Blick in das Queridifif der Kathedrale.

ift aus vergoldetem Silber und jeigt im Goḑrelief unter Kkleeblattbogen die widh= tigiten Scenen aus dem Seben Chrifti, und trägt an den Sdymalfeiten Chriftus und anderfeits die Znbetung der heiligen drei Iänige. Die Emaillierung

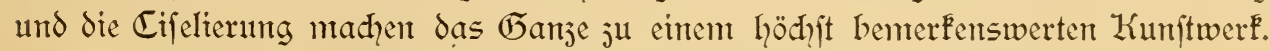

Der jüngere Reliquienjhrein, der des hl. Eleutherius (1247), ift unter den Goldfhmiedearbeiten des 2rittelalters berühmt. Er hat die form eimes Sarfo= 
phags (2fbb. 84). 2us dem durḑbrodyenen Kamm wadhjen drei reich emaillierte Knäufe heraus; er ijt ganj aus vergoldetem Silber gearbeitet, mit Zlusnalime ciniger Partien, die int Saufe der Reftaurationen erneut worden fint.

Seitlich fieht man unter Bogenreihen mit eleganten Säuldhen 21poftelfiguren, während an den Bogengiebelfeldern und an den Ecken Lqalbfiguren von Engeln in vorjügliđer 2lrbeit erfheinen. Zluf den Sdyrägen wieder figuren von 2lpofteln, der Ziadoma und der Zïrdhe, alle ftehend und in grofartigent Stil. 2In den Edhmalfeiten die figuren Chrifti und des hl. Eleutherins; wie alle anderen, find aud fie volle Rundfigurent.

Die Vorjügliđhleit der 2lrbeit, der Reid̨̧tum der Edeliteine unt Kameen, der nodh ju der Email = und filigranarbeit hinjutritt, maḑen als dem Schrein ein Werk von ganz hervorragendent Wert. 2ran Eernt den Küntfler nidht.

Die Sdireine jtehen fehr hod und es ijt deshalb fdywer, fie gut ju fehen; nur bei den feierlichiten Gelegenheiten werden fie von ihrem plat hernuter= genommen. Der Schrein der Zliadonna, der bei den Dlämen in hoher Derehrung fteht, hat in Jeiten der Lot mehrere 2liale die Reife nach flandern gemtaḑt. So etwas fontmit in den Firdylidgen 2lmalen nidht felten vor.

Die 2lusflymilffung und die Zlusftattung des Chors bieten nidhts Jutereffantes, mit 2lusnahme eines fehr intereffanten eifermen, mit $\mathfrak{S} e d e r$ überjogenen $\mathfrak{E} e f e p u l t e s$, das aus dem 15. Jahrhundert ftammt, und einiger fupfermer Sendhter, von denten jedoch eintige nur Zachbildungen find. Erbärntlidhe 2lialereien, gran in grau, nadh den Saframentbildern von Pouffin, entftellen cinigerma ezen dies fhöne 2rahitefturbild.

Int Chorumgang befinden fidh die meiften Bilder, die der Kathedrale an= gehören. 2lanthe dürfen ein ernjtes Jntereffe beanfpruchen. "Chriftus wird dem Dolke gejeigt" in lebensgrofen Galbriguren, wird Quintin 2rietips juge= đhrieben. Das Bild jeigt lebensvolle, aber gemeine Cypen; es fant der Sdhule des 2lntwerpenter 2lieifters angehören, rïhrt aber fidherlid niḑt von feinem Pinfel her. Es hat ein leudhtendes und harmonifhes Kolorit und ijt von gefḑiffter Zlusführung. Das Dradomnfeum in Zliabrib befitht von dem gleidgen Maler ein parar 2lltarflïgel, die ebenfalls dem 2lietfys jugejḑrieben werden.

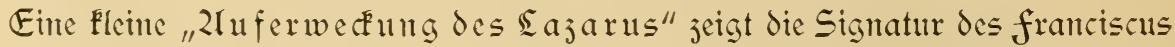
Dourbus und das Datum 1573. Die Werfe dicfes 2rieifters find felten. Da er der Edwwiegerfohn des Contelis floris war, der die Chorbülyte fduf, neben welder

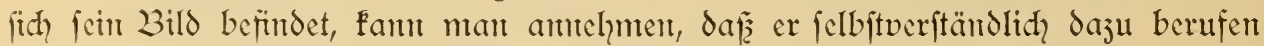
wurde, ein Werk für die Kathedrale ausjuführen.

ZTod) follte der Befhauer feine Zlufmerffamfeit auf das vorjüglidhe Porträt einer Lrome von van Doft ridhten, eine Saburt Chrifti von 2liartin de Dos und ganj befonders auf die Jufanmtenfellumg eitres 2litarienlebens, die jweifellos mit Recht dem Santeelot Blondeel jugef hriebent wird (2lbb. 85).

Wie in dem Bilde in S. Sauvur in Brügge ift die 2liadomta auf einer erhöhten

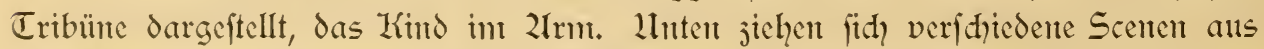
dem $\mathfrak{E}$ eben der Jungfran hin: dic Verf̈̈ndigung, die Leimfudhung u. 1. w., alles

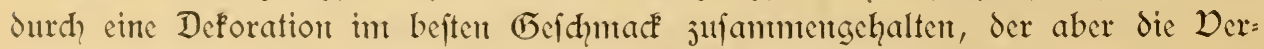
goldungen fehlent, die man in 23 londecls Werfen beftändig trifft. 


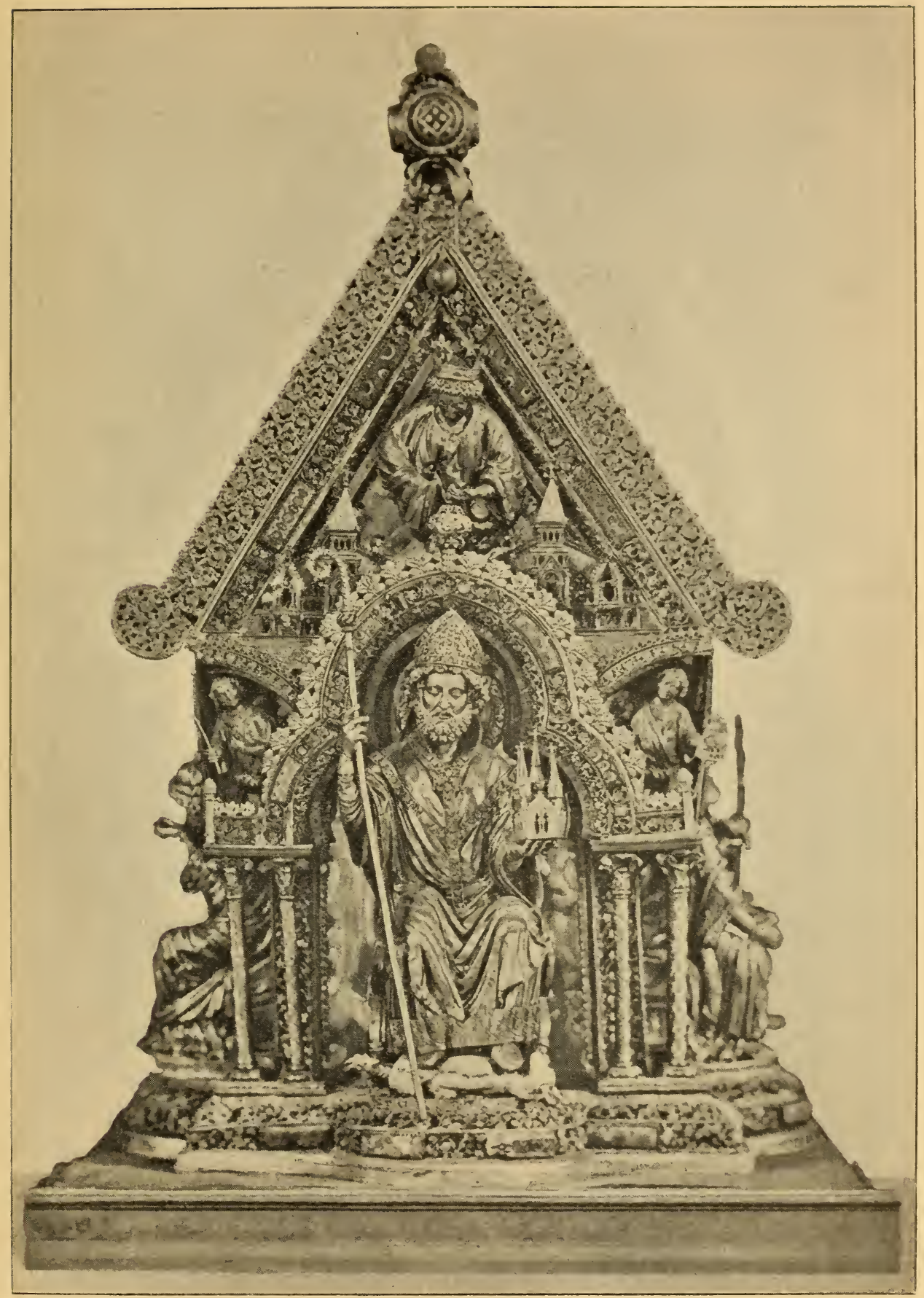

21bb. 84. Der Reliquienfarein des hl. Elentherius in der Kathedrale in Tournai. 


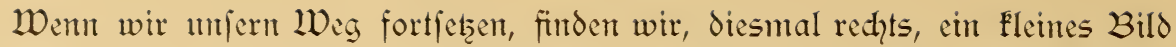
nach valt Dyck: Chriftus ant Kreuj, wo Engel das Blut des Erlojers in Kelḑen auffangen. Wir Fennen das Driginal diefer Kompofition, die von Gollar geftoḑen ijt, nidht; ohne J̄weifel ift es nidht bas Bild hier vor uns*").

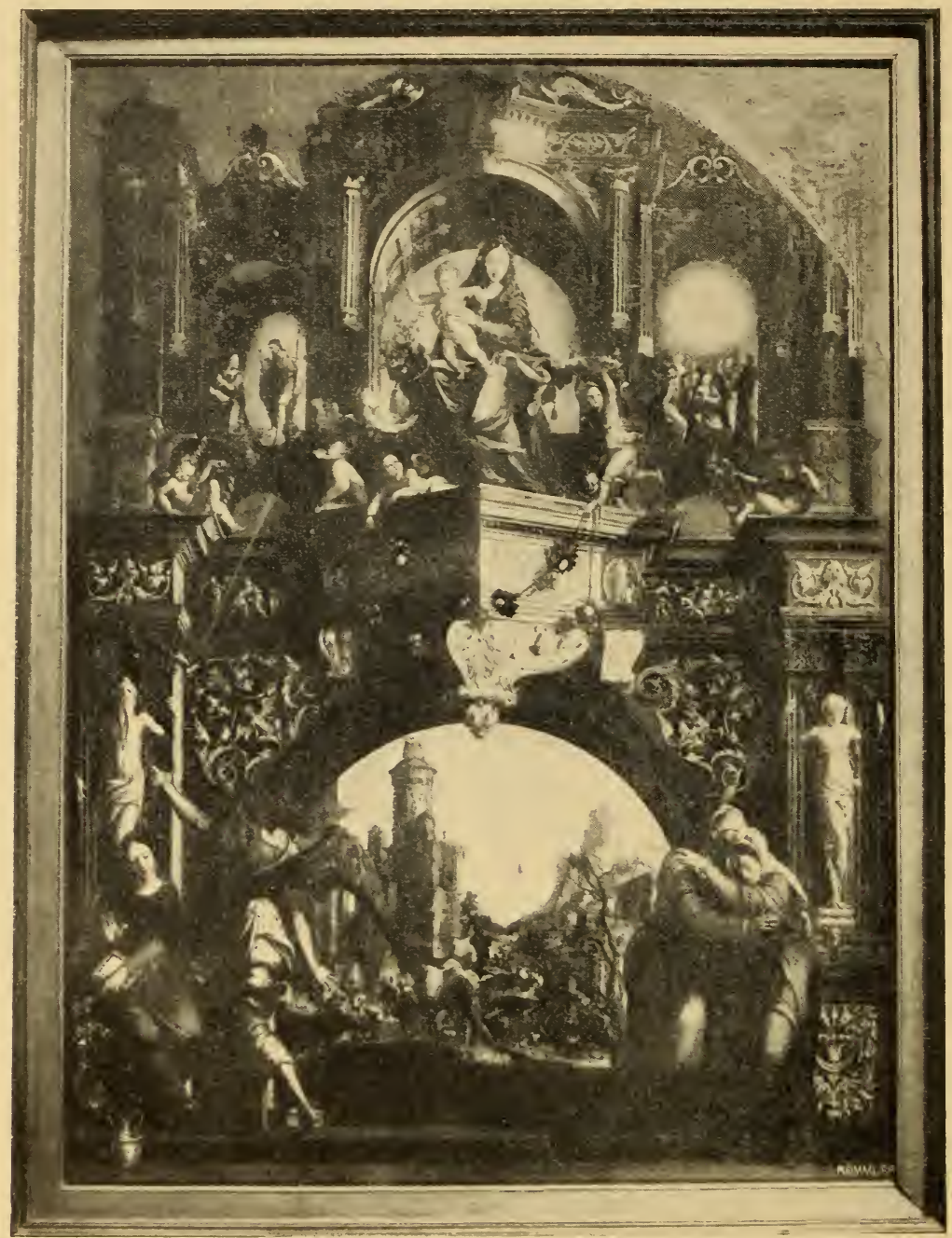

2bb. 85. Marienleben von Santelot Blondeel in der Kathedrale.

In der Chorhaube befindet fid ein hohes 2läarmordentimal, das jum Ge=

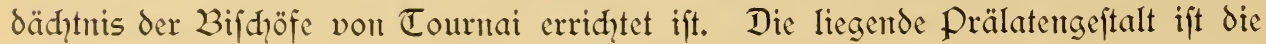

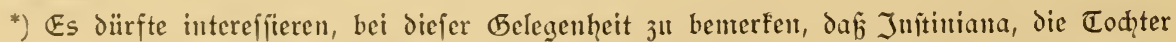
van Dyctss, dic damals fran Stepney hief, im Jahre 1660, als fie fid mit ihrem Gatten in 21ntwerpen befand, ein Bild malte, das denfelben Gegenftand behandelte und für ihre Cante Sufanme be. ftimmt war, die im 23eguinenhofe lebte. Dergl. Danden Branten: Geschiedenis der Antwerpsche Schilderschool, S. 344. 
von 2rarimilian Dilain aus Gent, und die Engelsgeftalten follen von Jérôme Duquesito feit. Das Ganje ift aus dem Zlnfang des 19. Jahrhunderts (21bb. 86).

Gar Fein Wert ift der őufdrreibutg jweier mittelmäfiger 2lltarflïgel, der Geimfudung und der 2lubetung der Könige an Sueas von seyden juju= meffen. Es fdeent, daf sucas von Seyden das Privilegium hat, überall die leţte ङufluḑt der Kritifer ju fein, die mit der Jufdreibung von Bildern in Derlegen= heit find.

Die Jahresjahl 1833 unten an einem 23ilde von Gallait, der Geilung des Blinden, ftimmt mit dem Charafter des Werkes nidht ïberem. Fallait war faunt 23 Jahre alt, als er das 23 ild funf, aber er lyat es in den letzten Jahrent feiner fünftlerifhen saufbahn übermalt - daher die J̄wiefpaltigfeit, die wir hier feftftellen.

In dem füdichen 2 rm des Querfdiffes über ement Zltar fieht mant ein gropes Zltarblatt, datiert von Jahre 1623. Es ftellt den Stammbaum der hl. Juıgfrau dar und trägt den Lamen eines Kü̈tflers, der mur durch dies einjige Werf befannt ift: 2r. van Legre. Wbwohl es unbedingt vlämif ift, verrät das grop̉e Werf doch italienifde Eimflüffe und ift durchaus nicht ohnte Wert. Die flïgel, die fith früher in Chorumgang befanden, find jetzt wieder an der 2littel= tafel befeftigt. Sie ftellen die Geburt Johannes des Täufers, 2líariae Dar= ftellung im Tempel, die Dermählung Vrarias und den Gohenpriefter ङađharias dar.

Die grofen Statuen, die man an Choreingang fieht, find von dent 2lntwerpenter Bildhauer 2richel Dervoort (1667-1737).

Die Kapelle des hl. subwig ift in gotifden Stil angebaut, fie liegt rechts vom Lauptidiff nad dem Querfdiff ju und intereffiert haupt=

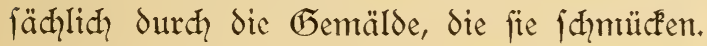

Das fegefeuer, ein gropeses Gemälde von Rubens, das ppejiell gentaht wurde, unt den Lauptaltar der Kathedrale ju jierent, ift durch Uebermalung gänjlich entiftellt. Die Kreujigung von Jordaens über dent Ultar gehört nicht zu den hervorragenden Werken des Künftlers, der diefen Begenftand mehrere zlăale behandelt hat; folḑe Gentälde befitzen namtentlid? die Paulsfirche in 2 nntwerpen, die Kathedrale von Bordeaur und das Mrujeunt von Rentes.

Lody ift ju benterken, da iz sambert sont= bard uidhts mit einem Bilde ju thum hat, das ihm die führer jufdreiben: "Ein König vou franfreid empfängt die päpltiche fahue". Bei verfhiedenen figuren exf́entut man bald, da衣 fie Golkzius entlehnt find, abgefehen davort,

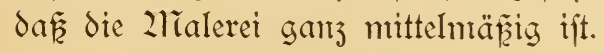

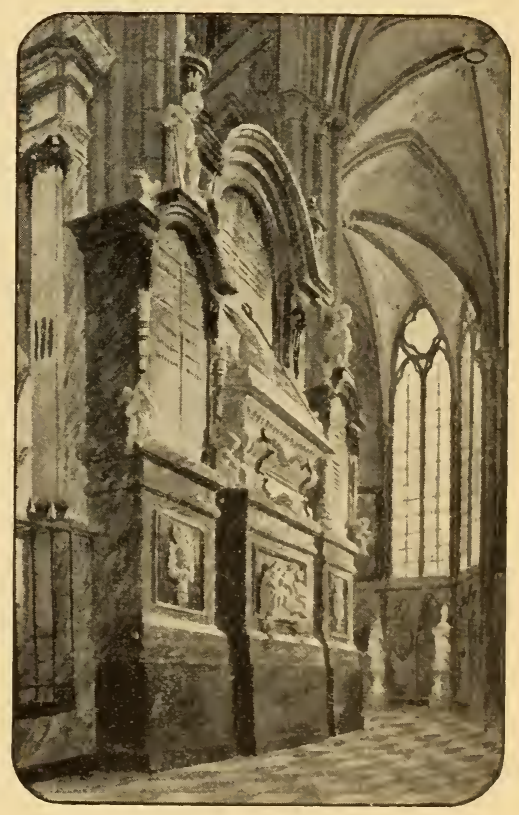

2bb. 86. Denfmal der Lifiţöfe in der Katheorale.

(Znă Soil, La Cathédrale de Tournai.) 
Jur Kathedrale gehört merfwürdigerweife Eeine Pfarrfirche; es wird dort Eein Gottesdienft gehalten, und das fogentannte Zitrdyfpiel von Zrotre Dante hat als Gotteshaus ein Zrebengebäude, in welches man durch das nördliḑe Seitenfhiif gelangt. Es ift int 16. Jaḩrhundert unter Leeintich VIII. entfanden uild bietet weder hinfichtlidh feinter 2lrdjiteftur nod in $B_{e j u g}$ auf die 2lusftattung oder fürrft:

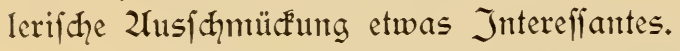

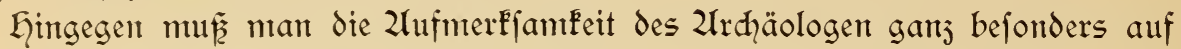
den reidhen Sdyat von Grabläulpturen lenfen, die teils als Epitaphien an den $\mathfrak{W}$ änden der Chorfapellen angebraḩt, teils in einem der Zébenräume des Kapitel: faales jufanmengeftellt fint.

อ̈unteift fehr befhädigt, gehören fie verjḩiedenen Epodhen an; die älteften Bei= fpiele fint aus dem 14., die jüngften aus dem 17. Jahrhundert. Sie geben $j^{\mathfrak{u}=}$ fammen ein bemerfenswertes Bild der Entwidflung der Plaftif in Tournai.

Die Reliefs, die in dent Korribor der Saf́riftei ausgeftellt find, ftanmen $j^{\mathfrak{u}=}$ meijt aus dem alten Refollef́tenfFlofter. Waagen erwähnt ihrer in dem oben an= gejogenen 2rrtifel mit cinem wahren Enthuftasmus.

Dor allen anderen mur man das Grabmal der famtilie des colard de Seclin von 1341 nennen. 2räan fieḩt da unter einer gotifhen BeF́rönung die 2liadonna mit dent Kind an der Brupt. Colard de Seclin in Dofforengewand Eniet linf́s neben jeiner frau; fein Sohn, der Wappenherold des Königs von franf́reid, ihm gegenüber. Der Kopf der 2radonna fehlt; der des Jefufindes und deffen Gändḑen verraten einen hervorragenden Künftler. "Don dem Kon= ventionell=5otifhen der falten mit den mageren und hohen Rippen, weldhes in der Regel den Skulpturen diefer Jెeit eigen ijt", fagt Waagen, "fittet fich hier Feine Spur. Es liegt denfelbent vielmehr eirte ebenjo genaue als gefdimadévolle Beobachtung der Lratur jum Grunde." 2luch die Enteenden Perfonen find bewunderungswürdig. Sie machen, wie Waagen fagt, den Eindruck wirflidher Porträts, die einer Deit vollfommener Irunftentwifflung angehören. ZTan glaubte diefes fdÿne Relief dem berühmten Bildhauer Eutllaume du Gardin 3 u=

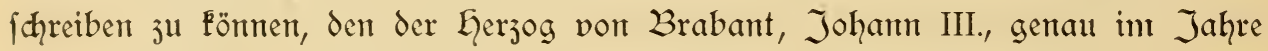
1341 beauftragte, ein Grabmal jum Gedäd̨tris feines Dnfels Geinrich, feiner Söhne und Entél, Johamn und Geinrich von Söwen, für die franjisłanterfirḑe

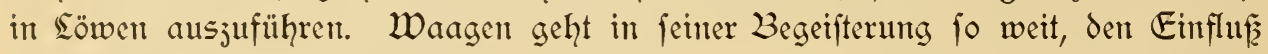
der Bildhaueridhule von Tournai auf Roger van der Weyden, der hier geboren und ausgebildet wurde (was der berïhmte Kumfthiftorifer niđ̧t gewulizt hat), als fehr wahrjheinlich hinjulfellen. Der f̧önte 2ultar der fieben Saframente des 2reifters, jetż int Zutwerpenter 2lunjeum, ftammt aus der Kathedrale. Jdy will bei diejer Felegenheit bemerken, dafí das Relief, um das es fidh handelt, urfprüng= lid mit Welfarbe bemalt war.

In der Kapelle des hl. Eleutherius im Chormmgang befindet fith jeţt das Grabural der familie Cottrel, datiert von 1380, Jas Waagen gleidffalls befḑreibt.

zran fieht Chriftus thronend in der Glorie, die Weltfugel ju feinen füfent. Jean Cottrel und feine drei Söhne futeen lint's unter dem Sd hut ihrer Patrone, der beiden Leiligen Johannes, Jafobus und Petrus; reḑts feine frau, feine drei 


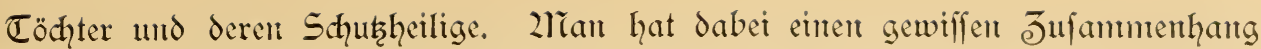
$j^{\text {wiffhen }}$ diefen Lqeiligen und den Einfiedlern auf $\delta \mathrm{cm}$ Zltarblatt des van Eyck in Gent hervorgehobert. Der Stil diefes Reliefs ftht aber fidher dem des Grabmals von Colard de Seclin nady.

Sehr bemerfenswert ift dic Fleine von 14.38 datierte (Frabplatte des Jehan du Bois und feiner Gattin Katharine Bernard (2lbb. 87). Die Jumgfrau, dic das Kint Jefus hält, fitz̧ auf cinem Throu vor einer Draperie, die von zwei Entgeln gehalten wird. Jehan du 23ois, feine frau und feime Toḑter, die iłhre Schutḩheiligen neben

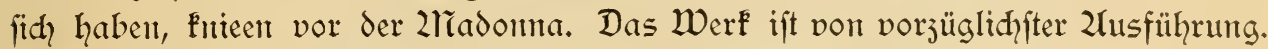

$2 \mathfrak{u}$ हैer den Reliquienfayreinen, die fid im Chor befinden, bewahrt die Kathe= drale in ihrem Sdyaţ eime beträđhtliḑe 2lenge Foftbarer Gegenftände. Sie werden it einem ovalen, von oben erlendhteten Raum gejeigt, wo eine Tapete von höchjtem Intereffe ausgeftellt ift. Sie ift 1402 von Pierot feré in 2lras gewebt, wie dies cin authentifhes Dofument ergiebt. In einer Reihe von lebensvollen für das Studium der Koftüm= und Sittengefḑiḑte der jeit aurerordentlich wertvollen Bildern ift die Segende der beiden Shuthheiligen von Tournai: S. Piat und 5. Eleutherius dargeftellt.

2lls Dofument jum Studium der Kunftgefhidhte in flandern in 2lufantg des 15. Jahrhunderts verdient diefe Tapete neben die 23ilder des 2lielhior Broe= derlam in Dijon geftellt ju werden. Seider hat fie im Sauf der Jahrhunderte

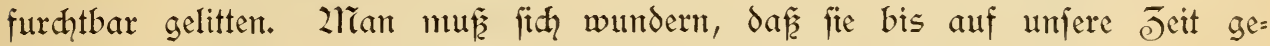
Fommen ift, wenn man bedenf̆t, $\mathfrak{j u}^{\mathfrak{l}}$ weldh niedrigen Jెwecken fie verwendet wurbe. Zritḩt allein hat fie als fukzteppich gedient, man hat mit iḩr fogar die Södher in den Dähern verftopft.

Eeringeres Intereffe haben $j^{2}$ ei andere Tapeten von 1554 ju beampruchen, die die Gefhidhte Jofephs darftellen. Wie die vorher genamten haben fie ange= fetzte Borduren.

Unter den Zoftbarfeiten, die den Zlirdhenfhat angehören, ift in erfter Sinte ein Diptychon aus Elfenbein ju nennen, deffen beide Platten als Einbanddecfe für cine jiemtlich wertlofe liturgifhe Lqandfdyrift verwendet find. 2luf der einen Seite ift der thronende Geiland dargeftellt, von Engeln und den 2lttributen der Evan= geliften umgeben; weiter unten fieht man den GeF́renjigten mit der 2radoma und

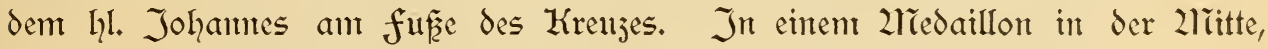
das von Engeln gehalten wird, ift das (Opferlantm dargeftellt. Der andere flügel des Diptychons, der vou gewiffen Kunftperftändigen für jünger gehalten wird, ftellt den hli. Zricafüs jwijhen jwei Diaf́onen dar.

Zlus dem 13. Jahrihundert ftammt ein Reliquienfreuz mit doppeltem Quer= balfen von jarter 2rrbeit, mit Rubinen und Smaragden reidh gejiert, das in der 2lïtte eine Reliquie des ḩl. Licolaus von Bari enthält - auf der Rüffeite fehr Foftbare Ziielloarbeit auf Silber.

Seblyaftes Intereffe crwedert die Sdyatullen, die dent Reliquienfdyrein des hl. Eleutherins entronmen find und von denten cins mit einent Seidengewebe fojt= barfter 2 rrbeit und vorzüglidfiter Erhaltung überjogen ift.

Die logenamute facfel der "Jumfer" (Torche des "Damoiseaux"), einer 
Brüderidhaft in Tournai, ftanmt aus dem 14. Jahrhundert. Sie ift cin fillberner

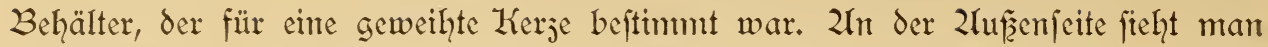
in Reliefarbeit die Wappen der meiften Zlitglieder diefer vorneḩmen Dereinigung. Bei eimigen ift nody die Emaillierung erhalten.

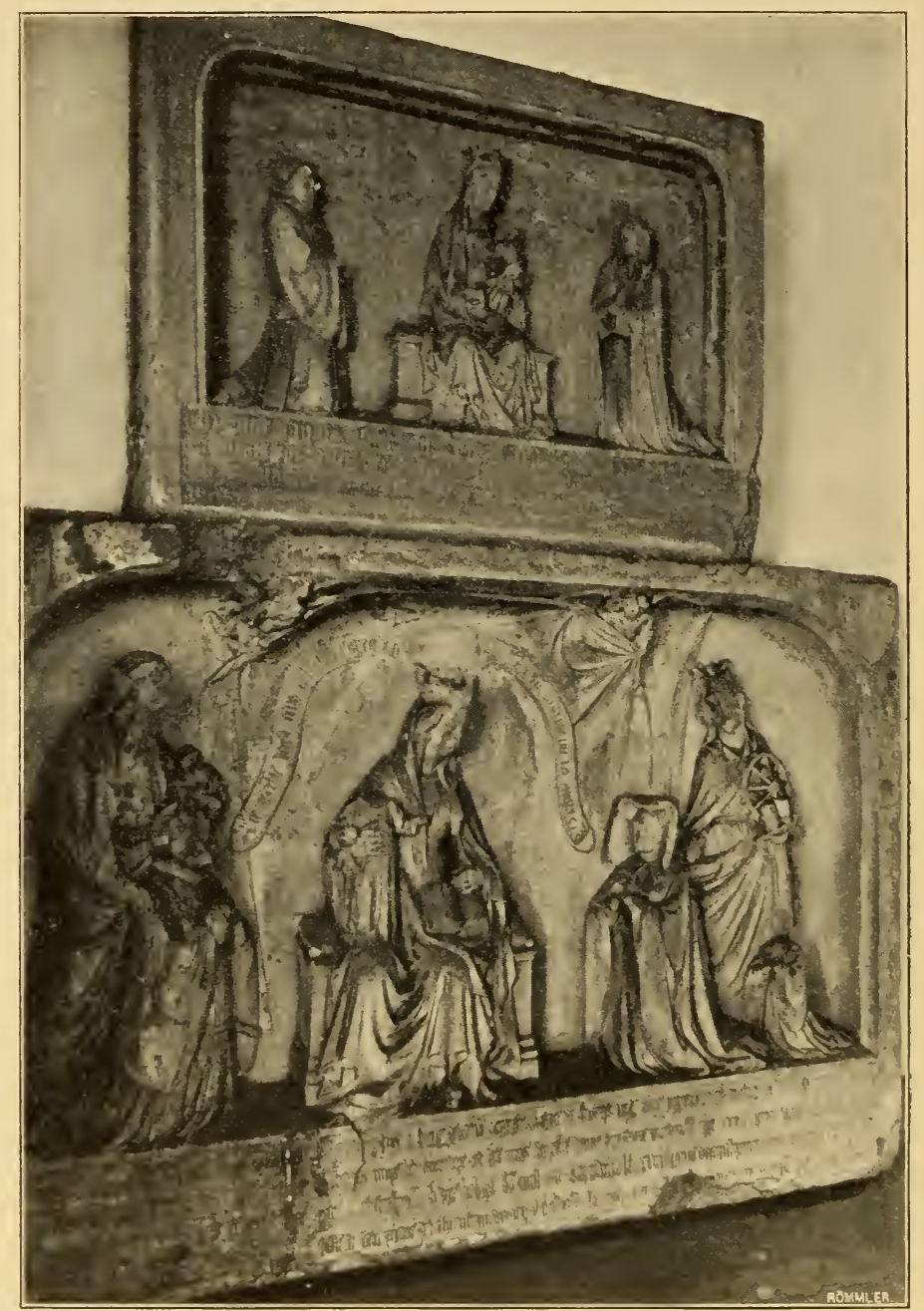

2ubb. 87. Grabplatte des Jehan du Bois und der Katharina Zernard in der Kathedrale.

Eeringeres Intereffe hat vom fünftlerifdyen Standpunfte aus der Reliquien= fąrein und die fahne der "Junfer", die beide aus dem 16. Jahrhumbert ftammert. Ein hübfdyer Pfalter aus dem 14. Jahrhumtert mit feiten 2lïniaturen und

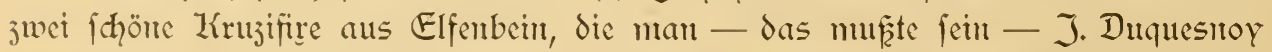
jugefdrieben hat, gehören noḑ ju den nemenswerten Ẽegenftänden, die in der Eafriftei aufbewahrt find.

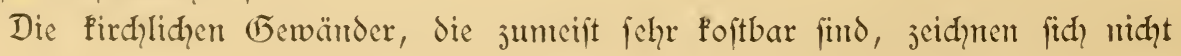


durch hohe Fünftlerifhe Bedeutung aus. Don ganj hervorragender Bedeutung ift - wie billig - das 2liekzgewant des hl. Thomas vol Canterbury von dunkel: roter Seide, olyne anderen Sdimuck als cinen fhönen Streifen von Eoldftoff mit demt als "Paradiesbaum" befaunten 2liotiv. Leute wird diefer koftbare Gegen= ftand im bifhüflichen Palajt aufbewahrt. Er ftammt aus der ehemaligen 2ubtei des hl. Zikedardus.

Ein roter Sammtmantel, der jetzt in cin Pluviale umgewandelt ift, foll von Karl V. bei der Kapitelfitżutg des goldenten Vliefzes, die 1531 in der Zathedrale abgehalten wurde, getragen worden fein. Das praḑtvolle Źleidungsftül", unferer 2reinung nach fpanifden Ulifprungs, ift mit einer Reihe volt fein in Gold cifeliertent Rankenwer' gefḑmüđt.

Der jogenante 2rupiffaal ift ein eleganter Salon im Stil des 18. Jahro

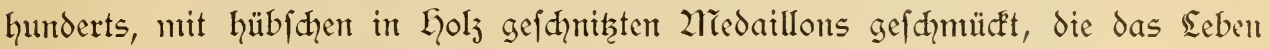
des hl. Ghislain darjtellen.

Lhm die Kathedrale ju verlaffen, gehen wir durd das Zordportal, das aus dent 11. Jahrhundert ftammt und, wie wir fhon gefagt haben, in Toumai unter dem Lamen "Porte mantille" befannt ift, eine wunderlidhe, verfdiedenartig, an

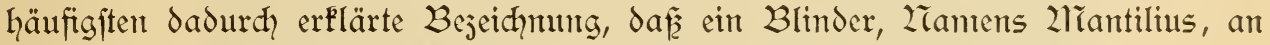
diefer Stelle von dem ḩl. Eleutherius geheilt worden fei (Zlbb. 88).

Wenn es audh verwegen fein mag, fich den Znfithten der gelehrten SoF́al= hiftorifer entgegenjuftellen, fo neigen wir dodh ju dem (5lauben, da ki die volfestün= liche Bencumung des Thores ganj einfach aus deffen form entftanden ift. In der That, der 2liantel der belgifhen frauen int 16. und 17. Jahrhhundert, die "2rante", woher Zrantille fommt, fo wie wir fie in den Stidyen jener Deeit dargeftellt fehen, hat genau die form des Bauteiles, der uns bel häftigt.

Wie dem mun auch fei - die rundbogige Thür mit doppelter 2richivolte, die durch dünte Säuldhen geftüţ̧ wird, ift in eine hohe, Fleeblattförmige Zrrkatur von anmutiger und origineller Zusführung gefafizt. Diefes Portal ift überdies

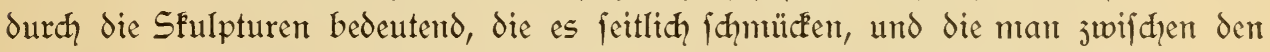
Säulḩen fehen Fann. Dom Standpunfte der DrnamentiF zeigen fie die Zlbhängig: Feeit von normännifhen Stil, und Waagen bemerft, da攴 die dort dargeftellten

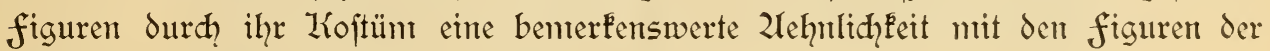
berühmten Tapete von Bayeur jeigen (2łbb. 89).

Die Greftalten, die auffällig in die Sänge gejogen find, jeigen eine fehr ins

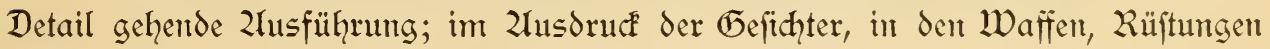
und der Gewandung. Da ift namentlid ein Krieger, der fid hinter einem grofzen Sdhild verftefft, von außzerordentliḑer Wirfung.

In den Kapitälen der Säulḑen verbindet fith die menfdyliḑe Geftalt mit einer Ornamentif́, in der fich eine bedeutende Phantafie offenbart. Wir Fönnen die fymbolifhe und emblematifhe Bedentung nidht ergründen, fondern wir be= gnügen uns damit, fie, ebenio wie die ganje đh̆̈̈r, der genaueften Beobad̨̧tung des Kunfthiftorifers ju empiehlen.

Wir Ghreiten die Stufen hinab, die von dem Thor nach dem 2läajienplats

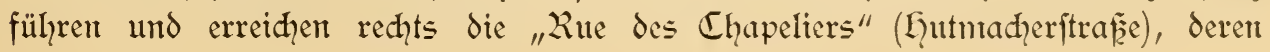


Biegung fith gewiffermafien nady der 2lpfis der Kathedrale geridhtet hat. Die Derwirflichung der freilegung des Domes würde leider aud? dic Ziederlegung eines Teiles diefer malerifhen Straje mit ihren anfpreḑenden faffaden herbei= führen.

2liehr als ein jierlicher Giebel, mehr als cin ḑarafteriftifhes Wahrzeiḑen fällt uns in die Zlugen. Fin Drahe aus vergoldetem Kupfer fdhmüaft 2rr. 33.

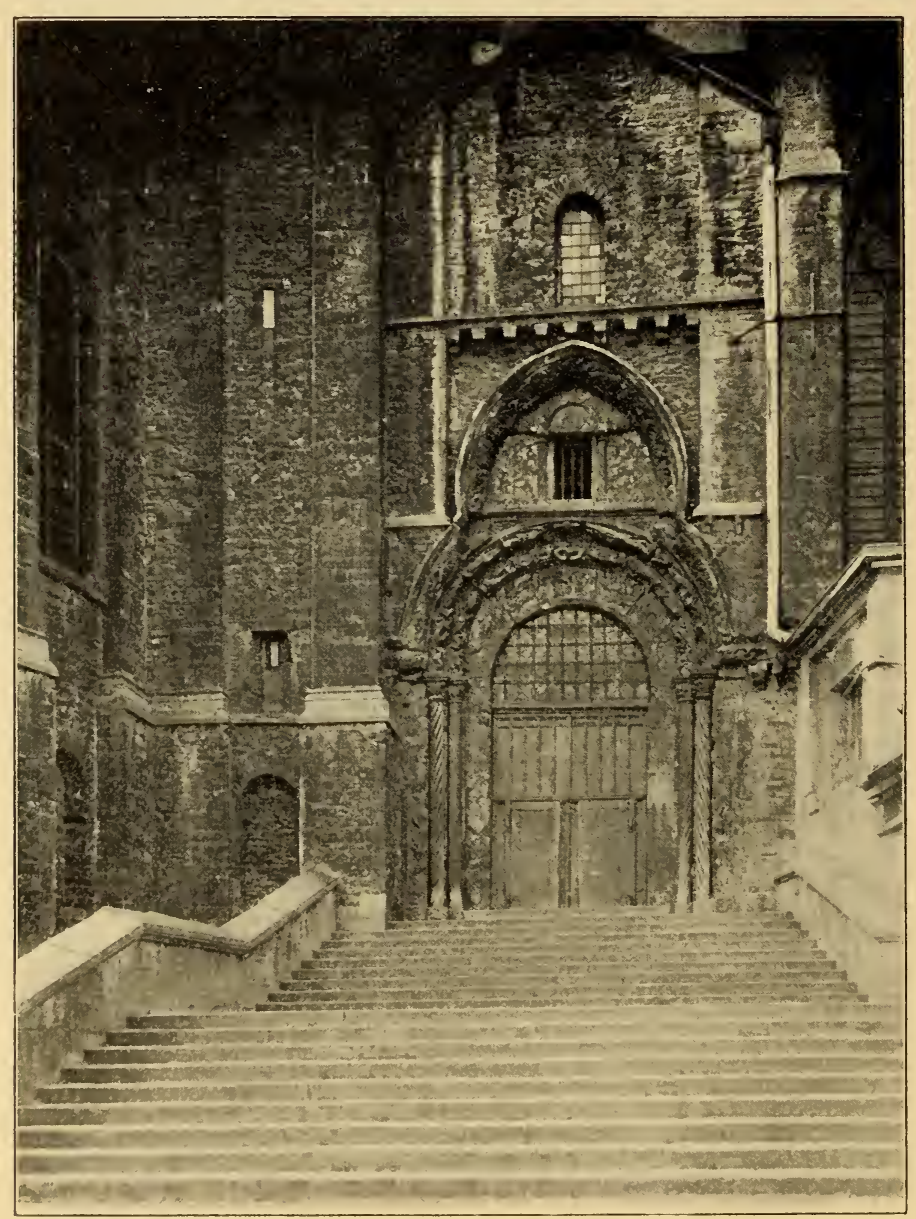

2lbb. 88. 27ordportal der Kathedrale, die fog. Porte Iltantille.

Diefer Stadtteil ift iibrigens aufererordentlid alt, wie es die Lutterbauten be=

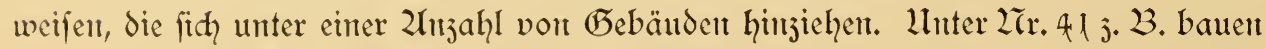
fich drei Stocḱwerke von Zellerräumen überemanter auf, von denen das unterfte aus dem 12. Jahrhumdert ftammen foll.

Die Rue des Chapeliers, die fich ftar" fenft, fteht fenfredht auf der Parifer Strape, wo fidh hie und da dharafteriftifdye faffaden zeigen und merfwilrdiger= weife ein dreiftöffiges $\mathfrak{L}$ aus $(\mathcal{L}(r .25)$ alle Wandlungen überdauert hat, ein Lqaus 
mad) vlämifdyem, fogar nad, Brïgger Typus, das, wie mant antehmen mur, in der Dergangenheit nidyt eine folde Zusmalume gewejen ift (2lbb. 90).

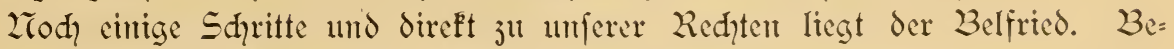

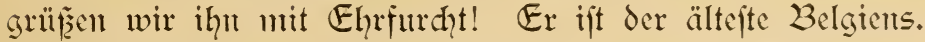

Er fteht ganj frei von allen benaḑbarten (நebäuden, und diefer ehrwiurdige Jenge vergangener Jahrhunderte nimmt die Spitze des gleidffientigen Dreieds

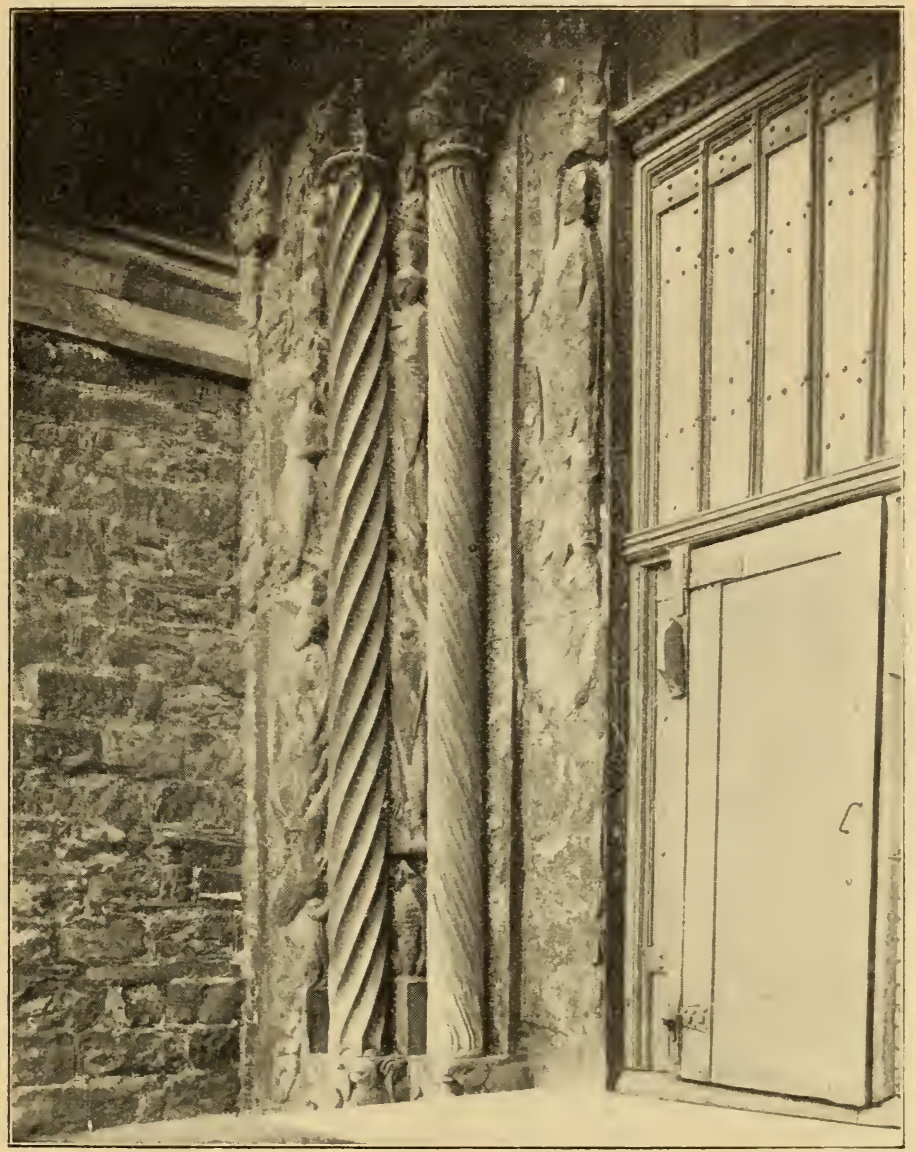

21bb. 89. Einzelheit von der Porte Mantille.

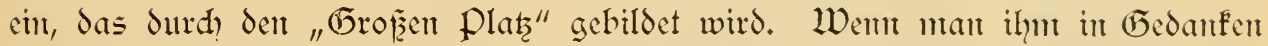

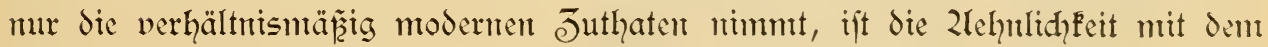
Belfried von Gent offenbar. Keineswegs von 2lnfang an, weil die mäd̨tigen Strebepfeiler bis jur erften Ealerie gingen und cine cinfadge Saterne für den Wädhter den Glocfenturm vertrat. Im 13. Jahrhundert verfah man ihn mit

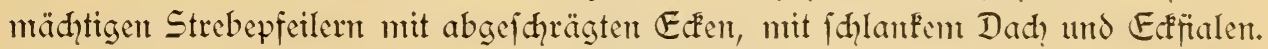

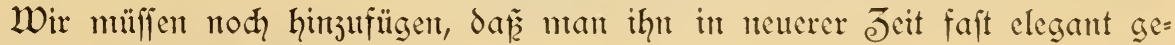

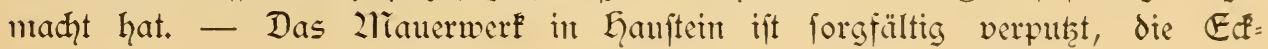




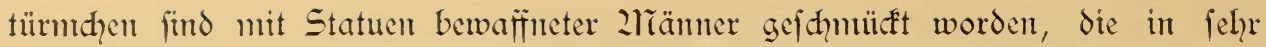
modernen Sim aufgefa fźt find; ein fteinerner 23 alfon mit durḑhrochenent vierblätt= rigen Ornament jieht fid um die erfte Galerie. Die Spifze fđ̧lief̧lid wurde mit einem neuen Ziupferdrachen befrönt.

Die Gefanthöhe des Belfrieds beträgt 72 2leter; die veriḑiedenen Stoct" = werke find durd gotifdhe fenfter erleuḑtet. Wir fagen Stockwerke, denn in der That, wem der Turm and mur jwei Galerien hat, von denen die 'jweite, die fidh am fur des Glocfenturms befindet, bis ju 50 2reter Gqöhe reidhen mag, fo finten fich doch in verfhiedenter $\mathfrak{G}$ öhe gewölbte Räume, die als Gefängniffe gedient haben, fogar bis in die Mittte des 19. Jahrhunderts.

Wenn man endlid auf 256 Stufen aut den fur des Glockenturms gelangt ift, findet man den Wähhter, der das 2Imt hat, die feuersbrünjte anjumelden, tags ourd cine fahne, nadyts durd eine Saterne. Die 2luspidht auf die Stadt wie auf das umliegende, von der Sdyelde durdyfloffene Sand ift wunderfḩ̈n. Der Blike auf die ganje Kathedrale hingegen ift wentiger günftig als der von dem Turm S. Brice (21bb. 62).

Der Belfried bejtz̧t ein fhönes Glodenfpiel', das jedod viel jünger ift als die Glocken, von denen die gröfzte, die "Bautloque", 1392 gegoffen, das Volf ju den Waffen rief. Eine jweite Glocke, der "Timbre", aus derfelben Jెeit, giebt

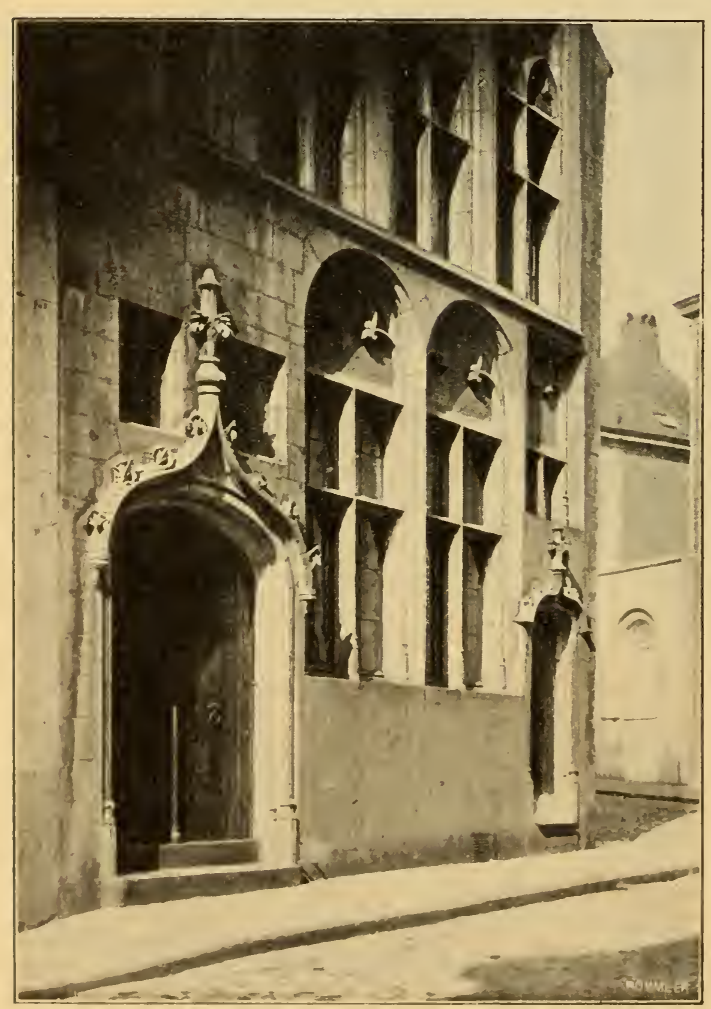

2ub. 90. Lqüs in der Rue de paris. die Stunden an und ift der feuer= melder. Der "Digneron" iḑlię̧lich ift lqente wie im 2rittelalter bie Flocke, die jur 2lrbeit ruft.

Die ungewöhnliche Geftalt der Grand' Place von Tournai foll nadh der 2Infiḑ̨t einiger Sdyrift= fteller Jurd das כ̄ufammenlaufen von jwei rönif ḑen Straf̧en ent= ftanden fein. Der Standpunft des Belfrieds, von wo aus das 2luge den Platz in feiner Gefamtheit umfaffen Eant, liefert jedenfalls den Beweis, da er er fid feit Jahr= hunderten nidht geändert hat.

Die norblidhe, das ift die rechte Seite, went man dem Belfried den Rücken fehrt, bietet fein mommentales Intereffe. zridgt fo die anderen Seiten des Dreied"s.

Sint's reihen fidd näntlid fdüne, alte 23 auten ameinander, die cinen paffenden Rahmen für die jierlidye Tudhhalle, bilden, die 
heute als zlüneum für 2lìalerei und Zlltertunsflunde dient. Diefe ganje Seite mit ihrer Derlängerung, der Ruue des 2lieaur, hat weniger wie die andere durd die aufeinander folgenden zliodernifierungen gelitten. Sḑlief̧lid tritt als Bafis des Dreiecfs, inmitten jienlidh eleganter faffaden, die Kirrhe St. Quentin hervor, eine der älteften in Tournai.

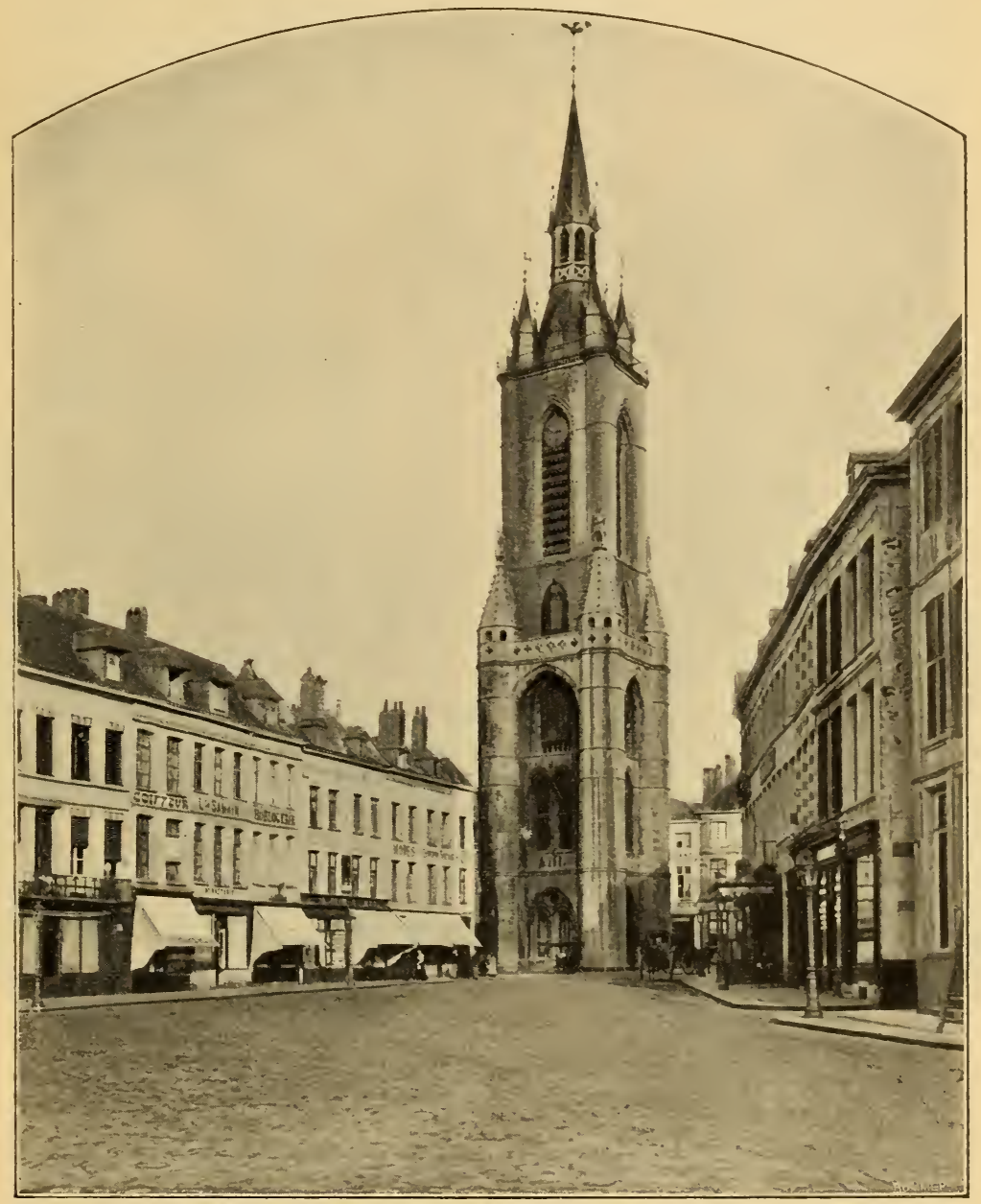

2ubb. 91. Der Belfried.

Die Bronjeftatue der Prinzeffin von Epinoy, Ehriftite von Salaing, die fid? in der 2ritte des Platzes erhebt, hält die Erinterung an die Geldin wadh, die während jweier 2lionate die farnejifhen Truppen in Sdyad jull halten wuËte.

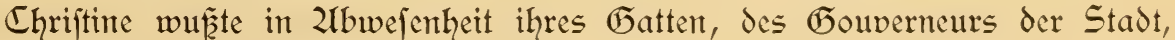
fo fehr den 2lüut der Einwohner ju beleben, dafiz fogar die frauen und die jungen 2rädchen an ihrer Seite auf den Wällen fämpften.

Eine Zidhte des Grafen von Lloorn, widerftand fie den Spaniem mit cinter 
wahren Wut, obwohl fie in den Reihen der feinde einen Bruter und einen Eđhwager wurzte. 2lit ihnen hatte fie ü̈ber die Kapitulation ju unterhandeln (50. 2Tov. 1581), nachdem fie 23 Käntpfe ausgehalten mo mehr als cinen mörde=

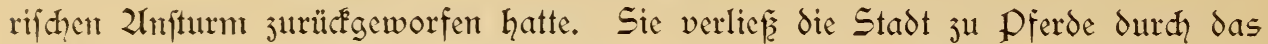
Et. Zliartinsthor an der Spitze der Befaţung mit fliegenden falqnen. Der fall Tournais gab ihy den Todesftor. Wentige 2ronate fpäter, ant 9. Juni 1582, ftarb fie in 2lutwerpen, wohin fie fidh jurill"gejogen hatte.

Die Statue, die 1863 enthüllt wurde, ift das Werp eines einheimifhen Künftlers, 21. Dutrieur. Jlgre hauptjächliche Bedentung liegt in der Erinterung,

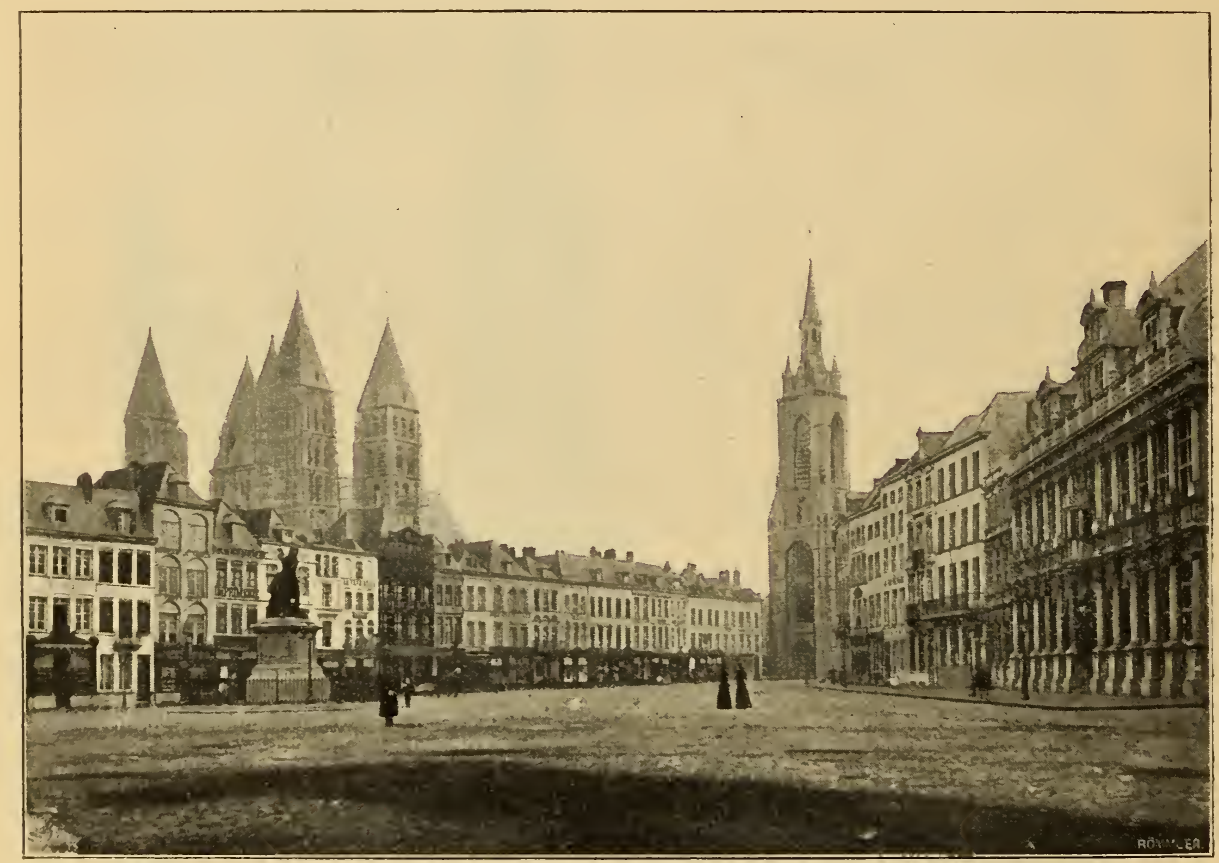

2lbb. 92. Die Grand' Place.

die fie waḑruft; unter beftimmten (befihtswinfeln gefehen, jeigt fie eine ausdrulfs= volle Silhonette.

Die IKirche St. Quentin, die mit ilyrer faffade faft vollitändig an der Weftfeite des

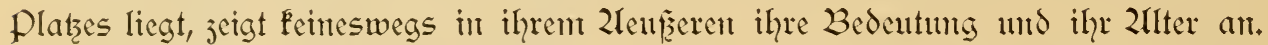
Sie ift int 12. Jahuhundert erridytet unt jum grofent Teil romantif gewefen, aber fie hat fich int Saufe der Jahrhumberte fehr beträdytlidh verändert. 2luf den erften 3 lite wiurde es fquierig fein, den $23 a n$ ju datieren - der allgememe Ein= druct würde juerft an irgend cinte anglifantifhe IKirche denfent laffen.

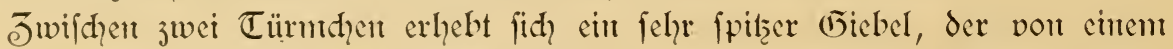
Irenj überragt wird und jwei Stocfwerfe mit fehr hohen und engen gotifdyen

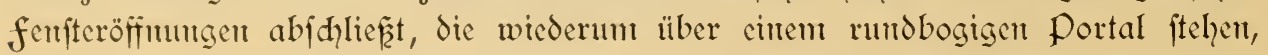
das vom Jahre 1845 datiert. 
Das Jumere maḑt durd, feine ungewöhnlidyen, feineswegs reizlopen Dis= pofitionen cinten grofacu Eindrut?.

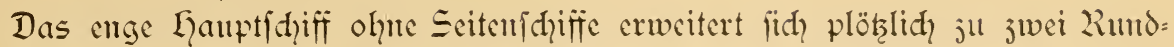

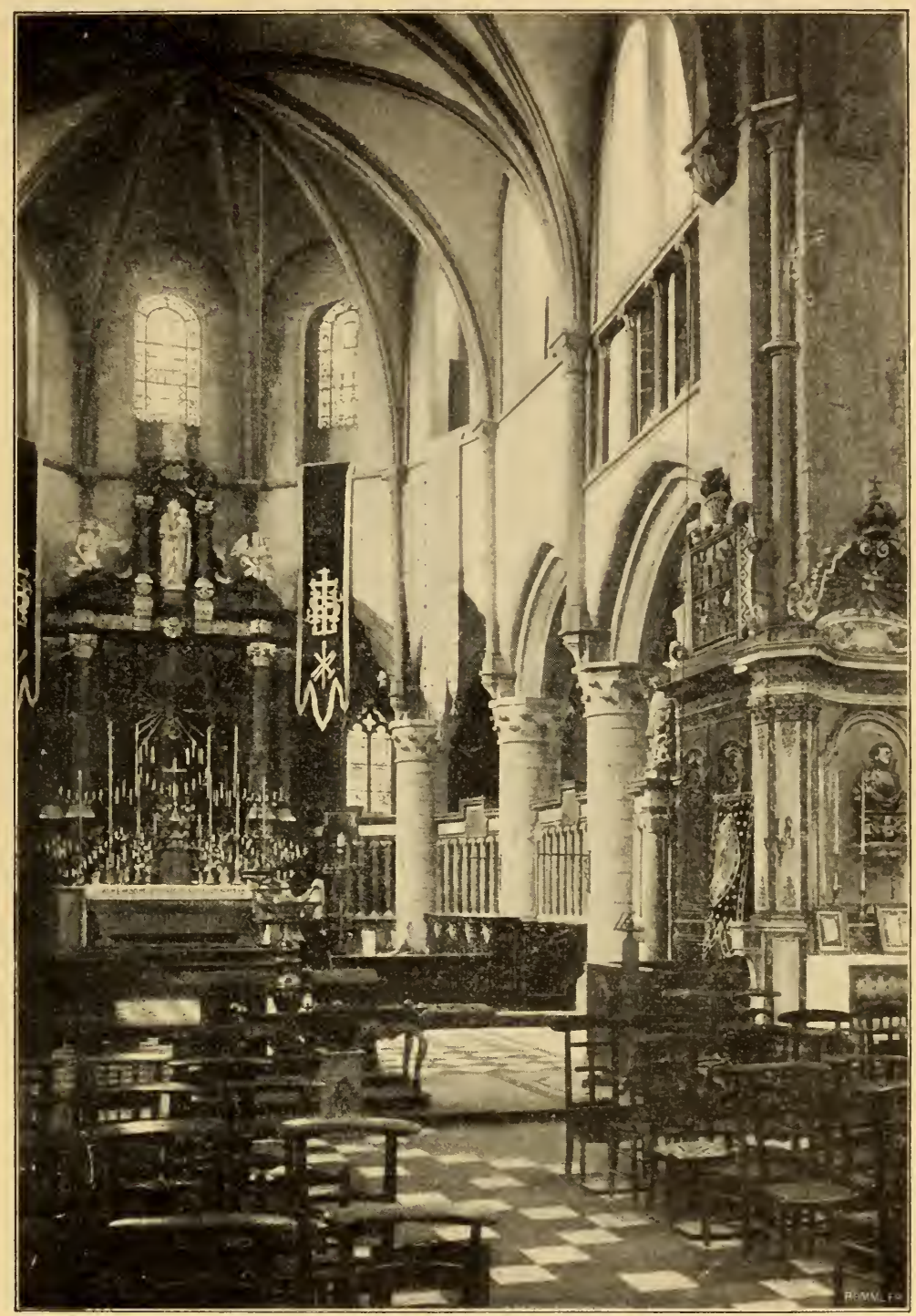

มbb. 93. Interes vou St. Quentin.

Fapellen, die fith an der Kreuzung des Furzent Querfhiffes befinden, das fich mur wentig über den romanifhen Chor erhebt.

Diefer Chor wurde im 16. Jahrhundert Surd einen Chorumgang vervoll: ftändigt, wohin orei aušen angebaute, abfidenförmige Zapellen fiđ̆ öfinten. Die Bogenftellutigen diefes Llmuanges geben ein malerifhes $B$ ild. 


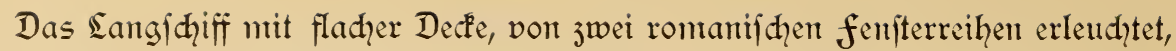
erḩ̈ht die eigenartige Wirfung aukerordentlich.

Ein 2rarmoraltar aus dent 17. Jahrhundert erhebt fidh am Elyoreingang. Da a er mit dem Stil der Kirche nidht übereinftimmt, brauht Faum hervorgehoben ju werden. Und doch hat der 2lnbliaf, das müffen wir geftehen, nichts Unan= genehmes.

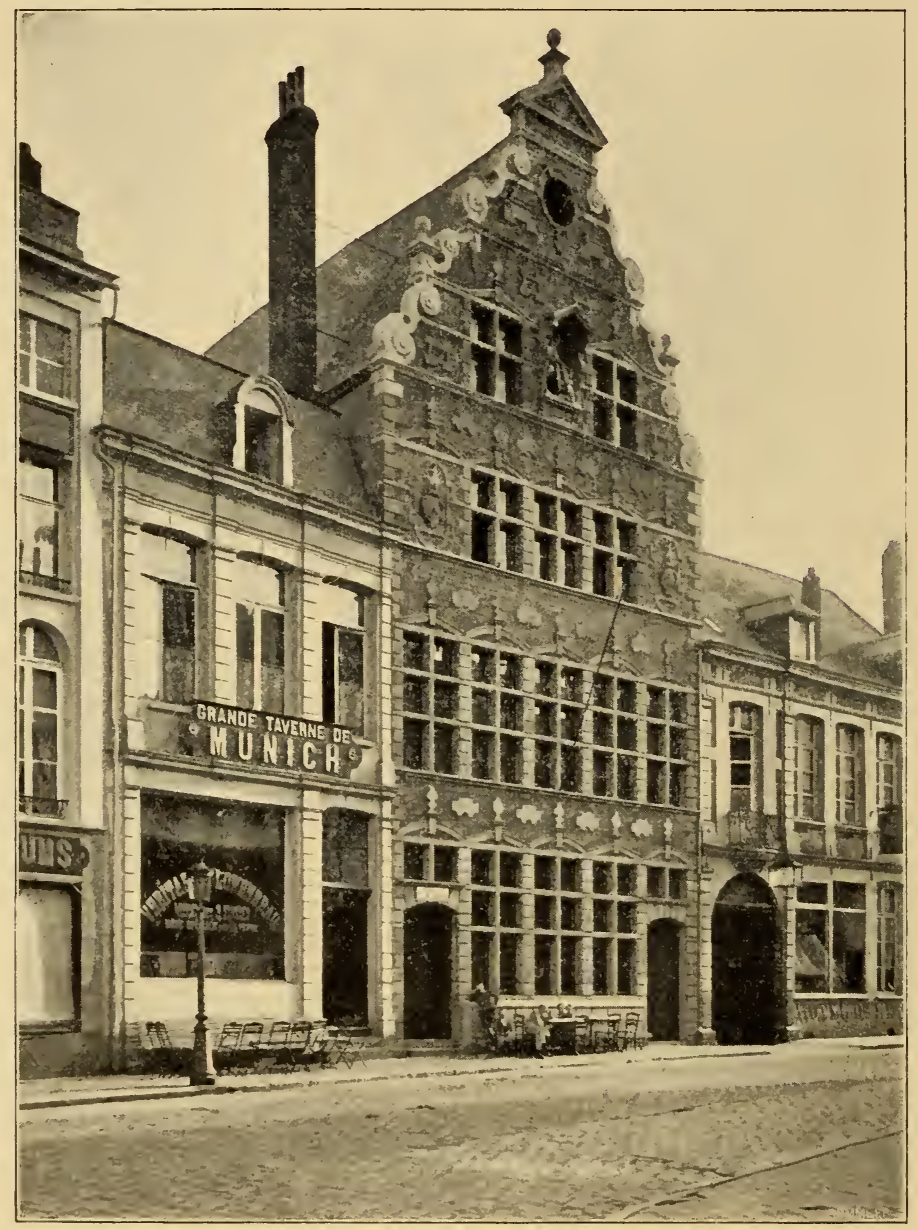

21bb. 94. Liaus des 17. Jaḩrh., "Café des Brasseurs", int der Kue des Mreaur.

Der Teil, woran der romanifhe Llriprung ganz Flar hervortritt, ift das breite Querfhiff mit fladhem 2lbjhluf́, wo fid cine Rojette über jwei gotifḑen fenfteröffmungen befindet. Dier gut ftilifierte Dfeiler, von Säuldhen cingefä̌t, tragen die Saterne.

Jm Chor vermifhen fid runbbogige fenfter mit den gotifḑen Bogen des Umgangs und den fenftern in flamboyantfitil, die ihn beleuchten.

ơ diefer bizarren Stilmifhlung fommt nodh eine marmorne elegante 
Chorfhranfe, die fith um das ganje Sanftuarium herumbieht. Einer 2lia domenftatue endich dient als Lififhe das fenfter im Eintergrund; fie hebt fith $10=$ mit fehr Fräftig vor dem lichtwollen Frunt ab. Diefe Juf ammenftellung ift jient= liḑ häufig, befonders in den Ziapellen, die von frauen befuḑt werden. Sie ent= ipricht fitherlid nidht dem Erufft des Drtes.

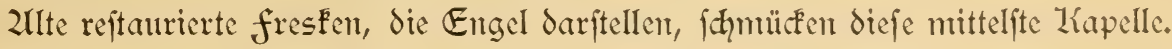

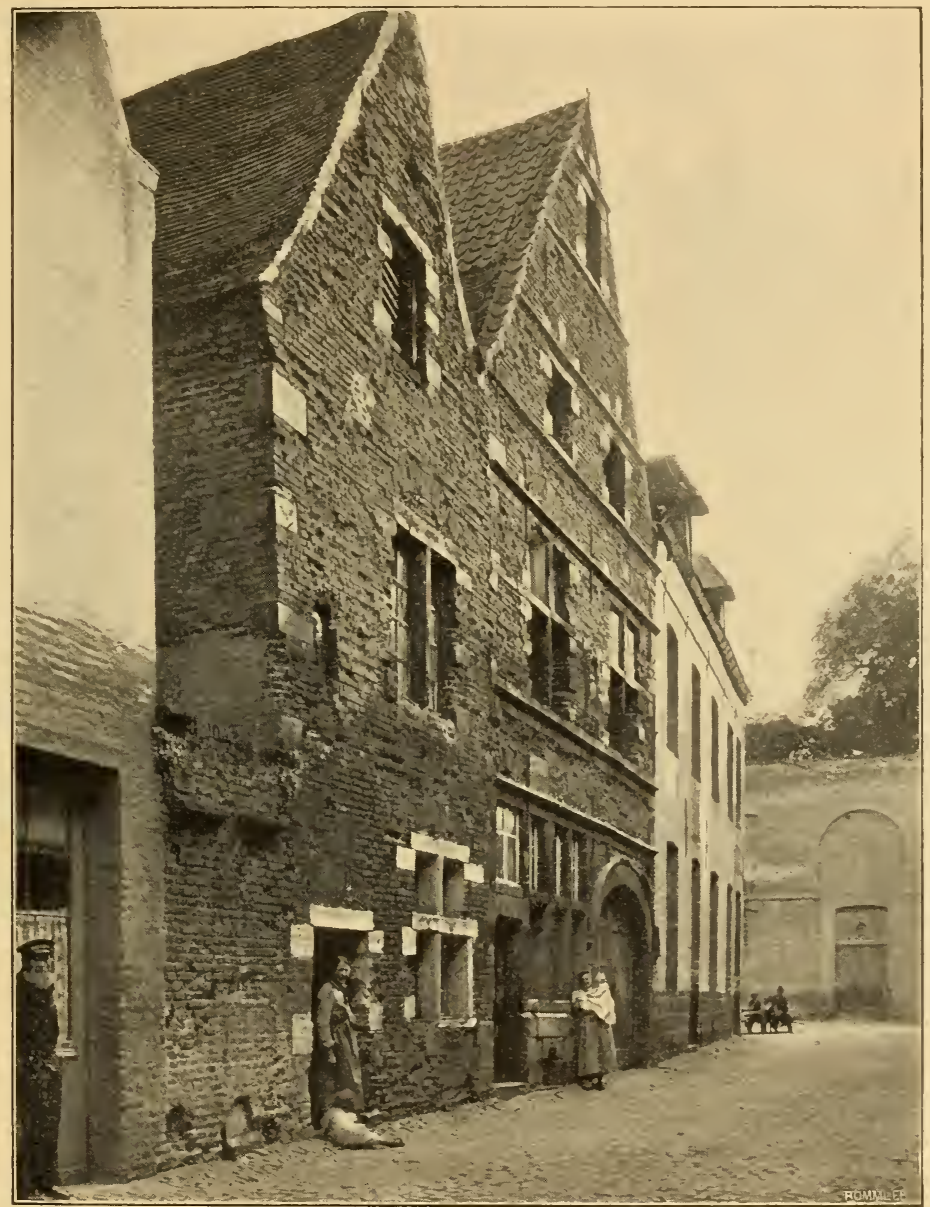

2łbb. 95. Liéduit des Sions.

Die Šlasmalereien fint modern, von den in der Kirdhe jerftrenten Gemälden jeichnet fith Feins Jurdh Fünjtlerifhen Wert aus.

Es ift niḑt ohne Intereffe, nebenbei die Kapelle ju nenten, dic feit demt 15. Jahrhundert der lieben frau von Gal (in Brabant) geweiht ift, deren Brïberichaft nod heute criftiert.

Inter den falfaben, die man in derfellen sinte mit der Ifirche fielyt, ift mur ein cinjiges Laus, das „le Porcelet" (bas Sḑweinchen) genant wird, mit feinem 
abgetreppten Giebel und feinen wedhjelnden Sdhidhten von Bau= und Bacfitein intereffant. Es ftammt aus dent 17. Jaḩrḩundert.

Dic Südfeite des Platzes aber, genauer ausgedrülfit die klue des 2lieaur, cr= fordert grök̨ere Zlufmerffamf́cit.

Wir finden hier unter 2ir. 10 das "Café des brasseurs" (Der Brauer) aus dem Jahre 1633, einen eleganten Typus jener Jeit. Das Bild des hl. Zliartin, das

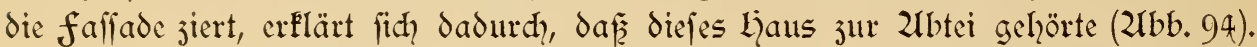

In dem daranjtokenden Gaufe, damals wie heute "Das hotel jut Kaiferin", wohnte Kaifer Jofeph II. auf feiner Reife in dem Ziiederlande 1781.

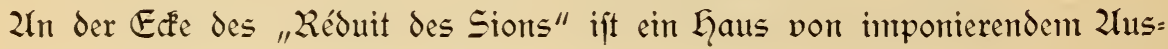

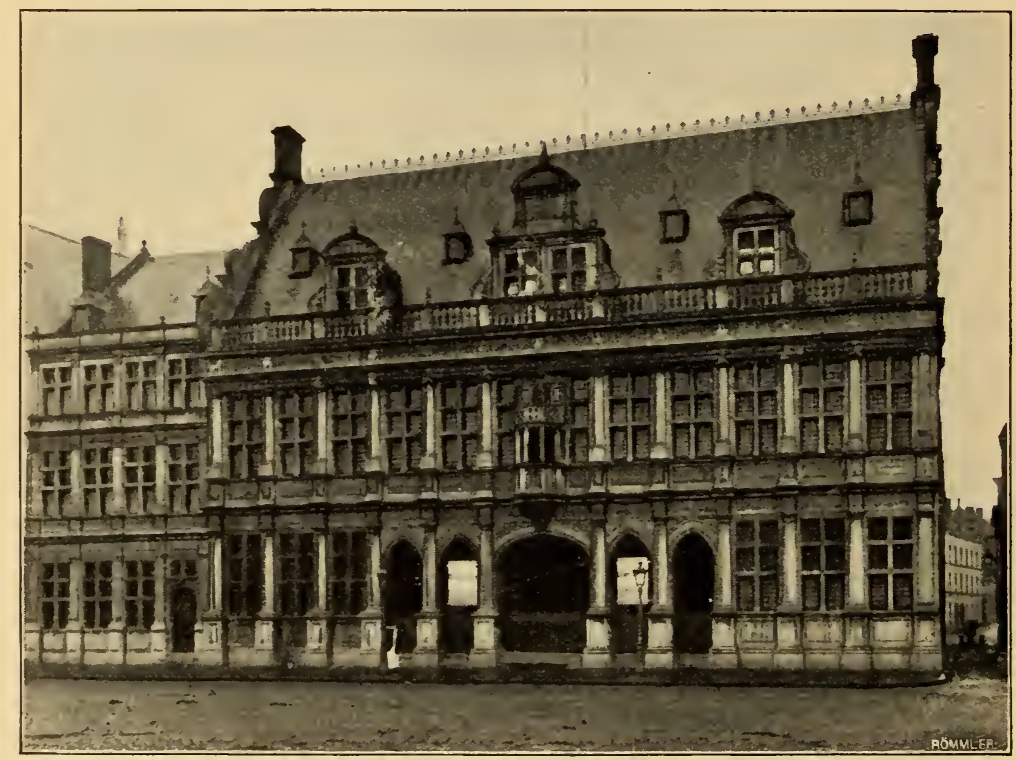

2ubb. 96. Das Mứeum (eḩemalige Tuthhalle).

fehen, in Gauftein. Es fülyrt die Ziummer 69 unt war ehedem Sitz der Vogtei. Seine drei übereinander gebauten Keller haben früher als Grefängnis gedient.

Diefer "Rébuit des Sions" weift Bauten auf, die unter die intereffanteften des alten Tournai ju rechnen find. 2ir. 14 und 16 in Badfitein und mit fteinernen

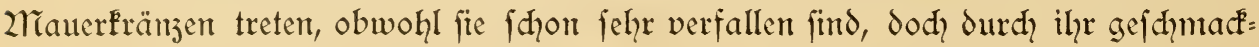
volles 2lusfehen in eimen jtarken Eegenfatz ju der banten Dhyfiognomie der jüngeren Läujer (2łbb. 95). Wie man uns fagt, werden fie in nädhjter Jeit verfḩwinden, dantit man den 2 Unforderungen einer jener Strafenregulierungen entfprechen Fönte, vor denten weder der ardhiteftonifdye Wert nod, die gefdidhtlidhe Bedeutung Gruade findet.

Die Jean Kammart=Stiftung - für fieben Witwen - die diḑt daneben liegt, geht auf 1540 zurür. Tournai ift reidh an biefer $2 \mathfrak{r}$ t von Stiftungshäujern,

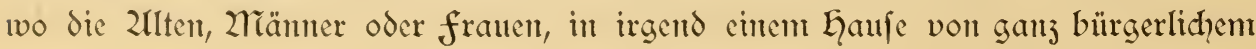


Zusfehen in Gemeinfanteit leben. Jumer nody an derfelben Seite des Plakes

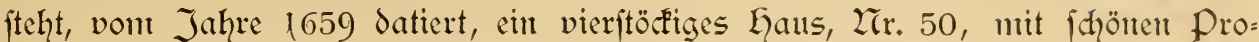
portionen und vornehmen Sinten. Eine hübfhe Thür mit vortretenden Dilaftern

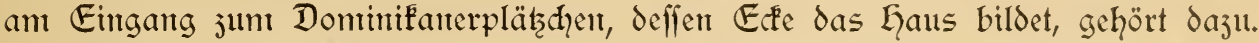

Die ehentalige Tudhhalle, das heutige 2lujeum, ift cin bemerkenswertes Beifpiel der niederländifhen Spätrenaiffance. Das Gebände ftammt ans dem 17. Jahr=

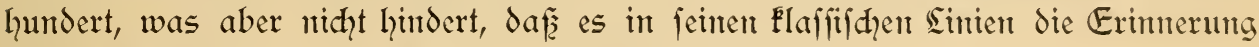
an die Rathäufer vort 2lutwerpen und Eent wadhruft.

2län nent als Erbauer der Tuḑhalle Quentill Rate, mit deffen Zanten fich unferes Wiffens Écine nemtenswerte Zrrbeit verbindet.

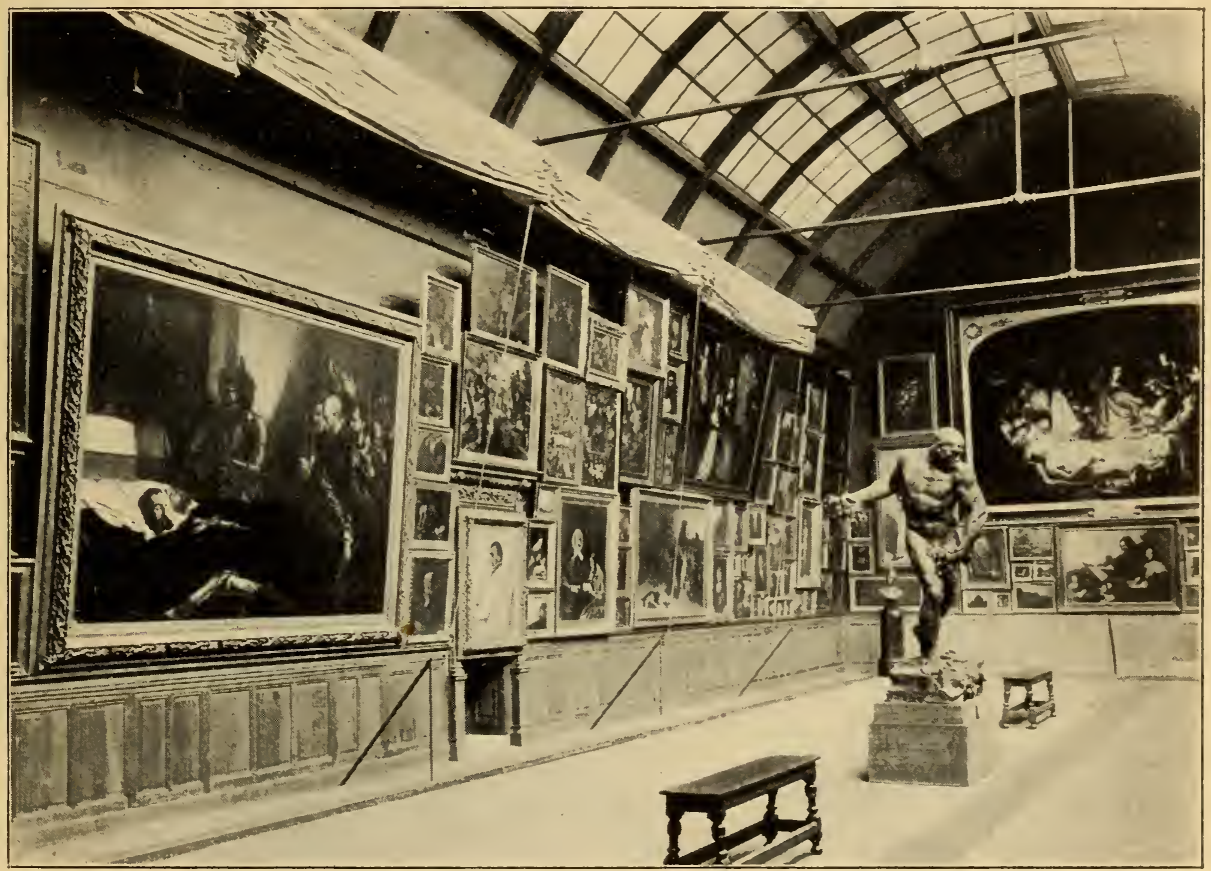

2ubb. 97. Die Bemäldefammluntg des Mufeums.

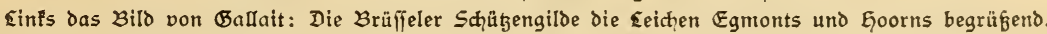

Die ganz aus Gauftein beftehende faffade mit eiment einjigen Stockwerk hat

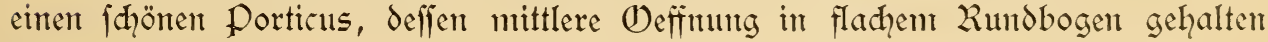
ift, während die vier Seitenöffmungen gotifh find. Die rechteckigen fenfter mit doppelten Querarment find von dorifhen unt iontifhen Lalbä̈ulen auf façettiertent Bajen flanfiert. Der 2ltittelteil trägt eine elegante Tribüne. Sdylief̧lidh, um das

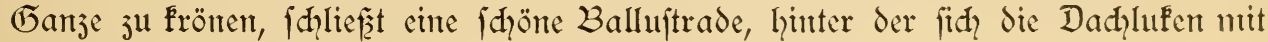
jierlichen Umrişlinien abheben, das Kranjgefints ab.

Fine lange Jeit aufgefdrobene Reftauration wurde endidh 1881 unter= nommen, aber der Jujammenfturz des Gebäudes wentige Wodhen darnad, drohte diefen ehrwürdigen Jengen der Dergangenheit von Tournat tur nod in der $\mathbb{E}_{\mathrm{r}}=$ intuerung weiter leben ju laffen. STlïclidherweife ftimmte diesmal die öffentlidhe 
2licinung für den Wiederaufbau. Diefer wurde nit der größzten Sorgfalt und der

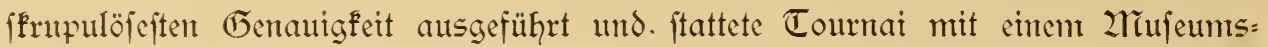

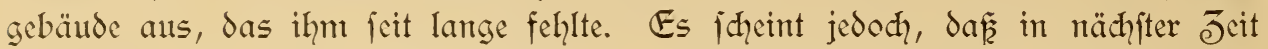
Dergröfzerungen nötig werden dürften - vielleiḑt wird fidh die Stadt genötigt

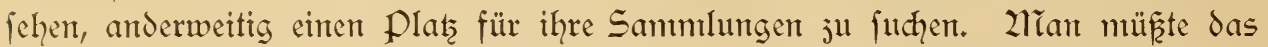
lef̧tere eher wünfhen, als da zas 2lusjehen des jetzigen 2rujeumsgebäudes durh Zlnbauten Deräıderungen erlitte, die feinen Eefamtcharafter entftellen würden. Eidfer ift, da bie Sammlungen fehr eng fteher.

Da fie vom Standpunfte der Kunft wie von dem der Gefhidhte intereffant fint, wären fie es wert, einen größzeren Ruf ju haben. Die Kunft nimmt in ihren veridhiedenen Exfheinungsforment eine bedentende Stellung in der Sefhidhte von Tournai ein.

2luęer der widhtigen Bildhauerfhule, deren wertvolle Bethätigungen wir auf jedem Sdhritt unfrer Wanderung durdh die Stadt bemerken, Fenten wir durd, vielfach benühte Quellen die frïhycitig erworbene Bedeutung Tournais für Cifelier=

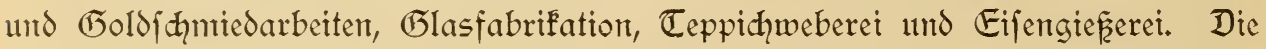
Keramif von Tournat wetteiferte im Saufe des 18. Jahrhunderts mit der von Sèvres.

Was die zlialerei anbetrifft, fo ift es, obwohl uns die ungewöhnlid reidh= haltigen Stadtarḑive eine 2lienge von Künftlern Fennen lehren, abgefehen von einem, der ju den gröfžten gehört, Rogier de la Pafture, befannter unter dem ZTamen van der Weyden, bis heute niḑt möglich gewejen, ein $\mathfrak{W e r k}^{\not}$ an irgend einen Künftlernamen, die in den authentifhen Quellen feit dent 14. Jahrhundert angegeben werden, ju Enüpfen.

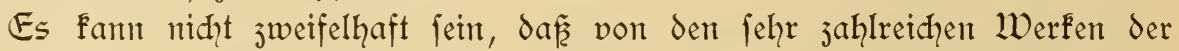
2raterei des 15. Jahrhunderts, die bis anf uns gefommten find, Toumai einen bedeutenden Teil für fich in 2Infprud nelymen darf. Unglünflicher Weife find diefe Bilder anonym. Sediglich durdh cinen J̈ufall hat ntan die Kerfunft des van der Wepden aus Tournai Fenten gelernt, der fo oft Roger von Brügge genannt wird; und der Jufall wird uns aud jweifelsohne auf die Spur weiterer Beftimmungen

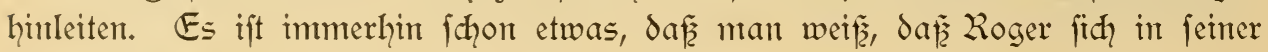
Daterftadt und unter Robert Campin ausbildete.

Das 2liufeum von Tournai ift übrigens nidyt reich an frühen Werfent und Feins davon ift von Bedentung. Der Katalog läpzt unter den Werken Rogers de la Pafture eine Zreujabuahme figurieren, in Lalbfiguren, deren Kompofition wohl von dem 2reifter herrïhren, deren Zusführumg aber niđht von ihm fein fant. Es handelt fith hier nur un eine der jahlreidhen Laḑ̧bildungen eines ver= loren gegangenen $\mathcal{D}$ orbilds, deren befte fidh unferes Wiffens int llufeunt von reapel befindet. Eine bemerfenswerte Geftalt des hl. Donatian, der das mit Sidhtern beftedte Rad hält, fheint uns mehr Zlured ant die ruhmwolle Ulrheber=

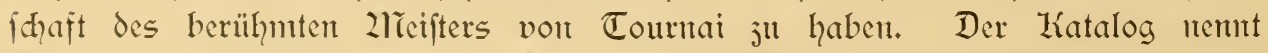
(5ofliart oder Zellegambe; wir fömten weder bie Land des einent nod die des altderen darit erfeement.

Johantes predigt vor cinter Zrizahl vour Gläubigen vou "Dan der 50es", ift vort dem Ziöluer 2licifter, der der 2lieifter der hl. 23artholomäus 
genant wird (2łbb. 98). Die Caufe Chrifti von Patinier ift eine Kompofition von 2liartin Sdyongauer in einer erweiterten Sandjhaft.

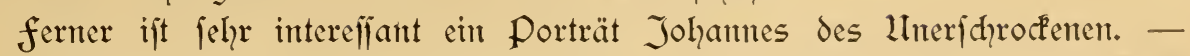
Die heilige familie, die der italienifhen Sdqule jugeteilt wird, ift das Werk

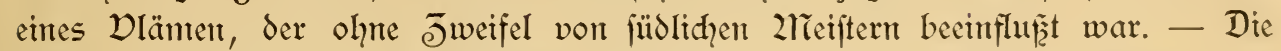
Sdneelandfhaft ift ein fragment, vielleiḑt eine Kiopie nadh dem Drigital des Bildes vom alten Pieter $\mathfrak{B r e u g h e l , ~ i m ~ 2 r u j e u m ~ j u ~ W i e n . ~}$

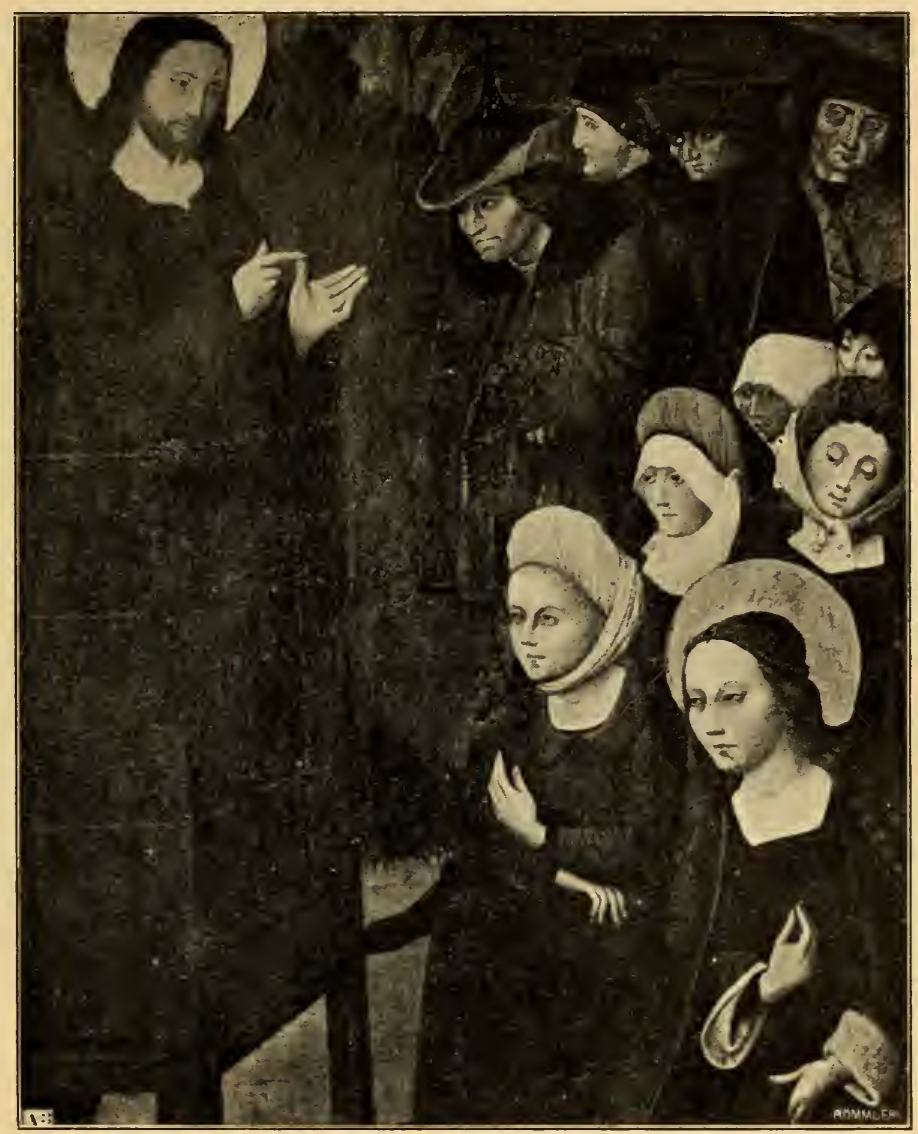

Ubb. 98. Johannes predigt Glänbigen. Dom Meifter des hุl. Bartholomäus. Mufeum.

Don Pieter Gluys ift wahridgeinlidh das merkwürdige Bild, das den Blaje= balgflider darftellt. Fin fehr intereffantes Bild ift aud die Jungfrau mit dem Kinde im Gejhmad des Sancelot 3 londeel.

Die Reihe der beftimmten 2lieifter weift mehre als ein intereffantes (tos: mälde auf.

Ein familienporträt in grofenen figuren, Seander van Dalen bejeiḑut unt vort 1649 datiert (21bb. 99), ift vielleicht vort dem Sḑüler des Paul de Dos, der als Sancelot van Dalen in der St. Sucasgilde in 2Untwerpen 1636-37 eingetragen war. Zlaag es fich übrigens um Sancelot oder Seander lqandeln, Éeiter von beiden 
ift bis auf den heutigen Tag durdh irgend eine andere Sdÿpfung als dicfe hier befannt. Ein bedeutendes fleines Stilllebeit von David de Feent, eins der feltenen Werke des 2lieifters, ein anderes jhöntes Stillleben, Joris vall Son bejeidhnet; ein Bild, fifhe darftellend, fehr bedeutend, trägt die Signatur des $\mathfrak{S}$. de Stoop, eines fehr feltenen 2lieifters; tote $\mathfrak{D}$ ögel von 2loriaenffen mit der Jahresjahl 1642; ein gropeses und jehr gutes famtilienporträt von Theodor van Thulden; eine jehr hübiche 2liarine von Bonaventura Peeters u. T. w.

Unter den fpäteren 2Teiftern finden wir $\mathfrak{S e}$ Brun mit einem grof zen Reiter= bild Sudwigs XIV., Gyacinthe Rigand mit einem bemerkenswerten Porträt des Bifhofs von Saint Zllbin, das übrigens von Sdhmidt geftodhen ift, das eirjige

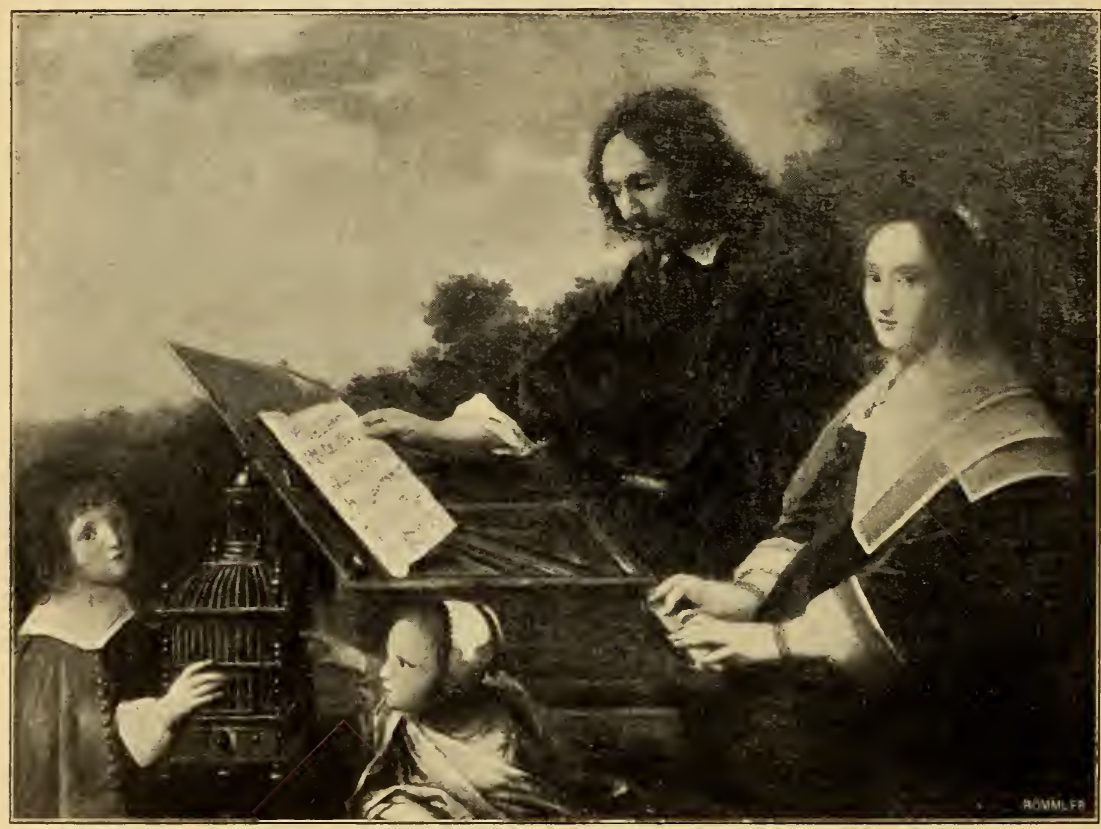

2bb. 99. familienbild von Seander van Dalen. Minjeum.

Gemtälde des "franjöjif hhen van Dyct" in Belgien (2lbb. 100); veridhiedene hübidhe Bilder von Souis Watteau, dem fogenamten Wattean von Sille.

Die zeitgenöffifhe Zhunft nimmt einen bedeutenden Plats im Riufeum von

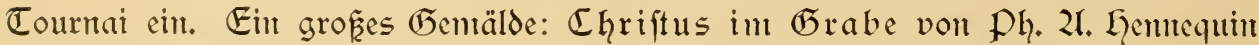
verrät den Einflur des Künftlers auf Sonis Gallait, feinen Sdhüler.

Don dem letzteren jeigt uns die Galerie in Cournai eine benterfenswerte Sammlung von WerFen, die beinahe aus allen Epodyen der $\mathbb{E} a u f b a h n$ diefes be= rïhnten Dertreters der belgifden 2lïalerfhule ftammen.

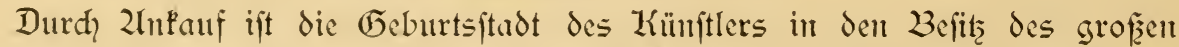
Gemäldes gefonmen, das als fein Gauptwerk gilt: Die Brüffeler Sdü̈zen= gilde erweift $\mathbb{E}_{\text {gmont }}$ und Goorn die letzte Ehre. Das Bild ftammt aus dem Jahre 1851 und heif̧t im Dolfsmunde "Die abgefduttenen Köpfe". Die 
Dertreter der Schüf̧engilde fḑreiten an den fterbliḑ̧en Lqüllen der beiden edlen (Dpfer der fpanifhen Tyramei in den Ziederlanden vorïber. Der Dorgang ift ergreifend. Die Seidhen fint vollftändig von einer fhwarjen Sammetdeçe verhüllt, von weldher fith ein filbernes Zrujifix abhebt, und nur die blutlofen Köppfe fint fichtbar. Die treffliche Kompofition, das glänzende Kolorit, die ener=

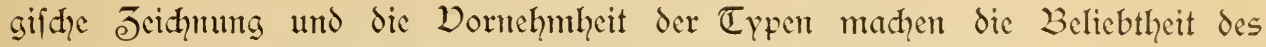
Bildes felbitverftändidy. (2luf unferer 2lbbilduntg 97 fiḑtbar.)

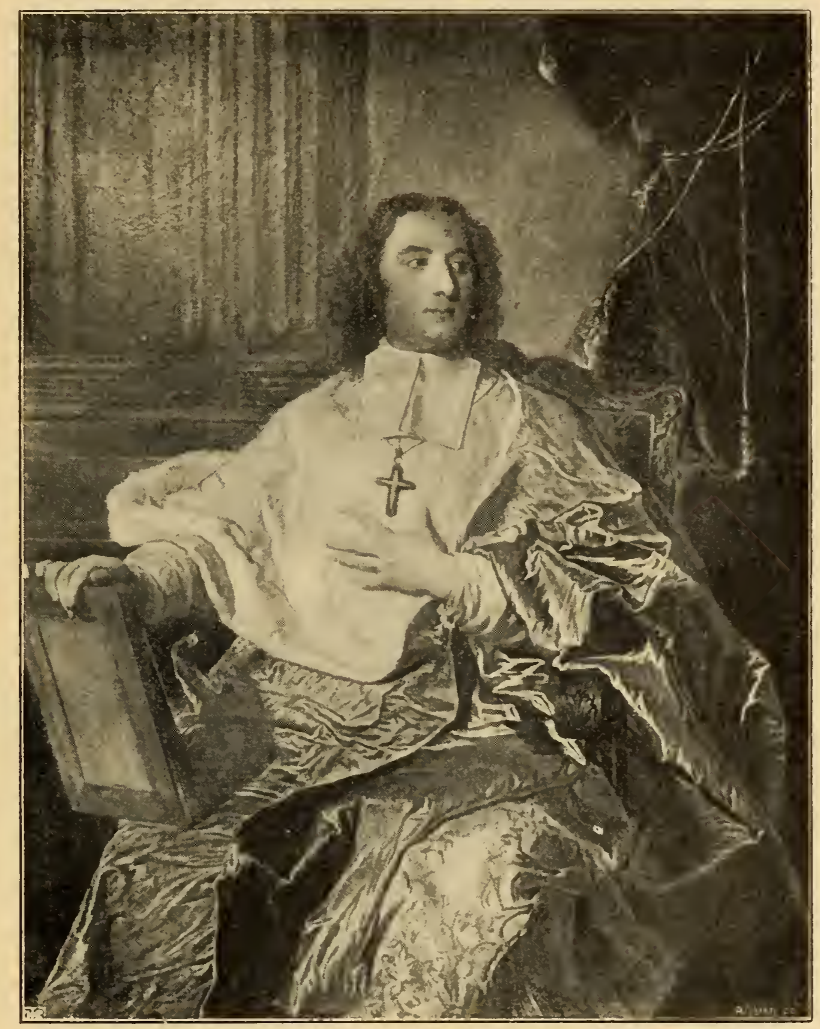

ubb. 100. Der Bifhof von St. Ulbin von Gyacinthe Rigaud. MTufeum.

Verfhiedene grofe und Fleite Porträts veramfhaulichen in intereffanter 2lrt dic Entwickelung von Gallait. Das Porträt von Pej ift ein Ingendwerḱ; das von Ch. 2l. Campan, das Gruppenporträt der 3 rï̈er Kaghe, find vorjüglidye fleime Sachen. Dann die Porträts in Sebensgröfie von der 2rutter und der Sdqwefter des Wialers, das des (Dberften Gallard, das man eine Symphonte in Weir nemten Fönte; das bedentende aber niḑt vollendete Porträt von Souts Gaghe, der in

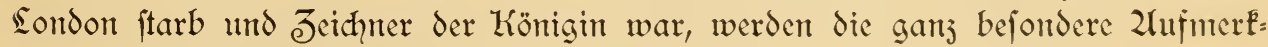
famfeit der fünftigen Zunftgelehrten verdienen.

Gaghe felbit ift im 2rufeun feiner Geburtsftadt mur durd ein 2lquarell ver= treten: Das Jmmere der Kathedrale von Siena. Fin grofzes 3 ill von Jof. van 

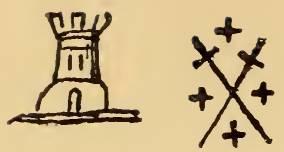

㗂
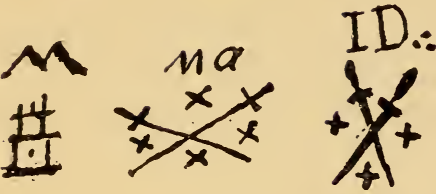

216b.101. Porjeflammarfen von Eournai. (Ziad, Soil.)

Severdond ftell eine Epifode alls der $\mathcal{D e r}_{\mathrm{r}}$ teidigung Tournais durd die prinjelfin voln Epinoy dar.

Dieje Gemälde und nod viele andere, ebenio wie SFulpturen, die hier nidht erwäḩnt werden fönnen, neh̆men den großzen Saal des Dberge= ¡dqoffes nady dem Plakze ju ein (abb.9z) und einen Teil der untlaufenden Galerien, die vormehmtidy für die 2lusftellung von 2lltertünern beftinmmt find. Diefe find mit fehr grofem Gefḑmat auf: geftellt und mit vollfommentem $\mathcal{D e r f t a ̈ n d n i s ~ v o n ~}$ dem Konfervator, Lerru Eugène Soil, geordnet. - Das Ganje ift erften Ranges. Die J̄ahl unt die Bedeutung der gallorömifhen Zlttertünter hat bei einer fo alten Stadt wie Tournai niḑts Ueberrafhendes. Der jüngfte und einer der erfolgreidfften funde ift der vont 7. 2liärz 1900. Er befteht aus Thongefäfenen, Glasflaihhen und Bronjen, von denen einige gantj hervorragend find. Don geringerer Bedeutung ift die Zlbteilung der merowingifhen Zlltertümer, die natürlich niḑts von dem Childeridhiḑat enthält anker etwa in Laahbildungen.

Die auperordentlid foftbare Sammlung von 2lïüzen und 2liedaillen, die von dem Grafen von Liedonthel angelegt und von diefem hervorragenden 2uumis= matifer hodhherjiger Weife dem 2lüpeum gefpendet worden ift, Fann für Coumai als unvergleidhlidh angefehen werden.

Die griechifḑen Zrünzen, die Kanten und Intaglien find ebenfo wie die Edelfteine der Stadt von Gerrn fauquej, einem der leţten fayencefabrifanten von Tournai, der 1843 in St. Zlmand \{tarb, der Stadt vermadyt worden.

2lian darf nidht vergeffen, eine lehr bemer"́enswerte Terracottaplatte mit figürlidhen Darftellungen aus dem 15. Jahrhundert ju betraḑtert.

Die Sammlung von Gläjern, fayencen und Porjellan fordert die ganj be= fondere 2lufmerffamteit des Zlltertumsforfhers heraus.

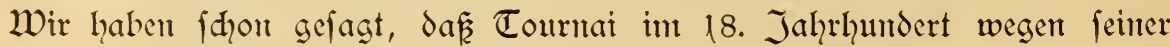
Feramifhen fabrifate weltberïhnt war. Dieje wurden nadh England, fogar nadh Rufiland ausgeführt. Jhy fabrif́szeidyen, das den Sammtern wohl befannt ift, ift der $\mathbb{C} u \mathrm{rm}$ in Gold oder farbig, aud die gefreujten Sdqwerter mit Krenjen in den

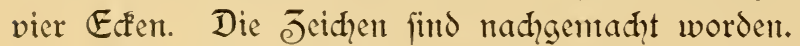

Wenn wir audh die Waffen, die fahnen, die Koptüntue von rein loḱalem Intereffe bei feite laffen, fo liegt uns dod, daran, cinen ganj hervorragenden

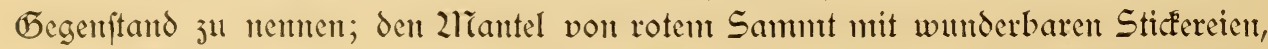
die die Werkée der Barmherzigłeit darftellen, und befäet mit den Jnitialen und Wappen vout Gutllanme fillaftre, 23ifhof von Tountai, Kanjler des goldenen Dliezes unter Karl dem Kü̈lynen.

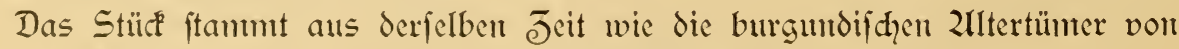
$23 e r n$ und Fann mit bicfen rivalifieren, was niḑt wenig fagen will.

Eintige wundervolle 2liamlkripte find hier anfbewahts: der pialter Eeinriḑs VIII., den er während feines 2lufenthalts in Tournai 1513 bentz̧te, mit 
entjülfenden Grifaillen, und befonders das Lhtfundenverjeichnis des Johannes= hofpitals, das von der Kommiffion der Bärgerhofpije geliehen wurde. Seine leider jehr befhäbigte Initialmuntatur ift des gropenen vlämifḑen 2linniatumalers des 16. Jahrhunderts, Simon Benning, würdig. 2lian fieht nodh im 2lüufeum die Seitenteile mit dem Wappen von England vom Chorftuhl Geinridhs VIII. in der

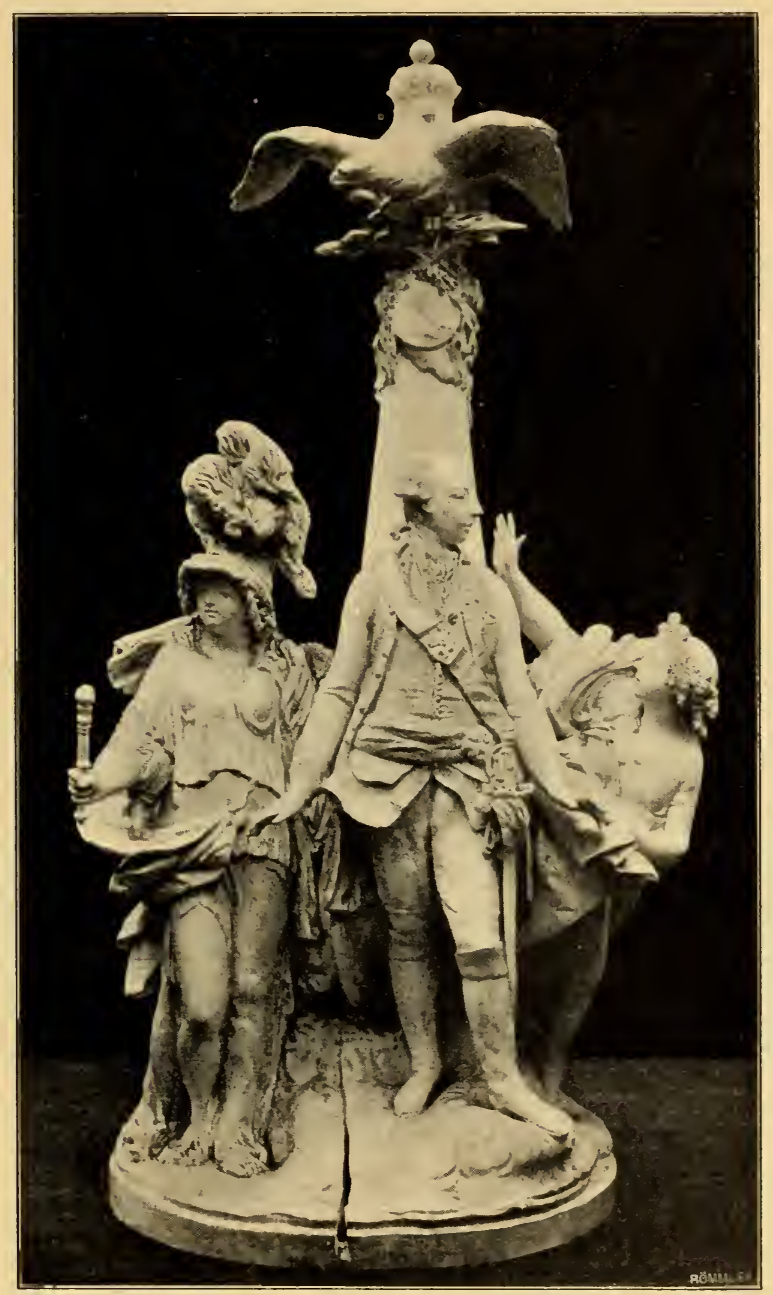

21bb. 102. Iofeph II. Gruppe aus Bisfuitporjellant bei Ģerrm Soil.

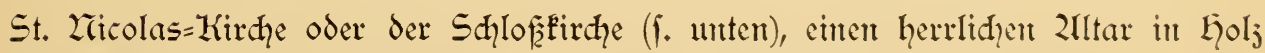

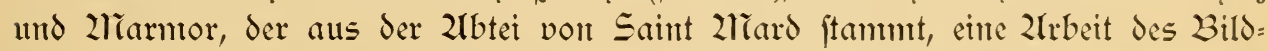
hauers Secreur, und die hübihe Statue der 2liadonna, weldhe frïher die Zrifhe der

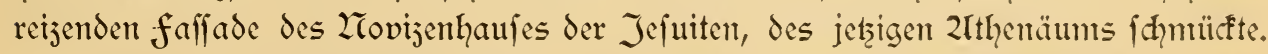

Diefer reidhe Kumfthdhaţ fteht leider fehr eng und der Jeitpunft fanm niḑt mehr länger hinausgefḑoben werden, wo man daran wird denfen milffen, if̧m ein feiner Bedentung mehr entipreḑendes Lnterfommen ju verfhaffent. 
Zud die Säle im Erdgefhof der ehentaligen Tudhhalle fordern den Bejudh des Kunftfreundes. Gier find Brudjitüle von SFulpturen aufgeptell, von denen methrere von hoher Dollfommenheit find. Befonders ift uns ein gravierter Grab: ftein des Willaume de Zlianet aufgefallen, ein Kunftwerf eriten Ranges. Zod, anderes von gleidher Bedeutung ift dort ju finden.

Ein anderes aud fehr wertvolles Stüf ift hier aufgeftellt, cin int verjüngten 2liañítabe ausgeführtes 2lodell der Kathedrale, eine unglaubliche Geduldarbeit von Daffeur (2Ubb. 74).

Es ift wirflith wunderlid, dafiz der Bürger von Tournai, der für feite Kathedrale fhwärmt, den Gefamteindrut von ihr mur durd? die feine 2lrbeit

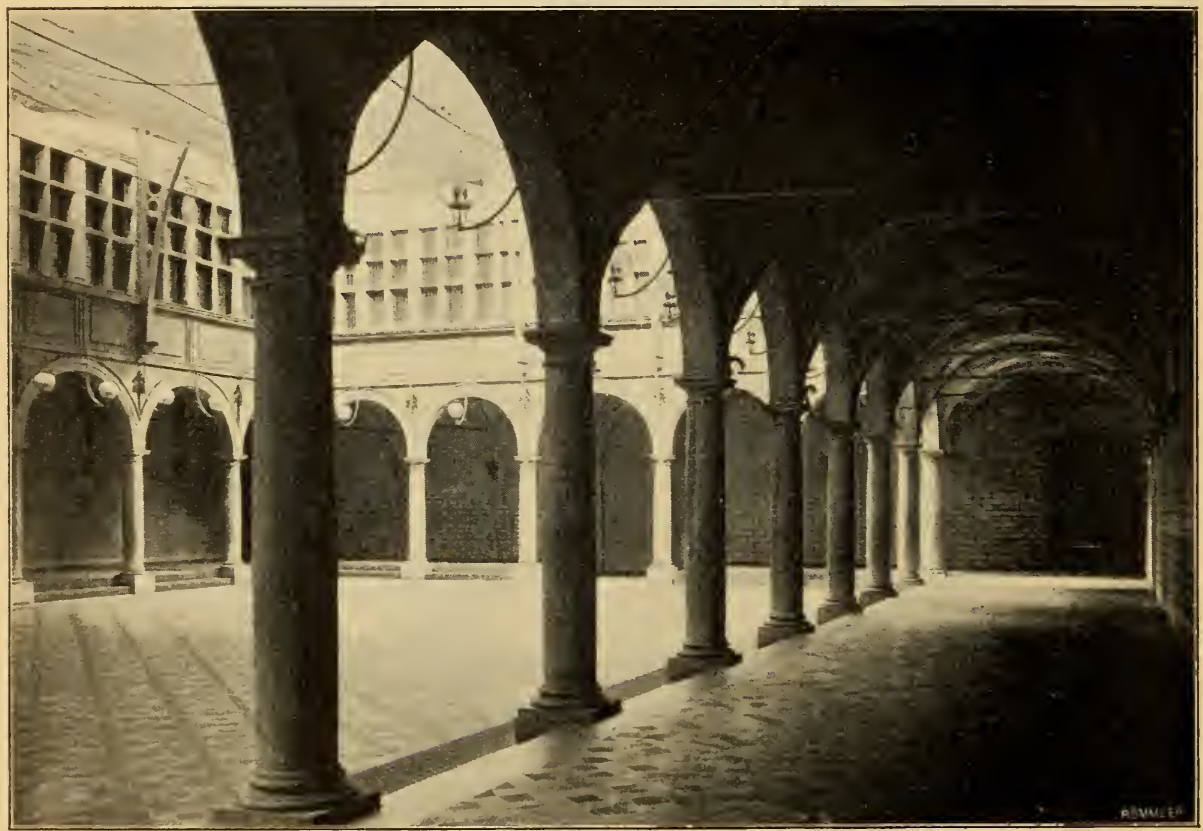

21bb. 103. Lofanfint des Mufeums (ehemalige Tuḑhalle).

erlangen Fann, deren Bedeutung vielletht der enthufiaftifhen Zufnahme, weld̨e die Joee der freilegung der Kathedrale fand, nidht fern fteht.

In der That ift der einjige (Drt, von dem man einen Gejantüberblif über die fünf đürmte erhält, das Ende des grofenen Plak̨es, am Eingang der Rue des 2lieaur (2łbb. 92). Bei dem nötigen 2lbjtant F́am man dic harmtonifhen Derhältniffe des herrlichen Stils, das vollfommtene Derftändnis, das bei dem Entwurf diefes Riejen= wer's gewaltet hat, genïgend beurteilen. Llnd dann begimnt man mit den Ein= wohnern von Tournai, die freilegung der 2lpfis und des Querjdhiffs, die hente nod durdh Parafiten von 23auten verborgen find, ju crträtmen und ju crfehnen.

Die Einterfaffade der Tudhalle ift niḑt unintereffant, und der Fleine Zcébondyel=Platz, wo fie fid erhebt, ift von einer fehr dharafteriftifd̨en Gejamt=

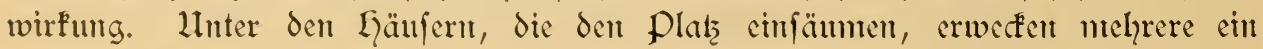


wirflidies Jutereffe, fo befonders eins mit Doppelgiebel, das aus dem 17. Jahr = hundert daticrt (2lbb. 104).

Die St. Georges=Straf̧e, die fith vor uns aufthut, fühnt uns in einten befonders chrwürbigen Teil der Stadt. Da ift $3^{\text {th }}$ mijerer Sinfen ein alter Turm, der freilid, durdh bie zweite Ringmaner fehr entfellt ift, feime 2lianern fint $1 \frac{1}{2}$ 2lieter biff.

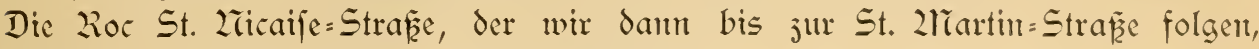

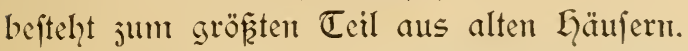

Sdyräg gegenüber, etwas nady red్ts öfintet fidh inmitten vort 23 auten vort vornehmem 2lnfehen ein monumentaler Thorbau - er führt in dent Ehrenhof des Rathaules. Don hier aus hat man einen intereffanten BlicF" ju gleidher Jeit auf

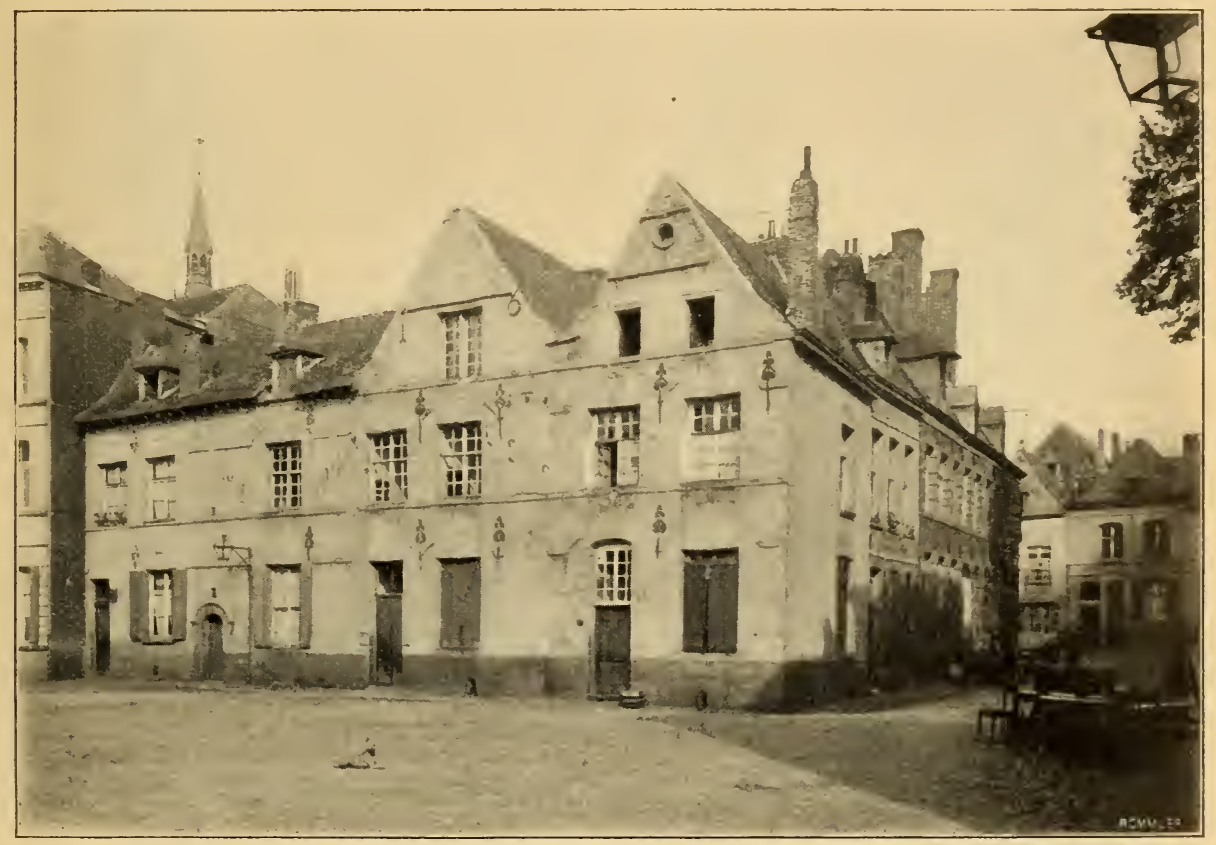

21bb. 104. Der 2iedonthel=plat5.

die Kathedrale und den Belfried, deren Türme ju einemt hödḩt anjiehenden Gefant= bilde julammenflief̧en (2lbb. 105).

Das Rathaus von Toumai (2lbb. 106), das feineswegs gefhafien wurbe,

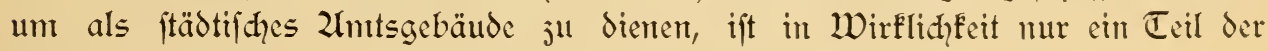

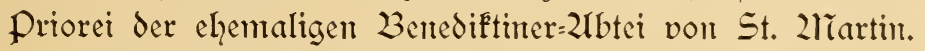

Es ift faum glaublid, unt giebt eine Joee von der Gleidgültigkeit, die unfere Dorfahren für die baulidyen Refte der Dergangentheit hatten, dafí das urfprüngliḑe Rathaus, die Halle des Consaux, die aus dem 18. Jahrhuntbert ftammite, 1818 abgetragen wurde! Shon vor diefer Jeit, 1809, war bie alte 2lbtei von St. 21Tartin der Siţ der ftäbtifhen Derwaltung geworden.

Don dem alten Bau find nad der Parfecite ju mur cinige jeşt vermanerte Bogen von dem gotifdyen Kreujgang erhalten. 
Das heutige Gabäude, das int 18. Jahrhundert erriḑtet wurde, jeigt fhöne proportionen im Flajifichen Stil und hat lediglich ein feḩ überhöhtes Erdgejhor dem eine elegante freitreppe vorgelagert ift.

Das Gauptgebände hat ein jehr vornehmes 2lusjehen; es ift mit Pilaftern verjiert, von einem Giebel bef́rönt und durch eine 2 ttif́ăa, die Vajen trägt, abge:

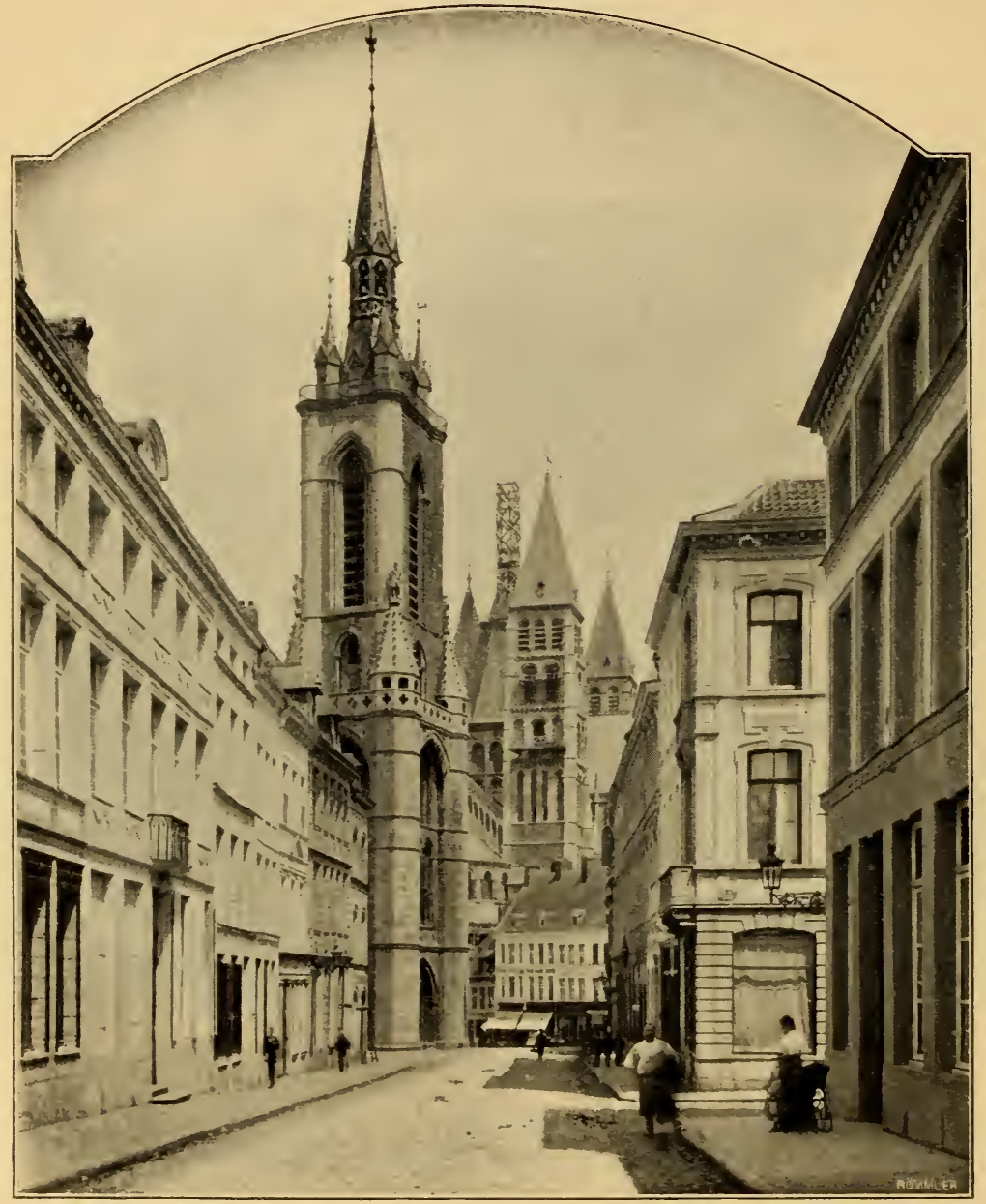

2ubb. 1.05. 23lick auf Belfried und Kathedrale.

fdyloffen. 2ln den Seiten erheben fid jwei Pavillone non demfelben Stil, oben nit cinem ovalen fenfter ausgeftattet. Die redttwinfeligen Seitenthallen, die jier= lidhen Blumenbecte geben dem Gantjen cin fehr impolantes Gepräge, das an die monumentalen Ställe des Sḑlofles von Shantilly denten läfizt, die übrigents gleidh= jeitig entftanden fint.

Das Jumere hat notwendigerweife der jeţigen 3 eftimmumg angepant werden

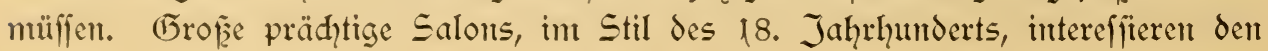


Zrrḑäologen wentger als die riefigen Zeeller, die fidh bis unter den Ehrenhof hinjiehen.

Jhye Eewölbe, die in vorjügliḑer Weife gefügt find, ruhen auf mäđhtigen Säulen mit romanifden Kapitellen. Drei StodFer fe fetzen fid fo aufeinander. Zrian vermutet, da ż fie als Eefängniffe gedient haben.

Das Zlter diefer Stelle und ihre uriprünglidhe Beftimmung machen dicfe Ulnterbauten jehr erflärliḑ. In der That ftand hier die alte romanifdye Kitrdhe. die durd die Zormannen jerftört und 962 wieder aufgebaut worden war.

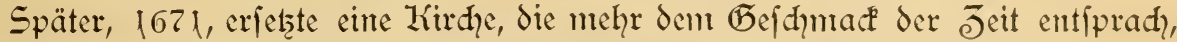
wenn fie auch niđht fđ̧öner war, das alte Crotteshaus. Subwig XIV. legte per=

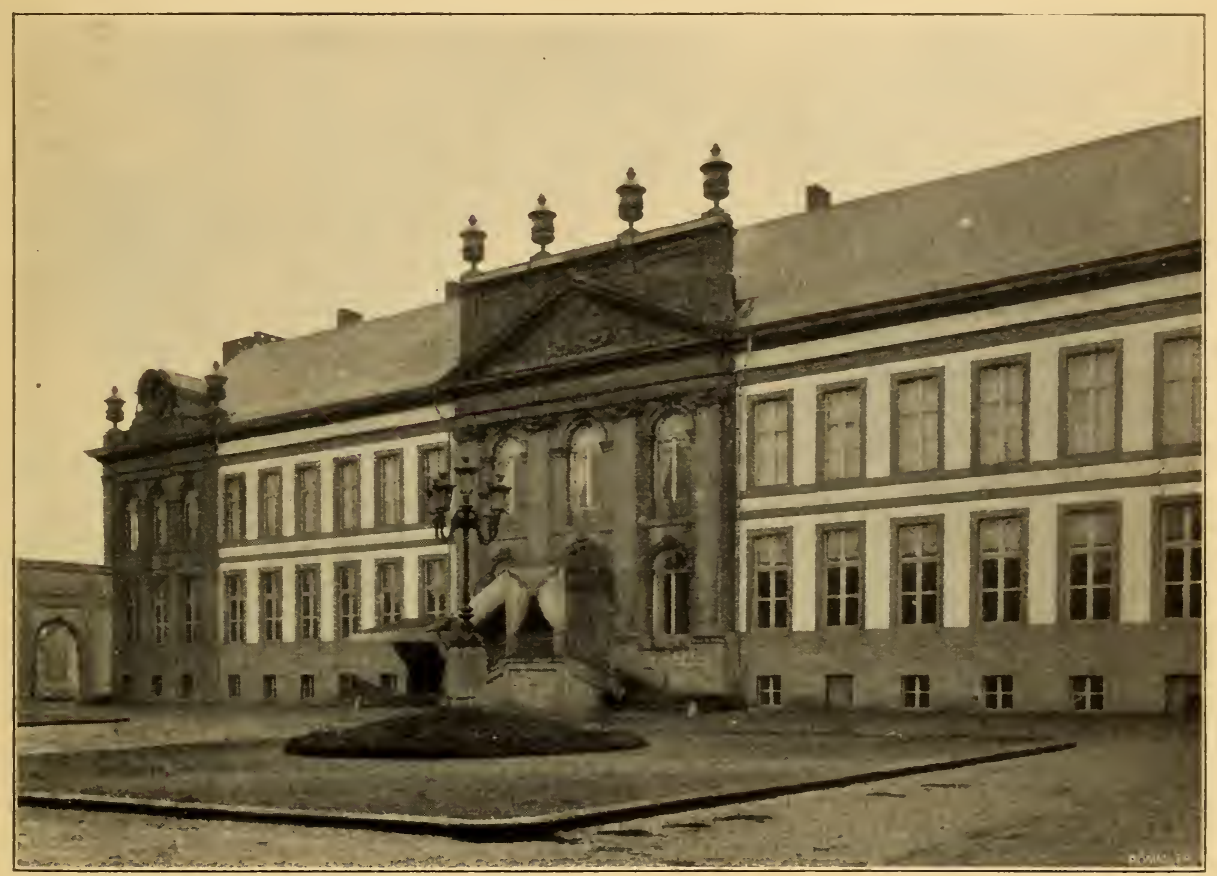

Zbb. 106. Das Rathaus.

jönlid den Grundftein mit einer 2rauerFelle, die nod hente aufbewaht wird. Diefe Kirche war fehr reidh. Zran Eonte dort jahlreidye Kumftwerle fehen. fiur die Zlbtei S. Wrartin malte Jordaens fein gro zes Gemälde: Der hl. Zliartin treibt einem Befeffenen ben Teufel aus, jeţt im 2lüfeum von Brüffel.

Der fhattige Parḱ, der das Rathaus untgiebt, ift nit ebenfoviel Zumit wie

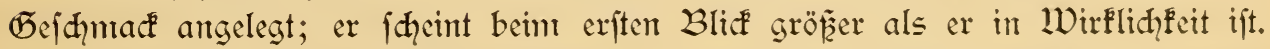

Reḑts von dem Palaft und fich von deffen Seitenfaffade abhebend, hat man 1891 eime Statue des Souis Fallait, des 2lialers von Toumai crriḑtet (1810 bis 1887). Die Bronjefigur ift von Guillaume Sharlier; fie ftellt den Zlünftler in

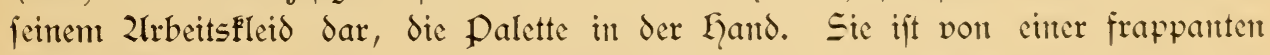

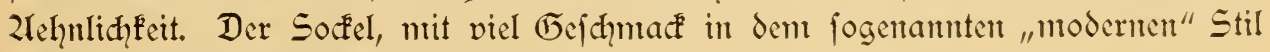
entworfen, ift ein WerE vor Lijorta. 
Wenn wir den Garten des Rathaules herabgehen, fommen wir über den

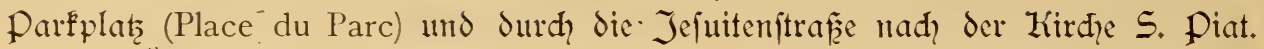

Ein" beträd)tlidger Teil der Jefuitenftraęe befteht aus den Gebäuden des bifḩöflidyen Sentinars, des ehemaligen Jefuitenfollegiums, deffen ZKirdye mit drei= fadyen Giebel in der Strafentront liegt unt gantj intereffant ift. 2ran hat den Plan daju cinem Brügger 2rrḑiteften jugefdrieben, cinem Drdensbruder; cr ift vielleiḑt derfelbe, der die jierlidhe Kapelle des ehemaligen 2rovijenthaufes in der Rue Duquesnoy erbaute, deren wir fhon gedaḑt haben.

Das fehr geräumige Sdiffi ift im gotifdyen Stil entworfen nnd Einzelheiten der SFulptur, wo die Znflänge an die Renaiffance überwiegen, bieten viel Inter=

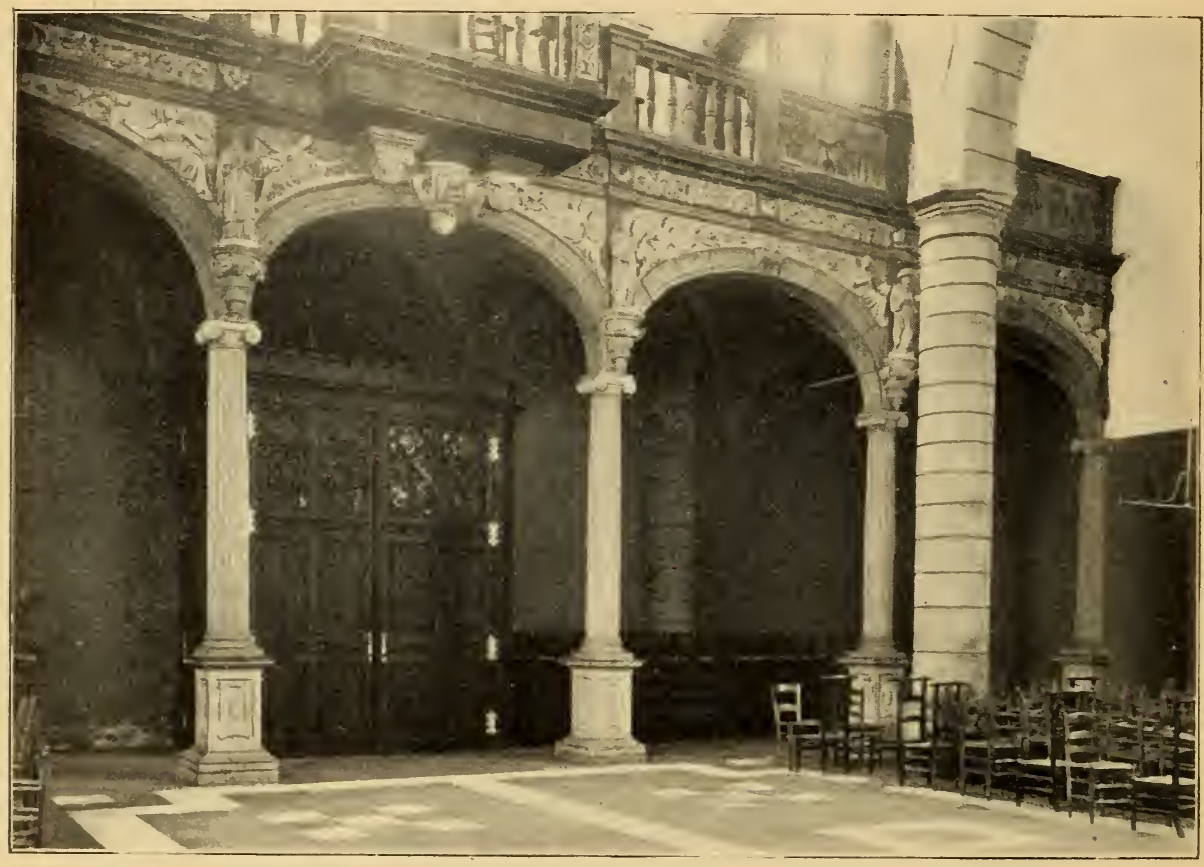

21bb. 107. Chorbühne in der Kird̨e des Seminars.

effantes. Die (Drgelbülnne am ZKirḑeneingang ift von wirfliḑer Sḑönheit. Sie ift aus fąwarzent 2rarmtor und mit SFulpturen von weifent 2liarmor gehöht. Entgelsfiguren unt Zragfteinen, das Ganje von eimer eleganten Baluftrade befrönt.

(1)hne mit der Chorbühne der Kathedrale bejonders in Bejug auf den defo: rativen Leiḑtum rivalifieren jul Fömten, verdient das "Dorale" des Seminars nut

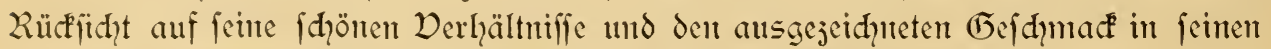
Details mit ifhnt verglidhen ju werden. Es ift eint 2leeifterwer".

Zady dem Seminar ift es nidyt olpue Jutereffe, reḑts die siue de Bive ein= juf d)lagen; fie ift ein Teil der alten 23efeitigungsmauer, deren Sinte fie folgt, um in der

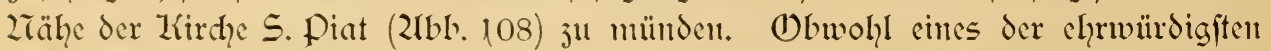
Banmerke - es ftammt aus dem 11. Jahrlyundert - hat die Zirdye S. Piat von ihrer urfprüngliḑen phyfiognontie wirflid, niḑts bewahrt, als cinen be= 
merḱenswerten Tum mit fünf rundbogigen Stocfwerken, bie fofort an die Türme der Kathedrale erimterm. Diefer Turm, der fidh alt die rechte Seite des Schifies

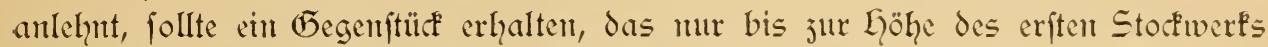
gefülngt ift. Ein dritter Tumm in der zhitte des Sdhifies follte das Eanje ver= vollftändigen unt, wie bemerft worden ift, an die Kathedrale erimnern. Die faffade und der Ehor fitto gotifd.

2rber nod viel mehre als das Zeurere ift das Jumere durd Llmbauten ent= ftellt worden. Der urfprünglide Plan war der einer 2 afilifa - man hat daran, als 2unbauten, Seitenfapellen gelegt.

Went man durd das nördlidfe Thor eintritt, bemerft man beiderfeits, in

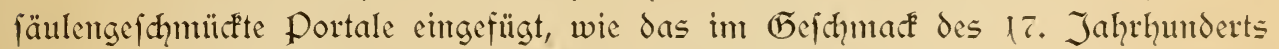
lag, die Porträts des Bildhauers Stephan Dailly, Gauptmanns der Bogenf ḩützen vom hl. Sebaftian, und deffen fran Jofephine Therefe Delmotte, jwei Bilder von vortrefflicher Qualität in der 2rrt von Cornelis de Dos.

Zlbgefehen von den Statuen, die die Portale fdymülén, welḑe fith über feitem Porträt und dem feiner frau aufbauen, hat Dailly nod die Zitrdye mit der Statue einer 2liadonna von fehr fḑöner 2rrbeit gejiert, die mant rïber dem Lauptaltar mit gewundenen Säulen fieht. Derfelbe Gauptaltar ift mit einem (5): mälde: Chriftus ant Krenlj, gefdumilcti, das in der 2lut des van Dyck entworfen und ausgeführt ift. Diefes Bild, in fdünem Stil gehalten, diente der Sdylof̌́lapelle als Sdymure. Sie ift volt Jafob van Doft, dent Vater. Redyts im Gintergrunt des Schiffes eime Kopie des Utbendmahls von Rubens, deffen (V)riginal fidh in der Brera (2railand) befindet.

Don derjelben Seite gelangt man durd eine Fleine Thür, die in die Diffe der Litirhenmaner eingelaffen ijt, diḑt neben dem Zltar des Lll. Lerjens Jefu in die fogenamte (5oethalsfapelle, die 1840 ganj entuert worden ift, aber in einer fehr eleganten Bauart. - Vran erjählt, daf́ in diefer Kapelle die Refte von Geimrid, Foethals beigeferzt worden feien, der der "feierliḑe Doftor" genant wurde; er ftarb 1293 und foll nady einer Infdyrift der Fründer diefer Kapelle feit, die in blumigent gotifhen Stil mit fefton=Rippen gehalten ift.

Unter den Eintriḑtungsftuiden der Kirdhe befindet fïh cin fąönes Sefepult aus Kupfer, vom Jahre 1403 datiert.

Das L haus 2ir. 22, Rue S. Piat, die Braueret voln S. Piat, ift voll 1644 datiert und ein hübihes Beifpiel alter Baufunft in einer Stadt, wo die Bauten diefer Jeit felten find. Es befteht ans Ganftein und Jiegeln und hat vier Stor" werke, fteinerne fenfterfreuze und einen abgetreppten Giebel.

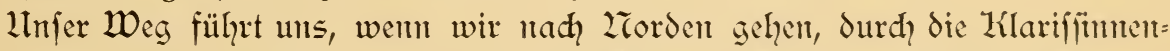
itrafze (rue des Clairisses), wo man an der Edpe der Rue des Carliers (2̌r. 12.) ein Gaus fieht, wo der Dolfsüberlieferung nach der hl. Diat gewohnt haben foll. Das Llaus ift in der That romanifh, aber derma zent entftellt, da es eh, ohe vor: herigen Lintweis, ganj der ZlufmerF́famfeit des Dorübergehenden entgehen würde.

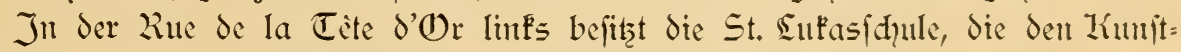
unterricht ganj nad den Prinjipien der Gotif erteilt, cine Zlnjahl alter SFulpturen, worunter fidh fehr hervorragende befindent. Sie find in Tournai felbft gefanmelt. 
Die Beftattung eines 2liöndhs, ein Relief von 1365, jtammt aus demt Klojter der Refollełten; das Epithaphium von Watiers 2 ntoine und deffen beiden frauen, woranf man Gott $\mathcal{D}$ ater und die Sdquţheiligen der Verftorbenen ficht, ift ein Werf́ đhönen Stils, von 14.. datiert; eine Kreuzabnahme, alls dem Ende des

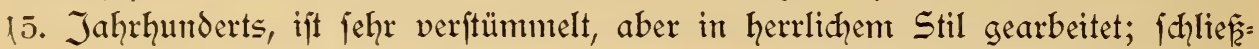

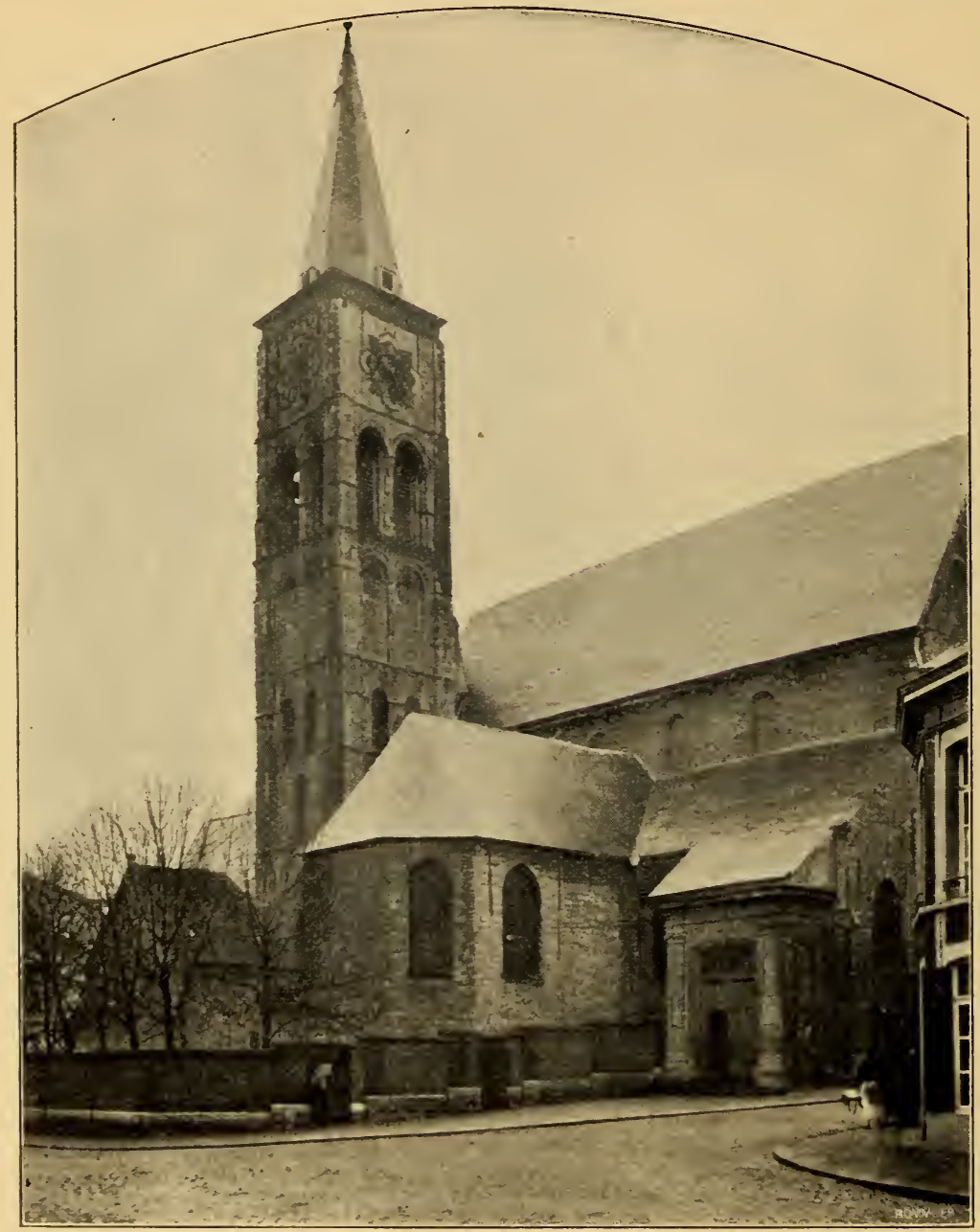

216b. 108. St. piat.

lich ift da, mit dem Datum 1556, ein Koljfigürdyel, das aus dem Gebälfe cintes alten Laufes herftanmt und ein intereffantes Stüf ift, fowohl durd die verdienft= volle Zlusfühnung wie durh die 2rot, wie es in der eiren Gälfte das Seben und

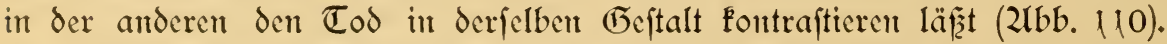

Wir wollen nidht unterlaffen, 2irr. 24 in der Rue Gallait $j^{11}$ erwähnen, das Geburtshaus des Vhalers, deffen Gedädtuts Tournai fehr hod hält und den es mit Dorlicbe Brüffel und 2lutwerpen in deren ftürmtifden Streiten unt den fünft= lerifhen Dorrang entgegenhielt. 
Die Rue de la Cordomerie, du Curé Zrotre=Dame, du four=Elqapitre grenjent an die Kathedrale. 2ran findet dort, befonders in der leţteren, Gäufer aus dem 15. und 16. Jahrhundert, dic allerdings jientlid entftellt fint; fie haben faft alle Keller aus der romanifhen Jet.

Zln der Eafe des 3 ij dhofplatzes (Place de l'Évéché) fteht ein 1755 crridhtetes

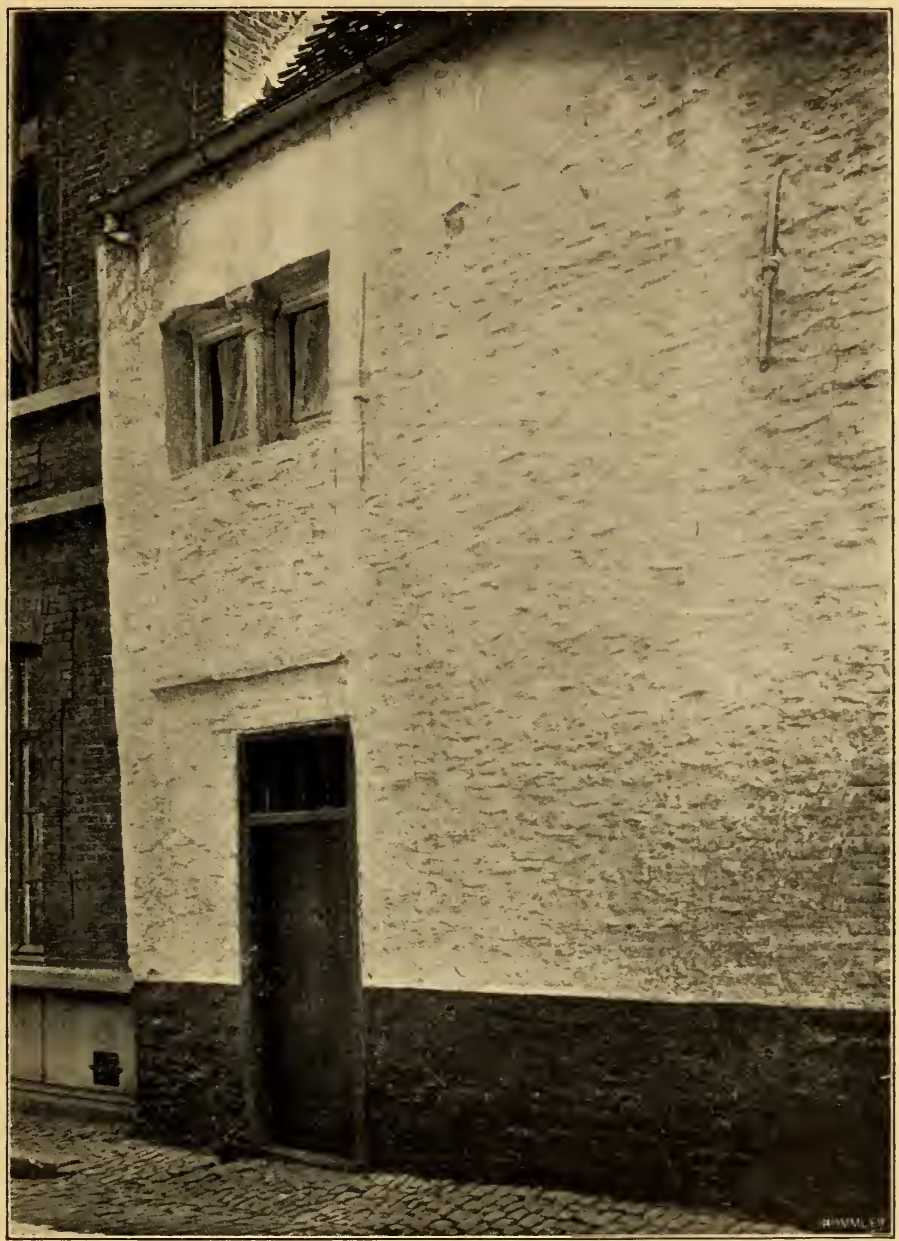

21bb. 109. Romanifhes Gaus Rue St. Piat 27r. 18.

Palais von grokéen Verhältniffen und vornehmem 2lusfehen, das mant das "Gotel des Invalides" der alten Geiftlidhen nennen Förnte. Es ift dies cinte Stiftung, die in das 13. Jahrhundert jurüçgeht. In cinem Teil des Gebändes, das cinte ganje

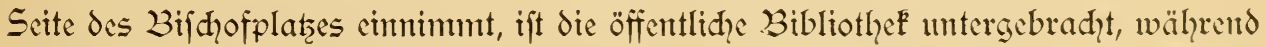
fïh auf der anderen Seite des Plaţes und in einer fdünen faffade von J̈iegeln unt Stein finh in dic (5oldjdymiedfra ju erftrecfend, das ehemalige Palais der Stände der sandfhaft vout Tournai (1754 erriḑtet) erhebt (2lbb. 111). Es dient als 2lufbewahrungsort für dic Stadt= und 
Staatsardhive von aujerordentliḑent Reidhtum. Don dem 13. Jahrhundert an find die Stadtregifter gewifferma zen ununterbrochen vorhanden. Das Z1rchiv hat fith int Saufe der leţten Jaḩe um eine foftbare Sammtlung ifonographifher und biblio= graphifher Dofumtente verntehrt, die fidh auf die Gefhidhte von Tournai bejichen unt die von Gerrn Dentajière gefanmelt worden fint.

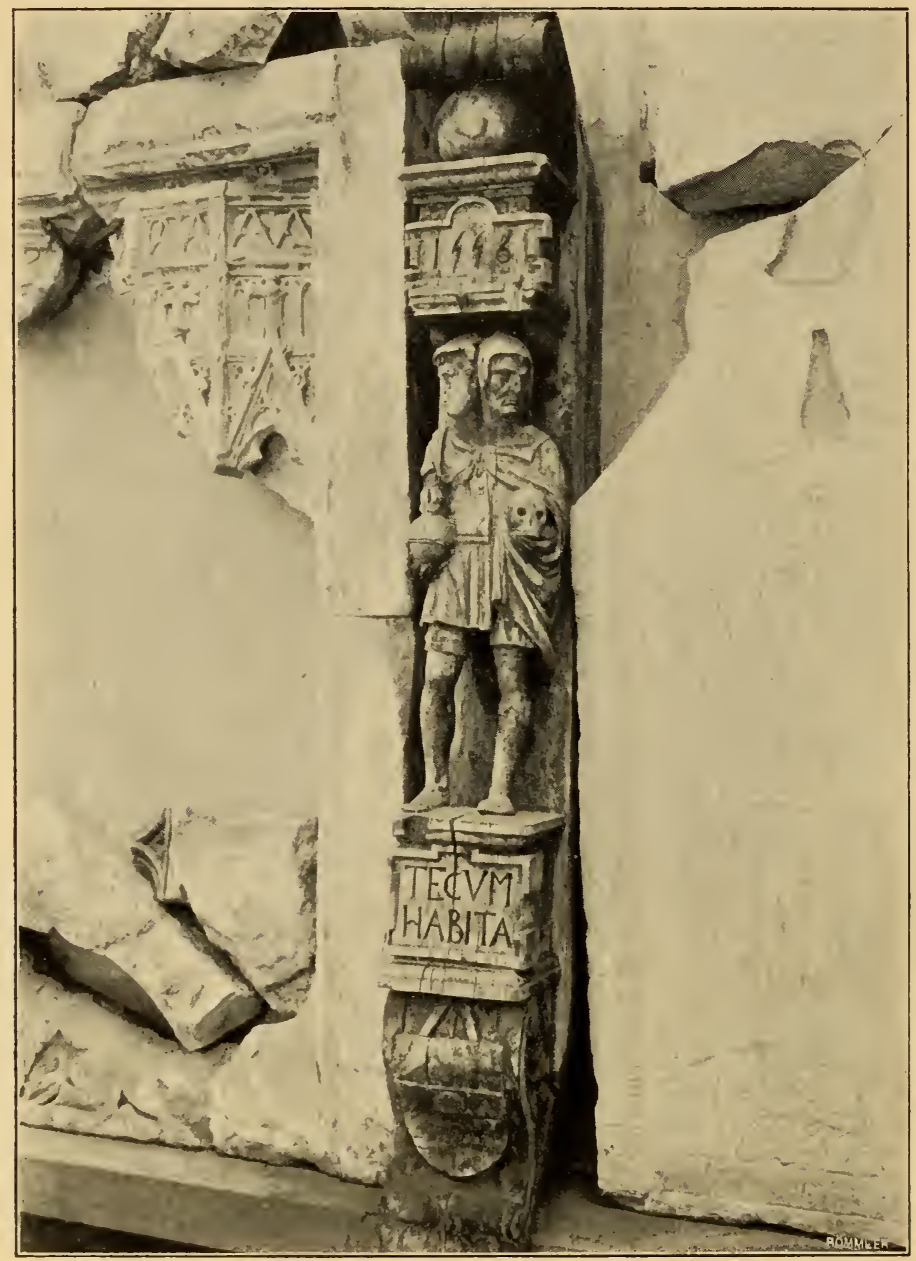

21bb. 110. Seben und Tod, Goljffulptur an der St. Iufasfinule.

Wir werfen cinen leţten Blick auf den Grofzen Plaţ und gelangen durd?

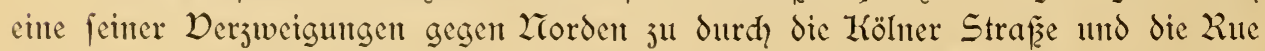
Piquet ju der fehr intereffanten Kirdye S. Jacques (Jaḱobsfirdyc). Ganz frei= ftehend fteigen ifhre eleganten formten vor uns auf unt obwohl fie faum 50 2leter

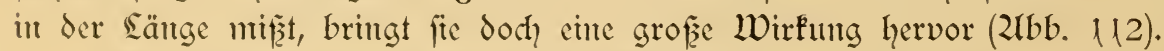

2lit Zusnalpme des romanifhen Turmes ift alles gotifh. Die reizenden

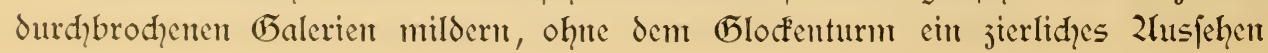


ju geben, was ju dem Stil uid,t paffen wïrde, werrigitens feinen ftrengen Charafter.

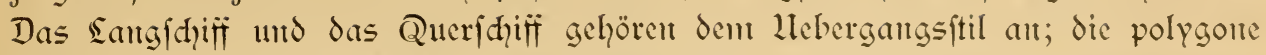

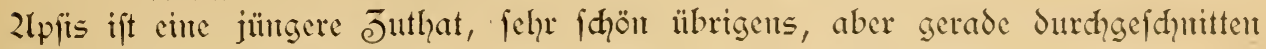
von dem überhöhten Dadje, das cinten vorkiagenden Giebel bildet, vor dent jwei Extürnte jtehen. Das sangfdiff mit fenten umlaufenden Galerien in der L des erjten Stocḱwerḱs, einer Zullage, wie wir fie analog in S. Zicolas wiederfinden werden, die Querfaiffe und ilyre fenfter mit dreifaḑen Sanjettbogen und cher Ropette darüber, bilden ein anf̧erordentlid) gelungenes (5anze, dem der Eindruck

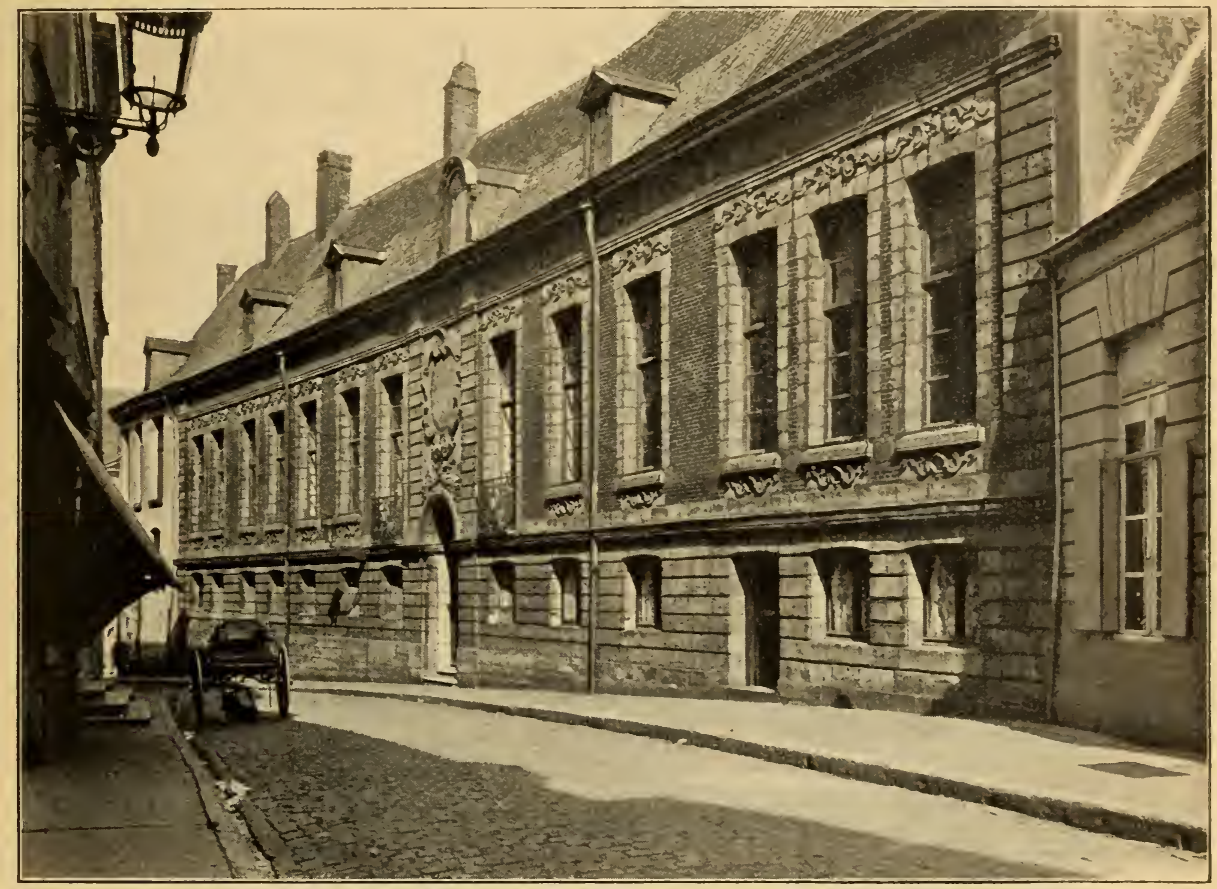

2ubb. 111. Das Stadt= und Staatsardiiv.

des Junteren vollitändig entfpriḑt, obwohl man jahlreiḑe Stufen herabfteigen mura um hiucinjufonmter.

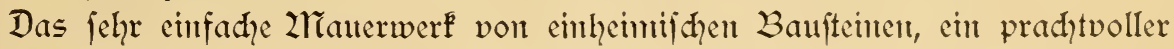
gangbarer Triforium, die ausgejeidnnete Reihe von fenftern, die Sdjutbelwölbung bilden ein fo harmontifhes Enfemble, wie man es felten in den Belgifduen Kirdien findet.

"Fins madt befonders einen tiejen Findruck auf den Befdaner," fagt Lerm 5. Cloquet, der über die Kirdie S. Jaeques eme geradeju ausfdilaggebende Studie gemad, hat, "das ift diefer riefige Bogen, der wie eine 23rülpe durd die 2litte der Kirche geworfen ift und eme jierlidhe Ealerie mit überfduttenen 230 gen trägt." Diefe Galerie führt rings um dic Dierung lerum. Eine intereffante Er= fheimung futd ant Choreingang eine Rofette und jwei Sanjettfenfter, weldye daju 
beftimmt waren, von aupen beleuḑtet ju werden, und die Stelle bezeidhnen, wo die neue 2lpfis anfängt, die, wie wir gefagt haben, höher als die alte ift.

Das Queridhifi, das wie das Kauptiḑiff eine vertäfelte Wölbung hat, jeigt fladye 2abjhlinffe und ladet mur fhwad aus. Keine alten Glasmalereien.

Die Choranlage ift durh die Scitenfapellen, weldhe durd eine doppelte Bogen= reihe mit der Gloḑaltarftätte verbunden find, eigenartig. Das Ganje ift aus dem



21bb. 112. Die Jafobsfirdie.

14. Jahrhhundert. Die Wölbungen diejer Kapellen fint mit hübjd̨en Engelgruppen deforicrt - im Gefhnmack des (1)ratoriums von Jacques Coeur in Bourges.

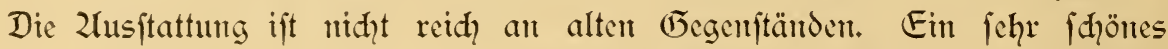
Sefepult, in 2rdlerform, ift von 1411 datiert und trägt den 2Tamen der Geberit : Jeante poullet, Witwe Parent.

Dafür befitż S. Jaeques cine bedentende zlienge von Foftbaren SFulpturen und Erabftenen von hoher fiunfterifher Bedeutung. Rechts vom Ehor in der SaframentsFapelle, die von Zrif́olaus d'zlvesnes gegründet ift, jeidqnet fidh das Epithaphium diefes Stifters als cin ganj ungewöhntidhes Kunftwerl aus. Es ift ganz polychromiert und ftellt den Derftorbenen und feine fran dar, wie fie vor der zliadomta Enieen, der fie von ihren Sdquţheiligen vorgeführt werden. 
Die Karmeliterftraje (rue des Carmes), die dem Gauptportal gegenüber liegt, zählt, vom Standpunft unferer Studie, ju dent intereffanteftent. Die 2liehrzahl ihrer Gäufer ftammt aus dem 17. Jahrḩundert. Gervorjuheben find befonders die

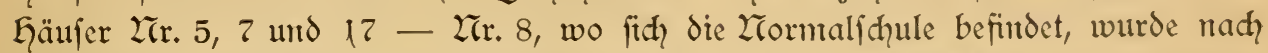
den Plänen von Wenceslaw Soebergher erbaut, 1618 , um als Eeihhaus ju dienent.

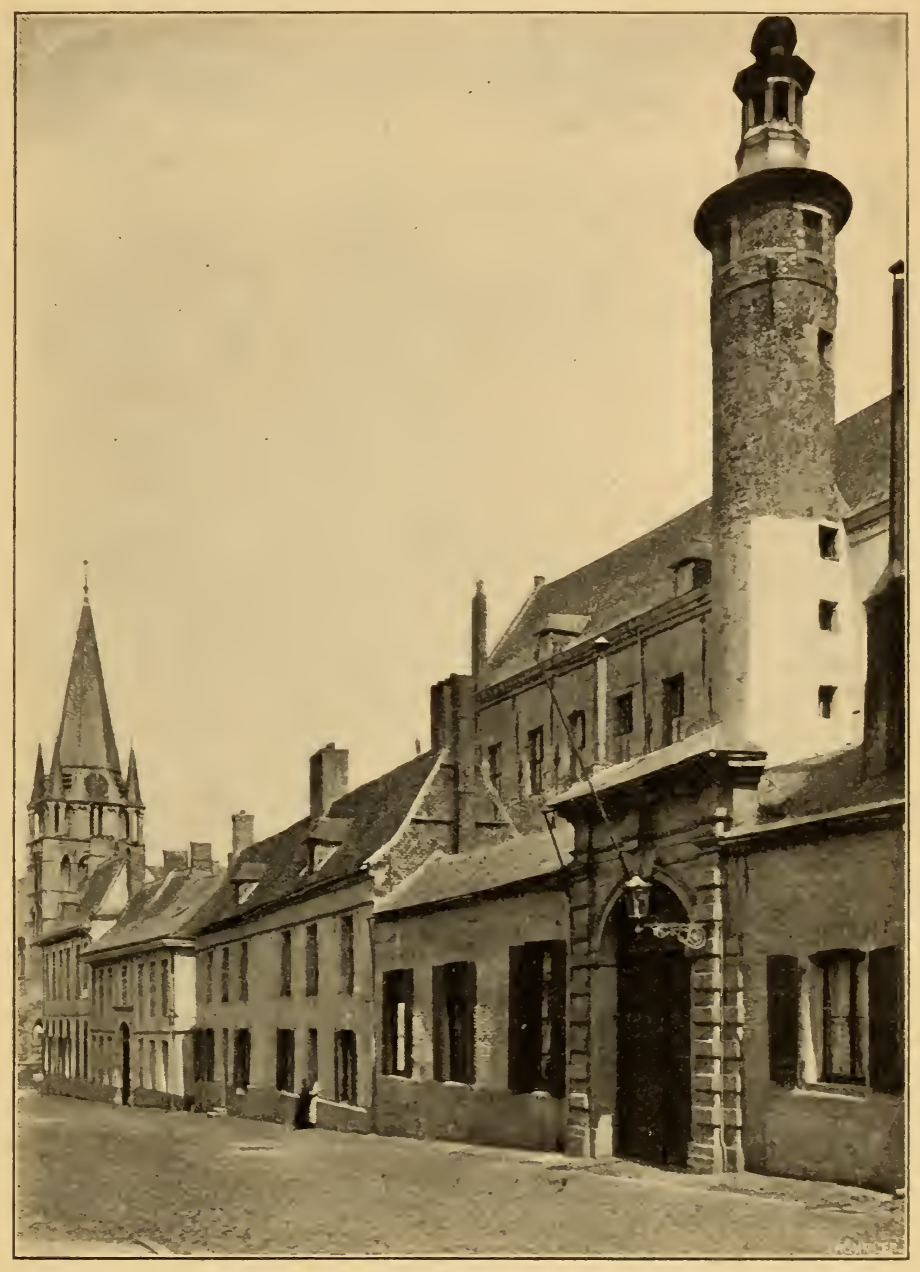

2bb. 113. Die 2Tormalfaule.

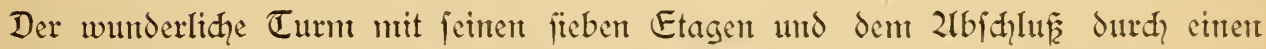

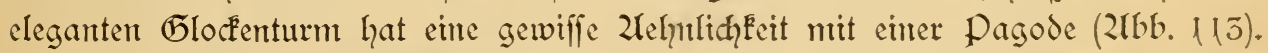

Coebergher, der Zrialer und Ingenteur war, verdient eiten Plaţ unter dent

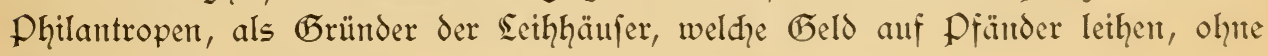
Jimfen dafür ju neḩmen.

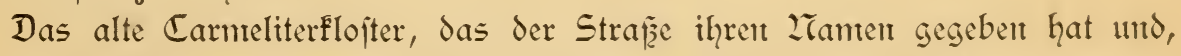

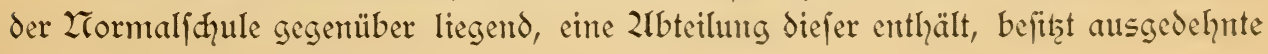


Frabgewölbe, wo in Zrifhen die Refte der ehemaligen 2lïtglieder der Ḱlofter= gemeinf haft ruher.

Die Kirdhe Ste. 2rarguerite, auf dent Siller Plaţ, fällt durdh ihren eigentüm= lidhen romanifhen Turm auf, der von einem bizarren Glod"enturm mit mehrfachen Zlusbauchungen gefrönt wird. Es ift das der einjige alte Teil diejes Gottes= haufes, das 1733 in Flafiffhem Stil mit einer hohen Kuppel reFonftruiert wurde. Es fehlt dem $\mathcal{B}$ an nidht eine gewiffe Würde.

Die führer zeigen, als diefer Kiirche gehörig, die flügel eines Bildes angeb:

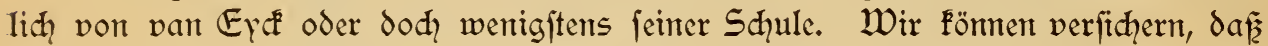
diefe Gremälde, ein Stifterporträt und ein hll. Bifhof, niḑ̨t älter als aus dem 16. Jahrhundert find und von mittelmäßzigen Fünjtlerifhen Wert.

Der 2liargaretenfirche gegenüber ift 1897 den franjöfil ḩen Soldaten, die 1852 unter den 2riauern 2lntwerpens gefallen find, ein DenËmal von anmutigen Derhältmiffen und anfprechenden formen crriḑtet worden, deffen Schöpfer Sonne: ville und Duboft find.

Die hüblḑe halb ftädtifḩe, halb ländliche Rue Blandinoise führt uns in die Zuguftinerftrafie; in Vorübergehen betraḑten wir die faffade des 2rontifaut= Golpizes (1653), eines ftattlidyen Bames, un nady der fđönen Zliagdalenenjtraf̧e ju gelangen, einer der imtpojanteften Derł́ehrsadern der alten Stadt. Die 2Tagda= Ienenftraf̧e, die eine Derlängerung der Clantfee von Tournai nach Courtrai ift, hat durchaus das Zlusfehen einer Ganutftrafze. Durd fie jog Sudwig XV., als er alls fontenoy Fam, in die Stadt ein.

Die Miaria=2liagdalenenfirche, die wir rechts fehen, ift, ohne die Bedeutung

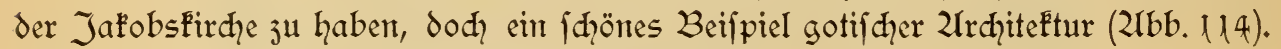
Jhre form ift von bemerkenswerter 2 rüd hernheit.

Die faffade mit fpärliḑen fenftern, maffiven ausladenden Strebepfeilern,

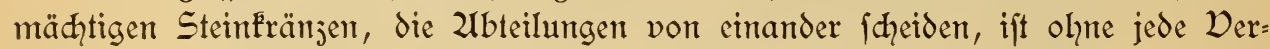
jierung. Don den beiden Türmen ift nur einer fertig; der andere ift bis ju jwei Dritteln feiner $\mathfrak{L}$ öhe gelangt und wäre leiḑt ju vollenden. Das Eanje ftammt aus dem 14. Jahrhundert.

Das Sdifff bildet ein Parallelogramm von 36 ju 21 2Metern. Der ebert= falls rechteclige, fehre viel engere Chor mif̧̆t mur 13 auf 9 2rieter. Die Kirdhe, die in orei Schiffe geteilt ift und Jurh gotifhe fenfter erlendhtet wird, ift in allen 区eilen mit Schindeln gedecḱt.

Eine Chorbülne aus dem 16. Jahrhundert in polydyromer Ljoljfdynizerei fieht man am Eingang; fie ift die Kauptjierde der Kirdhe. Die groken Zlpoftel= ftatuen, die nady dent jientlid allgemeinen Gebraud in Belgien an die Säulen

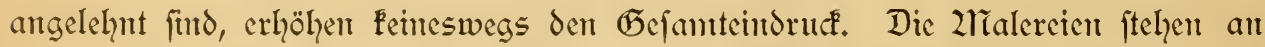
Eünftlerifhem Wert hinter den SFulpturen jurvï", die faft alle vortrefflidy find. Eine der bedeutendften, das Epithaphium von Jacques Jambon, einem $\mathfrak{I r}_{\mathfrak{j}} \mathrm{t}$, der 1621 geftorben ift, und von feiner frau, weldhes man im reḑten Seitenfdifff fieht, verdient trotz oder gerade wegen des verhältnismtäpig jungen Datums die 2Uuf= merffamét des Kenners ganj befonders unt offenbart die lange Dauer einer blühenden Bildhauerfḑule in Tournai. 
Gier in der Ste. 2rarie 2läadeleine verfäume man befonders nitht, die "Der=

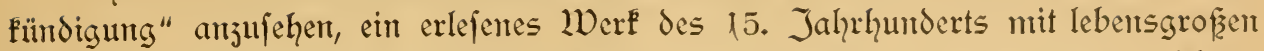
figuren. Want hat es nidht ohne Erund in Bejiehung jul einer gleidhen Kom= pofition des Roger van der Weyden gejez̧t. "Wem man die $\mathfrak{L}$ altung und den Zlusdruck des Engels ftudiert, fowie die Einjelheiten feines Gewandes, und ver=

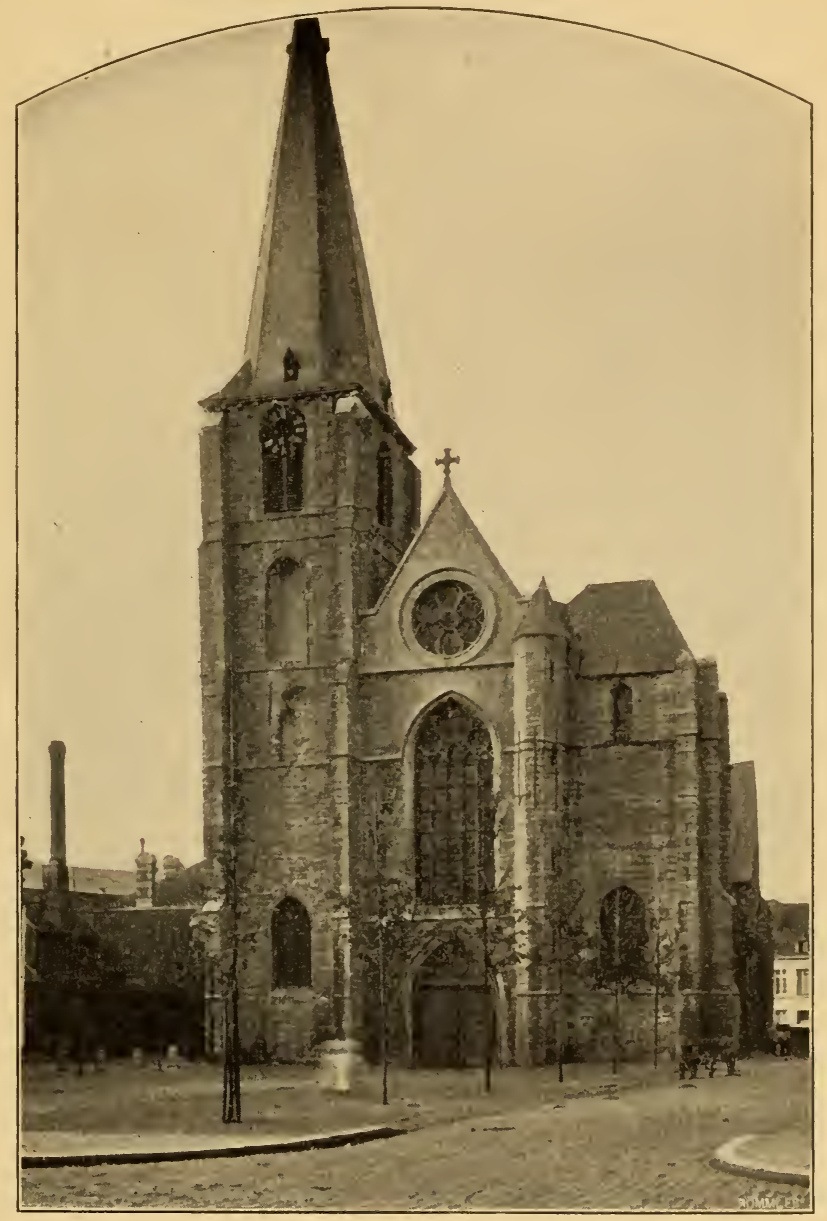

2bb. 114. St. Marie Madeleine.

gleicht dantn diefe figur mit der auf der "Derfündigung" von kioger van der Weyden, die int 2lufeum ju Zntwerpen aufbewahrt wird, fo wird mant jwifdhen beiden fo ausgejproḑene 2Tehnlidḩeiten bejonders in den Eitzelheiten der Gewant=

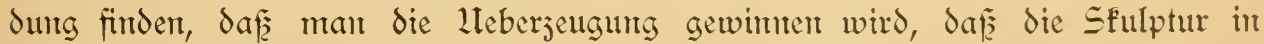

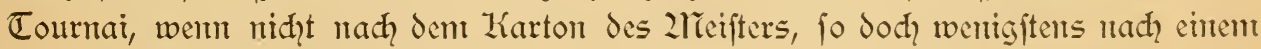
feiner ausgeführten Gemälde gearbeitet ift. So ftellen wir eine fö̈̈tlithe Spur der Werfiftatt feft, weldye diefer Güurftler in Tounnai hatte, deffen kulhm fidh nidgt 
lange in der engen Sphäre unferer lof́alen Sdqule cingefḑloffen halten formte, fondern bald die ganje Welt beftrahlte".*)

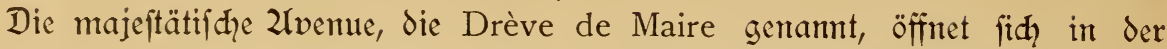

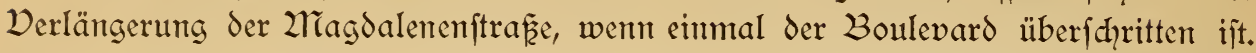
Reḑts liegt der Earten, Square de la Reine genant, wo aus einem flcimen Teidh ein Rejt des alten $B$ efeftigungswerkes auftaudyt.

Went wir immer redts bleiben, erreichen wir die Sdyelde, die hier, inmitten weit fich hinjiehender felder, unter $\delta \mathrm{er}$ Delwart= $\mathcal{B}$ rülfe, ftromtabwärts von dem Pont des Trous hinfliefzt, cinem der intereffanteften Refte der alten militärifhen 2lrchitef́tur, die fith in Belgien erhalten haben (2łbb. 115).

heute, wie in 2litttelalter, bejeidquet die fogenannte Brüle der 5 öher nad

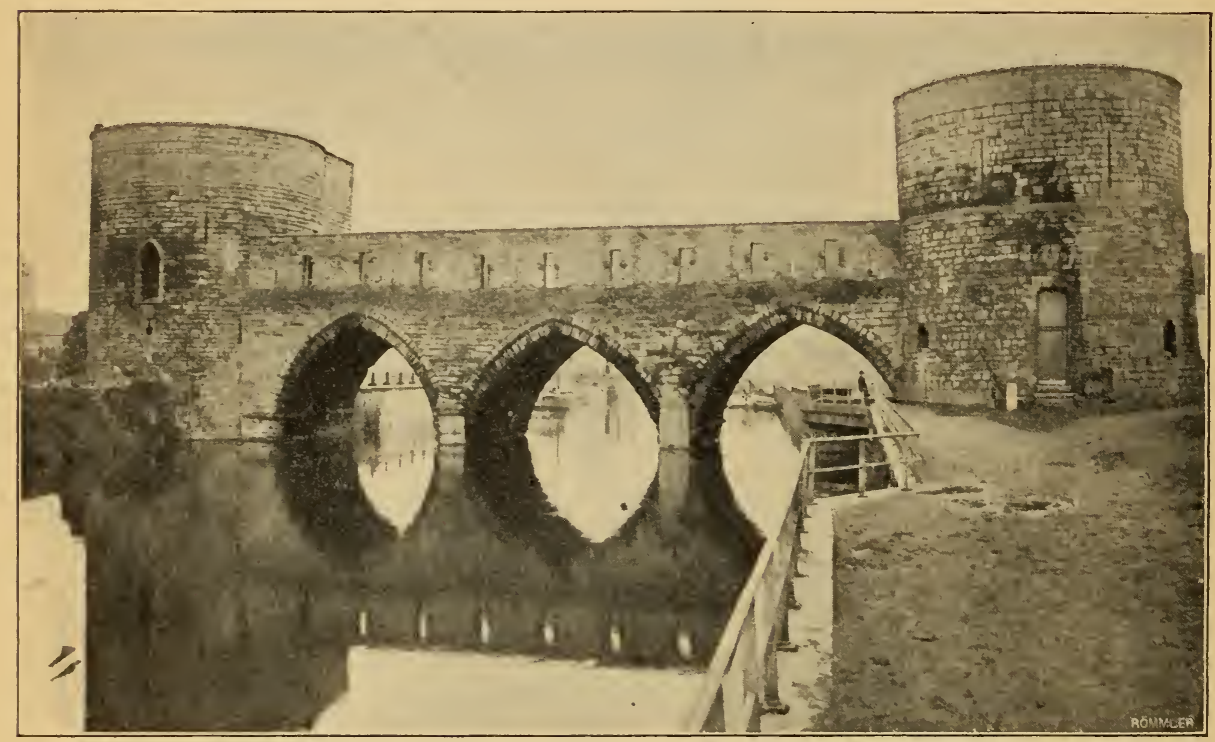

2ßbb. 115. Pont des Trous. Zaah der Sandfeite.

den 2rordweften ju die äufzerfte Stadtgrenje; fie ift cbenfo anjiehend für den Künftler wie intereffant für den Zunffforfdier.

Sie hat drei ïberhöhte Spiţbogen unt die Pfeiler ruhen auf dem Bodent des fluffes. Die hohe Bruftwehr, von Schiefîfharten durdhbrodhen, ftülz̨t fid an beiden Enden auf cinen Tum, dem jeţ̧ die Befrönung feḩlt. Das Eanje ift aus dem 15. Jahrhundert.

Don der Delwart=23rïfie ift der 23lick ganj cinjig; niemand, dem es vergönnt

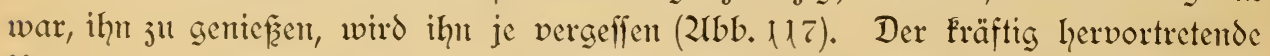
Dordergrund, der durd die chrwürdigen Steinlagen der 23rüffe gebildet wird,

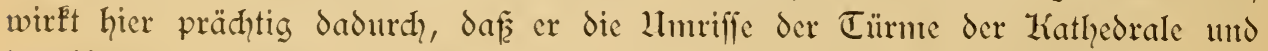
des Belfrieds jurïftreten läß̨̆, die fidh in der ferne vom Limmel abheben.

*) De la Grange et Cloquet. Etudes sur l'Art à Tournai. 


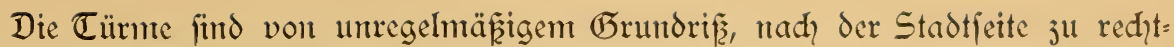
ecfig und von (Deffmungen durḑbroḑen, nad, der Sandfeite jul abgernndet.

Der am linfen 2lfer, dent Quai des Salines zu, hat nod einen fdyönent gewölbten Saal. Die Bogen, die cheden von einem zum andern himïbergefpannt waren, fint an ber äıl żeren Seite nod fiḑtbar.

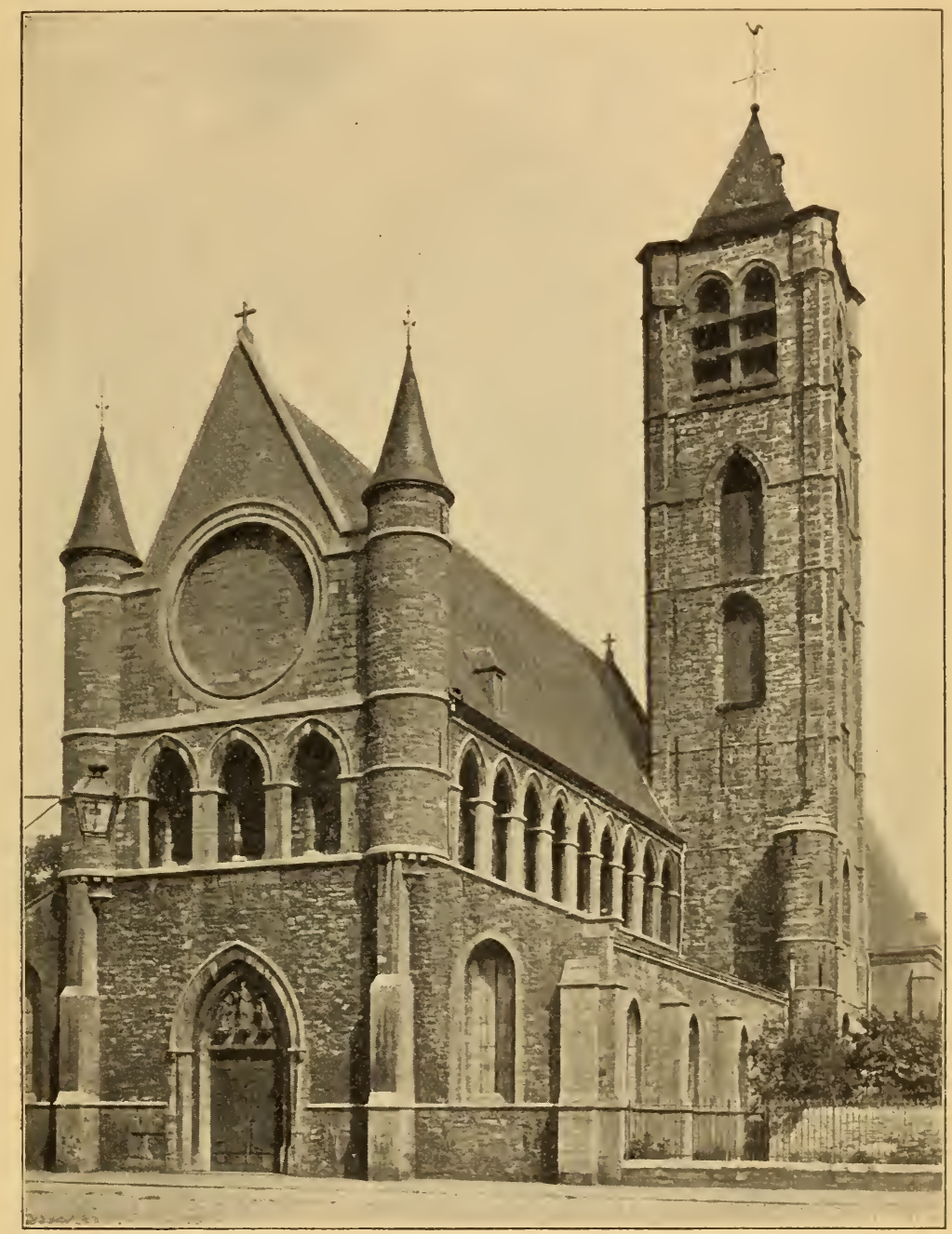

2ibb. 116. St. Ziffolas.

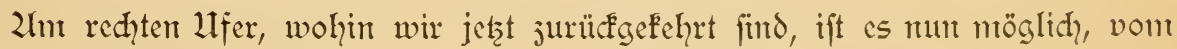
Quai de l'Arsenal durd die Rue du Désert in das fitlle Stadtviertel des "Château" cinjudringen, das die alte St. Licolas=Zitrdhe jum 2littelpunft hat (Z1bb. 116).

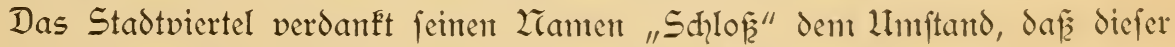

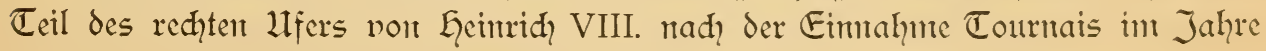
1513 in eine Citadelle umgewandit wurde. 
Der Pont des Trous bildete einen Teil der Befeftigungen und es ift wirflich wunderbar, da ż diefer Jెeuge vergangener. Jahrhhunderte die Wälle überlebt hat, die er hat erridhten, fidh umwandeln und endid an feiner Seite hat ftürzen jehen.

Don den englifhen Befeftigungsbauten fteht nod der furdhtbare Befeftigungs= turm, der immer mit dem Lamen des "Turms Geinriḑs VIII." bejeidhnet wird und den man rechts in einiger Entfermung fehen fann, wenn man vom Bahnhof fontmt (2lbb. 118).

Es fheint uns unbeftreitbar, da隹 das Stadtwiertel des "Château" bis heute eine befondere Phyfiognomie bewahrt hat. Seine breiten und einfamen Straęen

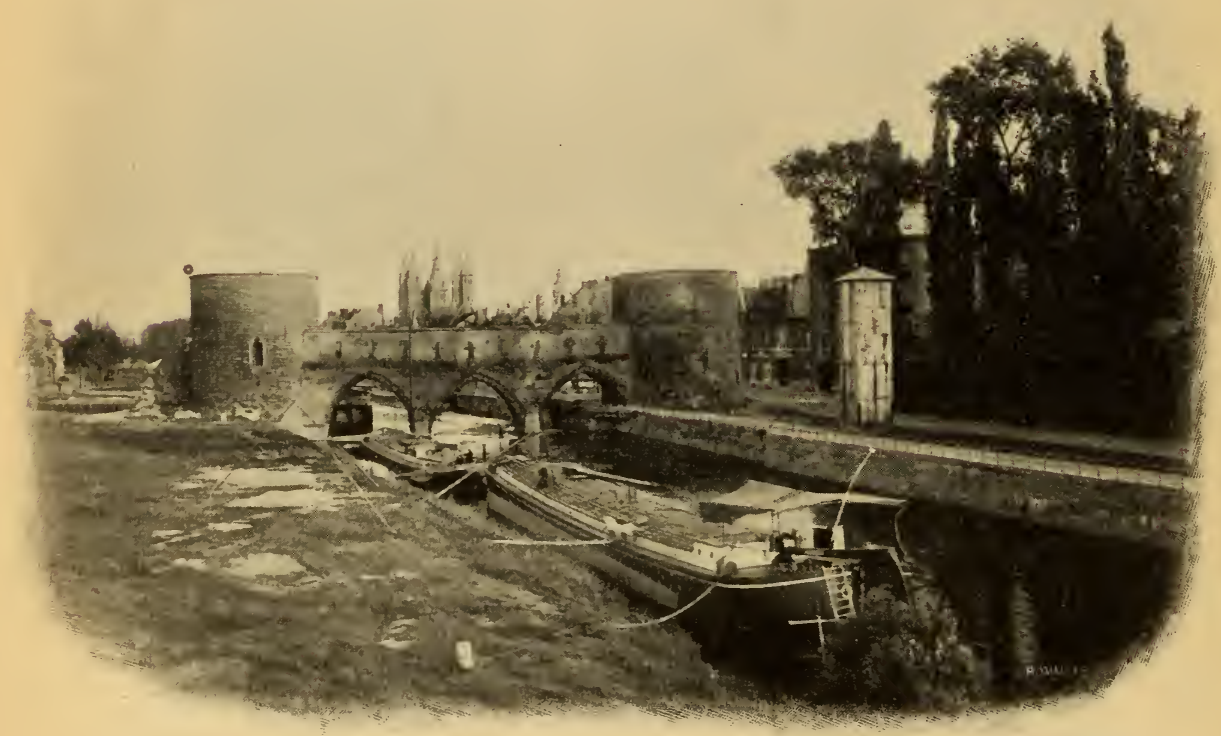

2łbb. 117. Der Pont des Trous mit der Sđhelde. Stadtfeite.

madyen den Eindruc einer gefallenen Frößze. Zllles fpridht hier von Derlaffenheit; 3wifhen dem Pflafter, da nur fehr felten der fur cines Dornbergehenden betritt,

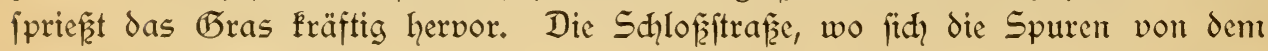
Palaft des Statthalters aus dem 16. Jahrḩundert erhalten haben; das đhöne

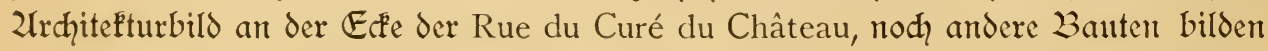
eine ausgejeiđhnt paffende Umgebung für die Zirų̧e St. Ziicolas "du Château", die jum gröferen Teil freifteḩt und die von ciner wahrhaft grofartigen Wir= fung ift (2lbb. 116).

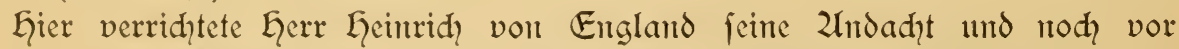
wenigen Jahren founte man in ber fogenannten "englifḑen" Kapelle reḑts im Eintergrund feinen Zirdhenftuhl mit dem Wappen der Tudor fehen. Wir haben den Seitenteilen davon im 2rufeum begegnet. 
Troţdent einige Teile romanifhen Charafter zeigen, gehört St. Ziicolas dent Ulebergang an und bildet ein organifhes (Eanje.

Eine elegante durdhbrodhente Galerie jieht fith durdh die falfade hin, wo der volt $j^{\text {wei }}$ Tümthen cingefarte (Giebel eine fenfterrofe von riefigen Pro= portionen aufweift. Der rechtecfige Turm an der füdliḑen faffade, der von einer Furjent pyramidenförmigen Spiz̧e befrönt ift, neight in fehr fidhtlicher Weife nadh Zorden. Die polpgone 2lpfis hat rundbogige fenfter; die der Seitemfdiffe fint

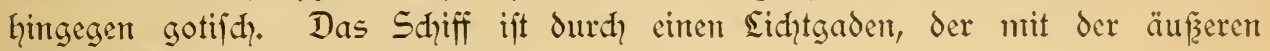
Galerie forrefpondiert, erleuḑtet.

Da das alte Ztiveau der Kirdye bedeutent unter dem der Straf̧e liegt, mu位 man hier, wie in St. Jacques jahlreiḑe Stufen hinabfteigen, was Éeineswegs für

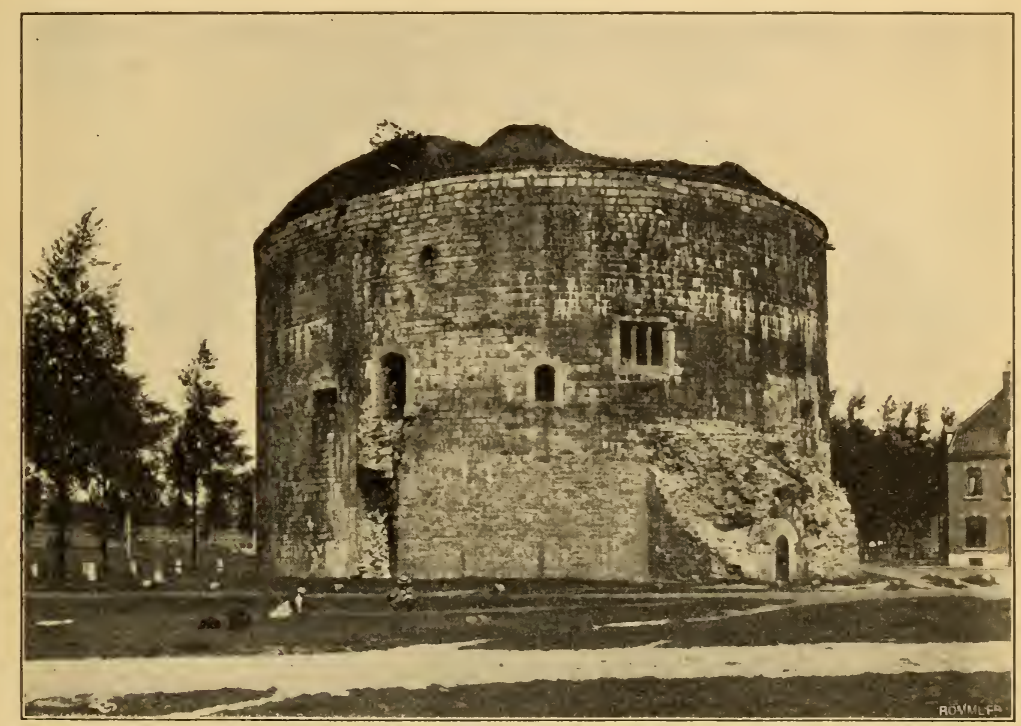

3bb. 118. Der đurm Geinrichs VIII.

den erften Eindruc vorteilhaft ift. Die Gefamtanordmung befiegt indeffen diefent Einwand, dent die Zrifolasfirche ift wirflidh in ihrer Gejanttheit ebenfo bedeutend, wie in ihren Einjelheiten.

Das fdöne getäfelte (Eewölbe, das durch die ganje Kirdhe geht, der impo= fante Chor, die Seitenfapellen (die SaframentsFapelle, die die "englifhe" genant wird, und die Zrotre=Dame=Kapelle) find von cleganter Bauart.

Die jah̆lreidhen Grabdenf́ntäler find an den Wänden angebraḩ̨ unt gehören ju den fhönen Beippielen ihrer 21rt. Es find weldye aus dent 14. Jahrḩutdert da, aber befonders aufgefallen ift uns cin Grabftein für jwei Perjonen, der niḑt weit vom Eingang aufgeftellt ift und, wie es fheint, aus dem 16. Jahrhundert ftammt. Das Epitaphium des 2lrnold von Guerle, der mit feiner frau unt feinen Kindern vor der 2radonna Ënieend daraeftellt ift, fam als eir SFulptur=

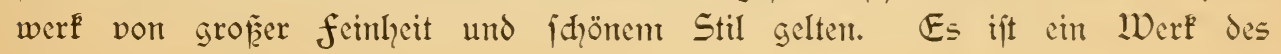


15. Jahrhunderts. - Das Udler=Lefepult, von 1382 datiert, folglid das ältefte in

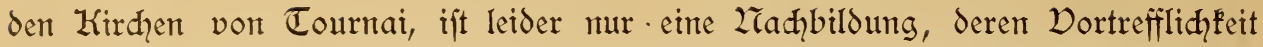
nidht über den Verluit des Driginals, das vor wenigen Jahren verf́auft worden ift, tröften Fann.

Durd̆ die Rue du Curé du Château erreiḑen wir die Place verte, an deren Ende fidh die düftre 2liaffe des Turms Lqeinridis VIII. erhebt. Das enorme Banl= werk, 20 2leter hod, mit einem Durdimeffer von 25 2rietern, hat nidhts, was fein ftrenges 2 usfehen milderte. Seine riefigen Bruchfteinlagen find durd Eifen= fpangen verbunden; feine 2rauent find bis 7 MTeter dicf. 2lian bemerf́t dort

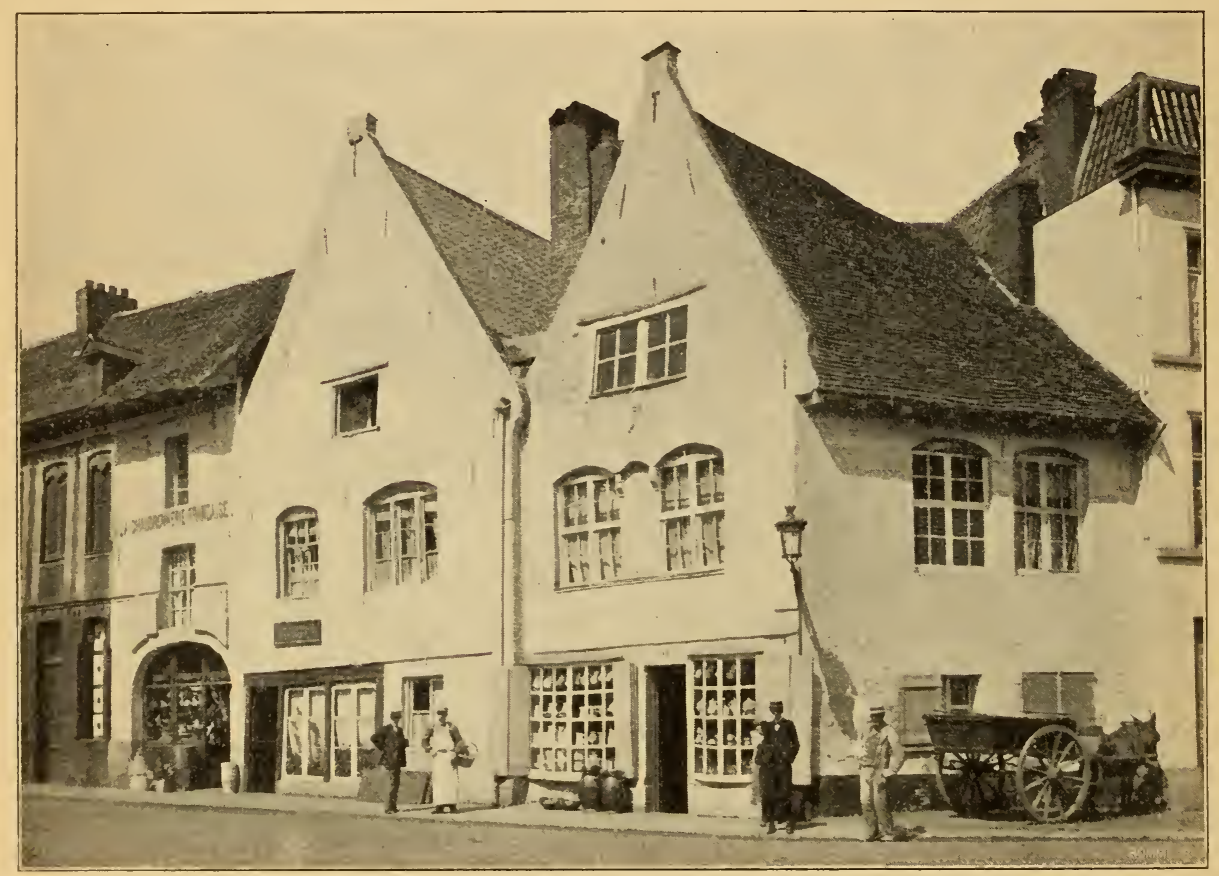

21bb. 119. Rue Royale 2ir. 10, 12 11td 14.

Derzahnungen, die feine frühere Derbindung mit der Befeftigungsmaner beweifen.

Eine in die Dide der 2raner eingelaffene Treppe verbindet die Stocfwerfe, denn der Turm enthält wirflid jwei runde Säle, die durd genan überentander liegende (Jeffungen in den Wölbungen belendţtet werden, eine 2Unlage, die fidt aud in anderen befeftigten Sdylöfern findet.

Don allem losgelöft, was heute feine Dajeinsbereḑtigung motivieren fönnte, intereffiert der Turm Ecimrids VIII. mur mehr als Eegenftand der Erimerung. Wird diefe Erimterung 2liaḑt genug haben, umt ihn vor dent Sdyidffal aller der Refte der Dergangenheit ju bewahren, die ohne erfiḑtliḑen (Frund jerftört worden

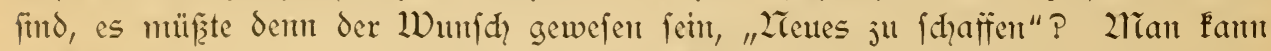
es faum glauber. Da glïflidherweife der Turm an dem Platze, wo er fteht, den

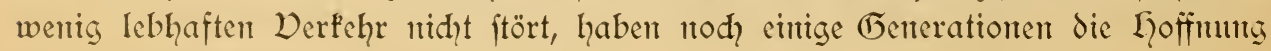
ihı aufreḑt ftehen ju fehent. 
Während cines Jeitraumes von vierjig Jahren ungefähr befand fidh die Zlnfunftftelle der Eifenbahn am Quai de l'Arsenal, diḑt beim Pont des Trous. Der Bau eines grofarartigen Bahnhofs, der das Weré des 2urchiteften Eenri Beyaert ift und 1879 dem Betrieb übergeben wurde, hatte die fofortige Schöpfung eines Syftems grofzer Derkehrrsadern jur ganj natürlidyen folge; diefe laufen nad, dem Stadtinnern und haben felbjtwerftändid, mur eine untergeordnete Bedeutung in demt malerifhen Tournai.

Seltfam ift es dody, dafiz fith mitten in der Königftrafze (Rue Royale) neben modernem Glanj eine Gäufergruppe erhalten hat, die mehrere Jahrhunderte alt und wie durch ein Wunder den Jurch die Schaffung der benaḑbarten Straken bedingten Enteignungen entgangen ift (2rbb. 119).

Die 2 rummern 10,12 unt 14 an der Elfe der Rue des Campeaur mit ihrem gemütlidyen Zlusfehen, ihren vorgebauten $\mathfrak{S a d e n}_{\text {mit }}$ den fleinen feniter= fheiben fheinen fid über bie prunf́vollen Sdqufenfter ringsumher luftig ju madhent.

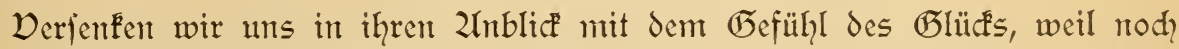
อెeit daju ift, und mit dem der Trauer, die wir entpfinden, wemt wir in bie jüge eines lieben Zlugehörigen fhauen, den fein Zllter baldigem und unansweidy= lichem Dahingehen weiht.

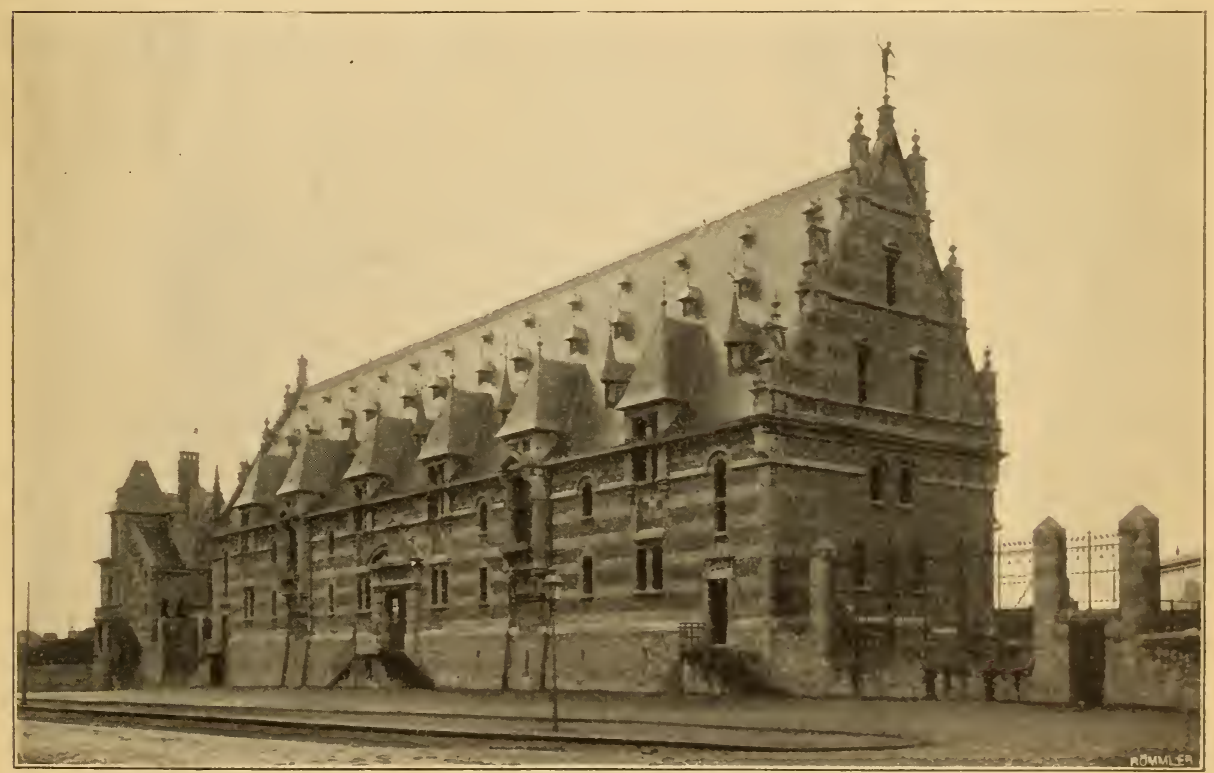

21bb. 120. Das paçhaus im Bahnhof. 


\section{Regifter.}

\section{(5e1tt.}

Die Sterndhen bedeuten eine Ubbiloung.

Ubtei von Bandeloo (Biblio= thef 51 .

St. 2Untoniusfai $3 z$.

Ipfelbrïcfe 29.

Irchiv (Provinjial) 2*. 3*.

Beguitenhof, grofer 36. $38^{*}$. fleitter 64 .

Belfried 16. 12*

Bibliothef 51 .

Biloque 59. 60. 62* $63^{*} 64^{*}$.

Borlunt, Ifabella $15 \%$.

Chormantel des hl. rivinus 14.

Dentmäler:

Bifhof Zllbert von Zllamont 8.

Zlmartus und Sivius 6.

Jaf́ob von Zrtevelde $4 . \overline{6}$.

rivinus Baumens 3 .

Jofeph Guislain $3 z$.

Kerchove de Denterghem, (5raf 62.

Criejt (2nt.) 6*.

Metdepentuingen 59 .

I. f. willems 4.

Dominif́anerflofter 26 *.

Draḩe vom Belfried 18.

vant Eyck=2Brïcke 58.

fechterfiguren $4.3 * 4.4$.

fifhmarft 31 *

fleifąhalle 29. $30^{*}$.

füritenthof 36.

Gedärmemarft 31 .

Georgshof 22. 23 *.

(5etreidefai 29.

- Gaus 27r. 8. - 29.

Grabntal des Bifhofs d'2llla mont $8^{*}$.

Grabunal der Margarethe von Bhifitlles 14.

Grabmal d. Cornel. Jantentus 14.

- d. Wilhelm Eindanus 14.

- des Joharn Palfyit $51^{*}$.

- des Untont Eriejt $6^{*}$.

Grabplatte des Wilhelm von

Leenemaer u. defien frau $44^{*}$.

Grabifteind. Gubbert van Eyck $5 z^{*}$.

Бraferichlo $31.32^{*} 33^{*} 34^{*} 35^{*}$.

Eaeghen, Dictor van der 12.
Gaus Gerhard des đeufels $2^{*} 3^{*}$. Gaus j. fliegend. Girfhen 4.5. $46^{*}$. Gaus der Kornmeffer $2{ }^{*}$. Gäufer des Kornmarft 25 * Gaus der freien Sdiffer 2 . Gaus der unfreien Schiffer 29. Iujtizpalajt 59. $61^{*}$.

Kantelaber in St. Bavo ?*. Kanone "Dulle Griete" 45. 4. $z$ *. Keure 43.

Kirchen:

Unmenfirche 65.

St. $\mathcal{B a v o} 4^{*} 5^{*}$.

- Chor $z^{*}$.

- Kandelaber $z^{*}$.

- Grabmal d.2uton Crieft $6^{*}$.

- Grabm.d.Bifhofs D'Allamont 8 *.

- Kanzel 9*.

- Rubers, Befehrg. des hl. Bavo $10 *$.

- Eyc, 2ubctung d. Sammes 12.13*.

- St. Zegidius $=\mathbb{K a}$, pelle 12.

- Kapelle d.h.Joo 12

Jafobsfirche $49^{*} 50^{*} 51^{*}$.

Michaelsfirđhe $26 * 28 * 29$.

Ziifolaifirhie 23. 24*.

Petersfirche 23. 24*.

Klofter der Dominifaner $26^{*}$.

Klojter $\delta$. bejdultht. Karmeliter 75 .

Konfervatorium der Mujuf 22.

Kornmelferhauts 2 .

Zräuterbrïcke 3 1. 32 \%

Zränterfai 26. $22^{*}$.

- Gaus am 27r. 4. - 26*.

Kiin it ler:

Zije, van 59.

Zrtois, Jacob vall 39.

Usifhe, Simt. valt 15.

Undenacrde, Liob. v. 40.

Zvont, Peter vant den 40 .

Zerghent, 27ic. 41.

Bonguereau 42 .
Brée, Mr. valt 59.

Brenghel, P. 40.

Bruỵn, Barthel de 39.

Claus, E. 42.

Cleef, van 21 .

Cluyjenaar 58.

Coebergher, $\mathfrak{2 v} .36$.

Coeck, peter 38.

Coxcie, Raph. 40.

Erayer, Gafp. de 40.

Delcourt, Jan 8.

Delvaux, Eorenj 9.

Devigne $=$ Quyo 3. 4. 2 .

Dillens, Julian 59.

Dubois, Lorenz

Duhaftel, franz 39. 48.

Duquesnoy, Gier. 6.

Dürer, 2llbr. 1. 4. 36.

Dyck, 2unt. vant $28 * 39$.

Eertveld, 2lndreas van 40.

Es, Jacob vall 40.

EycF, Gebr. vall 11 .

frédéric Léolt 42.

Grontwald 42.

Gals, fraits $41^{*}$.

Gamburfin 3 ?.

Geelant P. 44.

Geemsferck, MT. 38.

Geere, Jan de 64.

- Sucas de 9. 12.

Gefe, Dandelt 42.

Gorenbault, 5. 14. 65.

Gemeffen, I. van 38 .

I'Germitte 42.

bitghe, wilh. 15.

Gulle, 2hrjelm van 41 .

Jordaens 39.

Kauniuté, 23. D. 39.

Keldermans, 2R. 19.

Key, 21. đ. 40.

Knyุர̃, ivauter 40.

Koning, Ph. 4 1.

Kroyer 42 .

Sagye, Dict. 11.

Sentbach 42.

Letts, 2I. C. 29. 
Eeplat, Eg. 21.

Se Roy, Kipp. 42. 62.

Siemafere, 27if. de 25. 41.

Mahue, C. 40.

Matthey, J. 50.

Meire, B. van der 12 .

Meunier, C. 42.

Mey̧tens, 2n. v. 20.

Montald, C. 59.

Muyden, van 42 .

27eefs, p. 40.

Paelinta, I. 29.

peloufe 42.

Pourbus, $f_{r} \cdot 12,58$.

$$
\text { - J. } 38 .
$$

Roelandt 17. 58. 59.

Roll 42 .

Rombouts, ฮh. 39. 59.

Rooje 41 .

Rovej̧วан, B. da 8.

Rubens $10^{*}$ 15. 39 .

Rubder, I. de 4 .

Liude 42.

Saunage, 2Torb. 21 .

Seghers, D. 39.

Stalbemt, 21. 40.

Staffins, I. 4.

Suvée 59.
Tacye, 5 . de 58. 59.

Chys, P. 39. 40.

Denius, (1)to 11, 25.

Derbruggen, P. 5. 6.

Derhaeghen, P. I. 40.

Derwée, Zlfr. 42.

Digne, panl de 42 .

Dincotte 42.

Dries, Dredem. de 19.

Waghemafere, L. de 19.

Wit, Jacob de 39.

Jeghers, 5erh. 29.

Lagerhaus 26. $27 \%$.

Lapidarmufeum 18. $54 * 55$.

Seihhaus 36.

Maria Therefia 21.22 *

MTont Blandin 59.

Moriaen 22.

minjeum, ardäologifhes 40 \% $42 * 43 * 44^{*}$.

Mnı eum, Gemäldegalerie 38 ff. pläţe:

Buttermarft 16 .

freitagsmarft 4 .

Jafobsplaty 49.

Johannesplats 3. 15.

Kornmarft 23. $25^{*}$.

St. Pharahildenplats 31 .

Waffenplaty 59.

\section{Conruai.}

Ubtei von St. Martin 119. 2lthenäum 27. $28^{*}$.

Bahnhof $13 z^{*}$.

Belfried 103. 105* 120*.

Brauerei von St. piat 123.

Café der Brauer 108*.

Childerid I. 74.

Choncq clotiers 67 .

Chorbühne in der Kathedrale 91*.

Chorbihlque in der Kirdie des Seminars $122 \%$.

Diptydon 99.

Durdigangspforte (Fausse porte)

feptungsmaner 72 .

fif ḑmarft 81 .

Grabm. d. Jehan Du Bois 99.100*

Grabmal der familie Cottrel 98.

- des Jean de Dour 74.

- d. Urn. v. Guerle 135.

- des Jambons 130.

- des J.2lt. von polindove 34.
Brabmal des Colard de Seclin 98. Gaus rue des Bouthers St. Brice 25.

Gaus rue Madame 125.

Gaus des hl. piat 123.

Gaus "Le porcelet" 109.

Gäufer, romanifįe $25^{*} 26^{*}$.

Jofeph II. 11:*.

Kai des poiffortceaur 81 .

Kai Taillepierre 27r. 1. - 79 *.

Kai Difquin 81 *

Kapelle des 2iovizenhaufes der Iefuitert $7 z^{*}$.

Kirhen:

St. 3rice $73 * 75 \%$.

Jafobsfirdie 126. 122. 128*.

Johannesfirche 22 .

Kathedrale 69 * 80 * 82 * 87 * $89 * 90 * 91^{*} 93^{*}$.

- Chorbiahne $\mathfrak{v}$. floris $9 l^{*}$.

- Denfmal der 3 ijföfe $9 z^{*}$.
Provinzialardiviv $2 *$.

Rabot 37. 39*.

Reep (こ̄irfel) 3 .

Zefeft torium d.21btei St.Bavo 56*.

Reiterfigur (Brudjitïá) 42 *

Reliquienjąrein des hl. Maca, rins 14.

Ruinet der Zlbtei von St. Zavo 51 it. fif.

Stadthaus $1^{*} 19.20^{*} 21 *$.

Stapelhuis $27^{*}$.

Steen Berhard des Teufels $2 * 3 *$.

Steinmufeum $56^{*}$.

- Krieger vom 23elfried $58^{*}$.

- Relief mit der Beburt Chrifti $58^{*}$.

Strafien:

Briiggerftraf̧e 35 .

Ulte Burgitraf́e $46^{*}$.

van Eycfítra的 58. 60*.

felderitrafie 59.

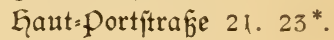

Goheftraf̧e 37.

Pfefferitrafe 35.

Torefen $48^{*}$.

Tuhballe 15. $12^{*} 18^{*}$.

Univerfität 58.

Dyot, Jooucus 11. 14*.
Kathedrale, Kapitelle $88^{*}$.

- Reliquienfarrein 92.93.95*.

Maria Magdalentenfirçe 130 . $131 \%$

lliargaretenfirhe 130 .

2Tifolaisfirche $133^{*}$.

St. Piat $122 * 124 *$.

St. Quentin 105. 106. 107*.

Klofter der Kreujträger $2 I^{*}$.

Kiin it Ier:

Zoriaenffen, 2. 92.

3 londeel, rane. 94. $96 \%$.

Bonillon, Mitic. 64 .

Bouts, Dierck 92.

Charlier, B. 121 .

Dailly, St. 123.

Dalen, Eeand. van $114^{*}$

Duquesnoy I. 97. 100.

Dutrieux, 21. 106*.

Dyck, 21. van 96.

floris, Cort. $91 *$. 
Eallait 97. 114. 121.

Gaghe, souis 115.

Geem, David de 114.

Gennequin, Ph. 21. 114.

Gorta 121.

Guys, P. 113.

Jordaens 92. 121.

Ie Ereur 81. 92.

Lefebure, G. de 92.

seyden, suc. van 92.

Lombard, ramb. 92.

Mafîs, Qu. 94.

Meifter des hl. Bartholo. mäus $113^{*}$.

Ziegre, m. van 9 .

Woit, Jacob valt 24.94. 123.

Pafture, Rog. de la 112 .

patinier 113.

Pourbus, franj 94.

Rate, Qutent. 111.

Rigaud, Lyac. $115 *$.

Ruberts 9 ?.
Severdonte, Jof. van 116.

Stoop, $\mathfrak{S}$. de 175 .

Deroun, 27ic. voll 93.

Dervoort, 2k. 9 ?.

Dos, Mart. de 94.

Weyden, Roger v. d. 112.131 .

ธuF́asidule 123. $126^{*}$.

Miufeum $110^{*} 111^{*} 118^{*}$.

27ormalfaule 129 *

Plätรe:

Grand' place 106 *.

27édonḑel.platj 118. $119^{*}$.

pont des trous 68. $132^{*} 134^{*}$.

porte Mantille 81.101.102*103*

Porzellanmarfen 116 .

Prinzefin von Epinop 105. 116. Rathans 119. 121 *

Réduit des Sions 109*.

Reliquienfąrein des hl. Eleu= therius $95 \%$.

Staatsardiviv $127^{*}$.
Stadtwall, alter 72 *.

Statue der Chriftine von Salaing, Prinzeffin von Epinoy 105*.

Strấfen:

Rue Barre St. Brice $26^{*} 22^{*}$.

- des Carliers 123.

- Jes Chapeliers 102.

- des Clairiffes $125^{*}$.

- des Croifiers 20*.

- Gallait 124.

Karmeliterîtrấfe 129.

Magdalenenf́trẩe 130 .

Rue des Meaux 108.

- de paris 104*.

- St. piat 123.

Quesnoy.Strafe 27.

Rue royale $136^{*}$.

Sd,

Tuab̧alle 105. 110*.

Eurur Geinriḑs VIII. $135 * 136$.

Wohnhaus des hil. piat 125.

\section{Die wichtigiten @uellenwerfe.}

\section{Gent.}

Duyse, Herm. van, Le Château des Comtes à Gand 1892 .

- Gand monumental et Pittoresque. 1885.

Gheyn, Chanoine van den, La Cathédrale de Saint Bavon, à Gand. rgor.

Heins, Arm., Vieux Coins de Gand. 1898 .

Inventaire archéologique de Gand. Catalogue déscriptif et illustré des monuments, œuvres d'art etc., antérieurs à I 830 , publié par la Société d'Histoire et d'Archéologie de Gand.

Potter, Frans de, Geschiedkundige Beschrijving der Stad Gend (noch unfertig).

Verhaegen, A., L'hôspital de la Byloque, à Gand. I889.

Kervyn de Volkaersbeke, Les Eglises de Gand $185 ;-1858$.

Wauvermans, Lieut. général, Le château des Comtes à Gand. I89 I.

\section{Toumat.}

Bourla, C., Tournai-Guide illustré. s. d.

Bozière, A.F.J., Tournai ancien et moderne 1864.

Capronnier, J. B., Les Vitraux de Cathédrale de Tournai. 1848 .

Cloquet, L., Monographie de l'Eglise Saint Jacques, à Tournai. I 88 I.

- Tournai et le Tournaisis. I884.

Grange, A. de la et Cloquet, L., Etudes sur l'Art à Tournai et sur les anciens artistes de cette ville. 1887 - 1888 .

Soil, E. J., La Cathédrale de Tournai, Guide illustré du visiteur.

- Faïences de Tournai (1670-1815).

- Tournai archéologique en 1895.

- Tournai en r zor, d'après un plan en relief, conservé à l'Hôtel des Invalides, à Paris; photogr. de René Desclée. 1897. 

